\title{
Design of composite sandwich panels for lightweight applications in heavy vehicle systems
}

Thomas H. Evans

West Virginia University

Follow this and additional works at: https://researchrepository.wvu.edu/etd

\section{Recommended Citation}

Evans, Thomas H., "Design of composite sandwich panels for lightweight applications in heavy vehicle systems" (2006). Graduate Theses, Dissertations, and Problem Reports. 4226.

https://researchrepository.wvu.edu/etd/4226

This Thesis is protected by copyright and/or related rights. It has been brought to you by the The Research Repository @ WVU with permission from the rights-holder(s). You are free to use this Thesis in any way that is permitted by the copyright and related rights legislation that applies to your use. For other uses you must obtain permission from the rights-holder(s) directly, unless additional rights are indicated by a Creative Commons license in the record and/ or on the work itself. This Thesis has been accepted for inclusion in WVU Graduate Theses, Dissertations, and Problem Reports collection by an authorized administrator of The Research Repository @ WVU. For more information, please contact researchrepository@mail.wvu.edu. 
Design of Composite Sandwich Panels for Lightweight Applications in Heavy Vehicle Systems

Thomas H. Evans

Thesis Submitted to the College of Engineering and Mineral Resources at West Virginia University

in partial fulfillment of the requirements

for the degree of

Master of Science

in

Mechanical Engineering

Jacky C. Prucz, Ph.D.

Samir Shoukry, Ph.D.

Gergis William, Ph.D.

Department of Mechanical and Aerospace Engineering

Morgantown, West Virginia

2006 


\section{ABSTRACT \\ Design of Composite Sandwich Panels for Lightweight Applications in Heavy Vehicle Systems}

\section{Thomas H. Evans}

Vehicle systems such as cargo freight and platform trailers are a primary source of transporting heavy cargo loads. The construction and materials used in a standard trailer design contribute significantly to the overall weight. The U.S. Department of Energy (DOE) and West Virginia University have conducted joint research to reduce the amount of fuel consumption of cargo transportation trailers by initiating a lightweight materials program. This study is aimed at the utilization of Fiber Reinforced Polymer (FRP) composites and Composite Sandwich technology in conjunction with innovative joining concepts to reduce trailer weight. Finite element modeling and experimental analysis reveal the benefits of using composite sandwich technology versus existing load bearing structures in a standard trailer design.

The composite sandwich technology in this work details the use of a core constituent that contributes to flexural stiffness while utilizing a design that addresses joining parameters of the faceplate and core. 


\section{TABLE OF CONTENTS}

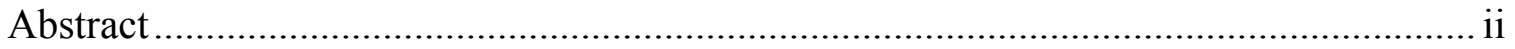

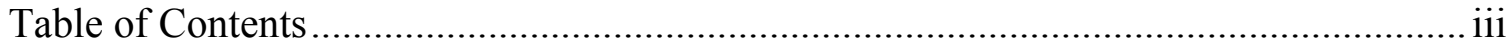

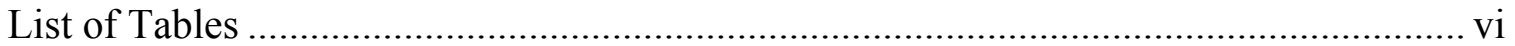

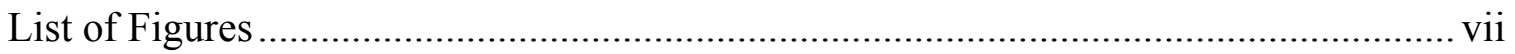

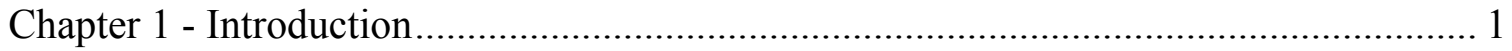

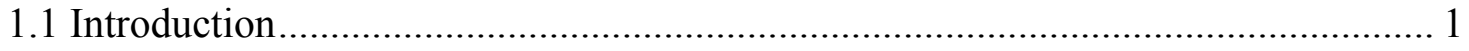

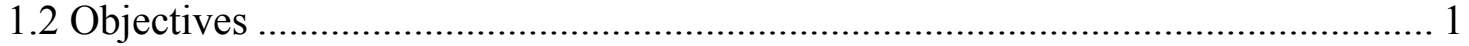

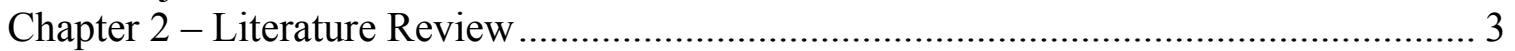

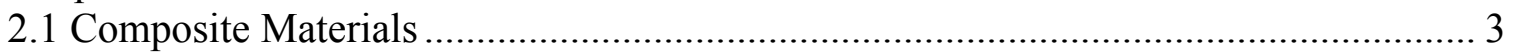

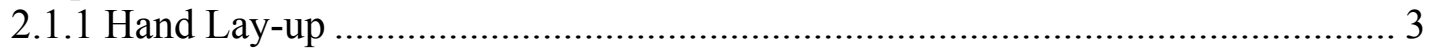

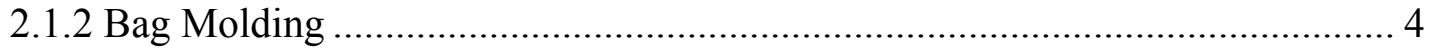

2.1.3 Autoclave Processing ............................................................................. 4

2.1.4 Compression Molding.................................................................................. 4

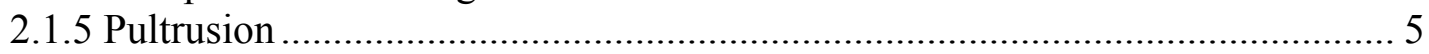

2.1.6 Resin Transfer Molding ........................................................................ 5

2.1.7 Filament Winding ……………………………................................... 5

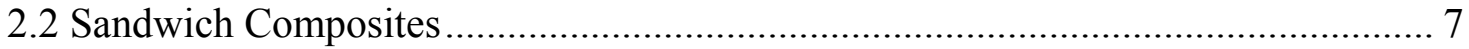

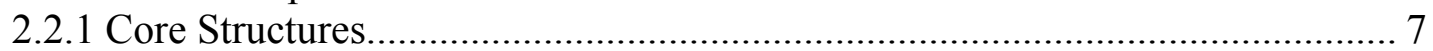

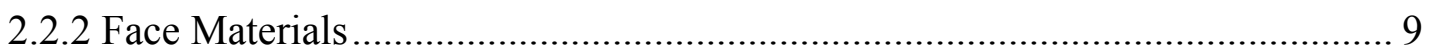

2.2.3 Properties of Fiber Composite ……………………................................ 10

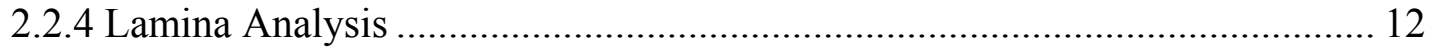

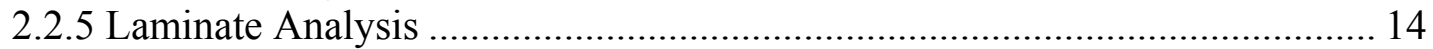

2.2.6 Plate Stiffness and Stress and Strain Variation.............................................. 15

2.2.7 Stiffness Properties of a Sandwich Structure ................................................. 20

2.3 Classical Theory of Laminate or Sandwich Plate Bending ................................... 21

2.3.1 Equilibrium Equations ………………………………................................ 21

2.3.2 Bending Analysis Excluding Transverse Shear Deformation Effects ............. 23

2.3.3 Bending Analysis Including Transverse Shear Deformation Effects .............. 24

2.3.4 Dynamic Loading of Laminates or Sandwich Panels ...................................... 25

2.4 Solutions for Rectangular Sandwich Plates ........................................................... 27

2.4.1 Navier Solution for Sandwich Plates with All Four Edges Simply Supported 27

2.4.2 Levy Solution for Plates with Two Edges Simply Supported ......................... 29

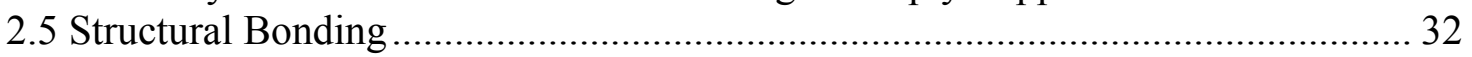

2.5.1 Composite Surface Preparation for Bonding Methods ..................................... 33

Chapter 3 - Joining Concepts ................................................................................... 35

3.1 Innovative Structural Joining Configurations …………......................................... 35

3.1.1 Development of Model Joints and Prototype Designs...................................... 35

3.2 Prototyping of Innovative Structural and Joining Concepts .................................... 40

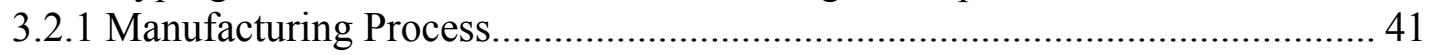

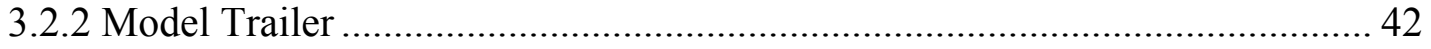

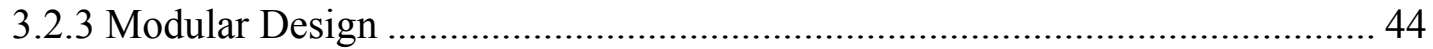

3.3 Theoretical Analysis and Performance Comparisons ……………………............ 45

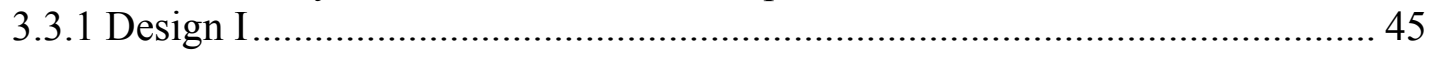

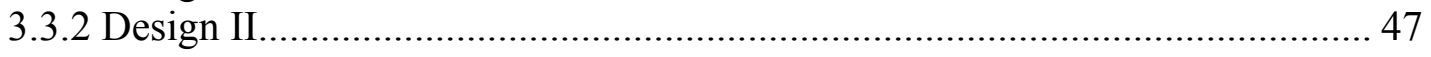




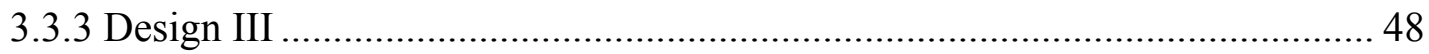

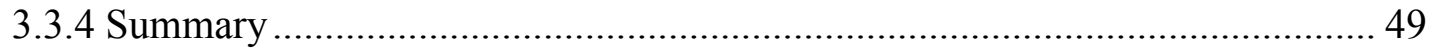

Chapter 4 - Analysis of Various Cross Sections for the Core Structure of Extruded

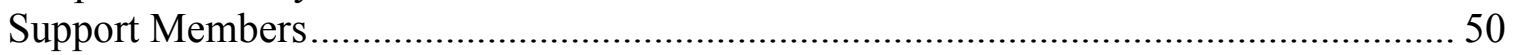

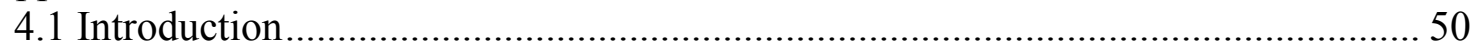

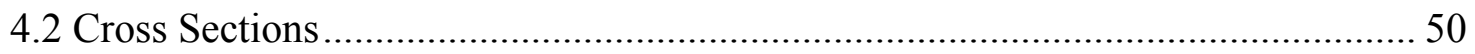

4.3 Bending Analysis ........................................................................................ 51

4.3.1 Bending Results .................................................................................... 52

4.3.2 Discussion of Finite Element Bending Results.............................................. 58

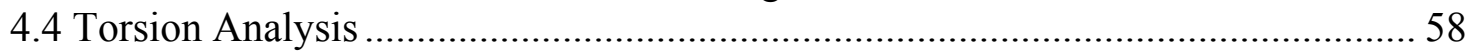

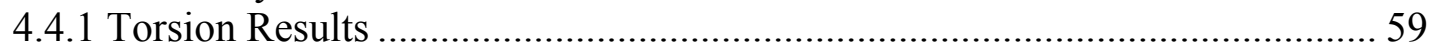

4.4.2 Discussion of Finite Element Torsion Results................................................. 68

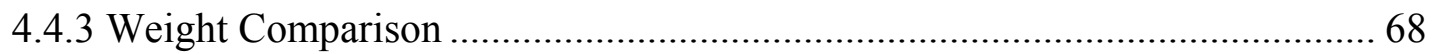

4.5 Panels with Tube Section Cross Members......................................................... 70

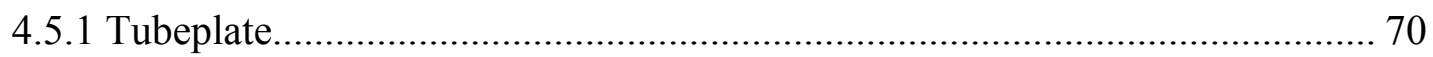

4.5.2 Tubegrate ……………………………………………………………..... 71

4.6 Sandwich Composite Panels with Aluminum Extruded Core Cross Members...... 71

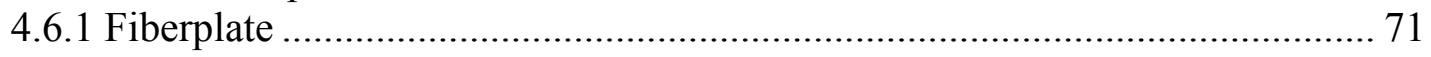

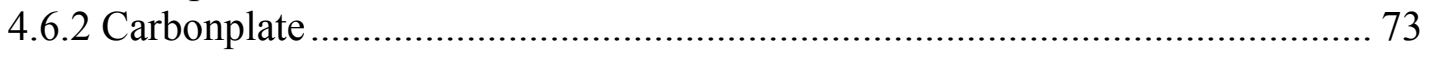

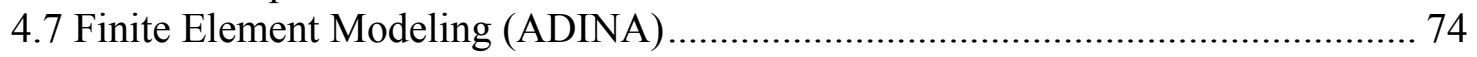

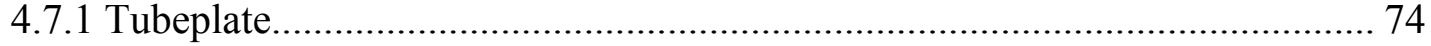

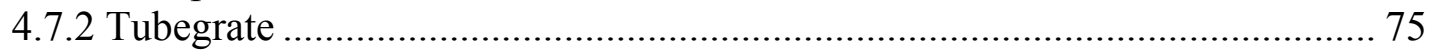

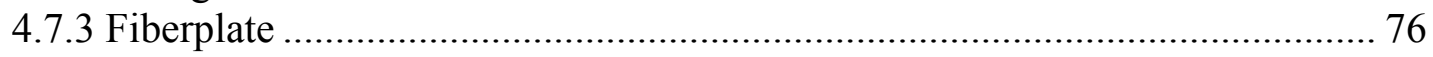

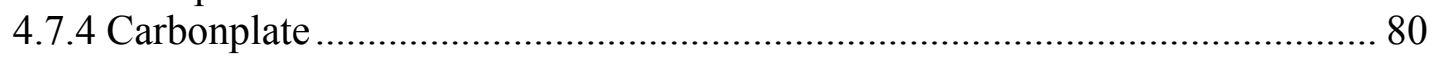

Chapter 5 - Instrumentation of Sandwich Panels for Experimental Testing ..................... 81

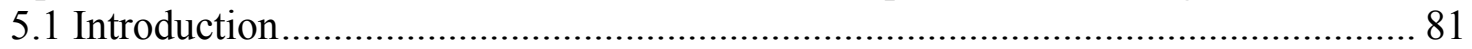

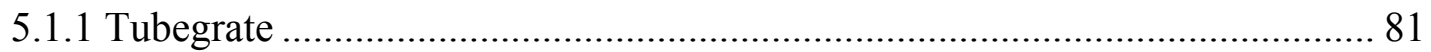

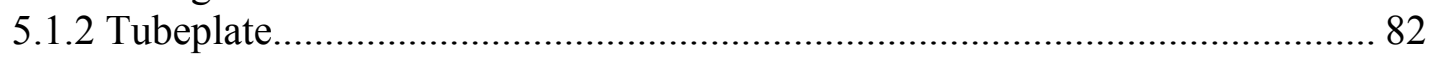

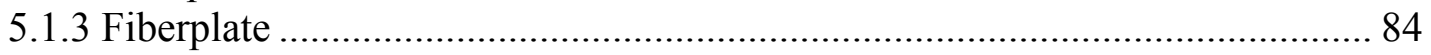

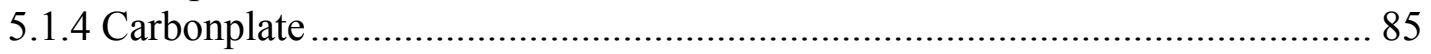

Chapter 6 - Experimental Testing of Sandwich Panels ……………............................. 87

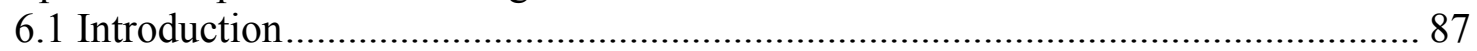

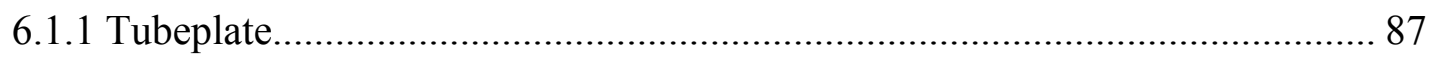

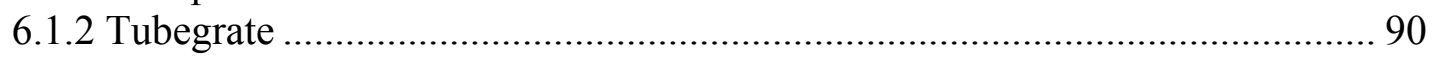

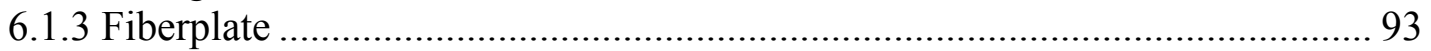

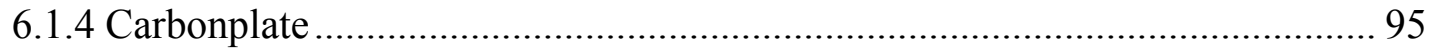

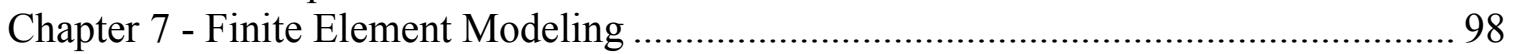

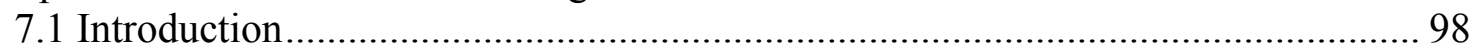

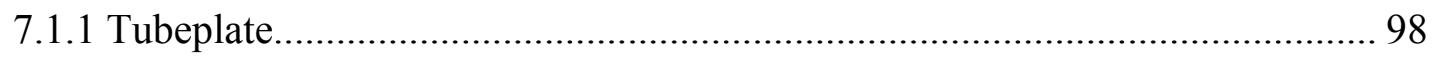

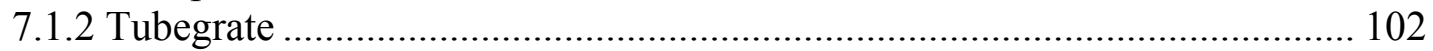

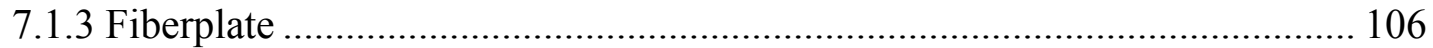

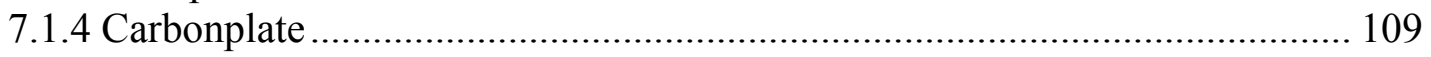

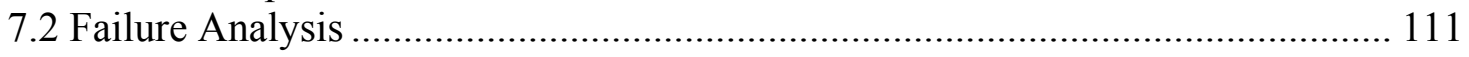

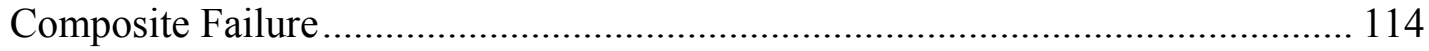

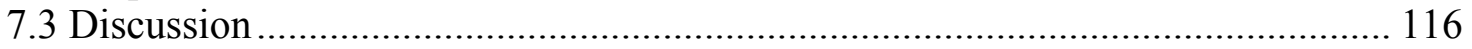

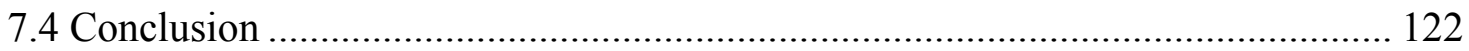




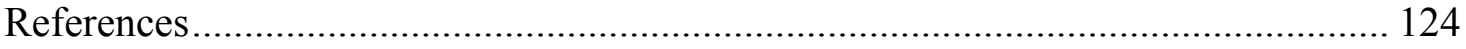




\section{LIST OF TABLES}

Table 3.1 - Design I Analysis for Alternative Materials................................................ 46

Table 3.2 - Design II Analysis for Alternative Materials ............................................... 48

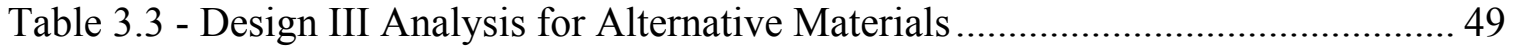

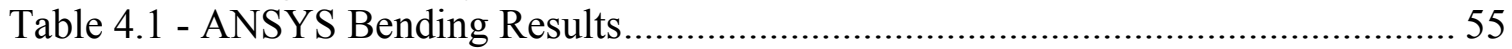

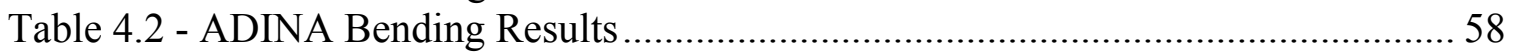

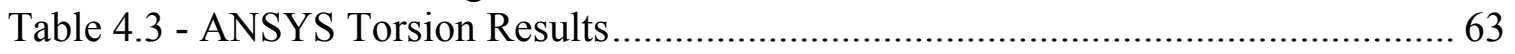

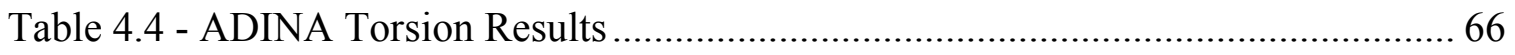

Table 4.5 - Comparison of ANSYS and ADINA Bending and Torsion Results .............. 66

Table 4.6 - Weight Comparisons between Alternative Cross-Sections ............................ 69

Table 7.1 - Failure Criteria for the Fiberplate and Carbonplate Core Structure ........113

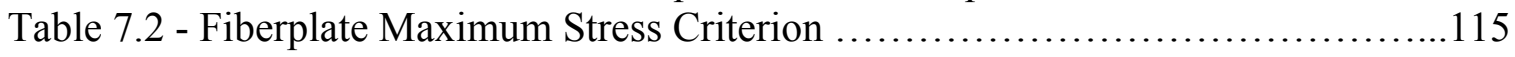

Table 7.3 - Carbonplate Maximum Stress Criterion ................................115

Table 7.4 -Weight of Panel Designs Compared to an Existing Trailer Section ............116 


\section{LIST OF FIGURES}

Figure 2.1: Types of sandwich core materials.

Figure 2.2: Schematic of a lamina with fibers and matrix. The lamina is unidirectional with the longitudinal fibers oriented in the 1 direction........................................ 11

Figure 2.3: Undeformed and deformed cross sections of a laminate plate.................... 16

Figure 2.4: Referencing of the stacking sequence for a composite laminate................... 17

Figure 2.5: A simply supported composite plate used for Levy solution analysis.......... 29

Figure 3.1: Alternative design concepts for the floor platform of a modified van trailer.35

Figure 3.2: Sandwich composite structure with aluminum tube core construction for flooring platform applications. Design concept C............................................... 36

Figure 3.3: Type D flooring alternative using composite I-beams as cross member

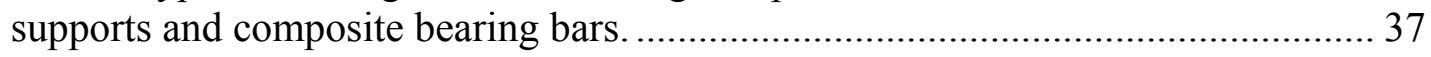

Figure 3.4: Connection method between side panels by an H-joint configuration........... 37

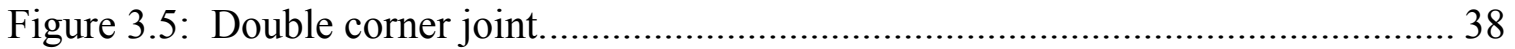

Figure 3.6: Corner joint for connecting the floor platform to the sidewall or side panels

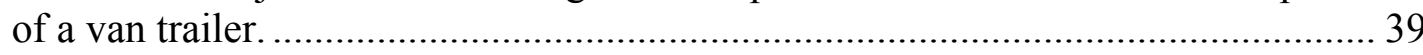

Figure 3.7: Alternative option for the corner joint connecting the side panels to the

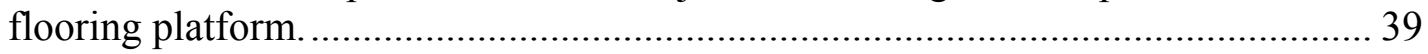

Figure 3.9: Unassembled sections of the model trailer............................................ 43

Figure 3.11: A method to assist the joining of segments for the mudular application of the van trailer design.................................................................................. 45

Figure 3.12: Alternative floor design I consisting of I-beam cross members and "bearing

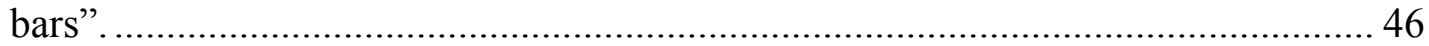

Figure 3.13: Alternative floor design II consisting of top platform supported by C-

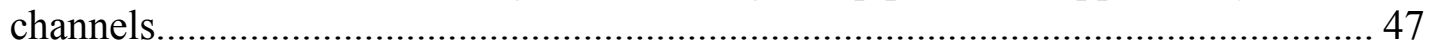

Figure 3.14: Alternative flooring design III consisting of a FRP top and bottom face plate and hollow cross tubes comprising the core structure....................................... 48

Figure 4.1: The six different cross sections of the core structure .................................. 50

Figure 4.2: Representation of a sandwich composite structure using the X2 core cross section.

Figure 4.3: Loading scenario, dimensions, and boundary conditions for bending analysis.

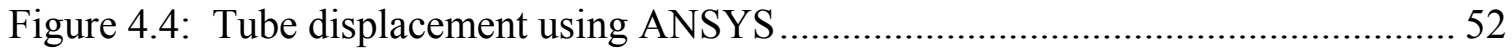

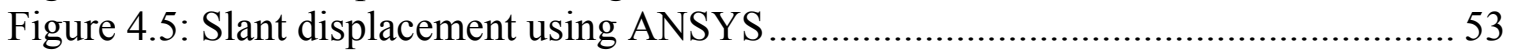

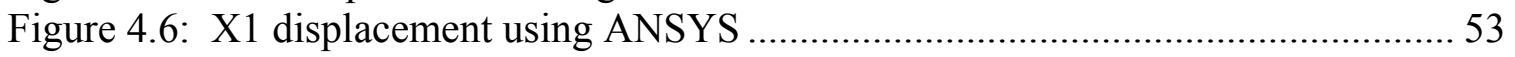

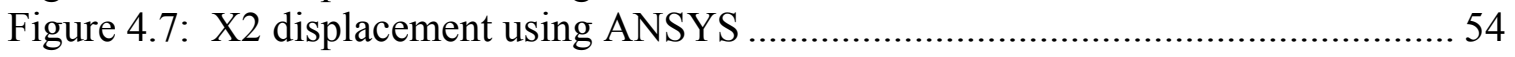

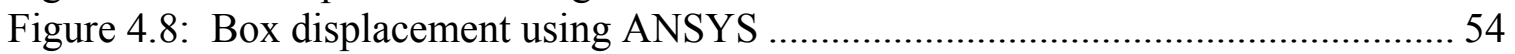

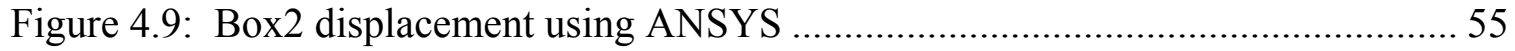

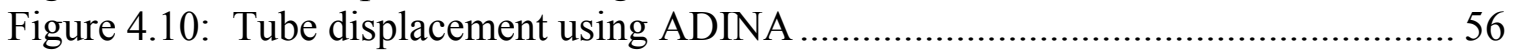

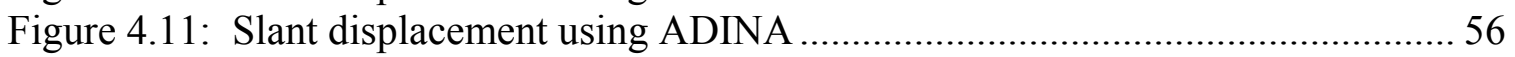

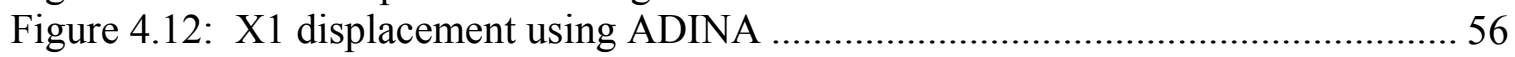

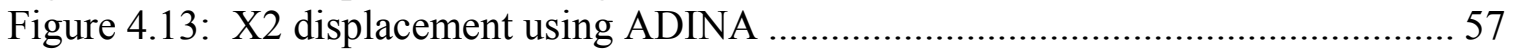

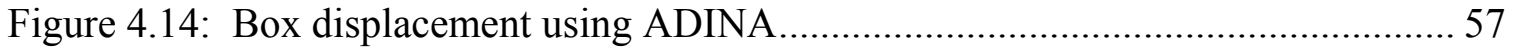

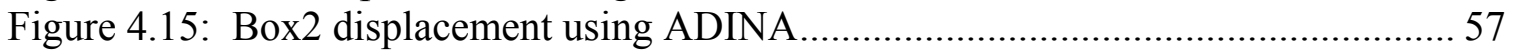


Figure 4.16: Loading scenario, dimensions and boundary conditions for torsional

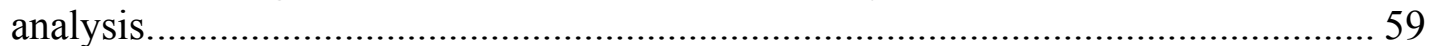

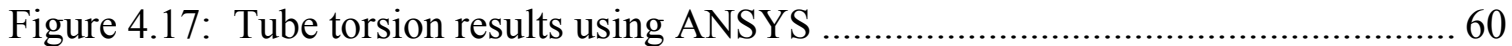

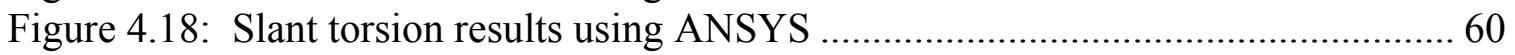

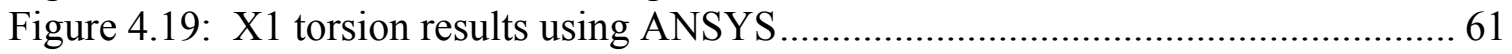

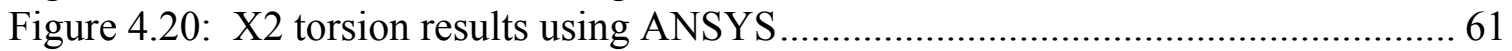

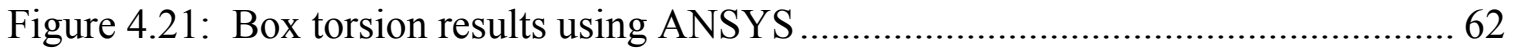

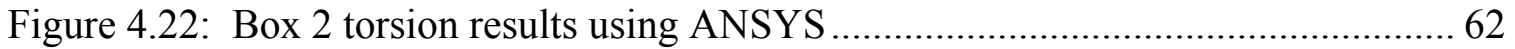

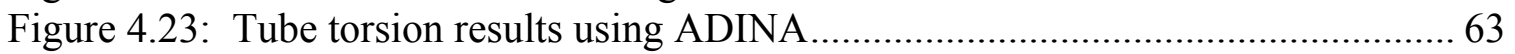

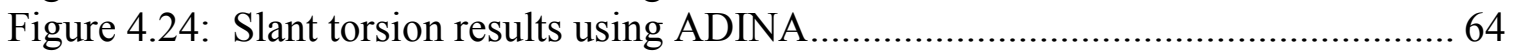

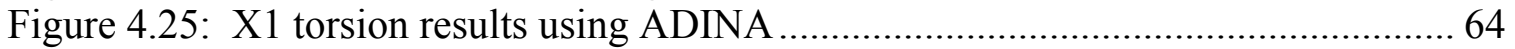

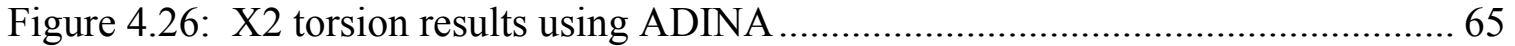

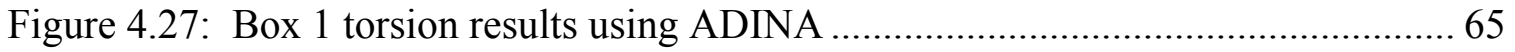

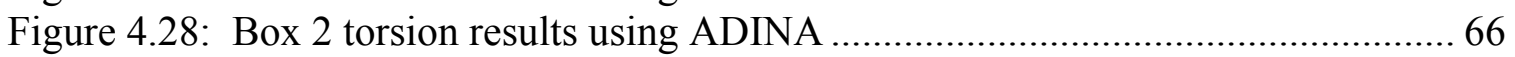

Figure 4.29: Plot of maximum bending deflection for tube cross members................... 67

Figure 4.30: Plot of maximum torsional stress within the tube cross section members.. 67

Figure 4.31: Plot of the weight comparison between cross tube members......................69

Figure 4.32: Schematic of the tubeplate (a) and the tubegrate (b) panel designs........... 70

Figure 4.33: Manufacturing process of the fiberplate design. This design incorporates

ribbed fiberglass face plates and extruded aluminum tubes as a core material. ....... 72

Figure 4.34: The fiberplate design with five aluminum tube cross members, fiberglass top and bottom face plates, and paper honeycomb rib stiffeners............................ 73

Figure 4.35: Tubeplate geometry, mesh, boundary conditions and applied load........... 75

Figure 4.36: Tubegrate geometry, mesh, boundary conditions, and applied load.......... 76

Figure 4.37: Fiberplate design with cross sectional view........................................... 77

Figure 4.38: Illustration of various surface configurations of the fiberplate design........ 78

Figure 4.39: Contour plot showing the thickness of each surface segment for the

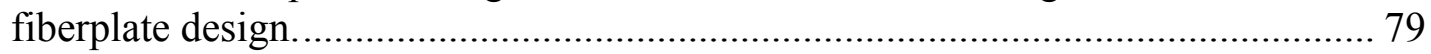

Figure 5.1: Instrumentation of tubegrate panel with uniaxial and rosette gages............ 81

Figure 5.2: Rosette strain gage placement for the tubegrate panel.............................. 82

Figure 5.4: The rosette strain gage placement for the tubeplate panel. ......................... 83

Figure 5.6: Instrumentation of the carbonplate panel with uniaxial strain gages centered on the middle cross member and strain gage rosettes on the inset of the edge

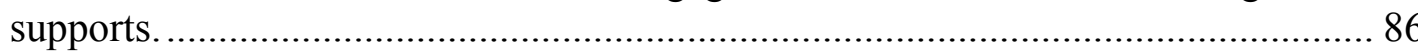

Figure $6.1(\mathrm{a})-(\mathrm{d})$ : The Load vs. Strain data plots of the tubeplate experimental test and

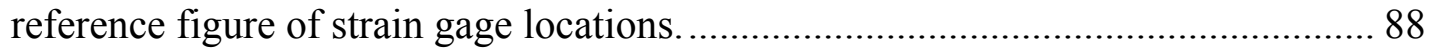

Figure 6.2: Shearing strain values for the tubeplate configuration at the inset of the simply supported edges.......................................................................... 90

Figure 6.3 (a) - (d): The Load vs. Strain data plots of the tubeplate experimental test and reference figure of strain gage locations......................................................... 91

Figure 6.4: Shearing strain values for the tubegrate configuration at the inset of the simply supported U-channel edges. .............................................................. 92

Figure 6.5 (a) - (d): The Load vs. Strain data plots of the fiberplate experimental test and reference figure of strain gage locations.

Figure 6.6: Shear strain values for the fiberplate configuration at the inset of the simply

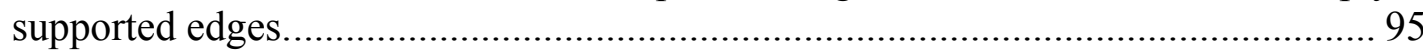


Figure 6.7 (a) - (d): The Load vs. Strain data plots of the carbonplate experimental test and reference figure of strain gage locations. ...................................................... 96

Figure 6.8: The shear strain values for the carbonplate panel at the inset of the simply

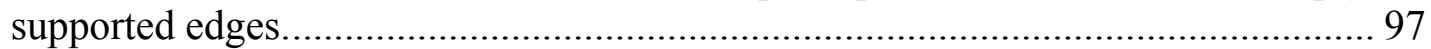

Figure 7.1: Tubeplate finite element model displaying the boundary conditions, load, and coupled degrees of freedom as weld connections.

Figure 7.2: Strain in the uniaxial direction corresponding to the strain gage placement in the experimental analysis.

Figure 7.3: Magnified view of the uniaxial strain next to the load area. Notice the stress concentration next to the weld point. .....

Figure 7.4: Shear strain plot of the tubeplate design. ............................................ 101

Figure 7.5: Magnification of shear strain contour plot at the rosette gage location. .... 102

Figure 7.6: Tubegrate finite element model showing the contact load, edge restraints, and coincident nodes...

Figure 7.7: Uniaxial strain of the tubegrate panel.................................................... 104

Figure 7.8: Magnified view of tubegrate uniaxial strain at strain gage location. .......... 104

Figure 7.9: Shear strain contour plot of the tubegrate panel....................................... 105

Figure 7.10: Magnification of the tubegrate shear strain rosette location. ................... 105

Figure 7.11: The fiberplate finite element model showing the simply supported edges

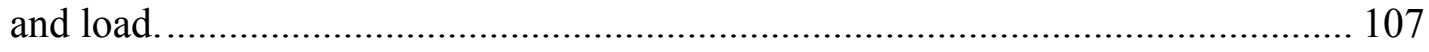

Figure 7.12: Uniaxial strain of the fiberplate panel................................................ 108

Figure 7.13: Shear strain contour plot of the fiberplate panel. .................................... 108

Figure 7.14: Uniaxial strain distribution of the carbonplate ..................................... 110

Figure 7.15: Shear strain distribution of the carbonplate........................................ 110

Figure 7.16: Contour plot of Von-Mises stress in the fiberplate. ............................... 111

Figure 7.17: Contour plot of the Von-Mises stress in the core of the fiberplate. .......... 112

Figure 7.18: Contour plot of the Von-Mises stress in the carbonplate. ........................ 112

Figure 7.19: Contour plot of the Von-Mises stress in the core of the carbonplate......... 113

Figure 7.20: Finite element models of the trailer section and the carbonplate.............. 117

Figure 7.21: Displacement contour plot of the trailer section model. .......................... 118

Figure 7.22: Displacement contour plot of the carbonplate-4 section......................... 118

Figure 7.23: Shear strain contour plot of the trailer section model. ............................. 119

Figure 7.24: Shear strain contour plot of the carbonplate-4 model. ............................. 119

Figure 7.25: Displacement contour plot of the fiberglass-4 model. ............................. 120

Figure 7.26: Shear strain contour plot of the fiberglass-4 model. .............................. 121 


\section{Chapter 1 - Introduction}

\subsection{Introduction}

The overall goal of this work is to devise weight saving solutions for heavy vehicle systems. The method chosen to achieve this goal is to replace heavy structural parts of a current trailer with lightweight composite structures, and develop the joining methods needed to implement the designs into a trailer structure. Throughout the process, several intermediate steps were taken, the first being the construction of a scaled model composite trailer system. The process of analyzing, designing, and fabricating a 1 to 4 scaled model using innovative materials and joining concepts served to provide an understanding of the problems and concerns involved with this type of design in heavy trailer systems. The model was built with the goal to reduce the overall weight of heavy trailer systems. Innovative materials and a modular design are the means utilized here to reduce the weight of the trailer.

For cost effectiveness, standard commercial materials were used to build the trailer model. However, the final design concept focuses on detailed sandwich composite design that will incorporate fiber reinforced polymer (FRP) composite sandwich structures as the primary method for weight reduction and load resistance. The primary areas where sandwich composites will be most effective are in the flooring platform, sidewalls, roof, and door of the haul trailer.

\subsection{Objectives}

The main objective of this study is to create design and joining methods that will allow the incorporation of lightweight composite plates, panels or structures into a van trailer design for an overall vehicle-system weight reduction. Innovative joining methods will create solutions to connect components in a large vehicle trailer system, in place of mechanical joints which include bolting and riveting.

The first step was to construct a scaled replica model of a haul trailer focusing on the possible designs for the floor, sidewalls, roof, and door using adhesive bonding and mating geometry parts as the primary methods to join various parts. The process was an 
investigative procedure to face first-hand the complications of fabricating a trailer haul with FRP composites and new bonding and joining methods.

The second step was to optimize the flooring structure, sidewalls, roof and rear door design to be most beneficial in weight saving and load bearing aspects. Several different design ideas were developed and studied. This work will detail the design, fabrication process, experimental testing and finite element analysis of these structures, and will determine their potential for implementation into a large trailer haul system, or complete composite trailer design. 


\section{Chapter 2 - Literature Review}

\subsection{Composite Materials}

\subsubsection{Hand Lay-up}

The hand lay-up process is also referred to as a wet lay-up. It combines the reinforcement fibers with a liquid resin in a mold. Layers of fibers are placed into the mold and saturated with the resin. The part is hand rolled to create a uniform resin coat and extract any voids or air pockets within the combination. Layers are added until the thickness or desired orientation of fibers is reached. The curing process is the final stage of the hand lay-up manufacturing; it involves the chemical process of the resin changing state from a liquid to a solid [2].

The lay-up process begins with the development of a proper mold to accommodate the desired part geometry and requirements of the curing process. The material used for a mold depends on the number of times the mold will be used, temperature and pressure of the curing process, and the manufacturing of the mold itself. To avoid the resin curing to the mold and damaging the finished part by forced removal, a release agent is applied to the areas where the mold and resin come into contact. Common release agents are wax, poly vinyl alcohol, silicones, and release fabric.

The fibers are then placed on the mold to be saturated with resin. The proper measurements of mixing ratio of the resin and catalyst must be carefully followed and mixed thoroughly before application. After the different layers of fabric have been applied to the mold and saturated with the resin, hand rollers are used to compress the layers together and against the mold. Hand rolling of the lay-up ensures removal of any air pockets that will become voids during the curing process if not removed. The curing process is usually done at room temperature. However, elevated pressures are sometimes applied to the part during the curing process to remove excess resin and air via bag molding [2]. 


\subsubsection{Bag Molding}

Pressure can be applied to a laminate during the curing process by using bag molding techniques. Vacuum bagging uses a flexible plastic or bag that is placed over the laminate and sealed. A vacuum pump is connected so the air is pumped out from the inside of the bag which ultimately applies a uniform pressure onto the top surface of the laminate. The pressure forces the laminate against the mold creating an accurate resemblance to the mold geometry while removing excess resin and air [3].

The three main methods of applying a pressure to a laminate are by pressure bag, vacuum bag, and autoclave manufacturing. Vacuum bagging is a popular manufacturing process because it is relatively inexpensive, allows large size parts to be manufactured, and the quality of the resulting part is mainly dependent on the manufacturer's skill and not a machining process.

\subsubsection{Autoclave Processing}

Autoclave processing assists vacuum bag and pressure bag molding by applying heat and pressure to a laminate during the entire curing cycle. Curing pressures for autoclave processing are usually in the range of 50-100 psi $\left(377.5-755 \mathrm{~kg} / \mathrm{m}^{2}\right)$. The benefits of autoclave processing are to produce a laminate with higher density and reduce the amount of time to completely cure a laminate [4].

Autoclave processing is expensive, timely and laborious. The high cost of autoclave processing is a result of the autoclave itself, industrial gases such as nitrogen used for pressurization, and specialized lay-up materials that are not affected by elevated temperature and pressure. However, autoclave processing produces high quality, complex laminates and is beneficial for large parts and average production quantities. The method is very common in aerospace applications but for the research done at the university level, autoclaves are not as common because of the expense involved. An autoclave was not used for the research in this work because of cost reasons.

\subsubsection{Compression Molding}

Compression molding is a molding method in which the molding material, generally preheated, is placed in an open heated mold with matching male and female dies. The dies then close onto the material by the means of a hydraulic press, the 
assistance of heat and fairly high pressure cures the fibers and resin. After the part has completely cured the mold dies are lifted and the finished part is removed from the mold [5]. Compression molding is a fairly simple method which allows for high productive rates and moderate operation costs.

\subsubsection{Pultrusion}

Pultrusion is a continuous process for manufacturing composites with a continuous cross-sectional shape. In this process, fibers are impregnated with resin and carried through a die which forms the reinforcement to the desired shape and then heat is applied to cure the part [6]. Pultrusion is effective because it is inexpensive and can produce parts of any length by converting continuous fibers and resin into a solid laminate. The process is performed by pulling continuous fibers through a heated die which shapes and cures the fiber and resin.

\subsubsection{Resin Transfer Molding}

Resin transfer molding (RTM) is an effective method to produce large continuous fiber composites. Complex shapes can be produced under short cycle times and the method provides the manufacturer with control of part specifications such as fiber orientation for optimum material properties [2].

The RTM process is performed by a mold with ports to inject resin into the dry fiber and outlets which allow air to escape. The process consists of placing the dry fiber in the mold and closing it. The liquid resin is pumped into the closed mold until it is completely full. The ports are then sealed and heat is applied. After the part has cured, the mold is opened and the finished composite part can be removed [2].

\subsubsection{Filament Winding}

Filament winding is an automated process in which continuous filament is treated with resin and wound on a mandrel in a pattern which will provide strength in one direction. "The process is performed by drawing the reinforcement from a spool or creel through a bath of resin, then winding it on the mandrel under controlled tension and in a predetermined pattern. The mandrel may be stationary, in which event the creel structure rotates above the mandrel, or it may be rotated on a lathe about one or more axes. By 
varying the relative amounts of resin and reinforcement, and the pattern of winding, the strength of filament wound structures may be controlled to resist stresses in specific directions. After sufficient layers have been wound, the structure is cured at temperature."[7]. The most common shapes to produce by this process are revolved surfaces such as pipes, cylinders, and spheres. 


\subsection{Sandwich Composites}

Sandwich composites are comprised of two face sheets or top and bottom layers with a core material placed or "sandwiched" between. This type of arrangement creates a light and stiff structure, because the stiff faces are distanced from the neutral axis, similar to the flanges of an I-beam. The faces carry the majority of the axial loading and transverse bending stress. The core serves to stabilize the faces against buckling and carries most of the shear forces [8]. When specific tailoring of a sandwich composite is

needed, the top and bottom face sheets may differ in material and thickness. A change of this nature would aide a sandwich composite which needs temperature resistance on one side more than the opposing side or perhaps one side will primarily carry an impact load or static deflection.

\subsubsection{Core Structures}

In sandwich composite design, there are no limitations as to what material can be used as a core structure. Developments of new core materials are a primary interest in sandwich composite design and have evolved tremendously over the years. However, there are four main categories: (a) foam, (b) honeycomb, (c) web, and (d) corrugated or truss core as seen in Figure 2.1. 


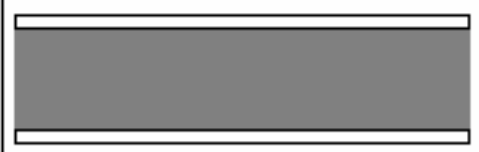

(a) Foam Core

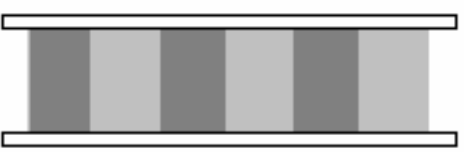

(b) Honeycomb Core

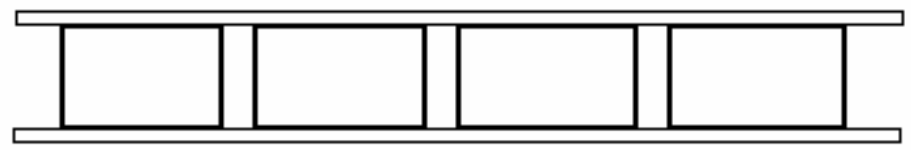

(c) Web Core

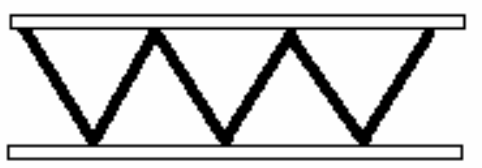

(d) Truss Core

Figure 2.1: Types of sandwich core materials.

The sandwich structures shown in Figure 2.1 have variations and different attributes for each type of core material. However, in all cases, the primary loading, both in-plane and bending, are carried by the faces, while the core resists transverse shear loads. It is acceptable to assume that in foam and honeycomb core sandwich composites all the in-plane and bending loads are carried by the faces only. In web-core and trusscore structures the core carries some of the in-plane and bending loads [9].

The main purpose of foam and honeycomb cores is to provide spacing between the face sheets and to carry the transverse shear loads. The increase in flexural stiffness from a monocoque construction to a sandwich composite can be shown mathematically. When comparing the different structures, the two share in-plane stiffness values. The difference can be shown in a flexural comparison.

Vinson [9] states the flexural stiffness per unit width, D, for a solid laminate panel is

$$
D_{\text {plate }}=\frac{2 E_{f} t^{3}}{3\left(1-v_{f}^{2}\right)}
$$

and the flexural stiffness of a sandwich panel with a foam or honeycomb core is 


$$
D_{\text {sand }}=\frac{E_{f} t h_{c}^{2}}{2\left(1-v_{f}^{2}\right)}
$$

The ratio of the flexural stiffness of the sandwich panel to that of the solid laminate plate is

$$
\frac{D_{\text {sand }}}{D_{\text {plate }}}=\frac{3}{4}\left(\frac{h_{c}}{t}\right)^{2}
$$

Analyzing the ratio shows that if the ratio of the face sheet thickness, $t$ to the core thickness, $h_{c}$ is $1 / 20$ then the flexural stiffness of the sandwich panel is 300 times greater than that of the solid laminate plate. By comparison, the sandwich construction with the same material and total face sheet thickness identical to the laminate thickness, results in lower lateral deflections, higher overall buckling loads, and higher natural frequencies.

\subsubsection{Face Materials}

The faces of a sandwich panel can be comprised of almost any material that is available in a thin sheet. This sole requirement allows many material options for the designer to utilize in sandwich panel construction. As described by Zenkert [10], the parameters which are of primary concern for developing a structurally sound sandwich panel are

- High stiffness resulting in flexural rigidity

- High compressive and tensile strength

- Impact resistance

- Aesthetics

- Chemical and environmental resistance

- Wear resistance 
The properties listed can be met by two different categories of face materials, metallic and non-metallic. Metallic face materials are most commonly sheet metals because of their geometry and applicability to a sandwich composite design. The advantages to using a metallic face sheet are low cost, good strength and stiffness, and high impact properties.

Non-metallic face materials are defined by fiber reinforced polymers (FRP). FRP are composed of fibers and matrix that define the traditional composite material. Typical fibers are glass, aramid, and carbon. These fibers are combined with a matrix by one of the manufacturing methods previously discussed to form an FRP composite. Orienting the fibers in the direction of applied loads utilizes their high stiffness and strength properties and tailors the composite laminate to resist and sustain loads. Having the ability to directionally tailor the stiffness and strength of a composite allows for reduction of material in directions that do not experience loads, this ultimately reduces the material being used (cost) and weight.

\subsubsection{Properties of Fiber Composite}

The structural properties of a composite plate can be predicted by utilizing the material properties of the constituents at a microscopic level. The microscopic level of a composite refers to its individual fibers and matrix. A laminate is comprised of multiple layers of lamina arranged in a stacked sequence. The approximation of finding laminate properties starts with the properties of the lamina and builds by approximation to an overall laminate definition of properties.

For computational purposes, it is best to use an orthotropic lamina because laminas usually are unidirectional, bidirectional, or random orientation. 


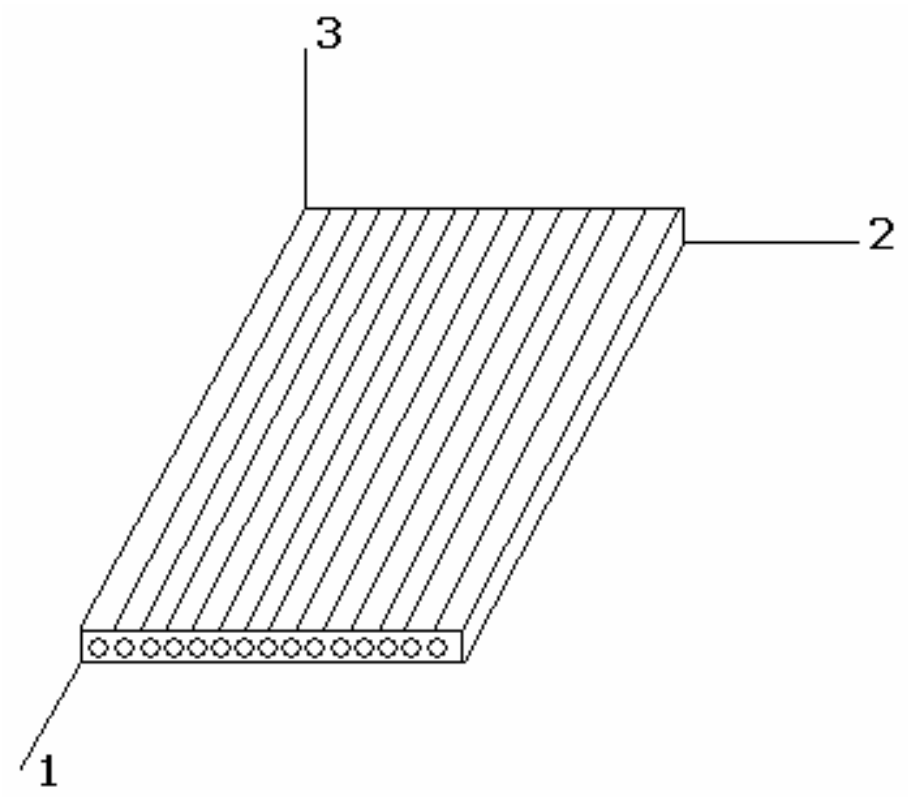

Figure 2.2: Schematic of a lamina with fibers and matrix. The lamina is unidirectional with the longitudinal fibers oriented in the 1 direction.

The rule-of-mixtures (ROM) [11] follows a linear volume fraction relationship between the composite and its corresponding constituent properties. ROM is an effective method for determining the Young's modulus, shear modulus, and Poisson ratios. Referencing Figure 2.2, the ROM equations for modulus and Poisson ratio values can be determined.

The average modulus in the fiber direction of Figure $2.2 E_{l}$ is

$$
E_{1}=E_{f} V_{f}+E_{m} V_{m}
$$

where $V_{f}$ and $V_{m}$ are the fiber and matrix volume fractions, respectively. The constituent properties are the fiber and matrix modulus values, $E_{f}$ and $E_{m}$.

The determination of the transverse modulus $E_{2}$ assumes that the stress is equal in both the fiber and matrix which maintains equilibrium in the transverse direction [8].

The transverse modulus is given by

$$
\frac{1}{E_{2}}=\frac{V_{f}}{E_{f}}+\frac{V_{m}}{E_{m}}
$$


The in-plane Poisson's ratio $v_{12}$ is equivalent to the negative ratio of the strain in the 2-direction to the strain in the 1-direction. The ROM equation for determining the inplane Poisson's ratio is

$$
v_{12}=v_{f} V_{f}+v_{m} V_{m}
$$

The determination of the in-plane shear modulus $G_{12}$ assumes that the shear stress in the fiber and matrix is equal. The average shear modulus of the lamina is given by

$$
\frac{1}{G_{12}}=\frac{v_{f}}{G_{f}}+\frac{v_{m}}{G_{m}}
$$

where $G_{f}$ is the fiber shear modulus and $G_{m}$ is the matrix shear modulus.

\subsubsection{Lamina Analysis}

Due to the thin nature of a composite lamina a state of plane stress can be assumed. A plane stress assumption in a lamina yields, $\sigma_{3}=\tau_{23}=\tau_{31}=0$. The stress and strain relations are then

$$
\begin{gathered}
\left(\begin{array}{l}
\varepsilon_{1} \\
\varepsilon_{2} \\
\gamma_{12}
\end{array}\right)=\left[\begin{array}{ccc}
1 / E_{1} & -v_{21} / E_{2} & 0 \\
-v_{12} / E_{1} & 1 / E_{2} & 0 \\
0 & 0 & 1 / G_{12}
\end{array}\right]\left(\begin{array}{l}
\sigma_{1} \\
\sigma_{2} \\
\tau_{12}
\end{array}\right) \\
\left(\begin{array}{l}
\sigma_{1} \\
\sigma_{2} \\
\tau_{12}
\end{array}\right)=\frac{1}{1-v_{21} v_{12}}\left[\begin{array}{ccc}
E_{1} & v_{21} E_{1} & 0 \\
v_{12} E_{2} & E_{2} & 0 \\
0 & 0 & G_{12}\left(1-v_{21} v_{12}\right)
\end{array}\right]\left(\begin{array}{l}
\varepsilon_{1} \\
\varepsilon_{2} \\
\gamma_{12}
\end{array}\right) \text { or } \sigma_{l}=Q_{l} \varepsilon_{l}
\end{gathered}
$$

where $l$ represents the local coordinate system. 
The properties of the lamina can now be determined. From these properties, we can describe the behavior of a laminate. It is first important to define coordinate systems which relate to the lamina and laminate structures. The local coordinate system $(1,2$, and 3 ) defines the position on the lamina. The global coordinate system (x,y, and $z$ ) defines the position on the laminate [10]. Since the properties in the local coordinate system are known a transformation from the local coordinate system to the global coordinate system is necessary. The transformation matrices are

$$
T=\left[\begin{array}{ccc}
c^{2} & s^{2} & -2 s c \\
s^{2} & c^{2} & 2 s c \\
s c & -s c & c^{2}-s^{2}
\end{array}\right] \quad T^{-1}=\left[\begin{array}{ccc}
c^{2} & s^{2} & 2 s c \\
s^{2} & c^{2} & -2 s c \\
-s c & s c & c^{2}-s^{2}
\end{array}\right]
$$

where $c=\cos \theta$ and $s=\sin \theta$. The transformation of stresses and strains between the local and global systems are written as

$$
\begin{aligned}
& \left(\begin{array}{l}
\sigma_{x} \\
\sigma_{y} \\
\tau_{x y}
\end{array}\right)=T\left(\begin{array}{l}
\sigma_{1} \\
\sigma_{2} \\
\tau_{12}
\end{array}\right) \\
& \left(\begin{array}{c}
\varepsilon_{1} \\
\varepsilon_{2} \\
\gamma_{12}
\end{array}\right)=T^{t}\left(\begin{array}{l}
\sigma_{1} \\
\sigma_{2} \\
\varepsilon_{y} \\
\gamma_{x y}
\end{array}\right)=T^{-1}\left(\begin{array}{l}
\sigma_{x} \\
\sigma_{y} \\
\tau_{x y}
\end{array}\right)
\end{aligned}
$$

The stress-strain equation for the global coordinate system therefore becomes

$$
\left(\begin{array}{c}
\sigma_{x} \\
\sigma_{y} \\
\tau_{x y}
\end{array}\right)=\left[\begin{array}{lll}
Q_{11} & Q_{12} & Q_{16} \\
Q_{12} & Q_{22} & Q_{26} \\
Q_{16} & Q_{26} & Q_{66}
\end{array}\right]\left(\begin{array}{c}
\varepsilon_{x} \\
\varepsilon_{y} \\
\gamma_{x y}
\end{array}\right) \quad \text { or } \sigma=Q \varepsilon
$$


The components of the $Q$ matrix which relate the global stresses to the global strains is determined from $[Q]=[T]^{-1}\left[Q_{l}\right][T]^{-t}$. The components of the $Q$ matrix can be written out as

$$
\begin{aligned}
& Q_{11}=Q_{l 11} \cos ^{4} \theta+2\left(Q_{l 12}+2 Q_{l 66}\right) \cos ^{2} \theta \sin ^{2} \theta+Q_{l 22} \sin ^{4} \theta \\
& Q_{12}=\left(Q_{l 11}+Q_{l 22}-4 Q_{l 66}\right) \cos ^{2} \theta \sin ^{2} \theta+Q_{l 12}\left(\sin ^{4} \theta+\cos ^{4} \theta\right) \\
& Q_{22}=Q_{l 11} \sin ^{4} \theta+2\left(Q_{l 12}+2 Q_{l 66}\right) \cos ^{2} \theta \sin ^{2} \theta+Q_{l 22} \cos ^{4} \theta \\
& Q_{16}=\left(Q_{l 11}-Q_{l 12}-2 Q_{l 66}\right) \sin \theta \cos ^{3} \theta+\left(Q_{l 12}-Q_{l 22}+2 Q_{l 66}\right) \sin ^{3} \theta \cos \theta \\
& Q_{26}=\left(Q_{l 11}-Q_{l 12}-2 Q_{l 66}\right) \sin ^{3} \theta \cos \theta+\left(Q_{l 12}-Q_{l 22}+2 Q_{l 66}\right) \sin \theta \cos ^{3} \theta \\
& Q_{66}=\left(Q_{l 11}+Q_{l 22}-2 Q_{l 12}-2 Q_{l 66}\right) \cos ^{2} \theta \sin ^{2} \theta+Q_{l 66}\left(\sin ^{4} \theta+\cos ^{4} \theta\right)
\end{aligned}
$$

\subsubsection{Laminate Analysis}

Composite materials including sandwich structures are composed of many lamina which are stacked in a defined sequence and orientation then bonded or cured together to form a laminate. Composites have the ability to optimize the orientation of each lamina layer which allows for tailoring of the material properties for given structure and set of loading applied to the structure.

Sandwich structures and laminates of several layers now embody a structure of nominal thickness. The stress-strain relationship for the $x-y-z$ coordinate system is defined by

$$
\left(\begin{array}{c}
\sigma_{x} \\
\sigma_{y} \\
\sigma_{x y} \\
\sigma_{y z} \\
\sigma_{x z} \\
\sigma_{x y}
\end{array}\right)=\left[\begin{array}{cccccc}
Q_{11} & Q_{12} & Q_{13} & 0 & 0 & Q_{16} \\
Q_{12} & Q_{22} & Q_{23} & 0 & 0 & Q_{26} \\
Q_{13} & Q_{23} & Q_{33} & 0 & 0 & Q_{36} \\
0 & 0 & 0 & Q_{44} & Q_{45} & 0 \\
0 & 0 & 0 & Q_{45} & Q_{55} & 0 \\
Q_{16} & Q_{26} & Q_{36} & 0 & 0 & Q_{66}
\end{array}\right]\left(\begin{array}{c}
\varepsilon_{x} \\
\varepsilon_{y} \\
\varepsilon_{z} \\
2 \varepsilon_{y z} \\
2 \varepsilon_{x z} \\
2 \varepsilon_{x y}
\end{array}\right)
$$

where the remaining undefined $Q$ values are 
$Q_{13}=Q_{112} \cos ^{2} \theta+Q_{123} \sin ^{2} \theta$

$Q_{23}=Q_{113} \sin ^{2} \theta+Q_{123} \cos ^{2} \theta$

$Q_{144}=G_{23}$

$Q_{33}=Q_{133}$

$Q_{155}=G_{13}$

$Q_{36}=\left(Q_{113}-Q_{123}\right) \cos \theta \sin \theta$

$Q_{l 13}=\left(v_{13}+v_{12} v_{23}\right) E_{33} / \Delta$

$Q_{44}=Q_{144} \cos ^{2} \theta+Q_{155} \sin ^{2} \theta$

$Q_{123}=\left(v_{23}+v_{21} v_{13}\right) E_{33} / \Delta$

$Q_{45}=\left(Q_{155}-Q_{144}\right) \cos \theta \sin \theta$

$\Delta=1-v_{12} v_{21}-v_{23} v_{32}-v_{31} v_{13}-2 v_{21} v_{13} v_{32}$

$Q_{55}=Q_{155} \cos ^{2} \theta+Q_{144} \sin ^{2} \theta$

For a laminate composed of $N$ lamina, the stresses and strains for the $k$ th layer of the laminate are related by the equation

$$
\left(\begin{array}{c}
\sigma_{x} \\
\sigma_{y} \\
\sigma_{z} \\
\sigma_{y z} \\
\sigma_{x z} \\
\sigma_{x y}
\end{array}\right)_{k}=[Q]_{k}\left(\begin{array}{c}
\varepsilon_{x} \\
\varepsilon_{y} \\
\varepsilon_{z} \\
2 \varepsilon_{y z} \\
2 \varepsilon_{x z} \\
2 \varepsilon_{x y}
\end{array}\right)_{k}
$$

where all matrices have the subscript $k$ because of the orientation of the particular lamina with respect to the global or $x-y$ coordinate system.

\subsubsection{Plate Stiffness and Stress and Strain Variation}

The extension and bending stiffness of a laminate is defined by the variation of stress and strain through the thickness of a laminate. Analysis takes into consideration that the bonds between layers are perfect resulting in continuous displacements across the lamina edges.

From Barbero [2], Zenkert [10], and Jones [11], the assumptions of plate stiffness are as follows for a thin laminate and referencing Figure 2.3.

(1) A line originally straight and perpendicular to the middle surface (line A-D) remains in this manner after the plate is deformed. This assumption is presumed from 
experimental observations and implies that shear strains $\gamma_{x z}$ and $\gamma_{y z}$ are constant through the thickness.

(2) Line A-D is assumed to have constant length therefore, the strain perpendicular to the middle surface is neglected or $\varepsilon_{z}=0$.

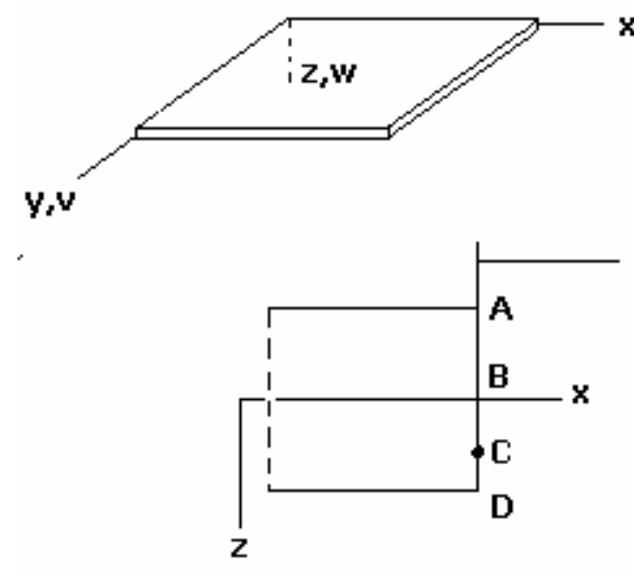

Undeformed Section

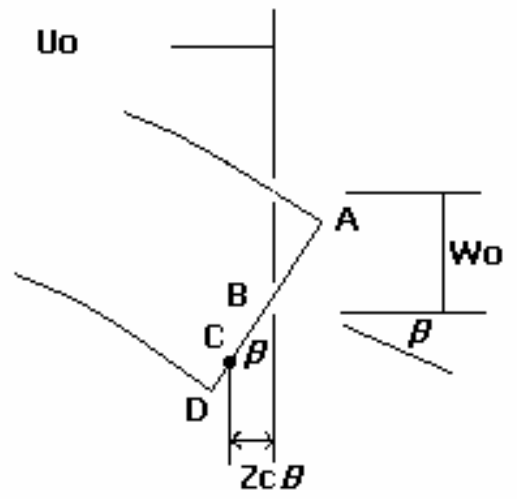

Deformed Section

Figure 2.3: Undeformed and deformed cross sections of a laminate plate.

Figure 2.3 shows a laminate plate and a removed cross section which is viewed in the $x z$ plane. The laminate displacements are labeled as $u, v$, and $w$ and are in the respective $x, y$, and $z$ directions. From assumption (1)

$$
u_{c}=u_{o}-z_{c} \beta
$$

where $\beta=\frac{\partial w_{o}}{\partial x}$.

The displacement, $u$, at any point $z$ through the laminate thickness becomes $u=u_{o}-z \frac{\partial w_{o}}{\partial x}$

and the displacement $v$ in the $y$-direction is 
$v=v_{o}-z \frac{\partial w_{o}}{\partial y}$

From the assumptions and classical plate theory, $\varepsilon_{z}=\gamma_{y z}=\gamma_{x z}=0$ the strains within the plate are defined as

$$
\begin{array}{lll}
\varepsilon_{x}=\frac{\partial u}{\partial x}=\frac{\partial u_{o}}{\partial x}-z \frac{\partial^{2} w_{o}}{\partial x^{2}} & \\
\varepsilon_{y}=\frac{\partial v}{\partial y}=\frac{\partial v_{o}}{\partial y}-z \frac{\partial^{2} w_{o}}{\partial y^{2}} & \text { or } & \left(\begin{array}{c}
\varepsilon_{x} \\
\varepsilon_{y} \\
\gamma_{x y}
\end{array}\right)=\left(\begin{array}{c}
\varepsilon_{x}^{o} \\
\varepsilon_{y}^{o} \\
\gamma_{x y}^{o}
\end{array}\right)+z\left(\begin{array}{c}
\kappa_{x} \\
\kappa_{y} \\
\kappa_{x y}
\end{array}\right) \\
\gamma_{x y}=\frac{\partial u}{\partial y}+\frac{\partial v}{\partial x}=\frac{\partial u_{o}}{\partial y}+\frac{\partial v_{o}}{\partial x}-2 z \frac{\partial^{2} w_{o}}{\partial x \partial y} & &
\end{array}
$$

where the midsurface strains $\varepsilon^{o}$ and the midsurface curvatures $\kappa$ are

$$
\left(\begin{array}{c}
\varepsilon_{x}^{o} \\
\varepsilon_{y}^{o} \\
\gamma_{x y}^{o}
\end{array}\right)=\left(\begin{array}{c}
\frac{\partial u_{o}}{\partial x} \\
\frac{\partial v_{o}}{\partial y} \\
\frac{\partial u_{o}}{\partial y}+\frac{\partial v_{o}}{\partial x}
\end{array}\right)
$$

$$
\left(\begin{array}{c}
\kappa_{x} \\
\kappa_{y} \\
\kappa_{x y}
\end{array}\right)=-\left(\begin{array}{c}
\frac{\partial^{2} w_{o}}{\partial x^{2}} \\
\frac{\partial^{2} w_{o}}{\partial y^{2}} \\
2 \frac{\partial^{2} w_{o}}{\partial x \partial y}
\end{array}\right)
$$

The next phase of laminate analysis is to relate the resulting forces and bending moments to the laminate strains and curvatures.

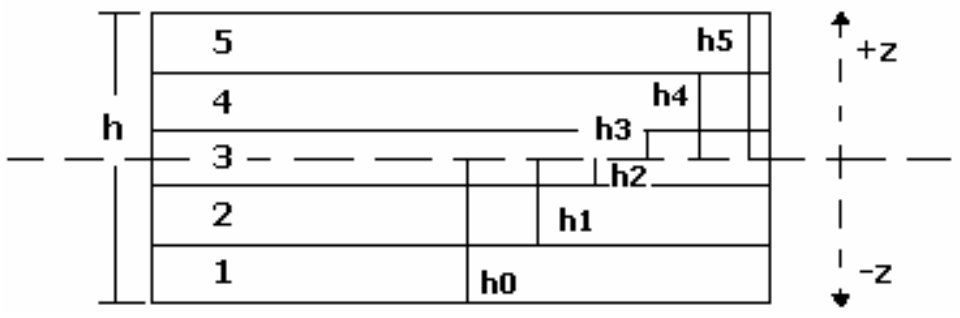

Figure 2.4: Referencing of the stacking sequence for a composite laminate. 
A five layer composite laminate of thickness $h$ is shown in Figure 2.4. The dimensions above the midplane $z=0$ is positive and below the midplane is negative. The distance to the top of the $k$ th layer is defined by $h_{k}$.

Following classical plate, beam, and shell theory the stress resultants $(N)$, stress couples $(M)$, and the transverse shear resultants $(Q)$ are defined per unit width of the overall structure without taking into account the number of lamina and their orientation.

$$
\left(\begin{array}{c}
N_{x} \\
N_{y} \\
N_{x y} \\
Q_{x} \\
Q_{y}
\end{array}\right)=\int_{-h / 2}^{h / 2}\left(\begin{array}{c}
\sigma_{x} \\
\sigma_{y} \\
\sigma_{x y} \\
\sigma_{x z} \\
\sigma_{y z}
\end{array}\right) d z \quad \text { and } \quad\left(\begin{array}{c}
M_{x} \\
M_{y} \\
M_{x y}
\end{array}\right)=\int_{-h / 2}^{h / 2}\left(\begin{array}{c}
\sigma_{x} \\
\sigma_{y} \\
\sigma_{x y}
\end{array}\right) z d z
$$

In plate and shell structures, the above resultants vary in both the $x$ and $y$ direction therefore, it is important to note the results are in force per unit length (width) and couple per unit length.

In a laminate or sandwich plate, the stress values across each lamina can be integrated. Since the stiffness matrix is constant for a single lamina, it can be removed from the integration over each layer but is accounted for in the summation of force and moment results for each layer.

Referencing Figure 2.4:

$$
\begin{aligned}
& \left(\begin{array}{l}
N_{x} \\
N_{y} \\
N_{x y}
\end{array}\right)=\sum_{k=1}^{N}\left[\begin{array}{lll}
Q_{11} & Q_{12} & Q_{16} \\
Q_{12} & Q_{22} & Q_{26} \\
Q_{16} & Q_{26} & Q_{66}
\end{array}\right]_{k}\left(\int_{z_{k-1}}^{z_{k}}\left(\begin{array}{c}
\varepsilon_{x}^{o} \\
\varepsilon_{y}^{o} \\
\gamma_{x y}^{o}
\end{array}\right) d z+\int_{z_{k-1}}^{z_{k}}\left(\begin{array}{c}
\kappa_{x} \\
\kappa_{y} \\
\kappa_{x y}
\end{array}\right) z d z\right) \\
& \left(\begin{array}{l}
M_{x} \\
M_{y} \\
M_{x y}
\end{array}\right)=\sum_{k=1}^{N}\left[\begin{array}{lll}
Q_{11} & Q_{12} & Q_{16} \\
Q_{12} & Q_{22} & Q_{26} \\
Q_{16} & Q_{26} & Q_{66}
\end{array}\right]_{k}\left(\int_{z_{k-1}}^{z_{k}}\left(\begin{array}{c}
\varepsilon_{x}^{o} \\
\varepsilon_{y}^{o} \\
\gamma_{x y}^{o}
\end{array}\right) z d z+\int_{z_{k-1}}^{z_{k}}\left(\begin{array}{l}
\kappa_{x} \\
\kappa_{y} \\
\kappa_{x y}
\end{array}\right) z^{2} d z\right)
\end{aligned}
$$


Removing the values $\varepsilon_{x}^{o}, \varepsilon_{y}^{o}, \gamma_{x y}^{o}, \kappa_{x}$, and $\kappa_{x y}$ because they are midsurface functions and not functions of the thickness, $z$ results in the previous equations taking the form of

$$
\begin{aligned}
& \left(\begin{array}{l}
N_{x} \\
N_{y} \\
N_{x y}
\end{array}\right)=\left[\begin{array}{lll}
A_{11} & A_{12} & A_{16} \\
A_{12} & A_{22} & A_{26} \\
A_{16} & A_{26} & A_{66}
\end{array}\right]\left(\begin{array}{c}
\varepsilon_{x}^{o} \\
\varepsilon_{y}^{o} \\
\gamma_{x y}^{o}
\end{array}\right)+\left[\begin{array}{lll}
B_{11} & B_{12} & B_{16} \\
B_{12} & B_{22} & B_{26} \\
B_{16} & B_{26} & B_{66}
\end{array}\right]\left(\begin{array}{l}
\kappa_{x} \\
\kappa_{y} \\
\kappa_{x y}
\end{array}\right) \\
& \left(\begin{array}{l}
M_{x} \\
M_{y} \\
M_{x y}
\end{array}\right)=\left[\begin{array}{lll}
B_{11} & B_{12} & B_{16} \\
B_{12} & B_{22} & B_{26} \\
B_{16} & B_{26} & B_{66}
\end{array}\right]\left(\begin{array}{l}
\varepsilon_{x}^{o} \\
\varepsilon_{y}^{o} \\
\gamma_{x y}^{o}
\end{array}\right)+\left[\begin{array}{lll}
D_{11} & D_{12} & D_{16} \\
D_{12} & D_{22} & D_{26} \\
D_{16} & D_{26} & D_{66}
\end{array}\right]\left(\begin{array}{l}
\kappa_{x} \\
\kappa_{y} \\
\kappa_{x y}
\end{array}\right)
\end{aligned}
$$

where the extensional stiffness matrix $A_{i j}$ is defined as

$$
A_{i j}=\sum_{k=1}^{N}\left(Q_{i j}\right)_{k}\left(z_{k}-z_{k-1}\right)
$$

the coupling stiffness matrix $B_{i j}$ is defined as

$$
B_{i j}=\frac{1}{2} \sum_{k=1}^{N}\left(Q_{i j}\right)_{k}\left(z_{k}^{2}-z_{k-1}^{2}\right)
$$

and the bending stiffness matrix $D_{i j}$ is defined as

$$
D_{i j}=\frac{1}{3} \sum_{k=1}^{N}\left(Q_{i j}\right)_{k}\left(z_{k}^{3}-z_{k-1}^{3}\right)
$$

The $A_{i j}, B_{i j}$, and $D_{i j}$ matrices are functions of the thickness, orientation, stacking sequence, and material properties of the layers of the laminate [11]. The presence of the $B_{i j}$ matrix indicates coupling between the bending and extension of a laminate loaded in in-plane tension. Also, a laminate which experiences a moment when the $B_{i j}$ matrix is present will also undergo extension of the middle surface.

A symmetric laminate, one that has identical orientation, thickness and material properties about the middle surface, results in a zero $B_{i j}$ matrix. Therefore, when a 
laminate is loaded with a set of in-plane forces only middle surface strains result. Also, under a set of bending moments only curvatures will be produced in the laminate [12].

\subsubsection{Stiffness Properties of a Sandwich Structure}

A midplane symmetric sandwich structure can be analyzed in the same method as a laminate but defining the bottom sheet as lamina 1, the core as lamina 2 and the top sheet as lamina 3 [9]. Assuming that each layer is isotropic then $[Q]=\left[Q_{l}\right]$ and the $A_{i j}$ matrix can be written as

$A_{i j}=\left(Q_{i j}\right)_{f} t_{f}+\left(Q_{i j}\right)_{c} h_{c}+\left(Q_{i j}\right)_{f} t_{f}=2\left(Q_{i j}\right)_{f} t_{f}+\left(Q_{i j}\right)_{c} h_{c}$

where the subscripts $f$ and $c$ reference the face and core, respectively. The height of the core is defined by $h_{c}$ and the thickness of the face sheet is $t_{f}$.

Similarly,

$$
D_{i j}=\frac{1}{3}\left(Q_{i j}\right)_{f}\left[\left(-\frac{h_{c}}{2}\right)^{3}-\left(-\frac{h_{c}}{2}-t_{f}\right)^{3}\right]+\frac{1}{3}\left(Q_{i j}\right)_{c}\left[\left(\frac{h_{c}}{2}\right)^{3}-\left(-\frac{h_{c}}{2}\right)^{3}\right]+\frac{1}{3}\left(Q_{i j}\right)_{f}\left[-\left(\frac{h_{c}}{2}\right)^{3}+\left(\frac{h_{c}}{2}+t_{f}\right)^{3}\right]
$$

The $B_{i j}$ matrix is not studied in this section because the limit is a midplane symmetric laminate and as discussed previous the $B_{i j}$ matrix is zero under this condition.

It is commonly assumed that the stiffness of the core is negligible compared to the stiffness of the face sheet. This assumption is valid for traditional sandwich composites which may have a foam, wood, or honeycomb core [13]. However, the research within this work not only uses traditional composite core assumptions but is progressive in the sense to introduce core structures that have respectable stiffness values alone. 


\subsection{Classical Theory of Laminate or Sandwich Plate Bending}

\subsubsection{Equilibrium Equations}

This section follows the work of Vinson [9,14] and Zenkert [10] and others contributing to the classical theory of laminates and sandwich panels.

The equilibrium equations for three-dimensional elasticity are written as

$$
\begin{aligned}
& \frac{\partial \sigma_{x}}{\partial x}+\frac{\partial \sigma_{y x}}{\partial y}+\frac{\partial \sigma_{z x}}{\partial z}+F_{x}=0 \\
& \frac{\partial \sigma_{x y}}{\partial x}+\frac{\partial \sigma_{y}}{\partial y}+\frac{\partial \sigma_{z y}}{\partial z}+F_{y}=0 \\
& \frac{\partial \sigma_{x z}}{\partial x}+\frac{\partial \sigma_{y z}}{\partial y}+\frac{\partial \sigma_{z}}{\partial z}+F_{z}=0
\end{aligned}
$$

where forces $F_{x}, F_{y}$, and $F_{z}$ are the body forces.

These three equations define a single layer or thin plate. For beam, plate, or shell theory the stresses must be integrated across the thickness of the structure to acquire a solution to the system.

As seen in the previous section the stress resultants and couples can be defined as

$$
\left(\begin{array}{c}
N_{x} \\
N_{y} \\
N_{x y} \\
Q_{x} \\
Q_{y}
\end{array}\right)=\int_{-h / 2}^{h / 2}\left(\begin{array}{c}
\sigma_{x} \\
\sigma_{y} \\
\sigma_{x y} \\
\sigma_{x z} \\
\sigma_{y z}
\end{array}\right) d z \quad \text { and } \quad\left(\begin{array}{c}
M_{x} \\
M_{y} \\
M_{x y}
\end{array}\right)=\int_{-h / 2}^{h / 2}\left(\begin{array}{c}
\sigma_{x} \\
\sigma_{y} \\
\sigma_{x y}
\end{array}\right) z d z
$$

For laminated plates and sandwich structures it is necessary to account for the stress discontinuities resulting from different layers, orientations, and material properties. Therefore the stress resultants for laminates and sandwich structures are 


$$
\left(\begin{array}{c}
N_{x} \\
N_{y} \\
N_{x y} \\
Q_{x} \\
Q_{y}
\end{array}\right)=\sum_{k=1}^{N} \int_{h_{k-1}}^{h_{k}}\left(\begin{array}{c}
\sigma_{x} \\
\sigma_{y} \\
\sigma_{x y} \\
\sigma_{x z} \\
\sigma_{y z}
\end{array}\right)_{k} d z_{k} \quad \text { and } \quad\left(\begin{array}{c}
M_{x} \\
M_{y} \\
M_{x y}
\end{array}\right)=\sum_{k=1}^{N} \int_{h_{k-1}}^{h_{k}}\left(\begin{array}{c}
\sigma_{x} \\
\sigma_{y} \\
\sigma_{x y}
\end{array}\right)_{k} z_{k} d z_{k}
$$

Studying the equilibrium equation in the x-direction or equation (1) from above, neglecting the $\mathrm{F}_{\mathrm{x}}$ body force, integrating by term across each layer and summing yields

$$
\frac{\partial}{\partial x}\left[\sum_{k=1}^{N} \int_{h_{k-1}}^{h_{k}} \sigma_{x_{k}} d z\right]+\frac{\partial}{\partial y}\left[\sum_{k=1}^{N} \int_{h_{k-1}}^{h_{k}} \sigma_{y x_{k}} d z\right]+\sum_{k=1}^{N} \sigma_{z x}\left(h_{k}\right)-\sigma_{z x}\left(h_{k-1}\right)=0
$$

or

$$
\frac{\partial N_{x}}{\partial x}+\frac{\partial N_{y x}}{\partial y}+\sigma_{z x}\left(h_{N}\right)-\sigma_{z x}\left(h_{o}\right)=0
$$

$h_{N}$ and $h_{o}$ are the top and bottom surfaces, respectively. The third term in equation (4) represents how the interlaminar shear stresses cancel each other out between plies and and between the face and core material. Therefore the only remaining terms are the shear stresses on the top and bottom layer are seen in the simplification in equation (5). The equilibrium in the y-direction follows as

$$
\frac{\partial N_{x y}}{\partial x}+\frac{\partial N_{y}}{\partial y}+\sigma_{z y}\left(h_{N}\right)-\sigma_{z y}\left(h_{o}\right)=0
$$

and in the z-direction

$$
\frac{\partial Q_{x}}{\partial x}+\frac{\partial Q_{y}}{\partial y}+\sigma_{z}\left(h_{N}\right)-\sigma_{z}\left(h_{o}\right)=0 \quad \text { or } \quad \frac{\partial Q_{x}}{\partial x}+\frac{\partial Q_{y}}{\partial y}+p_{1}-p_{2}=0
$$


Equations (5), (6), and (7) define the force equilibrium equations. The moment equilibrium equations can be defined for the $\mathrm{x}$-direction and the y-direction. For the $\mathrm{x}$ direction the moment equilibrium equation is

$$
\frac{\partial M_{x}}{\partial x}+\frac{\partial M_{x y}}{\partial y}-Q_{x}+\frac{h}{2}\left[\sigma_{z x}\left(h_{N}\right)+\sigma_{z x}\left(h_{o}\right)\right]=0
$$

and in the y-direction

$$
\frac{\partial M_{x y}}{\partial x}+\frac{\partial M_{y}}{\partial y}-Q_{y}+\frac{h}{2}\left[\sigma_{z y}\left(h_{N}\right)+\sigma_{z y}\left(h_{o}\right)\right]=0
$$

\subsubsection{Bending Analysis Excluding Transverse Shear Deformation Effects}

A mid-plane symmetric laminate with $B_{i j}=0$ reduces the plate bending equilibrium equations (7), (8), and (9) to

$$
\begin{aligned}
& \frac{\partial M_{x}}{\partial x}+\frac{\partial M_{x y}}{\partial y}-Q_{x}=0 \\
& \frac{\partial M_{y}}{\partial x}+\frac{\partial M_{x y}}{\partial y}-Q_{y}=0 \\
& \frac{\partial Q_{x}}{\partial x}+\frac{\partial Q_{y}}{\partial y}=-p_{1}(x, y)+p_{2}(x, y)=p(x, y)
\end{aligned}
$$

Solving the system of equations for $p(x, y)$ yields

$$
\frac{\partial^{2} M_{x}}{\partial x^{2}}+2 \frac{\partial^{2} M_{x y}}{\partial x \partial y}+\frac{\partial^{2} M_{y}}{\partial y^{2}}=-p(x, y)
$$

Using the characteristics of a mid-plane symmetric laminate which are $\mathrm{Bij}=0$ and uncoupling bending and twisting terms the equation 


$$
\left(\begin{array}{l}
M_{x} \\
M_{y} \\
M_{x y}
\end{array}\right)=\left[\begin{array}{lll}
B_{11} & B_{12} & B_{16} \\
B_{12} & B_{22} & B_{26} \\
B_{16} & B_{26} & B_{66}
\end{array}\right]\left(\begin{array}{c}
\varepsilon_{x}^{o} \\
\varepsilon_{y}^{o} \\
\gamma_{x y}^{o}
\end{array}\right)+\left[\begin{array}{ccc}
D_{11} & D_{12} & D_{16} \\
D_{12} & D_{22} & D_{26} \\
D_{16} & D_{26} & D_{66}
\end{array}\right]\left(\begin{array}{c}
\kappa_{x} \\
\kappa_{y} \\
\kappa_{x y}
\end{array}\right)
$$

becomes

$$
\left(\begin{array}{l}
M_{x} \\
M_{y} \\
M_{x y}
\end{array}\right)=\left[\begin{array}{ccc}
D_{11} & D_{12} & 0 \\
D_{12} & D_{22} & 0 \\
0 & 0 & D_{66}
\end{array}\right]\left(\begin{array}{c}
\kappa_{x} \\
\kappa_{y} \\
2 \kappa_{x y}
\end{array}\right)=\left[\begin{array}{ccc}
D_{11} & D_{12} & 0 \\
D_{12} & D_{22} & 0 \\
0 & 0 & D_{66}
\end{array}\right]\left(\begin{array}{c}
-\partial^{2} w / \partial x^{2} \\
-\partial^{2} w / \partial y^{2} \\
-2 \partial^{2} w / \partial x \partial y
\end{array}\right)
$$

Therefore the governing differential equation for a composite laminate or sandwich plate excluding transverse shear deformations, with no coupling terms, and under a later load $p(x, y)$ is

$$
D_{11} \frac{\partial^{4} w}{\partial x^{4}}+2\left(D_{12}+2 D_{66}\right) \frac{\partial^{4} w}{\partial x^{2} \partial y^{2}}+D_{22} \frac{\partial^{4} w}{\partial y^{4}}=p(x, y)
$$

\subsubsection{Bending Analysis Including Transverse Shear Deformation Effects}

From Whitney [15] and Vinson [9], the classical plate theory has been used thus far to derive the equilibrium and governing equations. This theory neglects the transverse shear deformation effects or stated, $\varepsilon_{\mathrm{xz}}=\varepsilon_{\mathrm{yz}}=0$. The classical plate theory is effective to acquire preliminary design analysis of structures to save on cost and time.

A more developed theory in the analysis of plates and sandwich structures includes the transverse shear effects or stated $\varepsilon_{\mathrm{xz}}$ and $\varepsilon_{\mathrm{yz}}$ are nonzero. $\varepsilon_{\mathrm{xz}}$ and $\varepsilon_{\mathrm{yz}}$ are defined as

$$
\varepsilon_{x z}=\frac{1}{2}\left(\gamma+\frac{\partial w}{\partial x}\right) \quad \varepsilon_{y z}=\frac{1}{2}\left(\psi+\frac{\partial w}{\partial y}\right)
$$


where $\gamma$ and $\psi$ are the rotations and are defined as $\frac{\partial u}{\partial z}$ and $\frac{\partial v}{\partial z}$ respectively. In classical plate theory $\gamma$ and $\psi$ took the values of $-\frac{\partial w}{\partial x}$ and $-\frac{\partial w}{\partial y}$ which ultimately produced $\varepsilon_{\mathrm{xz}}=\varepsilon_{\mathrm{yz}}=0$. However, when accounting for transverse shear deformation affects $\gamma$ and $\psi$ are unknown dependent variables which must be solved for yielding five unknowns to be solved for $\mathrm{u}_{\mathrm{o}}, \mathrm{v}_{\mathrm{o}} \mathrm{w}, \gamma$ and $\psi$.

Taking into account the nonzero values for $\varepsilon_{\mathrm{xz}}$ and $\varepsilon_{\mathrm{yz}}$ and revisiting the equilibrium equations from classical plate theory the governing differential equations for a symmetric laminate composite plate subjected to a lateral load are

$$
\begin{aligned}
& D_{11} \frac{\partial^{2} \gamma}{\partial x^{2}}+D_{66} \frac{\partial^{2} \gamma}{\partial y^{2}}+\left(D_{66}+D_{12}\right) \frac{\partial^{2} \psi}{\partial x \partial y}-2 A_{55}\left(\gamma+\frac{\partial w}{\partial x}\right)=0 \\
& \left(D_{66}+D_{12}\right) \frac{\partial^{2} \gamma}{\partial x \partial y}+D_{66} \frac{\partial^{2} \psi}{\partial y^{2}}+D_{22} \frac{\partial^{2} \psi}{\partial y^{2}}-2 A_{44}\left(\psi+\frac{\partial w}{\partial y}\right)=0 \\
& 2 A_{55}\left(\frac{\partial \gamma}{\partial x}+\frac{\partial^{2} w}{\partial x^{2}}\right)+2 A_{44}\left(\frac{\partial \psi}{\partial y}+\frac{\partial^{2} w}{\partial y^{2}}\right)+p(x, y)=0
\end{aligned}
$$

The three partial differential equations that govern a laminate or sandwich panel have three unknowns $\mathrm{w}, \gamma$ and $\psi$. As shown, the complexity of the laterally loaded system increases from the classical plate theory to the refined theory with the inclusion of transverse shear deformation effects.

\subsubsection{Dynamic Loading of Laminates or Sandwich Panels}

Dynamic loading is characterized by time dependent loads and the implementation of a time variable into the governing equation does not require the development of new theory.

The changes to the governing equation of the classical plate theory and the refined theory which includes transverse shear deformation including acceleration terms or the second derivative of the displacement term. 
For the classical plate theory, Vinson [9] and Dobyns [16], the governing equation of a homogenous plate becomes

$$
D_{11} \frac{\partial^{4} w}{\partial x^{4}}+2\left(D_{12}+2 D_{66}\right) \frac{\partial^{4} w}{\partial x^{2} \partial y^{2}}+D_{22} \frac{\partial^{4} w}{\partial y^{4}}+\rho_{m} h \frac{\partial^{2} w}{\partial t^{2}}=p(x, y, t)
$$

where the introduction of the inertia term $\rho_{m} h \frac{\partial^{2} w}{\partial t^{2}}$ and the time dependent load, $p(x, y, t)$ are changes from the classical plate theory governing equation. The term $\rho_{m}$ is the mass density of the plate material and $h$ is the thickness of the plate. For a composite laminate with different material layers $\rho_{m} h$ term must be summed throughout the laminate layers resulting in the equation form

$$
D_{11} \frac{\partial^{4} w}{\partial x^{4}}+2\left(D_{12}+2 D_{66}\right) \frac{\partial^{4} w}{\partial x^{2} \partial y^{2}}+D_{22} \frac{\partial^{4} w}{\partial y^{4}}+\frac{\partial^{2} w}{\partial t^{2}} \sum_{k=1}^{N} \rho_{m_{k}}\left(h_{k}-h_{k-1}\right)=p(x, y, t)
$$

When including transverse shear deformation effects, the three governing equations become

$$
\begin{aligned}
& D_{11} \frac{\partial^{2} \gamma}{\partial x^{2}}+D_{66} \frac{\partial^{2} \gamma}{\partial y^{2}}+\left(D_{66}+D_{12}\right) \frac{\partial^{2} \psi}{\partial x \partial y}-2 A_{55}\left(\gamma+\frac{\partial w}{\partial x}\right)-I \frac{\partial^{2} \gamma}{\partial t^{2}}=0 \\
& \left(D_{66}+D_{12}\right) \frac{\partial^{2} \gamma}{\partial x \partial y}+D_{66} \frac{\partial^{2} \psi}{\partial y^{2}}+D_{22} \frac{\partial^{2} \psi}{\partial y^{2}}-2 A_{44}\left(\psi+\frac{\partial w}{\partial y}\right)-I \frac{\partial^{2} \psi}{\partial t^{2}}=0 \\
& 2 A_{55}\left(\frac{\partial \gamma}{\partial x}+\frac{\partial^{2} w}{\partial x^{2}}\right)+2 A_{44}\left(\frac{\partial \psi}{\partial y}+\frac{\partial^{2} w}{\partial y^{2}}\right)-\rho_{m} h \frac{\partial^{2} w}{\partial t^{2}}+p(x, y, t)=0
\end{aligned}
$$

where $I=\frac{\rho_{m} h^{3}}{12}$ for a solid homogenous plate. Analysis of a composite laminate or sandwich composite plate uses the summation of $I$ through the laminate layers, $I=\frac{1}{3} \sum_{k=1}^{N} \rho_{m_{k}}\left(h_{k}^{3}-h_{k-1}^{3}\right)$. Therefore, the governing equations for a composite laminate or sandwich structure under dynamic loading effects are 


$$
\begin{aligned}
& D_{11} \frac{\partial^{2} \gamma}{\partial x^{2}}+D_{66} \frac{\partial^{2} \gamma}{\partial y^{2}}+\left(D_{66}+D_{12}\right) \frac{\partial^{2} \psi}{\partial x \partial y}-2 A_{55}\left(\gamma+\frac{\partial w}{\partial x}\right)-\frac{\partial^{2} \gamma}{\partial t^{2}} \frac{1}{3} \sum_{k=1}^{N} \rho_{m_{k}}\left(h_{k}^{3}-h_{k-1}^{3}\right)=0 \\
& \left(D_{66}+D_{12}\right) \frac{\partial^{2} \gamma}{\partial x \partial y}+D_{66} \frac{\partial^{2} \psi}{\partial y^{2}}+D_{22} \frac{\partial^{2} \psi}{\partial y^{2}}-2 A_{44}\left(\psi+\frac{\partial w}{\partial y}\right)-\frac{\partial^{2} \psi}{\partial t^{2}} \frac{1}{3} \sum_{k=1}^{N} \rho_{m_{k}}\left(h_{k}^{3}-h_{k-1}^{3}\right)=0 \\
& 2 A_{55}\left(\frac{\partial \gamma}{\partial x}+\frac{\partial^{2} w}{\partial x^{2}}\right)+2 A_{44}\left(\frac{\partial \psi}{\partial y}+\frac{\partial^{2} w}{\partial y^{2}}\right)-\frac{\partial^{2} w}{\partial t^{2}} \sum_{k=1}^{N} \rho_{m_{k}}\left(h_{k}-h_{k-1}\right)+p(x, y, t)=0
\end{aligned}
$$

\subsection{Solutions for Rectangular Sandwich Plates}

The general plate theory and governing differential equations have been previously discussed. Determining the solutions for rectangular sandwich plates may be the result of increasingly complex problems, therefore, solution strategies and techniques are provided for guidance.

It is best to use energy solutions for problems with discontinuous boundary conditions, multiple discontinuous or concentrated loads, general anisotropy, or thermoelastic problems. This section will be discussing the Navier solution for sandwich plates under loading.

\subsubsection{Navier Solution for Sandwich Plates with All Four Edges Simply Supported}

Solving by the Navier solution introduces a displacement function, $w(x, y)$ and a load function $p(x, y)$ which serve as separable solutions to sandwich plate analysis

$$
\begin{aligned}
& w(x, y)=\sum_{m=1}^{\infty} \sum_{n=1}^{\infty} A_{m n} \overline{X_{m}}(x) \overline{Y_{n}}(y) \\
& p(x, y)=\sum_{m=1}^{\infty} \sum_{n=1}^{\infty} B_{m n} \overline{X_{m}}(x) \overline{Y_{n}}(y)
\end{aligned}
$$

where, for a simply supported plate on all edges, $\overline{X_{m}}(x)$ and $\overline{Y_{n}}(y)$ are defined as 


$$
\overline{X_{m}}(x)=\sin \left(\frac{m \pi x}{a}\right) \quad \overline{Y_{n}}(y)=\sin \left(\frac{n \pi y}{b}\right)
$$

The values $a$ and $b$ are the dimensions of the plate in the $x$-direction and $y$-direction, respectively.

Solving for $B_{m n}$ determines whether the load $p(x, y)$ is continuous or discontinuous. The $B_{m n}$ value is used for isotropic or orthotropic plates, analysis including or excluding transverse shear deformation, and is for single lamina, laminates and sandwich plates.

$$
B_{m n}=\frac{4}{a b} \int_{0}^{a} \int_{0}^{b} p(x, y) \sin \left(\frac{m \pi x}{a}\right) \sin \left(\frac{n \pi y}{b}\right) d y d x
$$

Considering an orthotropic sandwich panel and ignoring transverse shear deformation effects the governing differential equation for the plate is

$$
D_{11} \frac{\partial^{4} w}{\partial x^{4}}+2\left(D_{12}+2 D_{66}\right) \frac{\partial^{4} w}{\partial x^{2} \partial y^{2}}+D_{22} \frac{\partial^{4} w}{\partial y^{4}}=p(x, y)
$$

as derived in previous sections. Thus, $A_{m n}$ is solved for and becomes

$$
A_{m n}=\frac{B_{m n}}{D_{11}\left(\frac{m \pi}{a}\right)^{4}+2\left(D_{12}+2 D_{66}\right)\left(\frac{m \pi}{a}\right)^{2}\left(\frac{n \pi}{b}\right)+D_{22}\left(\frac{n \pi}{b}\right)^{4}}
$$

A solution for the displacement function $w(x, y)$ allows determination of the magnitude and location of the maximum plate deflection. The derivatives of $w(x, y)$ are then used in the stress couple equations

$$
\left(\begin{array}{l}
M_{x} \\
M_{y} \\
M_{x y}
\end{array}\right)=\left[\begin{array}{ccc}
D_{11} & D_{12} & 0 \\
D_{12} & D_{22} & 0 \\
0 & 0 & D_{66}
\end{array}\right]\left(\begin{array}{c}
\kappa_{x} \\
\kappa_{y} \\
2 \kappa_{x y}
\end{array}\right)=\left[\begin{array}{ccc}
D_{11} & D_{12} & 0 \\
D_{12} & D_{22} & 0 \\
0 & 0 & D_{66}
\end{array}\right]\left(\begin{array}{c}
-\partial^{2} w / \partial x^{2} \\
-\partial^{2} w / \partial y^{2} \\
-2 \partial^{2} w / \partial x \partial y
\end{array}\right)
$$

where the maximum values and location of $M_{x}, M_{y}$, and $M_{x y}$ are determined. From the stress couples, the maximum stresses in the lamina, laminate, or sandwich panel are determined with the correct corresponding equations to the plate type. 


\subsubsection{Levy Solution for Plates with Two Edges Simply Supported}

The Levy solution [17,9] is effective for a composite plate with no bendingstretching coupling, having midplane symmetry, and simply supported opposing edges as more clearly defined in Figure 2.5.

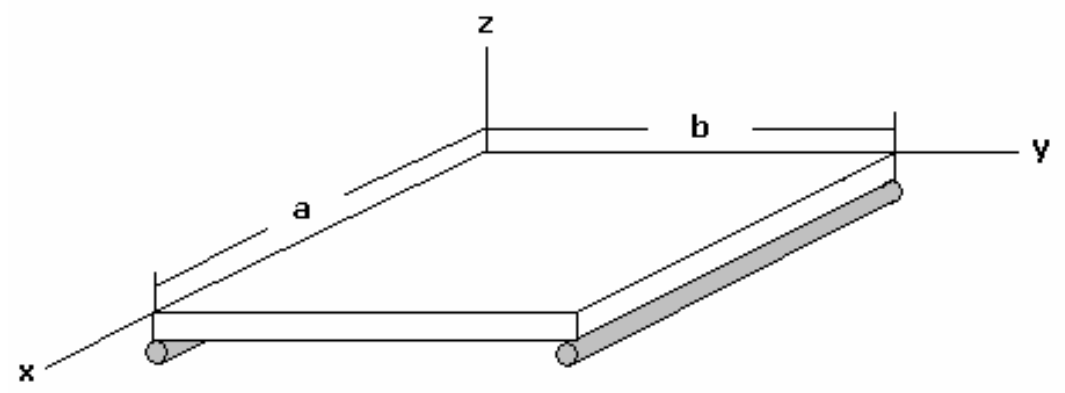

Figure 2.5: A simply supported composite plate used for Levy solution analysis.

Studying Figure 2.5, the boundary conditions for the plate are defined as

$$
\begin{aligned}
& w(x, 0)=w(x, b)=0 \\
& M_{y}(x, 0)=M_{y}(x, b)=0
\end{aligned}
$$

The steps following to the complete solution of the simply supported plate are taken directly from Levy [17] as analyzed by Vinson [9,14]. Levy assumes a single infinite half-range sine series satisfying the simply supported boundary conditions to be

$$
w(x, y)=\sum_{n=1}^{\infty} \phi_{n}(x) \sin \left(\frac{n \pi y}{b}\right)
$$

where $\phi_{n}(x)$ is currently an unknown function of $x$. The laterally distributed load $p(\mathrm{x}, \mathrm{y})$ can be defined as

$$
\begin{gathered}
p(x, y)=g(x) h(y)=g(x) \sum_{n=1}^{\infty} A_{n} \sin \left(\frac{n \pi y}{b}\right) \\
A_{n}=\frac{2}{b} \int_{0}^{b} h(y) \sin \left(\frac{n \pi y}{b}\right) d y
\end{gathered}
$$

Now, substituting equations (2) and (3) into the governing differential equation of the plate (4) and dividing by $D_{1}$ yields 


$$
\frac{d^{4} \phi_{n}(x)}{d x^{4}}-\frac{2 D_{3}}{D_{1}} \lambda_{n}{ }^{2} \frac{d^{2} \phi_{n}(x)}{d x^{2}}+\frac{D_{2}}{D_{1}} \lambda_{n}^{4} \phi_{n}(x)=\frac{A_{n} g_{n}(x)}{D_{1}}
$$

where $\lambda_{\mathrm{n}}=\mathrm{n} \pi / \mathrm{b}$

$D_{1}=D_{11}$

$D_{2}=D_{22}$

$D_{3}=\left(D_{12}+2 D_{66}\right)$

To acquire a homogenous solution to equation (5) the right hand side is set to zero and $\phi_{n}(x)=e^{s x}$. The result is divided by $e^{s x}$ and becomes

$$
s^{4}-\frac{2 D_{3}}{D_{1}} \lambda_{n}^{2} s^{2}+\frac{D_{2}}{D_{1}} \lambda_{n}^{4}=0
$$

For an isotropic plate $D_{1}=D_{2}=D_{3}$ and the roots of equation (6) are easily determined as $\pm \lambda_{n}$ and $\pm \lambda_{n}$. However, for an orthotropic plate, there are three sets of roots and the depend upon the magnitude relation of $\left(D_{2} / D_{1}\right)^{1 / 2}$ to $D_{3} / D_{1}$.

When $\left(D_{2} / D_{1}\right)^{1 / 2}<\left(D_{3} / D_{1}\right)$ :

$\phi_{n h}(x)=C_{1} \cosh \left(\lambda_{n} s_{1} x\right)+C_{1} \sinh \left(\lambda_{n} s_{1} x\right)+C_{3} \cosh \left(\lambda_{n} s_{2} x\right)+C_{4} \sinh \left(\lambda_{n} s_{2} x\right)$

$\left(D_{2} / D_{1}\right)^{1 / 2}=\left(D_{3} / D_{1}\right):$

$\phi_{n h}(x)=\left(C_{5}+C_{6} x\right) \cosh \left(\lambda_{n} s_{3} x\right)+\left(C_{7}+C_{8} x\right) \sinh \left(\lambda_{n} s_{3} x\right)$

$\left(D_{2} / D_{1}\right)^{1 / 2}>\left(D_{3} / D_{1}\right):$

$\phi_{n h}(x)=\left(C_{9} \cos \lambda_{n} s_{5} x+C_{10} \sin \lambda_{n} s_{5} x\right) \cosh \left(\lambda_{n} s_{4} x\right)+\left(C_{11} \cos \lambda_{n} s_{5} x+C_{12} \sin \lambda_{n} s_{5} x\right) \sinh \left(\lambda_{n} s_{4} x\right)$

Which case is to be solved depends on the status of the design process. If the material to be used and the orientation of fibers need to be determined for a particular design, then multiple cases should be solved to satisfy the boundary conditions and determine which parameters are best for the design. If material and orientation have already been specified then the $D$ values will be known and only one case needs to be solved. 
$\phi_{n h}(x)$ refers to the relevant homogenous portion of the solution, the particular solution, $\phi_{n p}(x)$, is summed with the relevant to satisfy any set of boundary conditions on the $\mathrm{x}$-edges of the plate. If the lateral load $\mathrm{p}(\mathrm{x}, \mathrm{y})$ is linear at most in the $\mathrm{x}$-direction the particular solution is

$$
\phi_{n p}(x)=\frac{A_{n} g_{n}(x)}{\lambda_{n}^{4} D_{2}}
$$

The boundary conditions will decide the homogenous and particular solutions and then can be used to determine $\phi_{n}(x)$ by

$$
\phi_{n}(x)=\phi_{n h}(x)+\phi_{n p}(x)
$$

From equation (2) the displacement function, $w(x, y)$ can be determined which yields the displacements results at any point on the plate. The partial derivatives of the function $w(x, y)$ result in the curvatures for a composite laminate or sandwich plate and are calculated by

$$
\kappa_{x}=-\frac{\partial^{2} w}{\partial x^{2}} \quad \kappa_{y}=-\frac{\partial^{2} w}{\partial y^{2}} \quad \kappa_{x y}=-\frac{\partial^{2} w}{\partial x \partial y}
$$

The stresses in each of the $k$ lamina layers can the be determined by

$$
\left[\begin{array}{c}
\sigma_{x} \\
\sigma_{y} \\
\sigma_{x y}
\end{array}\right]_{k}=\left[\begin{array}{ccc}
Q_{11} & Q_{12} & 0 \\
Q_{12} & Q_{22} & 0 \\
0 & 0 & Q_{66}
\end{array}\right]_{k}\left[\begin{array}{c}
\kappa_{x} \\
\kappa_{y} \\
\kappa_{x y}
\end{array}\right] z
$$

The stress values resulting from equation (13) are relevant to the different layers of the laminate or if studying a sandwich plate where, $\mathrm{k}=1$ is the top face, $\mathrm{k}=2$ is the core material, and $\mathrm{k}=3$ is the bottom face sheet, analysis of the lamina in each layer must first be analyzed then globalized to the sandwich layer and onto the whole sandwich plate. 


\subsection{Structural Bonding}

Bonding and structural joining concepts are critical technologies for developing innovative designs and structural configurations. Adhesive bonding is a supplementing factor to aide a geometrically joined structural or can be used alone as the main joining constituent. Numerous studies on structural bonding have been performed and reported on and can be further studied in the works of Hart-Smith [18], John and Kinloch [19] and Ojalvo [20] Tong and Steven [21] are a few contributing to the research of bonding applications.

Within a structural part, there are commonly areas where the components that comprise the structural part need to be connected to serve the design purpose. Depending on the application, materials used, cost, manufacturing process, and other parameters the type of connection is chosen. Common methods of connection include bolts, rivets, welds, brazes, or adhesive bonding. Fiber-reinforced composite materials, which undergo severe damage when using bolting and riveting joining methods making them more susceptible to interlaminar shear with the substrate, are more suitable for adhesive bonding methods and through joint innovation and proper adhesive bonding methods can be as effective as traditional bolting or riveting.

Mechanically connected joints rely on the strength of the fastener (bolts, rivets, screws, etc.) and the strength of the members being joined therefore, the loads are transferred by two locked surfaces being joined. Bonded joints have load bearing capabilities resulting from a surface attachment. The strength of the surface attachment is a function of the surface energies of the adhesive and the bonding surface. In this type of bonding, the loads are transferred from one member to another across an interface which is controlled by the adhesive molecular attractions. The advantages and disadvantages of adhesive bonded joints are duplicated from Tong and Steven [21]. 


\section{Table 1}

Advantages of Bonded Joints

Limitations of Bonded Joints

Ability to form light weight, stong and stiff

Can not be disassembled structures

Ability to join dissimilar materials; e.g. metal to composite materials

Residual stresses may be created due to difference in coefficients of thermal expansion

Ability to sufficiently join thin sheet materials

Limits to thickness joined with simple configurations

Improved stress distribution, no stress concentration in adherends, unlike mechanical fasteners which produce points of stress concentrations Enhanced fatigue properties due to improved stress distribution Sensitive to peel or through thickness stress, i.e., a bonded joint is generally stronger under shear but weak in cleavage pull

Poor resistance to elevated temperature and fire

Improved corrosion resistance e.g., minimizing galvanic corrosion by interposing a non-conducting barrier between the metallic adherends Smoother surface finishes, with an absence of fastener heads, weld heads, etc Bonding process can be automated, most convenient and cost effective joining; e.g., complex castings may be produced in several pieces and bonded together

Prone to environmental degradation, uncertain long term durability under severe service conditions

Toxicity and flammability problems

Inspection can be difficult, quality control becomes critical, i.e. the effectiveness of adhesive bonding can not fully be assessed by inspection techniques currently available

\subsubsection{Composite Surface Preparation for Bonding Methods}

There are many factors to consider when analyzing and designing structural joints. The considerations are different when adhesively bonding metallic surfaces or fiber-reinforced composite polymers (FRP). The most critical of these factors is the preparation of the FRP composite during its manufacturing stages. If using an FRP composite in a joining situation, the surface which will be bonded should be manufactured and cured to accept secondary bonding after the initial FRP layup procedure. Meaning, the use of a peel ply on the area where an adhesive bond is to be made will leave a rough finish which allows stronger adherence to the mating surface or one can forego using a peel ply on the bonded surface and later treat the bonding area by sanding techniques for surface roughing [22]. 
Prior to bonding, the surface of the composite should be thoroughly cleaned of any foreign material that will come between the interface of the bonded areas. Abrasion of the bonded area or roughening the surface to increase surface and surface energy prior to adhesive bonding is used to roughen the resin matrix and expose, but not rupture, the reinforcing fibers. The surface roughening can be done by hand or machine sanding post layup process or by incorporating a peel ply in the layup process [20], as mentioned previously. 


\section{Chapter 3 - Joining Concepts}

\subsection{Innovative Structural Joining Configurations}

\subsubsection{Development of Model Joints and Prototype Designs}

The preliminary lightweight design concepts for the flooring design of the trailer are shown in Figures 3.1, 3.2, and 3.3 below. Figure 3.1 displays two types of sandwich panel configurations, A and B, for the floor structure of a trailer. Type A consists of a polymer composite top plate with an extruded ribbed composite bottom plate. The combined structure formed by joining these plates provides both a lightweight and stiff floor platform. Type B panel is composed of polymer composite top and bottom plates with aluminum $\mathrm{C}$-channels sandwiched between the plates as the core material. A major advantage of the aluminum $\mathrm{C}$-channel core is that it facilitates the joining of the bogey and the kingpin sections to the floor structure of the trailer. The main disadvantage is the need of bonding between the aluminum beams and the polymer matrix composite panels.

\section{Flooring Construction}

A

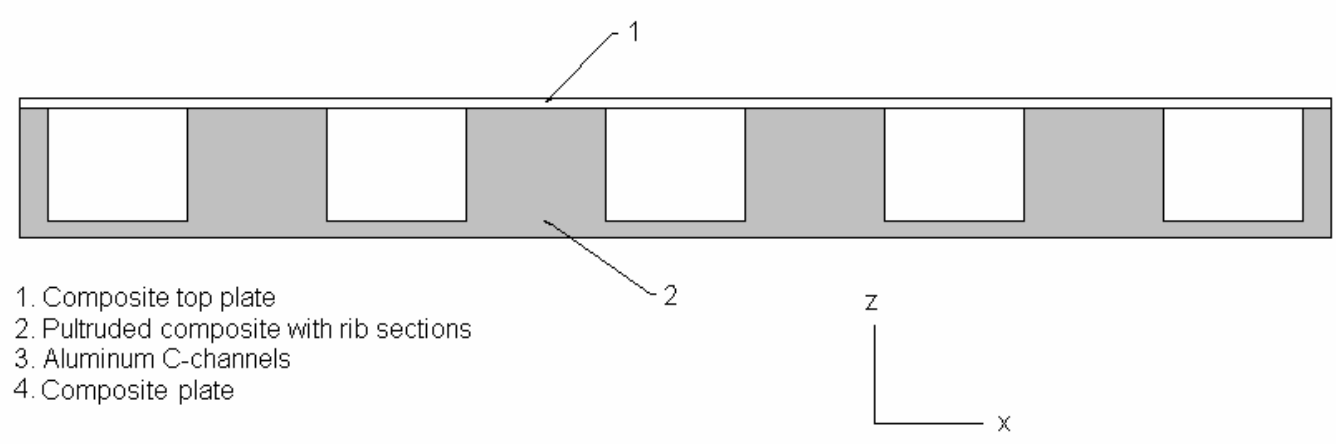

B

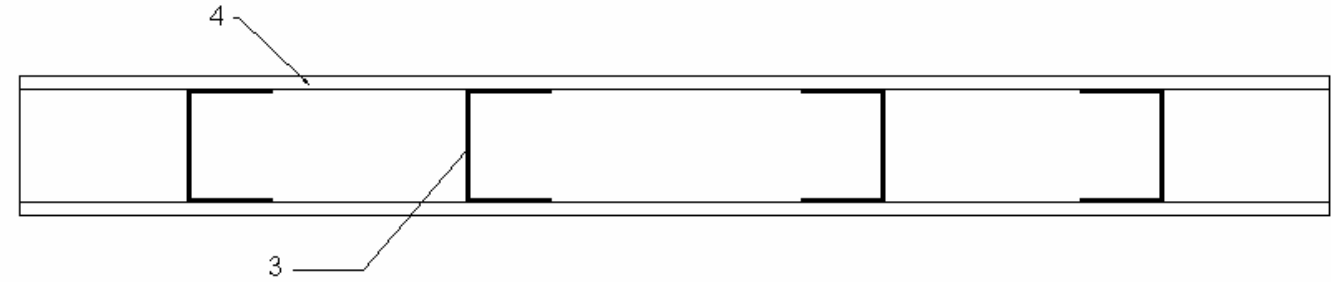

Figure 3.1: Alternative design concepts for the floor platform of a modified van trailer.

Type C floor construction as shown in Figure 3.2 below, is comprised of a top and bottom extruded polymer composite plate with small ribbed sections. The small ribbed 
sections apply a restraint to aluminum or titanium pipes of square cross section. The main advantage of this design consists of the benefit that the top and bottom plate geometry allows for easy joining of metal and polymer composite areas, without complicated and expensive bonding methods. The metal core material provides good accessibility for joining of the bogey and kingpin sections to the flooring structure.

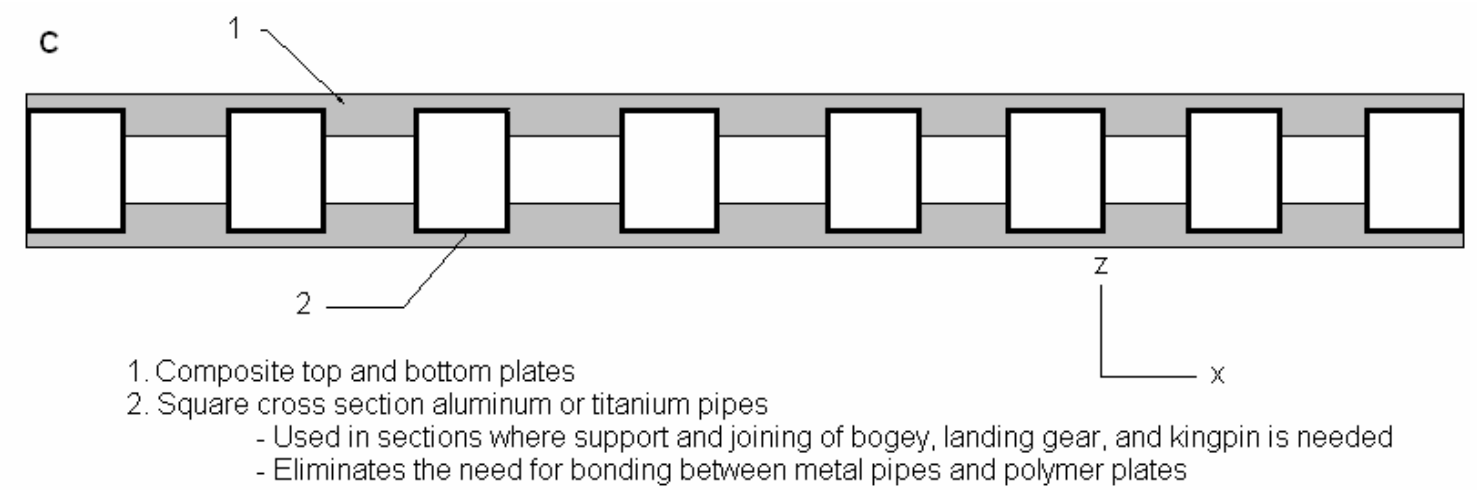

Figure 3.2: Sandwich composite structure with aluminum tube core construction for flooring platform applications. Design concept $C$.

Type D floor construction, as shown in Figure 3.3, consists of fiberglass I-cross beams connected through fiberglass bearing bars running along the trailer axis through the web centers. The advantages of this type of construction is its good suitability to forming connections at the bearing bar location between the floor panel and the structures above or below the floor. The composite I-beam structure is beneficial as a lightweight design. The addition of top and bottom plate coverings is needed to enclose the I-beam sections which will create a solid flooring platform. The options for the plate coverings will be discussed later in this work through advancements of the I-beam design. 
D

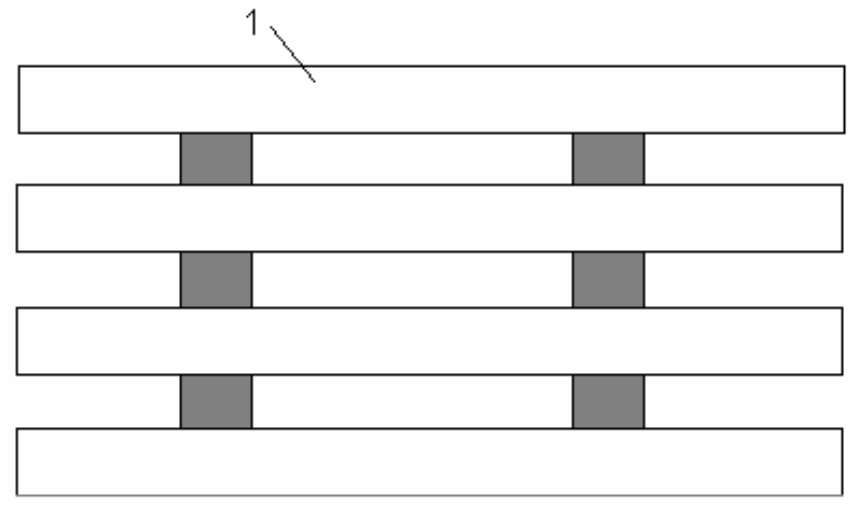

(Top View)

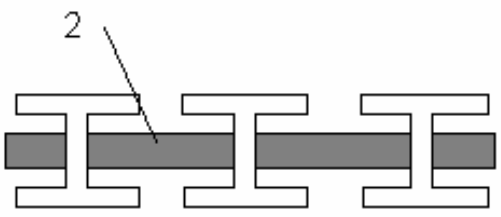

(Side View)

1. Fiberglass I-beam

2. Bearing Bar

Figure 3.3: Type $D$ flooring alternative using composite I-beams as cross member supports and composite bearing bars.

The side panels of the scaled prototype trailer are segmented to allow for small sliding and bending deflections throughout the surfaces of the side and top panels. The fiberglass panels forming the sidewall of the trailer are connected by an $\mathrm{H}$-joint that houses two side panels and is reinforced by adhesive bonding in the final design configuration.

\section{Side Panel H-Joint}

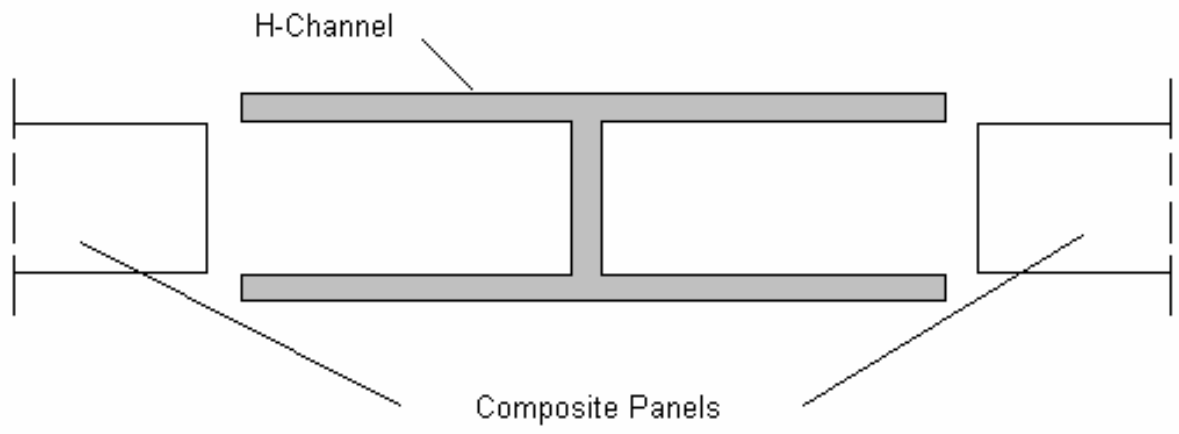

Figure 3.4: Connection method between side panels by an $\mathrm{H}$-joint configuration

The double corner joint configuration is utilized to connect the ceiling panel to the side panels. It allows joining by an integrated fit between two sidewall panels and allows for reinforcement by adhesive bonding. 


\section{Double Corner Joint}

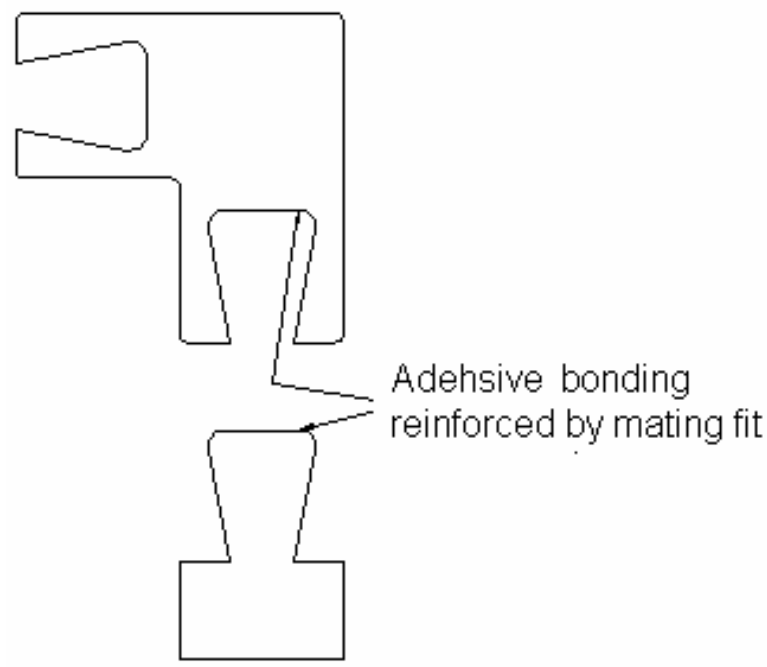

Figure 3.5: Double corner joint.

Figure 3.6 shows a configuration for the corner joint connecting the flooring to the side panels. The spacing between the composite top plate and bottom plate of the sandwich flooring platform will house the insert from the joint. In order to allow such a joint configuration, the core material of the sandwich floor panel will not run the full width of the floor, so that sufficient room is available for the insert. Adhesive bonding will aid the structure in this case and secure the integrity of the joint between the side and bottom plates. 


\section{Composite top plate \\ 2. Extruded bottom or core structure \\ 3. Corner joint connecting the floor and side panels}

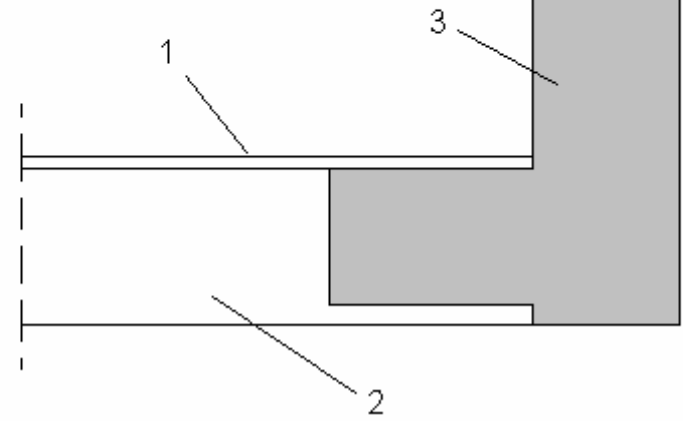

Figure 3.6: Corner joint for connecting the floor platform to the sidewall or side panels of a van trailer.

An alternative option for the corner joint involves two fiberglass angles that are adhesively bonded to the I-cross beams of the floor and side panels. The legs of both the interior and exterior angles are bonded to the floor and the vertical sections of the angles are bonded to the side panels of the trailer.

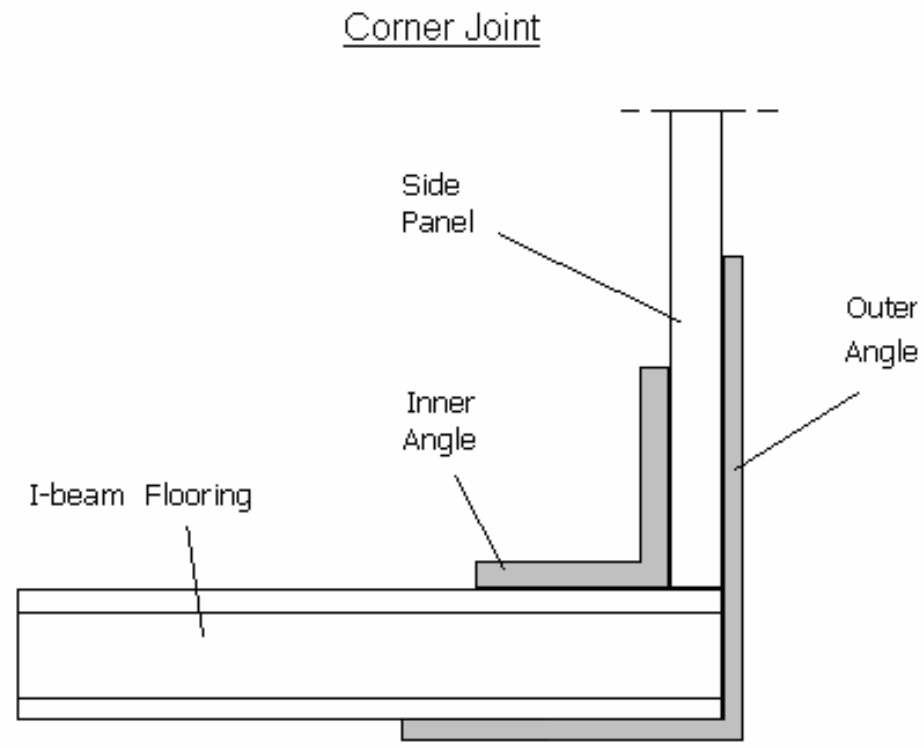

Figure 3.7: Alternative option for the corner joint connecting the side panels to the flooring platform. 
The trailer has been designed to be modular, which allows sections to be removed and replaced. This design concept ultimately reduces the transportation weight of the trailer. Three segments in the trailer are removable. In the model, the sections are each 1 foot sections. For a standard $48 \mathrm{ft}$. trailer, the three removable sections will be $4 \mathrm{ft}$ in length and allow for a resulting trailer ranging in length from $36 \mathrm{ft}$ to $48 \mathrm{ft}$ in increments of $4 \mathrm{ft}$. More on the modular design will be discussed later.

The method of connecting the segments in the trailer will vary with the different concepts for the flooring structure. The segment connection studied in this report and used in the model is for the I-cross beams and bearing bars floor design (type D).

\subsection{Prototyping of Innovative Structural and Joining Concepts}

A prototype of a van trailer was constructed at a 1 to 4 scale. The main purpose of building a solid model is to investigate experimentally in simulated conditions the potential benefits and drawbacks of various joining configurations and sandwich composite implementation. The constructing and structural testing of such a model provides reliable, extensive data for comparative assessments of alternative joining methods and material selection, mostly through finite element modeling and analysis.

The primary design criteria guiding the fabrication of a scaled trailer prototype are the achieving of optimal tradeoffs between structural weight and performance, based on extensive use of lightweight, strong and durable components, connected by fastener-free joints that allow easy assembly and maintenance. The construction of the prototype model involves optimum tailoring of fiberglass composite panels, I-beams, and angles to meet typical design specifications. A hybrid combination of aluminum and fiberglass components has been used as a preliminary step towards designing and prototyping an advanced trailer structure. This approach is cost effective and will provide the means to implement high performance advanced sandwich structures into the model design after the initial fabrication process has been completed and studied. 


\subsubsection{Manufacturing Process}

The building of the prototype model was performed in distinctive phases in order to allow continual assessment of the feasibility, potential advantages and disadvantages of different design configurations. Phasing of the fabrication process allowed incremental improvements in the design and fabrication concepts. The first phase was the construction of the rear section of the trailer model. The process of fabricating this section progressed into the following trailer sections and provided an effective method to culminate the full trailer model design

The following commercial parts and materials have been used thus far in the construction of the trailer prototype:

- $1 / 2 "$ thick fiberglass panels

- 1" Standard fiberglass I-beams

- Fiberglass bearing bars

- Fiberglass angles

- Anodized aluminum H-channels

- Anodized aluminum J-channels

- Anodized aluminum U-channels

- Anodized aluminum cornering channels

Custom carbide tipped tools were used to cut the fiberglass panels and the Ibeams in order to tailor each to the design specifications of the trailer. The fiberglass panels are used to build the top and side walls of the trailer. Cross I-beams are the main structural elements of the floor and are designed to carry the static and dynamic loads applied on the trailer bed during its commercial operation. The assortment of fiberglass I-beams is reinforced by fiberglass "bearing bars" which run the length of the trailer and connect the I-beams through the web of each. Besides providing structural reinforcement, the fiberglass bearing bars will provide connection points for the bogey, landing gear and kingpin of a trailer. Aluminum H-channels and edge corners were manufactured and tailored to provide strong connections between adjacent side panels, as well as between the side and top panels. The H-channels are anodized aluminum with 1/4" openings to fit the thickness of the side panels. The H-channels had to be cut to the proper height and trimmed properly to allow proper spacing and matching with the corner 
edge trim. The U-channels and the J-channels are used as trim sections for the rear door of the trailer.

The side panels have been bonded in order to secure the integrity of the H-channel joints. Furthermore, the side panels of the trailer have been segmented to allow structural flexibility and effectively absorb typical static, thermal, and dynamic forces associated with typical loading scenarios. All the structural joints in the trailer will be secured by adhesive bonding methods. The bonding process requires sanding or roughing of areas in contact, following by thorough cleaning of the bonded areas. Araldite 2021 toughened methacrylate adhesive was used to bond the fiberglass to metal components. The main advantage in choosing Araldite 2021 is that it provides a bond that fills voids and gaps between the mating parts and it also exhibits elastic characteristics in its cured state. The bonding between fiberglass angles and fiberglass panels was done with epoxy for secure adhesion.

\subsubsection{Model Trailer}

Figure 3.8 shows a section the trailer model and the different types of joints, channels, and angles that comprise the trailer model as described previously. Figure 3.8 shows the model in early stages of development and only displays the front section of the trailer. Bonding and joining of the structure was the final phase in the manufacturing process. Once completed, the three sections of the trailer were complete and shown figure 3.9 below. 


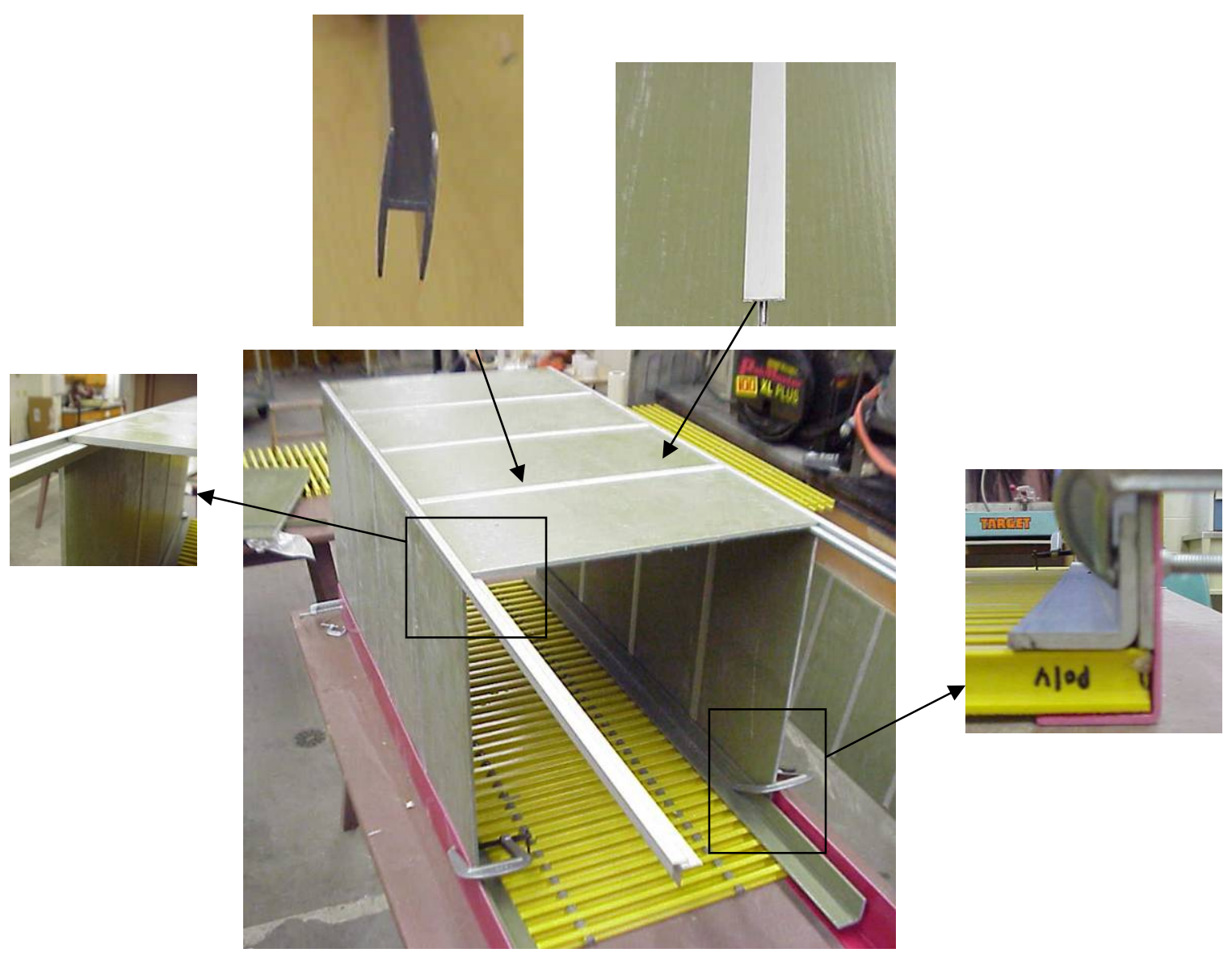

Figure 3.8: Scaled prototype of the replica 1 to 4 trailer model emphasizing the locations and types of joints.

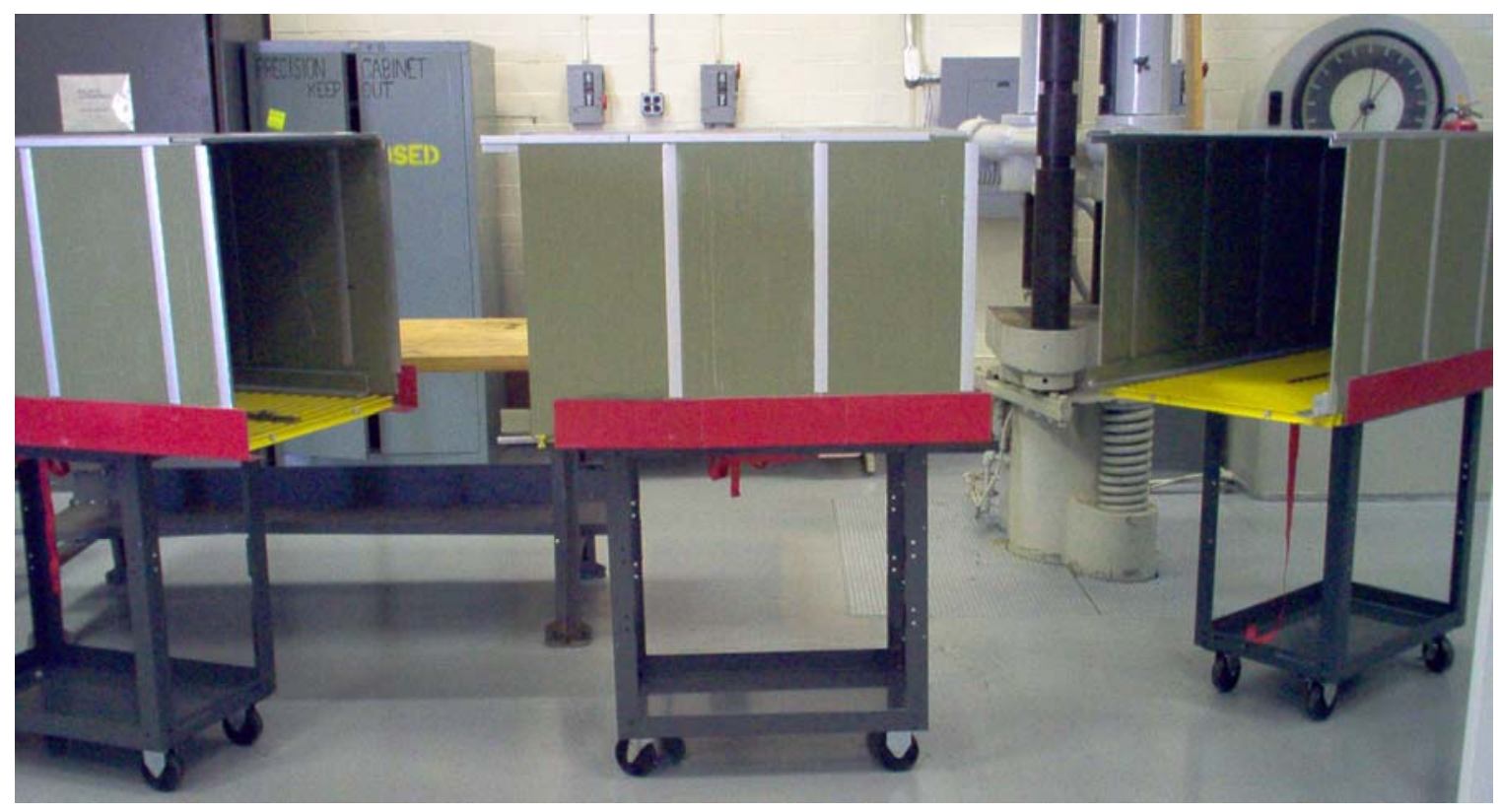

Figure 3.9: Unassembled sections of the model trailer. 


\subsubsection{Modular Design}

The concept of creating a modular trailer design, in which sections of the trailer could be removed if unused, must be facilitated with adequate mechanical joining structures. The main area for connecting the middle segments and the front and rear sections of the trailer are the flooring cross beams. The cross beams in each segment are joined by "beam connectors" which are shown in figure 3.10. The connectors join the segments by securing the flanges of three consecutive I-beams to a reverse U-channel.

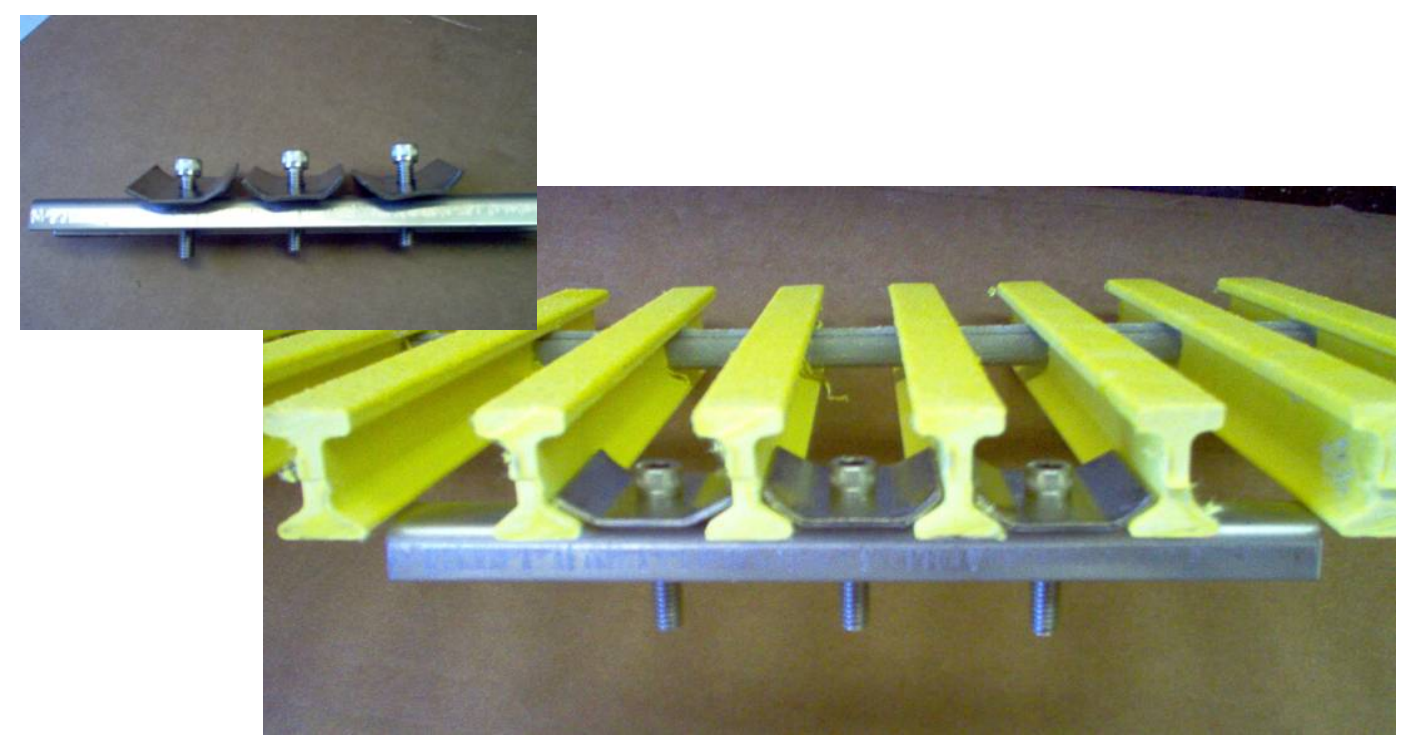

Figure 3.10: Method of joining the segments of the van trailer by connecting the I-beam cross members

A method to assist the beam connectors in joining the trailer segments is shown in Figure 3.11. This concept involves an extension of the interior angles and the top edge rails of the double corner joint. The angles and edge rails of one segment will extend onto the flooring and side panels of the adjacent segment providing added stability and rigidity to the modular design. 


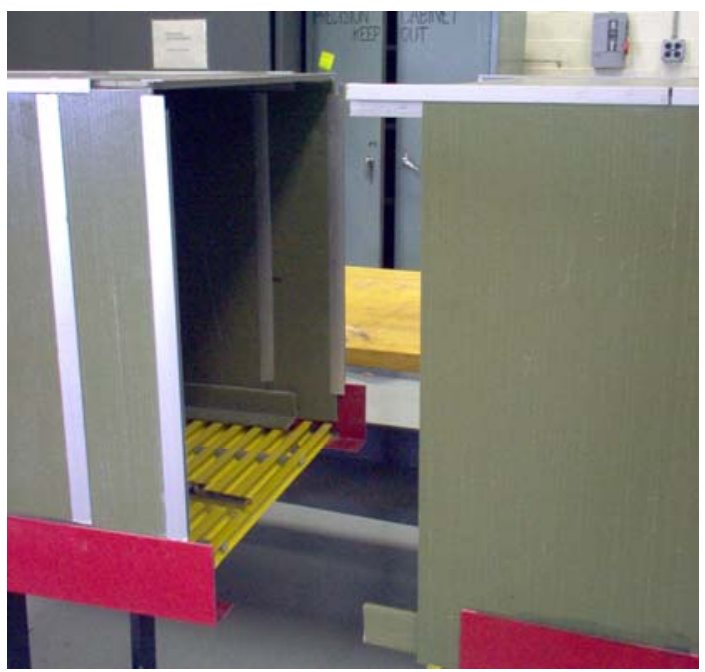

Figure 3.11: A method to assist the joining of segments for the mudular application of the van trailer design.

\subsection{Theoretical Analysis and Performance Comparisons}

The main focus for implementation of new design concepts is to reduce the weight of a standard trailer while upholding or increasing the stiffness and structural rigidity. The area which greatly contributes to the weight of the existing trailer is the floor platform. Several alternative lightweight designs were analyzed in a comparative study as possible sources to replace the structural floor and conclude with high strength and weight saving characteristics.

The design criteria which had to be met by each design concept were:

- The factor of safety must be greater than 2.0.

- The mid-span deflection of a cross beam in an alternative floor design must not exceed that of a similar steel beam used in the existing floor structure.

\subsubsection{Design I}

The first alternative floor design consists of I-beam cross members with "bearing bars" in the transverse direction and connected through the I-beam web. The specific minimum dimensions needed to meet the design requirements stated above are listed for 
various alternative materials in Table 3.1. The tables for each design in this section display the edge deflection, factors of safety for the required dimensions, and the weight of the unit floor area for each alternative material option.
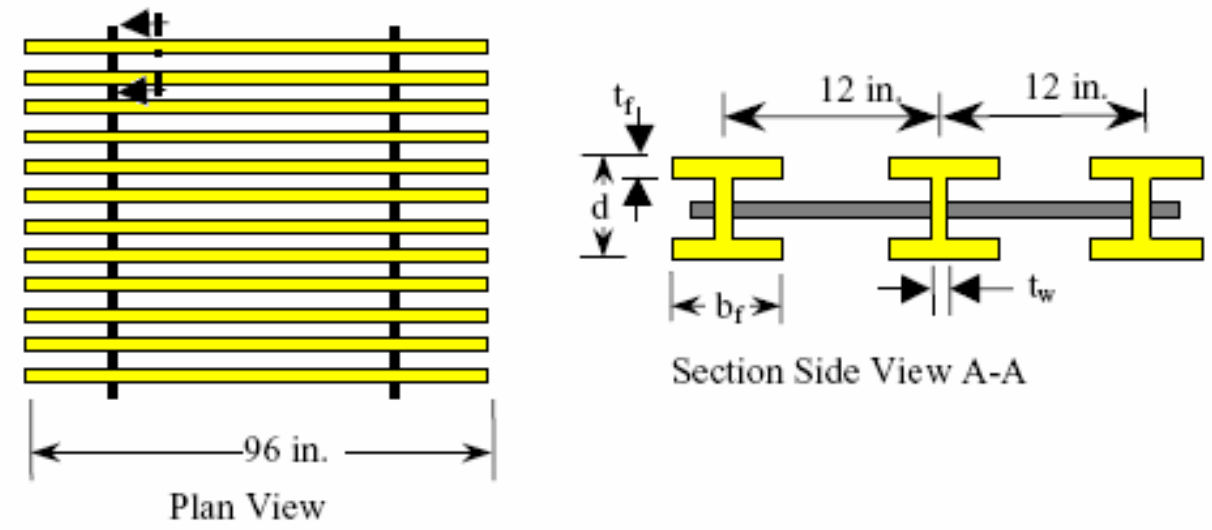

Section Side View A-A

Figure 3.12: Alternative floor design I consisting of I-beam cross members and "bearing bars".

The results displayed in Table 3.1 show that using an alternative material for the steel I-beams of a common van trailer floor can induce as much as a $69 \%$ weight reduction. The carbon-carbon and the magnesium alloy respectively are 1.98 and 1.44 $\mathrm{lb} / \mathrm{ft}^{2}$; this value correlates to a $69 \%$ and $78 \%$ weight reduction. However, the standard alloy I-beam dimensions for the magnesium alternative material does not meet the factor of safety requirement which is exceeding 2.0.

The weight reductions displayed in Table 3.1 are critical parameters for implementing alternative materials as a weight reducing concept. Following research will also continue analyzing alternative materials along with design changes to increase structural performance as well.

Table 3.1 - Design I Analysis for Alternative Materials

\begin{tabular}{|c|c|c|c|c|c|c|c|c|c|c|c|c|}
\hline \multirow{3}{*}{ Alternative Material } & \multicolumn{4}{|c|}{ SIZE } & \multirow[b]{2}{*}{ Section } & \multirow{2}{*}{$\begin{array}{c}\text { Unit } \\
\text { Weight }\end{array}$} & \multirow{2}{*}{$\begin{array}{l}\text { Young's } \\
\text { Modulus }\end{array}$} & \multirow{2}{*}{$\begin{array}{l}\text { Ultimate } \\
\text { Strength }\end{array}$} & \multirow{2}{*}{$\begin{array}{c}\text { Flexural } \\
\text { Stress }\end{array}$} & \multirow{2}{*}{$\begin{array}{c}\text { Factor of } \\
\text { Safety }\end{array}$} & \multirow{2}{*}{$\begin{array}{l}\text { Mid Span } \\
\text { Deflection }\end{array}$} & \multirow[b]{2}{*}{ Weight } \\
\hline & $\mathrm{d}$ & bf & tw & tf & & & & & & & & \\
\hline & in & in & in & in & in3 & $\mathrm{lb} / \mathrm{ft} 3$ & ksi & $\mathrm{ksi}$ & \begin{tabular}{|c|}
$\mathrm{ksi}$ \\
\end{tabular} & & in & $\mathrm{lb} / \mathrm{ft} 2$ \\
\hline STEEL & 4 & 2.5 & 0.16 & 0.25 & 2.61 & 490 & 30500 & 80 & 18.23 & 4.39 & 0.57 & 6.47 \\
\hline Aluminum & 8 & 2.25 & 0.13 & 0.19 & 4.62 & 169 & 10300 & 35 & 10.30 & 3.40 & 0.47 & 6.50 \\
\hline Glass-Epoxy & 8 & 4 & 0.38 & 0.38 & 13.9 & 104 & 2800 & 30 & 3.42 & 8.77 & 0.58 & 4.61 \\
\hline Carbon-Carbon & 6 & 3 & 0.25 & 0.25 & 5.32 & 98.6 & 20595 & 155 & 8.94 & 17.34 & 0.28 & 1.98 \\
\hline Nitronic 19D Stainless St. & 4 & 2.5 & 0.16 & 0.25 & 2.61 & 482 & 30000 & 103.6 & 18.23 & 5.68 & 0.58 & 6.38 \\
\hline Nitronic 30 Stainless Steel & 4 & 2.5 & 0.16 & 0.25 & 2.61 & 491 & 28000 & 160 & 18.23 & 8.78 & 0.60 & 6.50 \\
\hline Nitronic 60 Stainless Steel & 4 & 2.5 & 0.16 & 0.25 & 2.61 & 490 & 26000 & 117 & 18.23 & 6.42 & 0.61 & 6.30 \\
\hline Magnesium & 4 & 2.5 & 0.16 & 0.25 & 2.61 & 490 & 6380 & 26.8 & 18.23 & 1.47 & 0.87 & 1.44 \\
\hline
\end{tabular}




\subsubsection{Design II}

The next alternative design consists of a sandwich composite with top and bottom fiberglass plates and core material comprised of C-channel cross beams as illustrated in Figure 3.13. As stated earlier in this work, sandwich composite construction is an effective means for developing a lightweight design and to maintain or increase bending resistance. Composite sandwich technology is used in various design concepts throughout the remaining part of this work as the method to create the desired weight savings without compensating with a loss in structural rigidity.

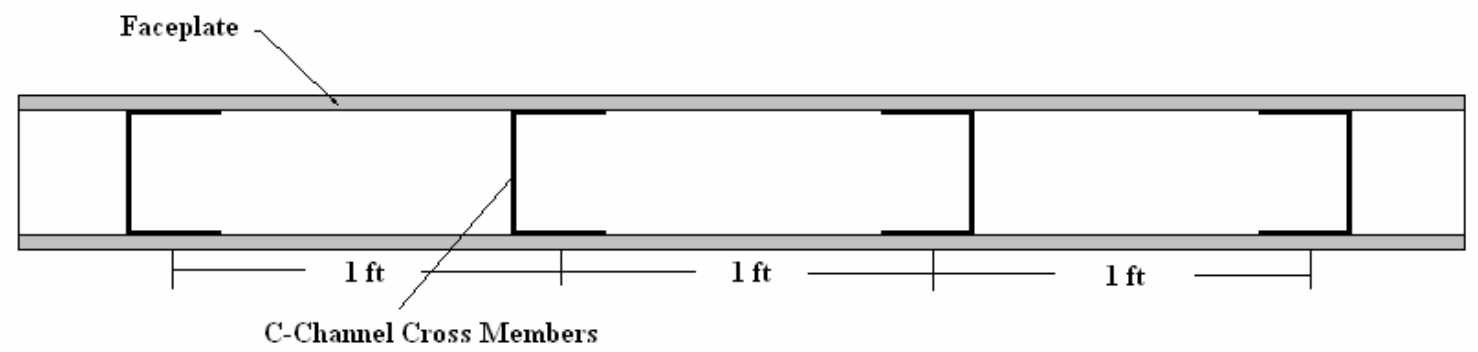

Figure 3.13: Alternative floor design II consisting of top platform supported by C-channels.

Table 3.2 lists the resulting characteristics of the C-channel beams (Design II) for each alternative material selection. Again, the carbon-carbon and magnesium selections are clearly the best choice for weight saving capabilities. In this design, carbon-carbon outputs a $67 \%$ weight reduction compared to the current steel design and magnesium alloy creates a $61 \%$ reduction. The magnesium alloy now exceeds the required minimum factor of safety of 2.0 and can be considered a possible alternative in Design II. 
Table 3.2 - Design II Analysis for Alternative Materials

\begin{tabular}{|c|c|c|c|c|c|c|c|c|c|c|c|c|}
\hline \multirow{3}{*}{ Alternative Material } & \multicolumn{4}{|c|}{ SIZE } & \multirow[b]{2}{*}{ Section } & \multirow{2}{*}{$\begin{array}{c}\text { Unit } \\
\text { Weight }\end{array}$} & \multirow{2}{*}{$\begin{array}{l}\text { Young's } \\
\text { Modulus }\end{array}$} & \multirow{2}{*}{$\begin{array}{l}\text { Ultimate } \\
\text { Strength }\end{array}$} & \multirow{2}{*}{$\begin{array}{c}\text { Flexural } \\
\text { Stress }\end{array}$} & \multirow{2}{*}{\begin{tabular}{|c} 
Factor of \\
Saftey
\end{tabular}} & \multirow{2}{*}{$\begin{array}{l}\text { Mid Span } \\
\text { Deflectio }\end{array}$} & \multirow[b]{2}{*}{ Weight } \\
\hline & $\mathrm{d}$ & bf & tw & $\mathrm{tf}$ & & & & & & & & \\
\hline & in & in & in & in & in3 & $\mathrm{Lb} / \mathrm{ft} 3$ & $\mathrm{ksi}$ & $\mathrm{ksi}$ & $\mathrm{ksi}$ & & in & $\mathrm{Lb} / \mathrm{ft} 2$ \\
\hline STEEL & 5 & 1.70 & 0.19 & 0.32 & 3.00 & 490 & 30500 & 80 & 26.31 & 3.04 & 0.40 & 6.70 \\
\hline Aluminum & 6 & 3.30 & 0.20 & 0.35 & 7.01 & 169 & 10300 & 35 & 6.79 & 5.16 & 0.41 & 4.03 \\
\hline Glass-Epoxy & 10 & 2.80 & 0.50 & 0.50 & 18.49 & 104 & 2800 & 30 & 2.57 & 11.66 & 0.35 & 5.50 \\
\hline Carbon-Carbon & 6 & 1.70 & 0.37 & 0.37 & 4.85 & 98.6 & 20595 & 155 & 9.81 & 15.80 & 0.30 & 2.21 \\
\hline Nitronic 19D Stainless St. & 5 & 1.70 & 0.19 & 0.32 & 3.00 & 482 & 30000 & 103.6 & 15.86 & 6.53 & 0.40 & 6.59 \\
\hline Nitronic 30 Stainless St. & 5 & 1.70 & 0.19 & 0.32 & 3.00 & 491 & 28000 & 160 & 15.86 & 10.09 & 0.42 & 6.72 \\
\hline Nitronic 60 Stainless St. & 5 & 1.70 & 0.19 & 0.32 & 3.00 & 490 & 26000 & 117 & 15.86 & 7.38 & 0.43 & 6.51 \\
\hline Magnesium & 5.98 & 3.27 & 0.21 & 0.35 & 7.01 & 490 & 6380 & 26.8 & 11.26 & 2.38 & 0.66 & 2.59 \\
\hline
\end{tabular}

\subsubsection{Design III}

The third design is a sandwich panel composed of ribbed FRP faceplates and a core material of hollow cross tubes as illustrated in Figure 3.14. Table 3.3 lists the minimum dimensions of the hollow cross beams to meet the required standards stated above for each material analyzed.

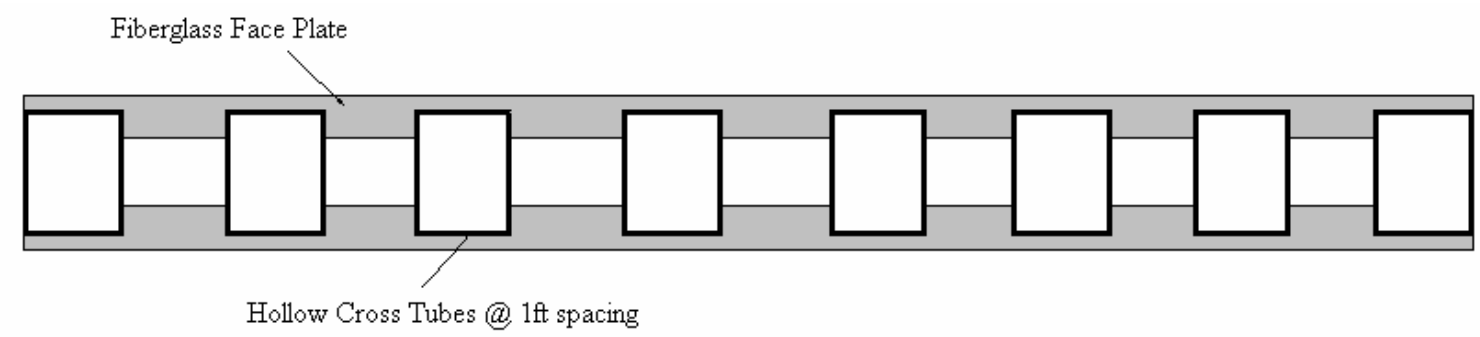

Figure 3.14: Alternative flooring design III consisting of a FRP top and bottom face plate and hollow cross tubes comprising the core structure.

The results of Table 3.3 display the highest weight reduction in the carbon-carbon and magnesium material alternatives. However, the magnesium alloy contributes larger deflection values and the lowest factor of safety value. The fiberglass and carbon fiber contributions are appreciated in the weight reduction area but the required dimensions to secure a reasonable factor of safety need to be adjusted. Specifically in this design, the carbon-carbon configuration attains a 15.80 factor of safety. A large factor of safety value gives insight that the design is over engineered and changes in material and design parameters should be inspected with cost as an optimizing factor. 
Table 3.3 - Design III Analysis for Alternative Materials

\begin{tabular}{|c|c|c|c|c|c|c|c|c|c|c|c|}
\hline \multirow{3}{*}{ Alternative Material } & \multicolumn{3}{|c|}{ SIZE } & \multirow{2}{*}{ Section } & \multirow{2}{*}{$\begin{array}{c}\text { Unit } \\
\text { Weight }\end{array}$} & \multirow{2}{*}{$\begin{array}{l}\text { Young's } \\
\text { Modulus }\end{array}$} & \multirow{2}{*}{$\begin{array}{l}\text { Ultimate } \\
\text { Strength }\end{array}$} & \multirow{2}{*}{$\begin{array}{c}\text { Flexural } \\
\text { Stress }\end{array}$} & \multirow{2}{*}{$\begin{array}{c}\text { Factor of } \\
\text { Saftey }\end{array}$} & \multirow{2}{*}{$\begin{array}{c}\text { Edge } \\
\text { Deflection }\end{array}$} & \multirow[b]{2}{*}{ Weight } \\
\hline & $\mathrm{d}$ & $\mathrm{bf}$ & $\mathrm{tw}$ & & & & & & & & \\
\hline & in & in & in & in3 & $\mathrm{Lb} / \mathrm{ft} 3$ & ksi & ksi & $\mathrm{ksi}$ & & in. & $\mathrm{Lb} / \mathrm{ft} 2$ \\
\hline STEEL & 4.0 & 3.0 & 0.313 & 3.72 & 490 & 30500 & 80 & 12.79 & 6.26 & 0.08 & 12.70 \\
\hline Aluminum & 6.0 & 3.0 & 0.313 & 7.03 & 169 & 10300 & 35 & 6.77 & 5.17 & 0.08 & 5.83 \\
\hline \begin{tabular}{|l} 
Glass-Epoxy \\
\end{tabular} & 9.0 & 6.0 & 0.311 & 7.66 & 104 & 2800 & 30 & 6.21 & 4.83 & 0.16 & 6.99 \\
\hline Carbon-Carbon & 6.5 & 2.0 & 0.236 & 4.85 & 98.6 & 20595 & 155 & 9.81 & 15.80 & 0.06 & 6.00 \\
\hline Nitronic 19D Stainless St. & 4.0 & 3.0 & 0.313 & 3.72 & 482 & 30000 & 103.6 & 12.79 & 8.10 & 0.08 & 12.49 \\
\hline Nitronic 30 Stainless St. & 4.0 & 3.0 & 0.313 & 3.72 & 491 & 28000 & 160 & 12.79 & 12.51 & 0.09 & 12.72 \\
\hline Nitronic 60 Stainless St. & 4.0 & 3.0 & 0.313 & 3.72 & 490 & 26000 & 117 & 12.79 & 9.15 & 0.08 & 12.32 \\
\hline Magnesium & 6.0 & 3.0 & 0.313 & 3.72 & 490 & 6380 & 26.8 & 12.79 & 2.10 & 0.36 & 3.75 \\
\hline
\end{tabular}

\subsubsection{Summary}

After initial theoretical analysis, design III will be utilized as the specific design structure with the highest potential as the best possible alternative for a van trailer floor. This conclusion was based on the multiple facets of design III optimization which include but is not limited to, tailoring and optimizing the faceplates structure, core structure, material selection and dimensioning. Also, a crucial topic for this work and for design III is the joining procedure between the faceplate FRP structure and an alloy core material. This design provided the most encouragement for a successful method to combine sandwich structure technology comprised of FRP faceplates and metallic core structures in a heavy vehicle flooring system with beneficial weight saving capabilities.

The solution and study of this field is detailed later in the work and reverts back to the geometrical matching between joining parts previously discussed. The next sections show the study of optimizing the structure of design III to create the best possible solution for a lightweight and effective flooring platform. 


\section{Chapter 4 - Analysis of Various Cross Sections for the Core Structure of Extruded Support Members}

\subsection{Introduction}

Various preliminary design concepts of the core material for the previously discussed Design III, or for the best option for trailer floor platform, were compared on the basis of a single section of the core structure. Six different designs were analyzed by weight, maximum displacement and maximum stress under bending and torsion loads. Each concept was kept uniform by length, thickness, loading and boundary conditions. Finite element modeling of the alternative structures was performed in both ANSYS and ADINA finite element programs.

\subsection{Cross Sections}

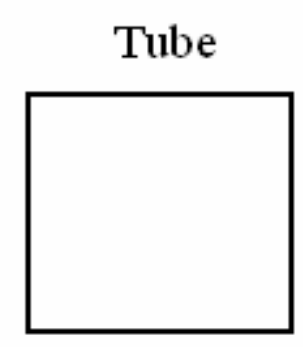

$\mathrm{X} 2$

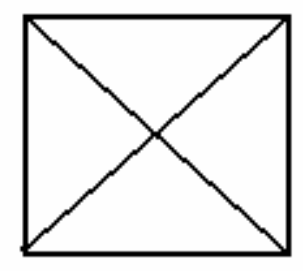

Slant

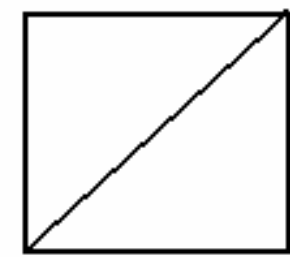

Box 1

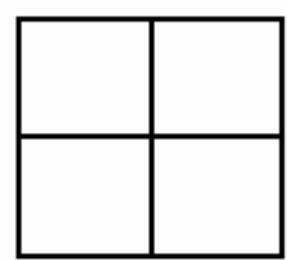

$\mathrm{X} 1$

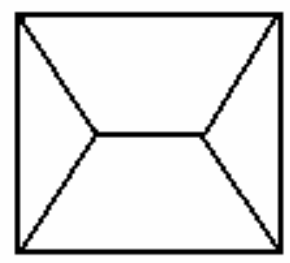

Box 2

Figure 4.1: The six different cross sections of the core structure.

The cross sections being compared are shown in Figure 4.1. The cross sections represent a single part of the core structure of the flooring sandwich plate. Any of these sections will be repeated to form the core structure for the entire flooring platform. 
Figure 4.2 displays a possible flooring arrangement using, for example, the $\mathrm{X} 2$ section from Figure 4.1.

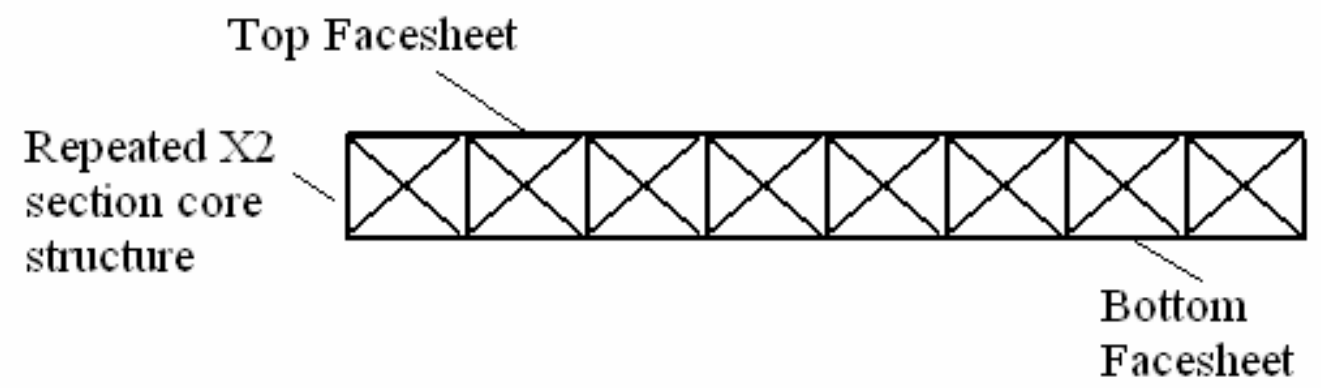

Figure 4.2: Representation of a sandwich composite structure using the X2 core cross section.

Figure 4.2 shows how a single cross section will be repeated to build the core structure of the entire flooring. Therefore, to determine which arrangement is most beneficial, a finite element analysis and a weight analysis were performed. For accuracy and consistency, all loading, thicknesses, elements, element sizes, and boundary conditions were kept constant during the analysis of the different sections.

\subsection{Bending Analysis}

The parameters for the finite element bending analysis are given in this section. Referencing Figure 4.3, the load direction is in the negative $y$ direction and has a value of 10 psi. This load is distributed over shell elements with dimensions of 0.5 in., 0.5 in., 0.02 in. in length, width, and thickness, respectively. The material properties correspond to standard aluminum with a Young's modulus value of $26 \times 10^{6}$ psi and a Poisson's ratio of 0.33 . 


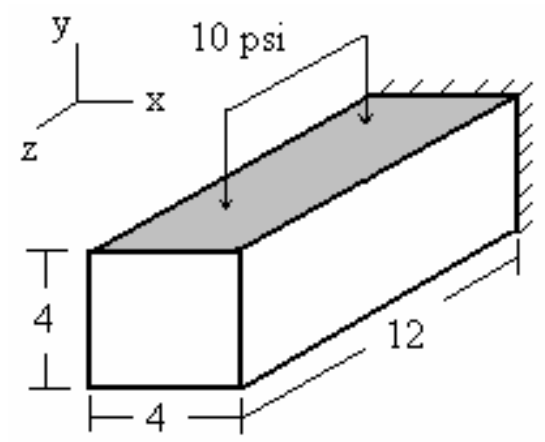

Figure 4.3: Loading scenario, dimensions, and boundary conditions for bending analysis.

Material: Aluminum

Elastic Modulus: $26 \times 10^{6} \mathrm{psi}$

Poisson's ratio: 0.33

Loading: 10 psi in the negative $y$ direction

Elements: Shell

Element size: 0.5 in.

Element thickness: 0.02 in.

Section Dimensions: 4 x 4 x 12 x 0.02 in.

\subsubsection{Bending Results}

The ANSYS generated results are displayed in the following figures. The results display plots of maximum displacement distributions from an applied load of $10 \mathrm{psi}$. The corresponding numerical values of maximum displacements are summarized in Table 4.1.

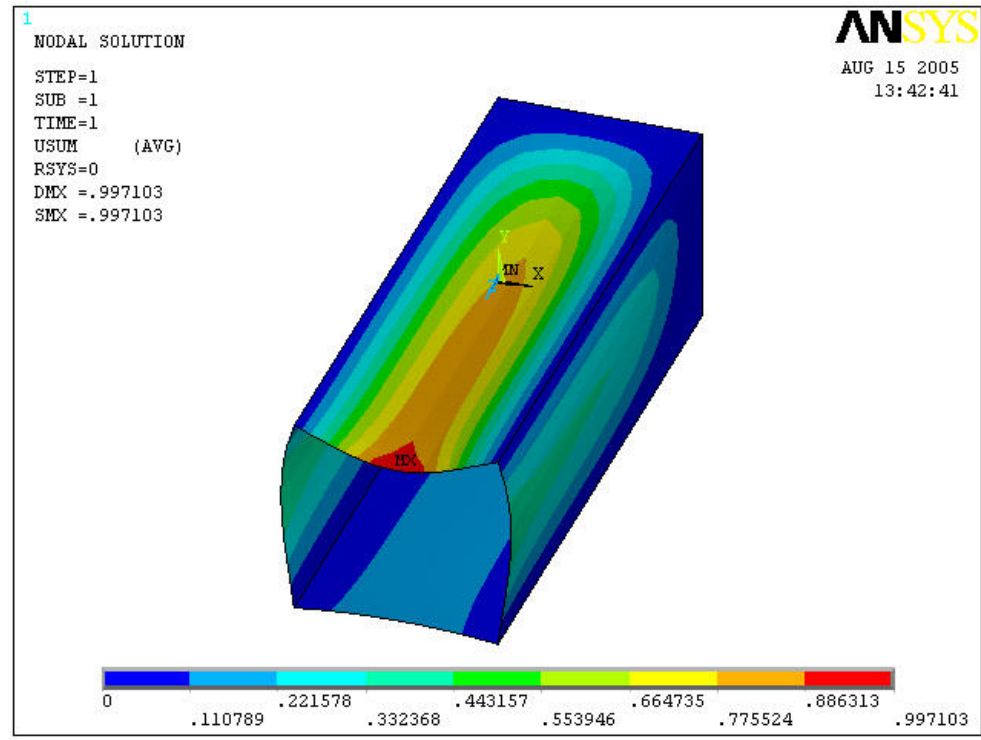

Figure 4.4: Tube displacement using ANSYS 


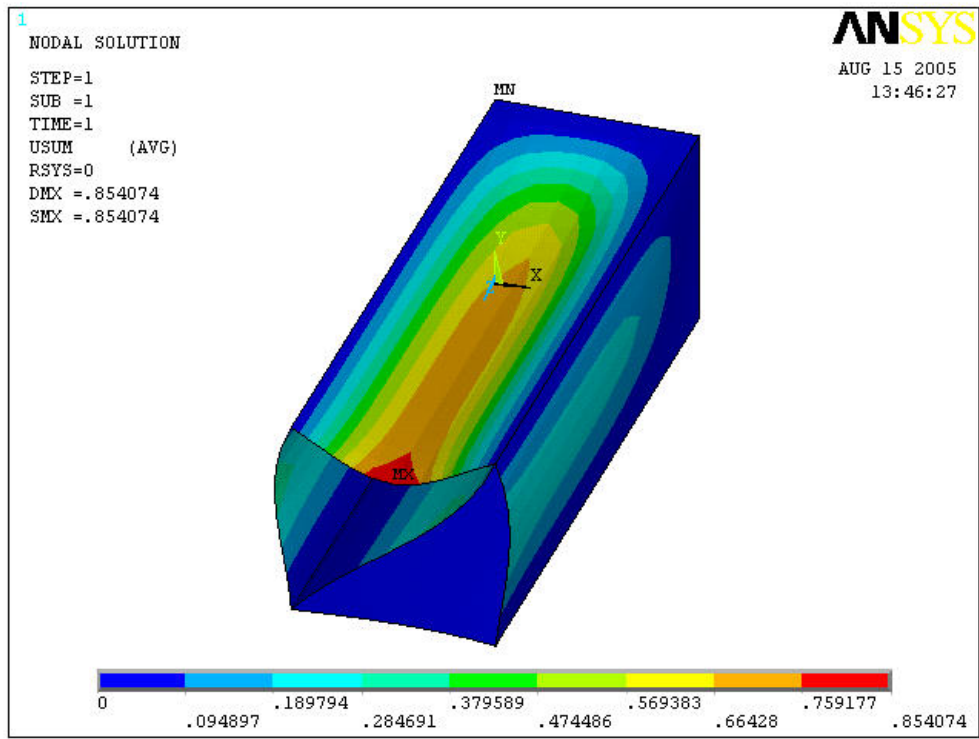

Figure 4. 5: Slant displacement using ANSYS

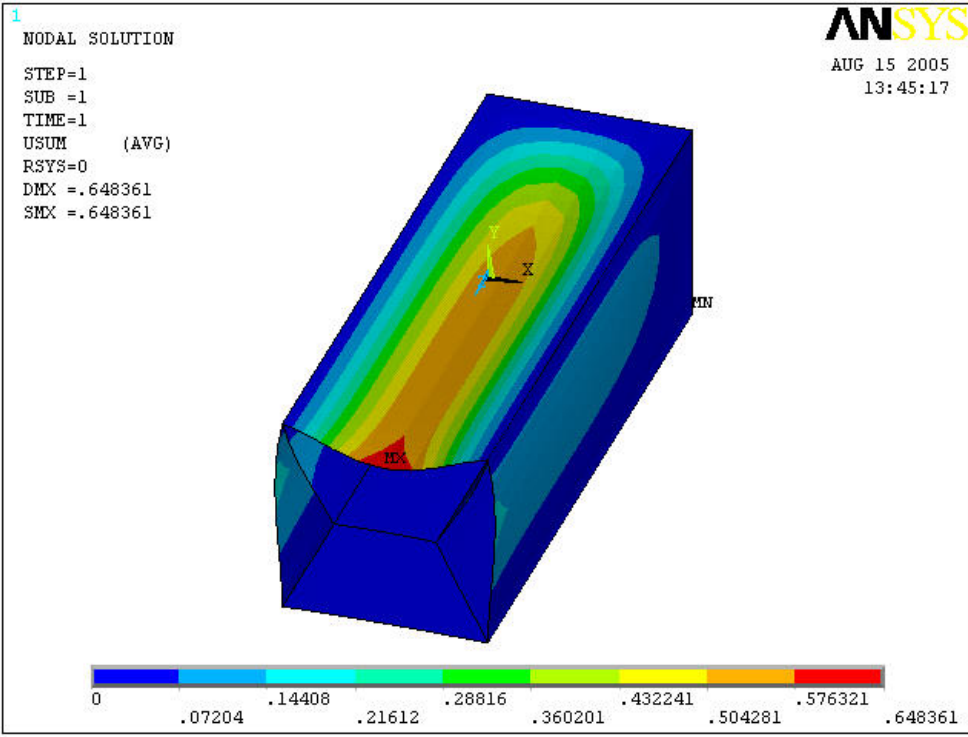

Figure 4. 6: X1 displacement using ANSYS 


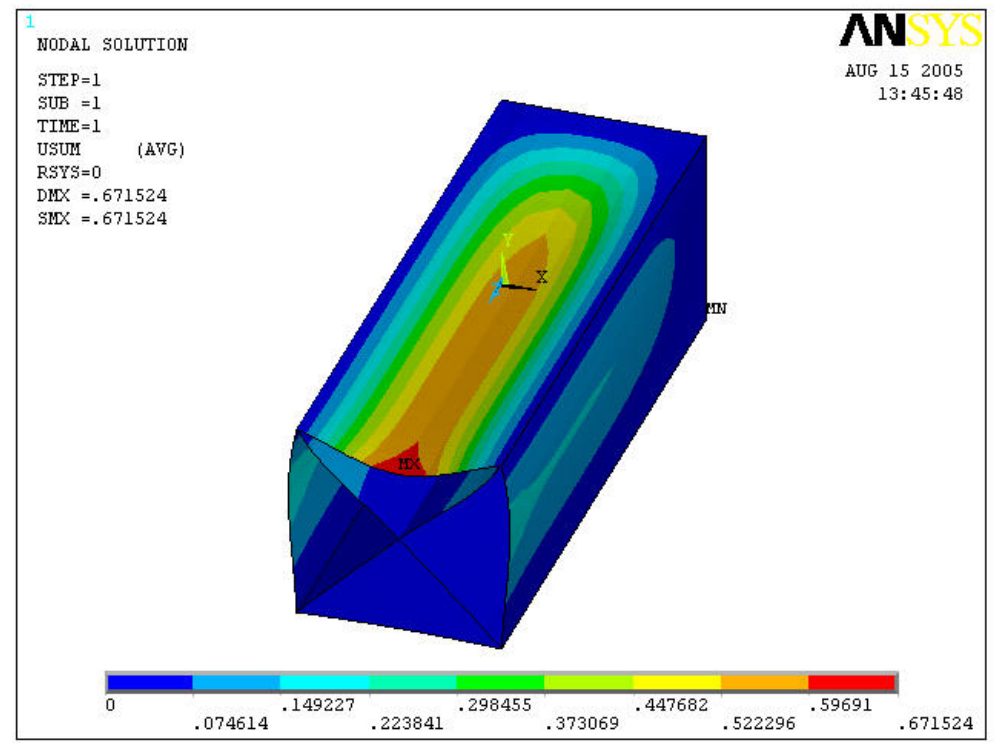

Figure 4. 7: X2 displacement using ANSYS

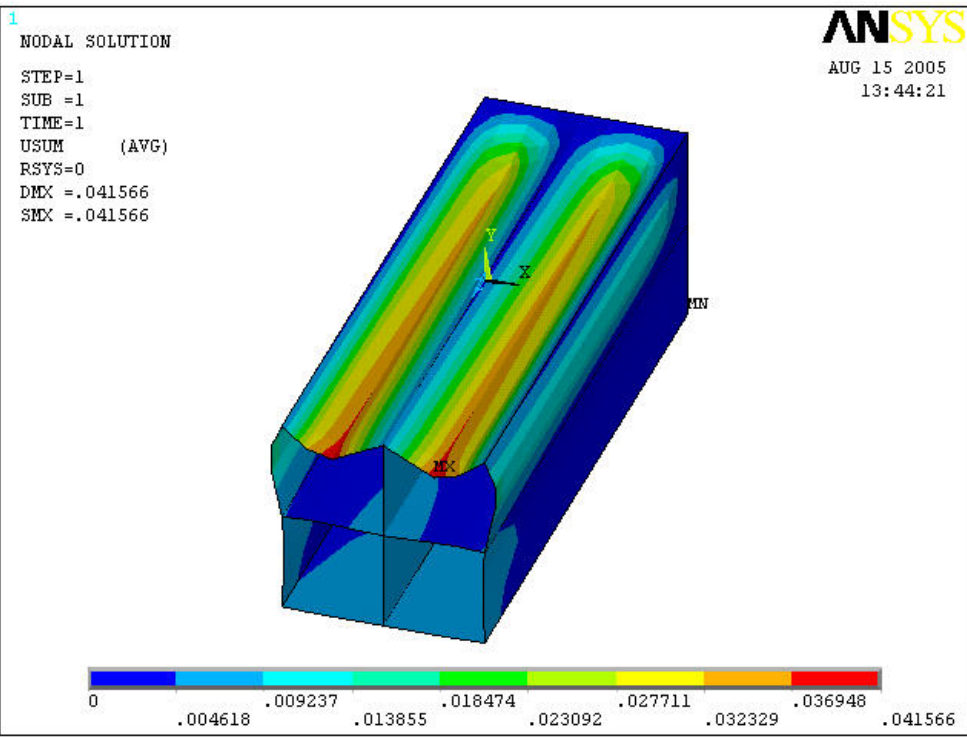

Figure 4. 8: Box displacement using ANSYS 


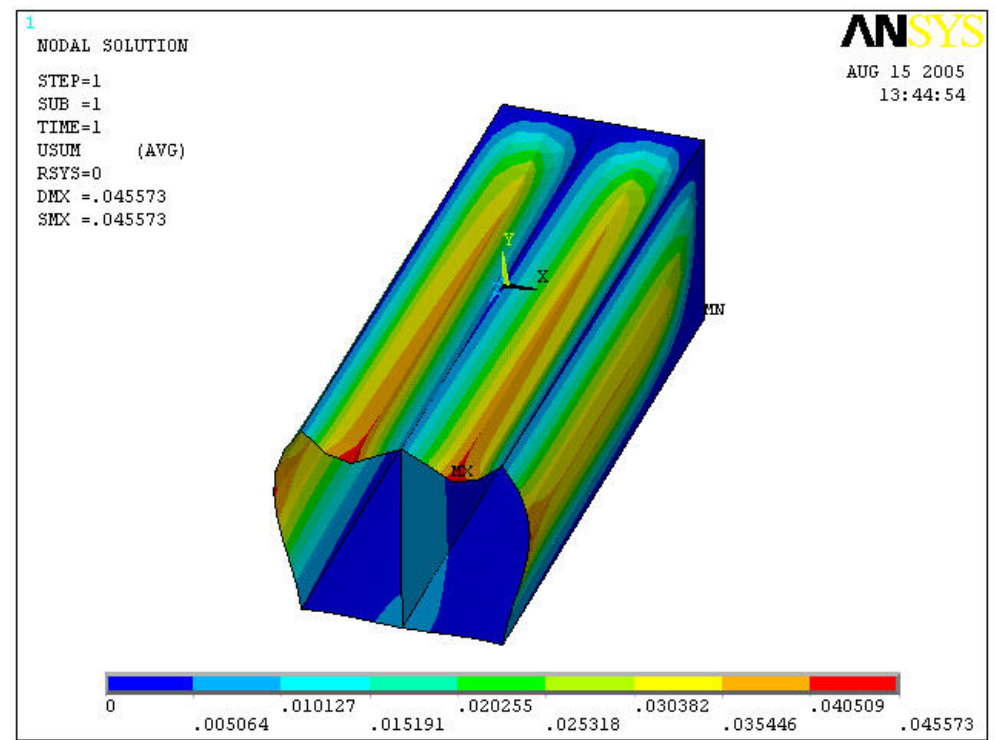

Figure 4. 9: Box2 displacement using ANSYS

Table 4.1 - ANSYS Bending Results

\begin{tabular}{|c|c|}
\hline \multicolumn{2}{|c|}{ ANSYS Bending Results } \\
\hline Cross Section & Maximum Displacement (in.) \\
\hline Tube & 0.997103 \\
\hline Slant & 0.854074 \\
\hline X1 & 0.648361 \\
\hline X2 & 0.671524 \\
\hline Box 1 & 0.041566 \\
\hline Box 2 & 0.045573 \\
\hline
\end{tabular}

The ADINA generated results are displayed in the following figures. The same loading and boundary conditions were applied to all the cross sections in both ADINA and ANSYS models. 


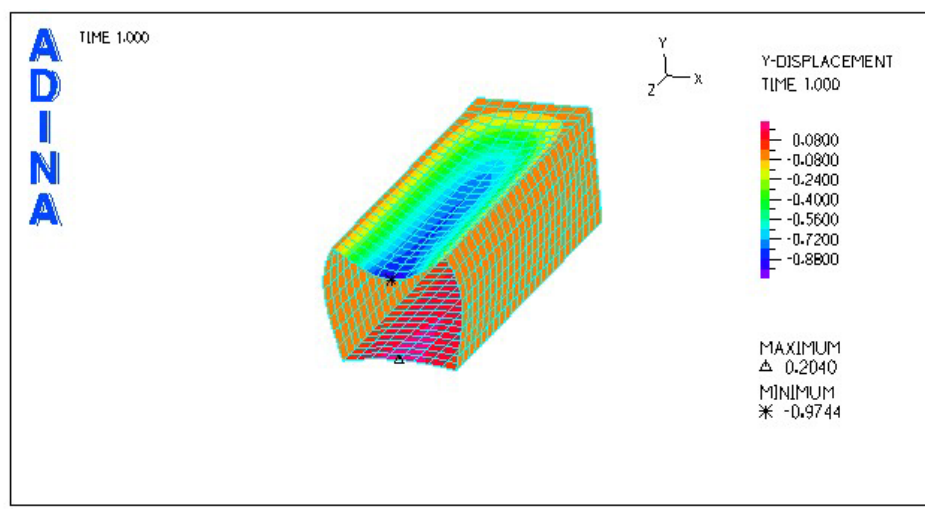

Figure 4.10: Tube displacement using ADINA

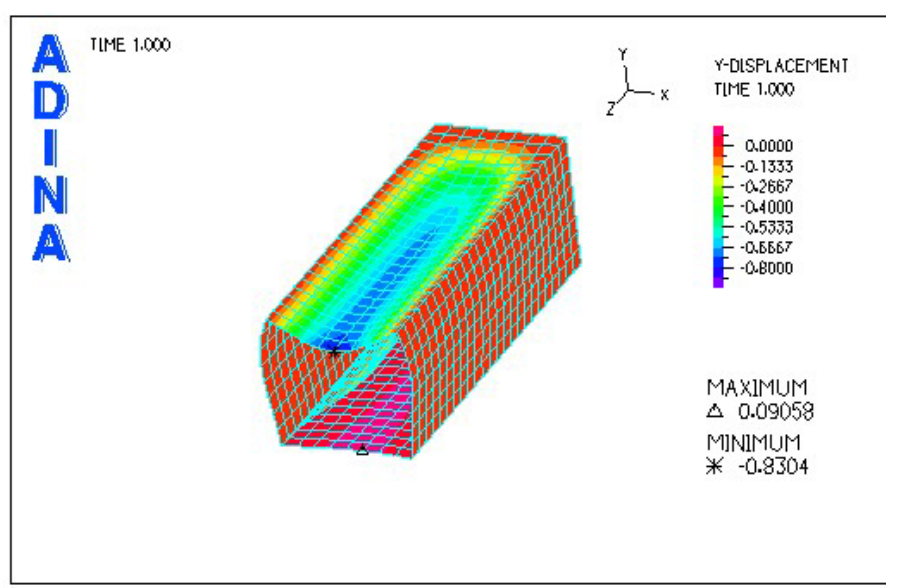

Figure 4.11: Slant displacement using ADINA

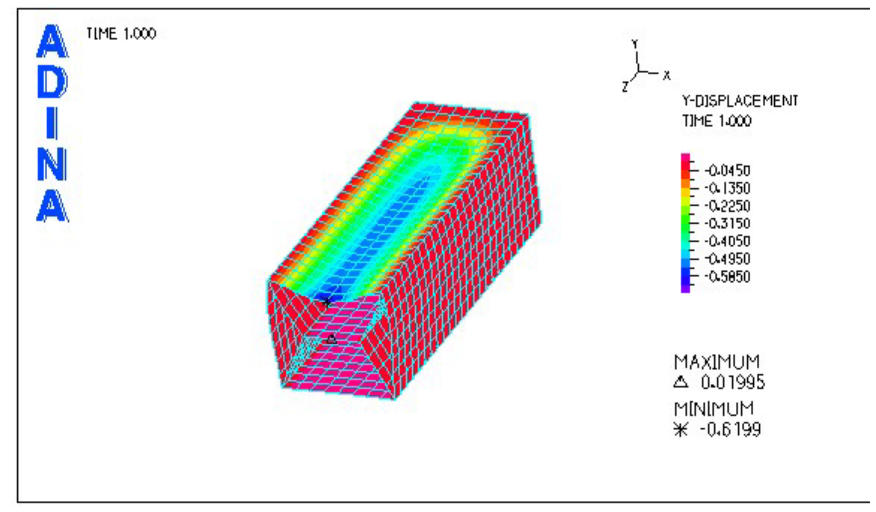

Figure 4.12: X1 displacement using ADINA 


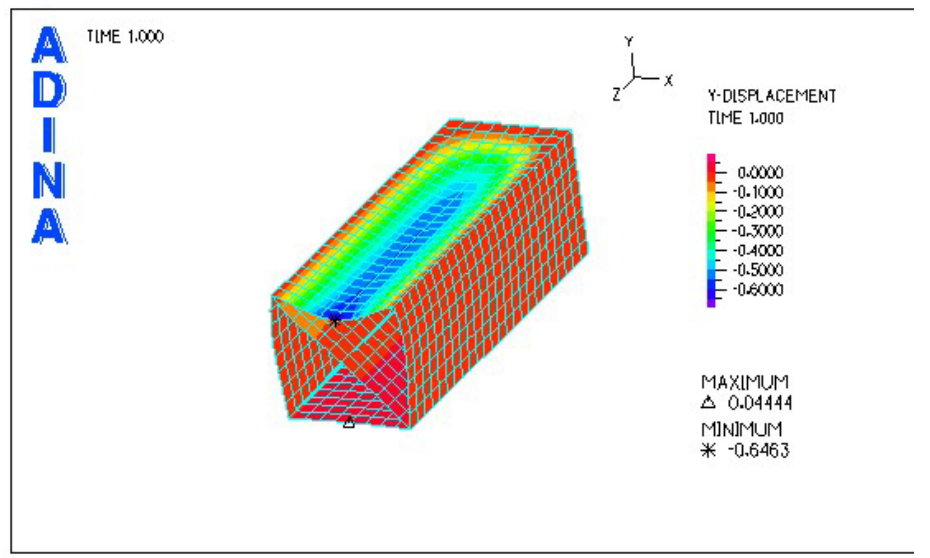

Figure 4.13: X2 displacement using ADINA

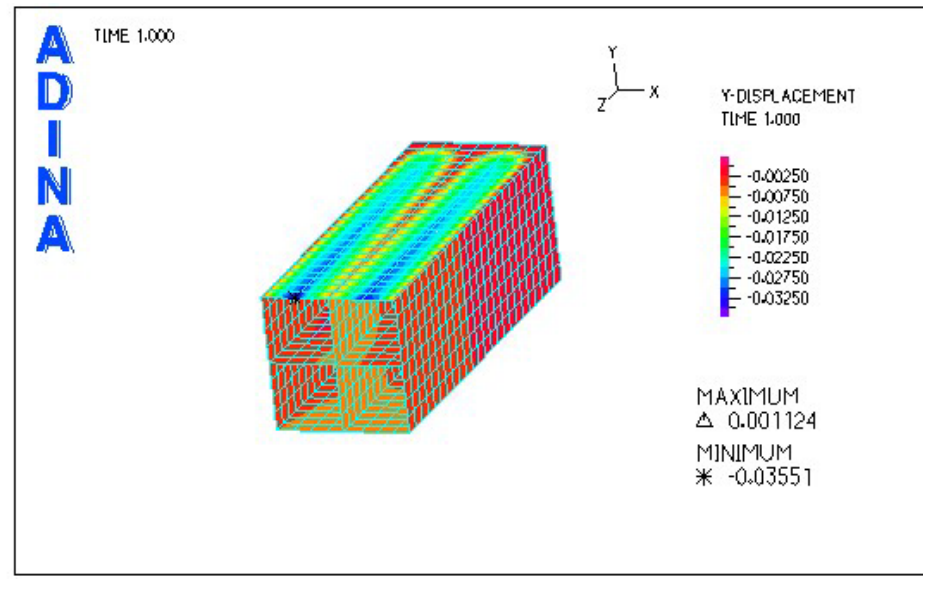

Figure 4.14: Box displacement using ADINA

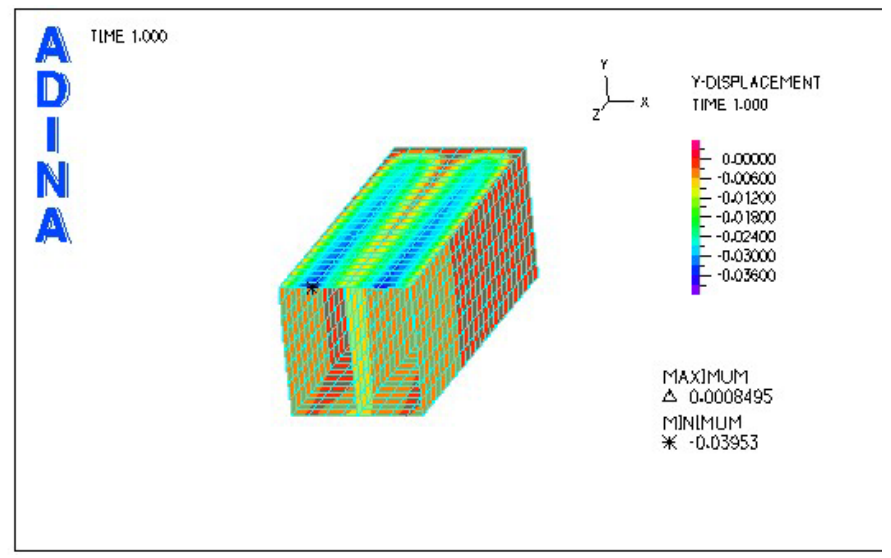

Figure 4.15: Box2 displacement using ADINA 
Table 4.2 - ADINA Bending Results

\begin{tabular}{|c|c|}
\hline \multicolumn{2}{|c|}{ ADINA Bending Results } \\
\hline Cross Section & Maximum Displacement (in.) \\
\hline Tube & 0.9744 \\
\hline Slant & 0.9304 \\
\hline X1 & 0.6199 \\
\hline X2 & 0.6463 \\
\hline Box & 0.0355 \\
\hline Box 2 & 0.0395 \\
\hline
\end{tabular}

\subsubsection{Discussion of Finite Element Bending Results}

The most effective cross section in regards to bending stiffness is the Box section. This section had a maximum displacement of 0.0355 inches. The least effective cross section for bending resistance is the Tube section. This section experienced a maximum displacement of 0.9744 inches. Comparing the two sections indicates that the Box section is stiffer to bending because of its middle support section, and it reacts with properties comparable to an I-beam. The Box section has a slight advantage over the Box 2 section because of the middle cross segment which restricts a large curvature of the sidewalls in bending. It is important to note that the maximum displacements all occur at the top, center-edge location farthest from the fixed support end.

The Tube section is a commonly extruded section and is easily available in commercial sales. The engineering aspect in question is if using an uncommon section, which requires special production costs, but has higher bending stiffness is worth the cost compared to the tube section's commercial availability and cost benefit? A valid option is to experiment and modify the tube section extrusion by compensating for the higher displacement values with face plates that will create a sandwich panel with bending stiffness capabilities.

\subsection{Torsion Analysis}

A torsional load was applied to the cross sections from Figure 4.1 and the results were compared by the maximum shear stress reached in each section. Similar to the 
procedure followed in the bending analysis, all the cross sections were modeled in ANSYS and ADINA with all loading, geometry, and boundary conditions kept constant throughout the analysis. The shell element divisions used in both the bending and torsional analyses were sized at uniform dimensions of 0.5 inches. Uniform element divisions were important in applying a uniform pressure for bending and an equal torsional load distribution from element to element.

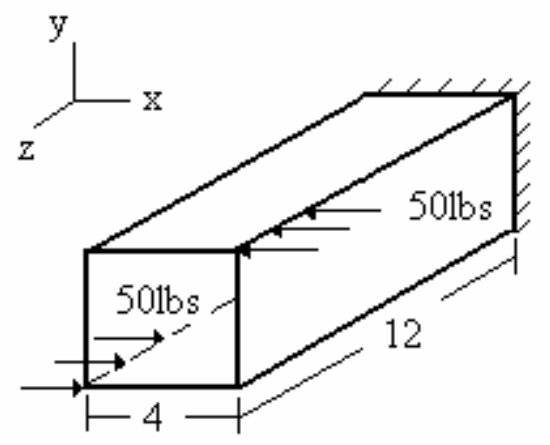

Figure 4.16: Loading scenario, dimensions and boundary conditions for torsional analysis.

Material: Aluminum

Elastic Modulus: $26 \times 10^{6} \mathrm{psi}$

Poisson's ratio: 0.33

Loading: $50 \mathrm{lbs}$ on each node

Elements: Shell

Element size: 0.5 in.

Element thickness: 0.02 in.

Section Dimensions: 4 x 4 x 12 x 0.02 in.

\subsubsection{Torsion Results}

The ANSYS generated results are displayed in the following figures. The results display plots of the maximum stress distributions from an applied load of $50 \mathrm{lbs}$. 


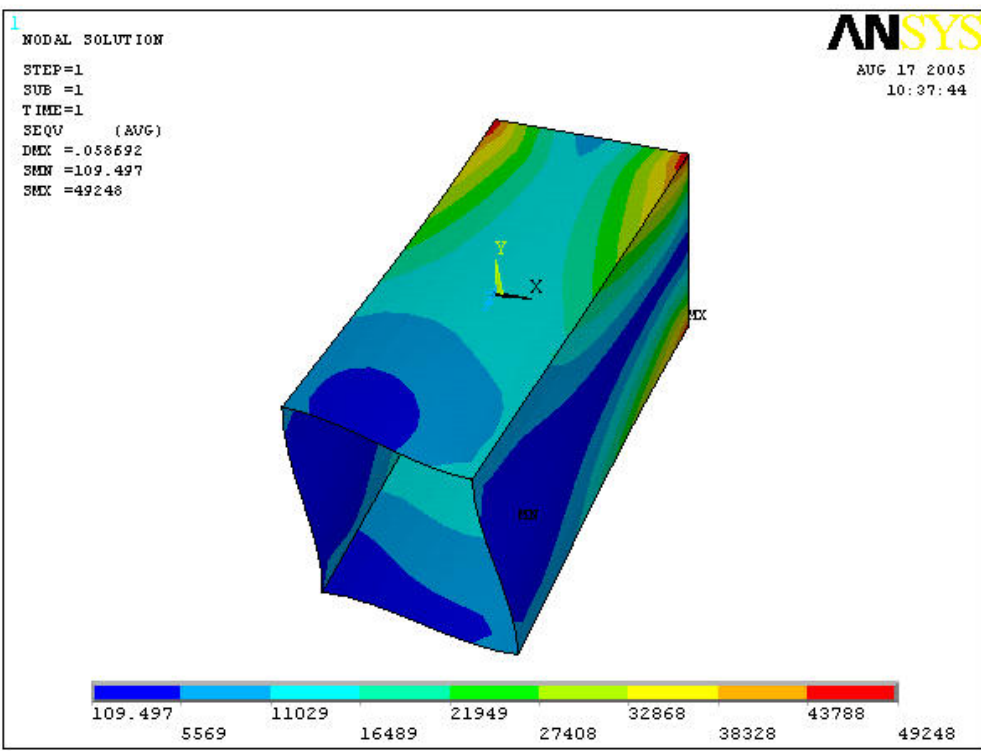

Figure 4.17: Tube torsion results using ANSYS

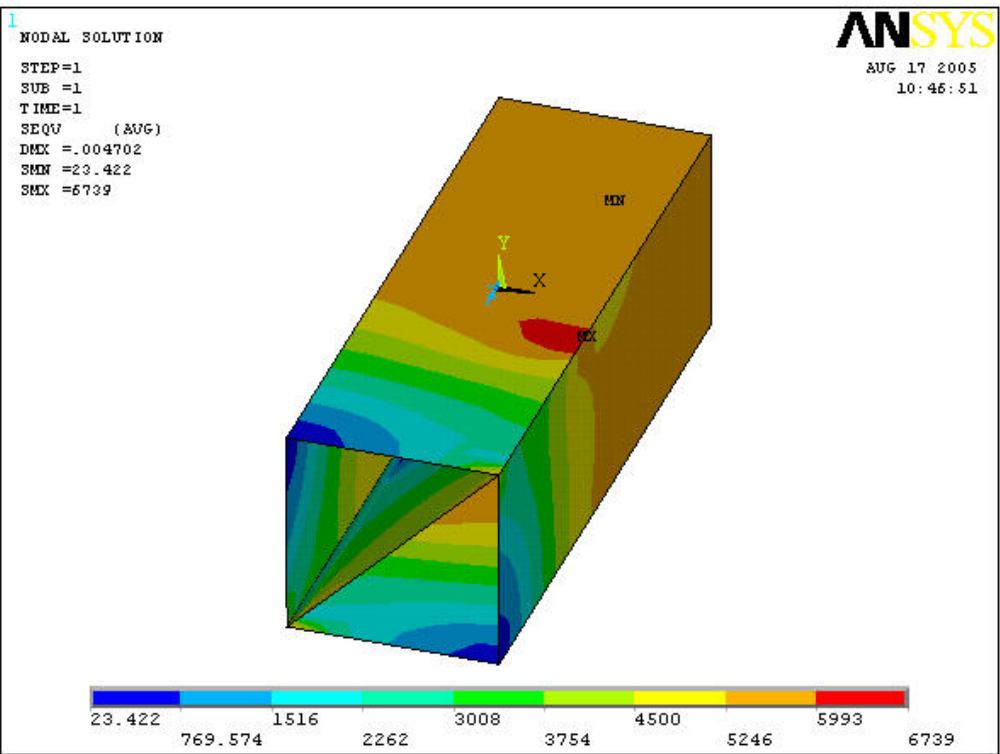

Figure 4.18: Slant torsion results using ANSYS 


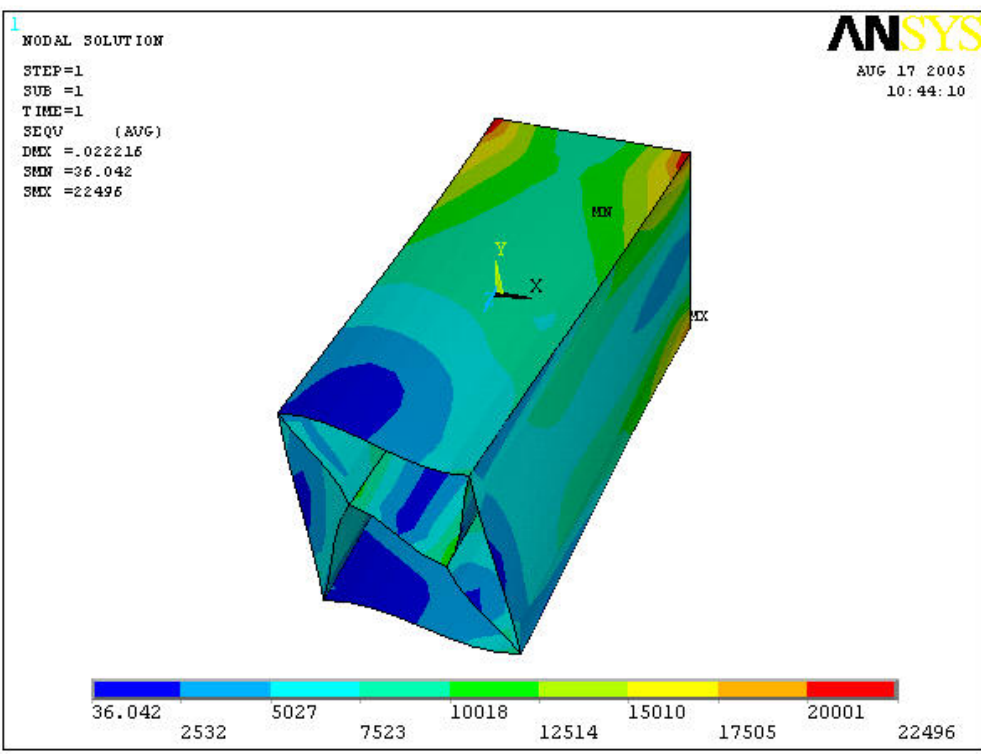

Figure 4.19: X1 torsion results using ANSYS

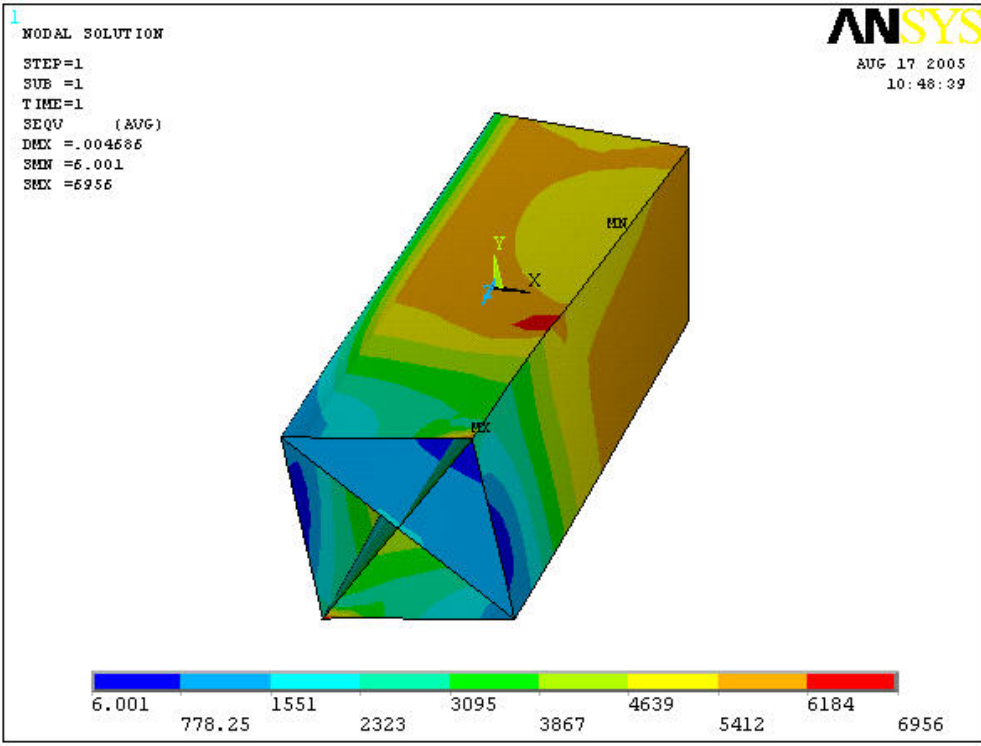

Figure 4.20: X2 torsion results using ANSYS 


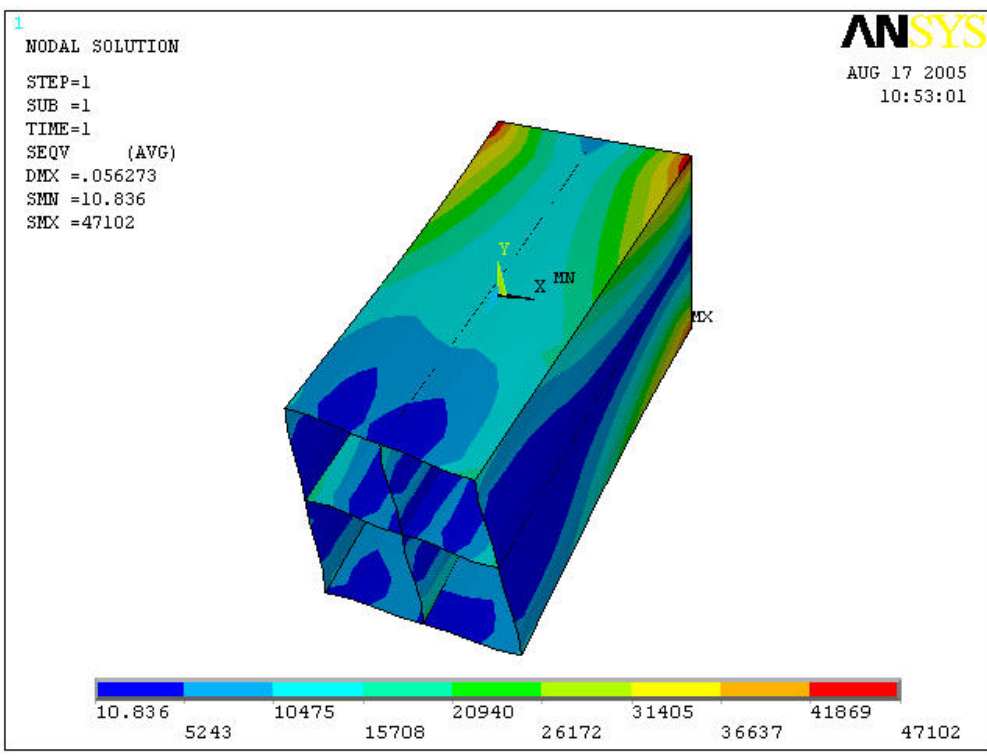

Figure 4.21: Box torsion results using ANSYS

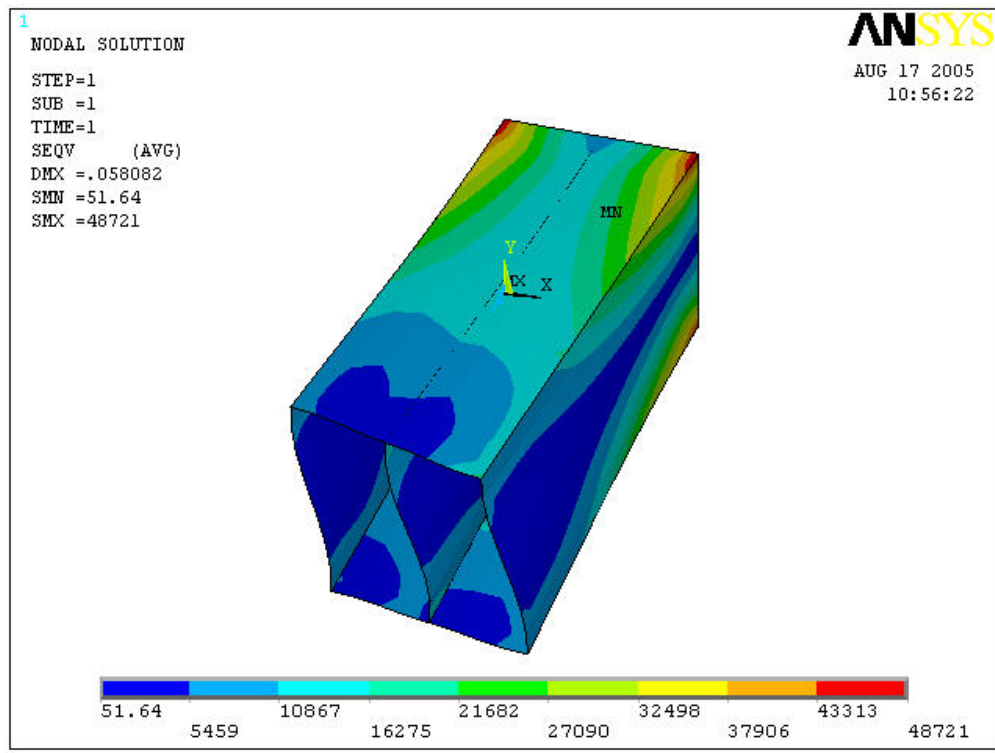

Figure 4.22: Box 2 torsion results using ANSYS 
Table 4.3 - ANSYS Torsion Results

\begin{tabular}{|c|c|}
\hline \multicolumn{2}{|c|}{ ANSYS Torsion Results } \\
\hline Cross Section & Maximum Shear Stress (psi) \\
\hline Tube & 49248 \\
\hline Slant & 6739 \\
\hline X1 & 22496 \\
\hline X2 & 6956 \\
\hline Box & 47102 \\
\hline Box 2 & 48721 \\
\hline
\end{tabular}

The ADINA generated results are displayed in the following figures. The same loading and boundary conditions were applied to the cross sections in both the ADINA and ANSYS models.

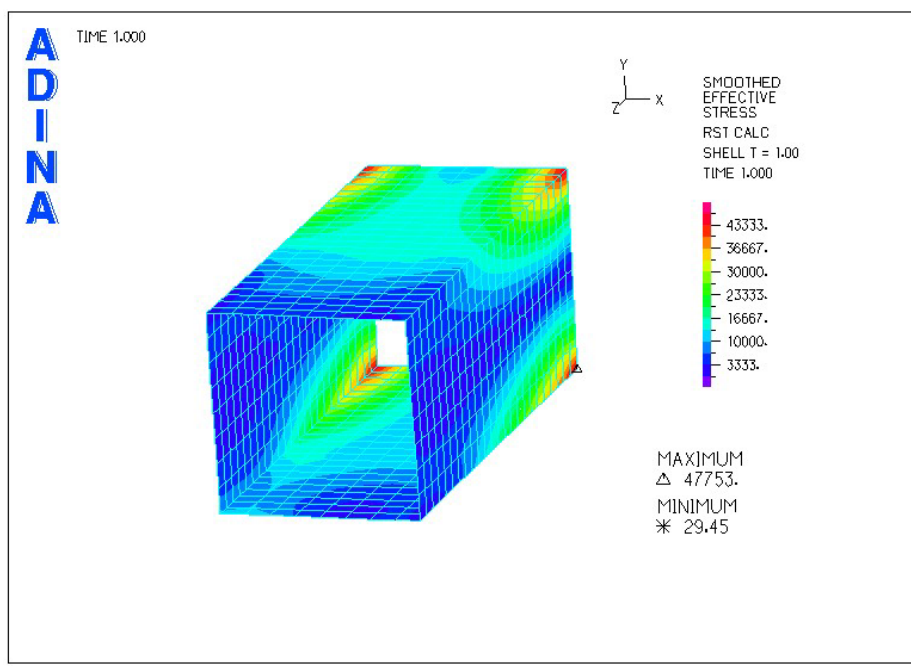

Figure 4.23: Tube torsion results using ADINA 


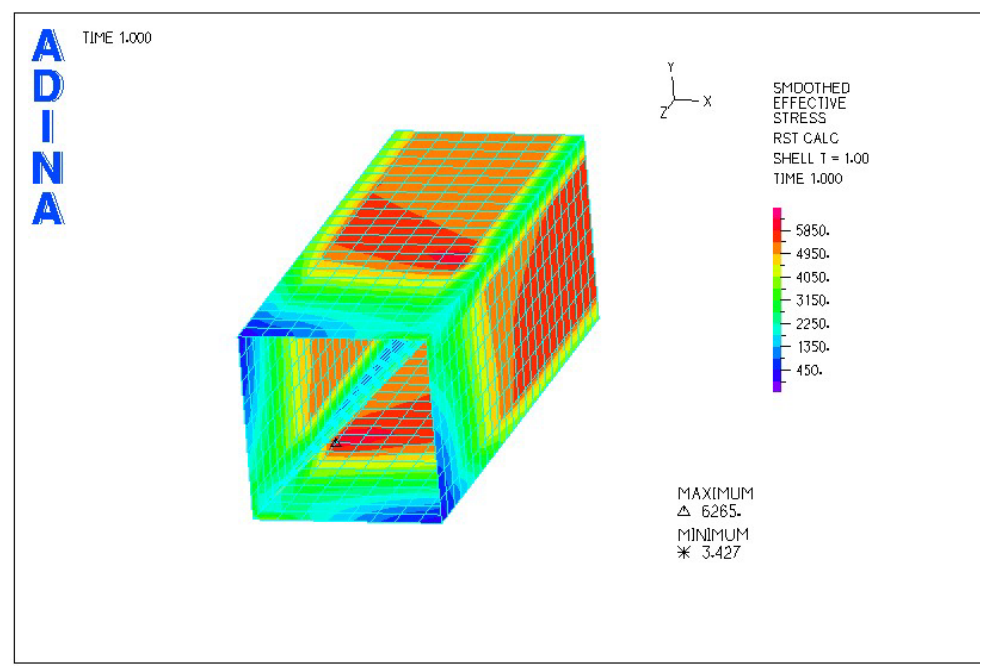

Figure 4.24: Slant torsion results using ADINA

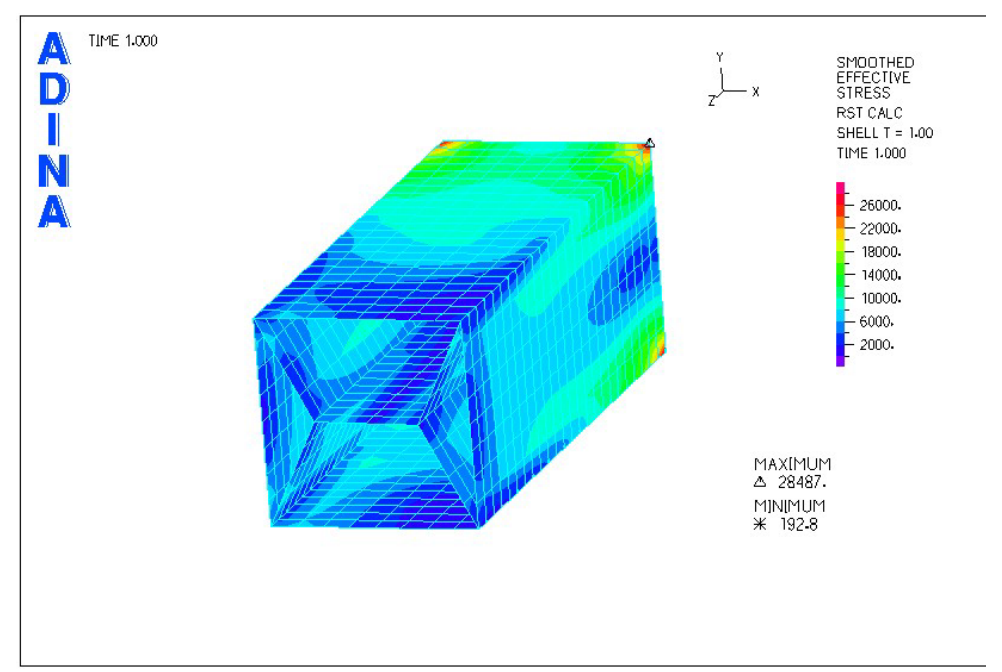

Figure 4.25: $\mathrm{X} 1$ torsion results using ADINA 


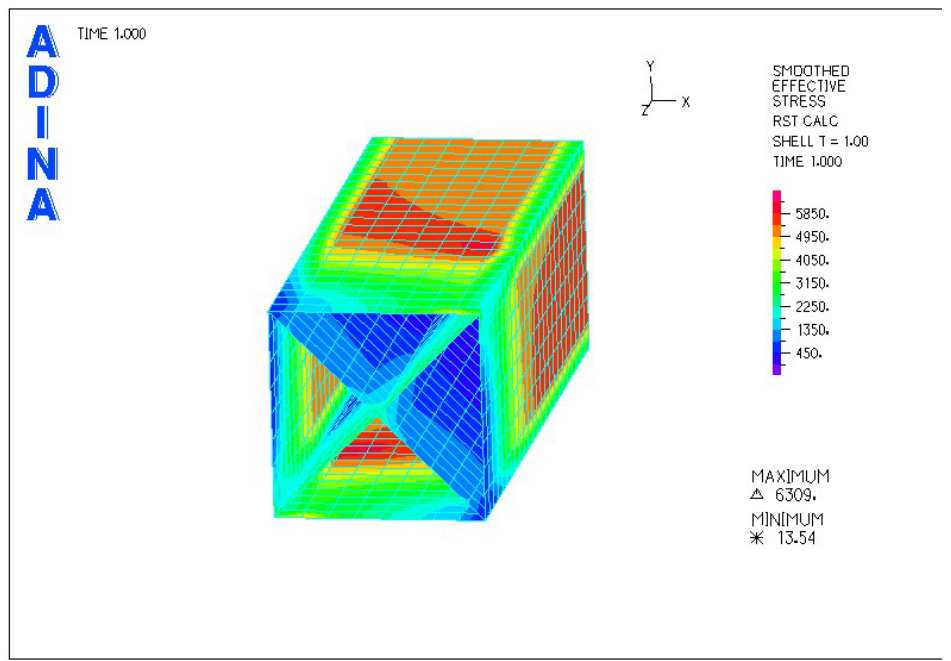

Figure 4.26: $\mathrm{X} 2$ torsion results using ADINA

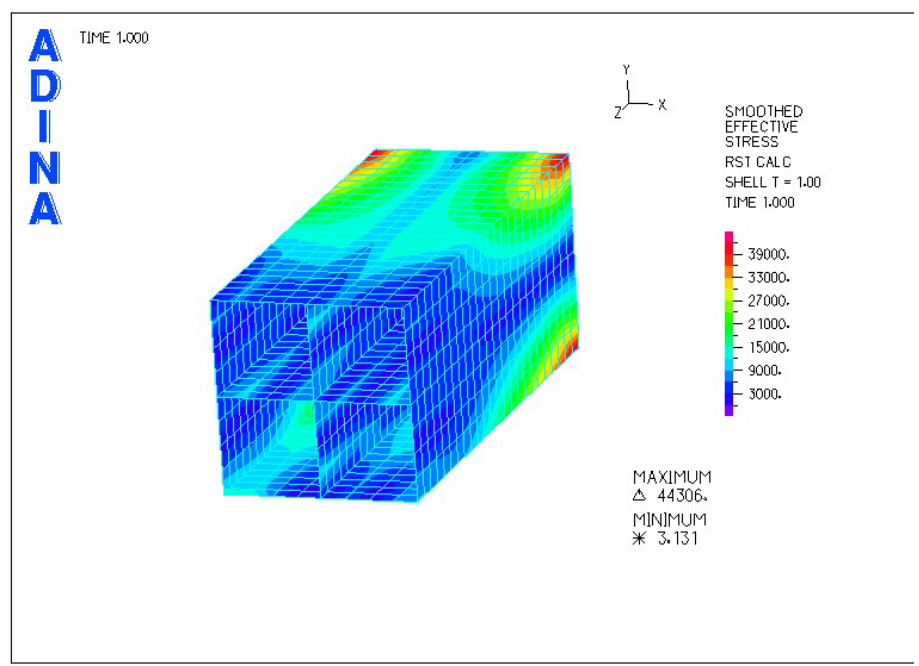

Figure 4.27: Box 1 torsion results using ADINA 


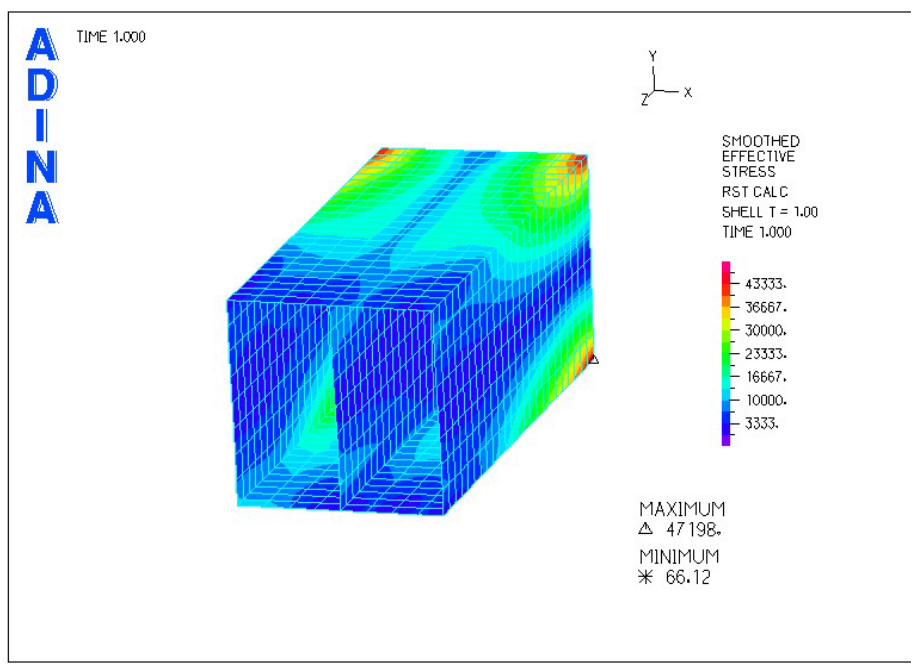

Figure 4.28: Box 2 torsion results using ADINA

Table 4.4 - ADINA Torsion Results

\begin{tabular}{|c|c|}
\hline \multicolumn{2}{|c|}{ ADINA Torsion Results } \\
\hline Cross Section & Maximum Shear Stress (psi) \\
\hline Tube & 47753 \\
\hline Slant & 6265 \\
\hline X1 & 28487 \\
\hline X2 & 6309 \\
\hline Box & 44306 \\
\hline Box 2 & 47198 \\
\hline
\end{tabular}

\section{Comparison of Bending and Torsion Results}

Table 4.5 - Comparison of ANSYS and ADINA Bending and Torsion Results

\begin{tabular}{|c|c|c|c|c|}
\hline & $\begin{array}{c}\text { Bending } \\
\text { ADINA }\end{array}$ & $\begin{array}{c}\text { Torsion } \\
\text { ADINA }\end{array}$ & $\begin{array}{c}\text { Bending } \\
\text { ANSYS }\end{array}$ & $\begin{array}{c}\text { Torsion } \\
\text { ANSYS }\end{array}$ \\
\hline $\begin{array}{c}\text { Cross } \\
\text { Section }\end{array}$ & Max Deflection & Max Stress & $\begin{array}{c}\text { Max } \\
\text { Deflection }\end{array}$ & Max Stress \\
\hline Tube & 0.9744 & 47753 & 0.997103 & 49248 \\
\hline Slant & 0.9304 & 6265 & 0.854074 & 6739 \\
\hline X1 & 0.6199 & 28487 & 0.648361 & 22496 \\
\hline X2 & 0.6463 & 6309 & 0.671524 & 6956 \\
\hline Box1 & 0.0355 & 44306 & 0.041566 & 47102 \\
\hline Box2 & 0.0395 & 47198 & 0.045573 & 48721 \\
\hline
\end{tabular}




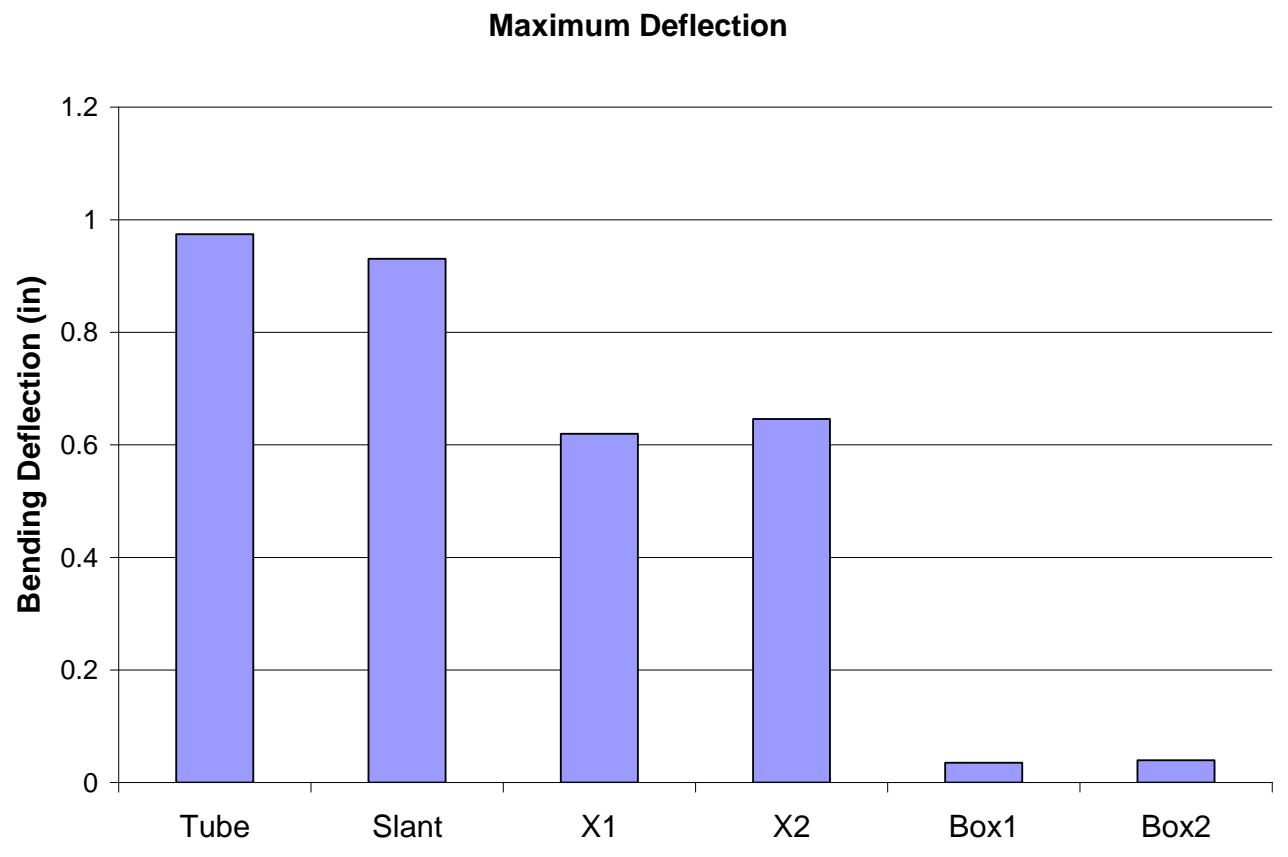

Figure 4.29: Plot of maximum bending deflection for tube cross members.

Torsion Stress

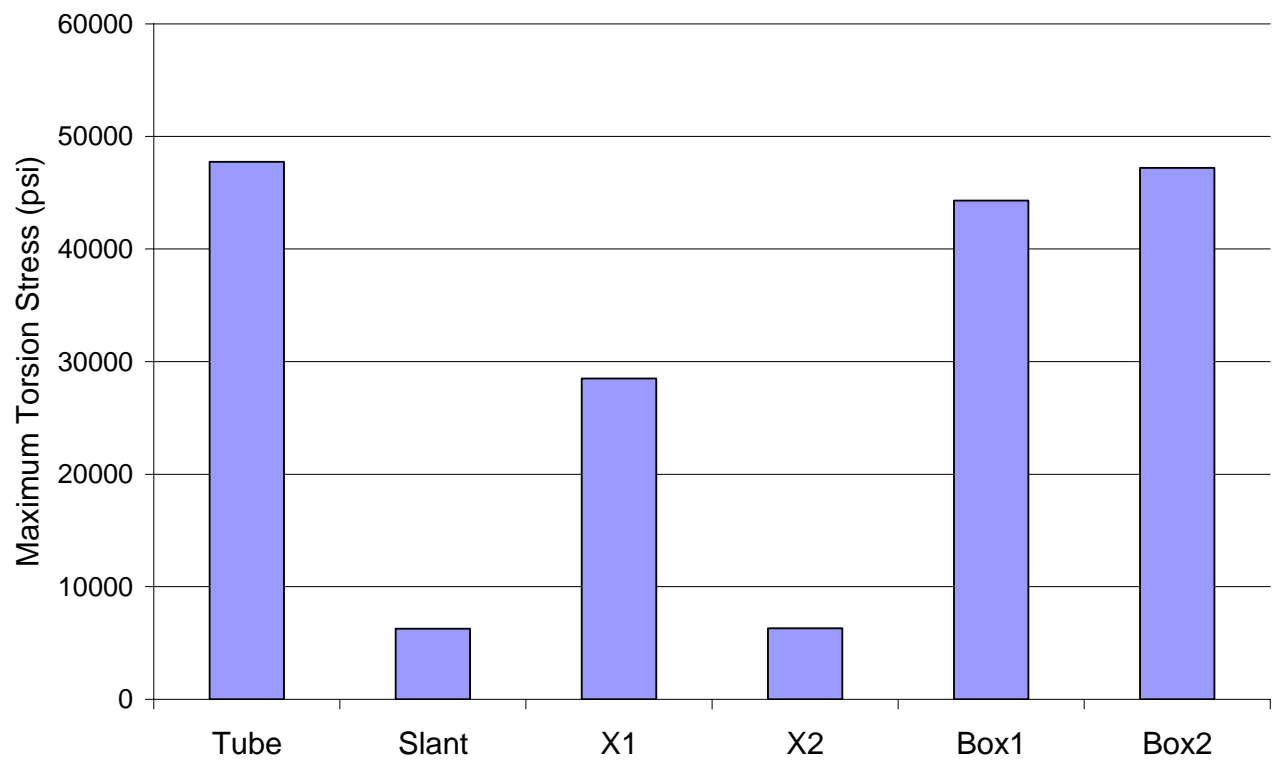

Figure 4.30: Plot of maximum torsional stress within the tube cross section members. 


\subsubsection{Discussion of Finite Element Torsion Results}

The results of the torsional loading in the cross section members show that the Slant and the $\mathrm{X} 2$ configurations are the most effective designs for minimum stress values, while the Box1, Box2, and Tube sections exhibit the highest stress levels. The diagonal supports that connect to the inside corners of the Slant, X1, and X2 extrusions are effective for resisting the applied torsion.

\subsubsection{Weight Comparison}

The structural weights of the different cross sections considered in this thesis are compared on the basis of one-square foot section which would be implemented into the trailer flooring. The existing trailer floor weight has also been determined as a baseline for assessing the weight savings achievable by using the sandwich composite design with the various cross sections described above as core materials.

The existing trailer floor is composed of 54 cross member (SI Beams) which are spaced at $1 \mathrm{ft}(0.305 \mathrm{~m})$, and the length of each is $8 \mathrm{ft}(2.44 \mathrm{~m})$. The cross members contribute a total weight of $4,104 \mathrm{lbs}(1861.5 \mathrm{~kg})$. Adding to the cross member weight is the oak floor which contributes 5,227 lbs $(2370.9 \mathrm{~kg})$ and covers $432 \mathrm{ft}^{2}$.

\section{Cross Beam Weight:}

54 cross beams $=4104 \mathrm{lbs} \quad \frac{4104 \mathrm{lbs}}{54 \text { beams }}=76 \frac{\mathrm{lbs}}{\mathrm{beam}}$ $\frac{76 \frac{\mathrm{lbs}}{\mathrm{beam}}}{8 \frac{\mathrm{ft}}{\mathrm{beam}}}=9.5 \frac{\mathrm{lb}}{\mathrm{ft}} \quad 9.5 \frac{\mathrm{lb}}{\mathrm{ft}} \times 1 \frac{\mathrm{beam}}{\mathrm{ft}}=9.5 \frac{\mathrm{lb}}{\mathrm{ft}^{2}}$

\section{Oak Floor Weight:}

oak floor $=4645 \mathrm{lbs} \quad$ floor area $=54 \mathrm{ft} \times 8 \mathrm{ft}=432 \mathrm{ft}^{2}$

$\frac{5227 \mathrm{lbs}}{432 \mathrm{ft}^{2}}=12.1 \frac{\mathrm{lbs}}{f t^{2}}$ 


\section{Trailer Floor Weight per Square Foot:}

weight of beams $=9.5 \frac{\mathrm{lbs}}{\mathrm{ft}^{2}} \quad$ weight of oak floor $=12.1 \frac{\mathrm{lbs}}{\mathrm{ft}^{2}}$

weight per square foot $=9.5 \frac{\mathrm{lbs}}{\mathrm{ft}^{2}}+12.1 \frac{\mathrm{lbs}}{\mathrm{ft}^{2}}=21.6 \frac{\mathrm{lbs}}{\mathrm{ft}^{2}}$

Table 4.6 - Weight Comparisons between Alternative Cross-Sections

\begin{tabular}{|c|c|c|c|c|}
\hline Cross & Surface & Individual Section & Square Foot & Square foot \\
\hline Section & Area & Weight (lbs) & Surface Area & Weight (lbs) \\
\hline Tube & 192 & 0.54912 & 576 & 1.64736 \\
\hline Slant & 259.8 & 0.743028 & 779.4 & 2.229084 \\
\hline X1 & 311 & 0.88946 & 933 & 2.66838 \\
\hline X2 & 327.6 & 0.936936 & 982.8 & 2.810808 \\
\hline Box1 & 288 & 0.82368 & 864 & 2.47104 \\
\hline Box2 & 240 & 0.6864 & 720 & 2.0592 \\
\hline Trailer Floor & N/A & N/A & N/A & 21.6 \\
\hline
\end{tabular}

Weight Comparison

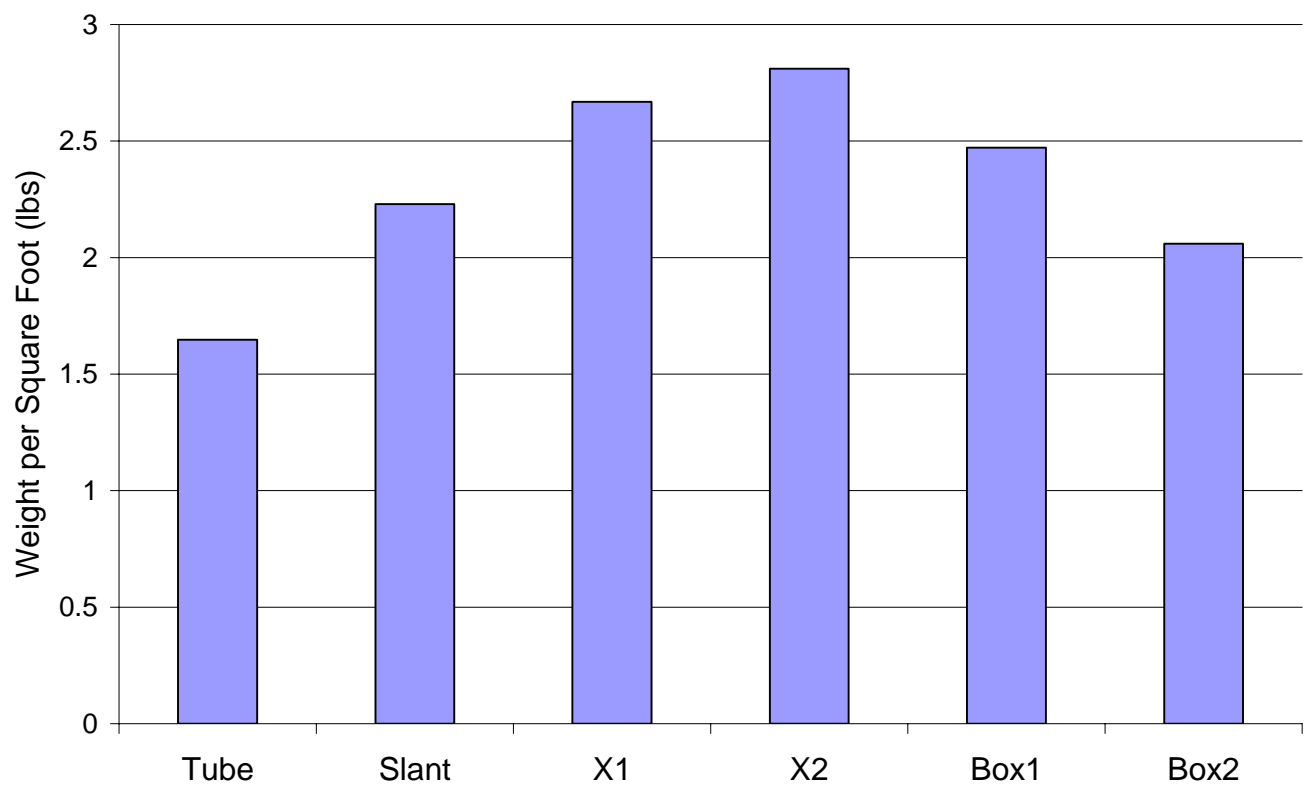

Figure 4.31: Plot of the weight comparison between cross tube members. 


\subsection{Panels with Tube Section Cross Members}

The prior analysis of various cross section aluminum extrusions as a load bearing component for heavy vehicle flooring, indicates that the concept of using this structural design is promising, which initiated further study. To pursue such investigation, different panel configurations were manufactured for use in experimental testing and finite element modeling.

The objective of this phase of research is to find a design that incorporates the bending resistance and weight saving capabilities of the extruded sections and also produces a lightweight structural platform. The initial panel design consisted of a repeated pattern of the different cross sections. However, to maximize weight savings and still maintain loading resistance, different configurations of the cross members were studied. The initial designs were the repeated cross section panel and a "grated" panel, as shown in Figure 4.32 (a) and (b), respectively.

(a)

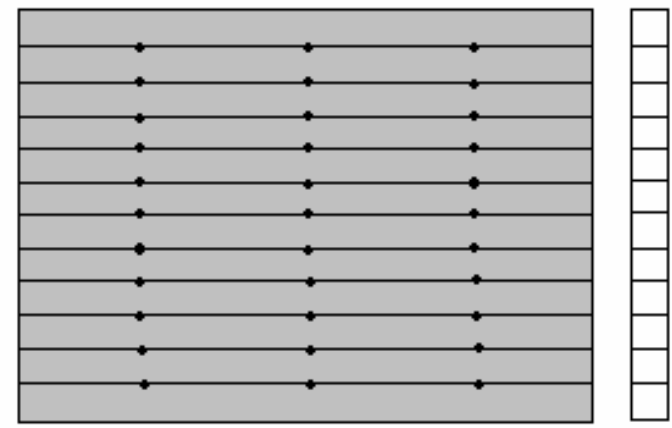

(b)

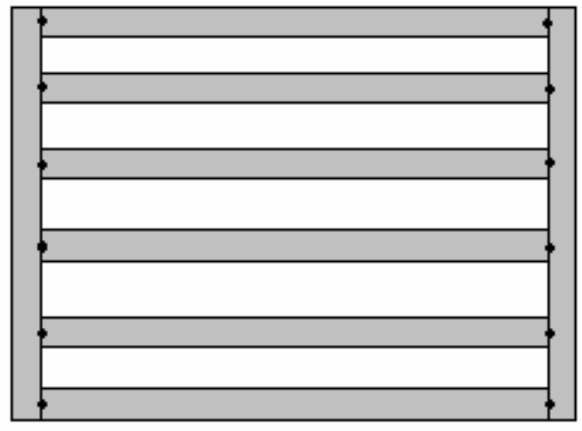

- Weld Points

Figure 4.32: Schematic of the tubeplate (a) and the tubegrate (b) panel designs.

\subsubsection{Tubeplate}

The fabrication process differed for each panel. The tubeplate design in Figure 4.32 (a), was manufactured by cutting 12 inch aluminum tube sections to compose a square foot panel design. The cut edges were sanded to eliminate any burs, allowing the tube edges to be butted closely together. Once the tubes were placed into position, the 
twelve aluminum tubes were clamped tightly together and welded at the points shown in Figure 4.32 (a).

\subsubsection{Tubegrate}

The fabrication of the tubegrate design, Figure 4.32 (b), differed from the tubeplate by the incorporation of the edge U-channels and the weld point locations. The grated design eliminated half of the cross member tubes used in the tubeplate as a means of reducing weight. Experimental and theoretical analysis of these designs will answer the question of which panel will best resist certain loading situations and how to maximize the ratio of weight savings to structural stiffness and integrity.

\subsection{Sandwich Composite Panels with Aluminum Extruded Core Cross Members}

\subsubsection{Fiberplate}

The third panel design incorporates the extruded sections studied in this report as a composite sandwich core material. Composite sandwich designs are effective for resisting bending loads with the potential for weight saving capabilities. The concept to incorporate the extruded sections as a core material was motivated by the bonding quandary between composite and metal sections, the joining challenge to eliminate bolting and fastening methods, and a method to provide a lightweight, strong, and low cost way to produce a structurally sound and easily manufactured panel design.

The fiberglass and aluminum tube core panel is a complex design that involves ribbed paper honeycomb, sheet aluminum stiffeners, E-glass $18 \mathrm{oz} / \mathrm{sq}$. yd woven fabric, fiber content 52 vol- $\%$ and five $3 / 4$ inch extruded aluminum tubes. The illustration of the design and basic manufacturing process is depicted in Figure 4.33. This figure shows the process and materials used to create the "fiberplate" composite sandwich panel. 


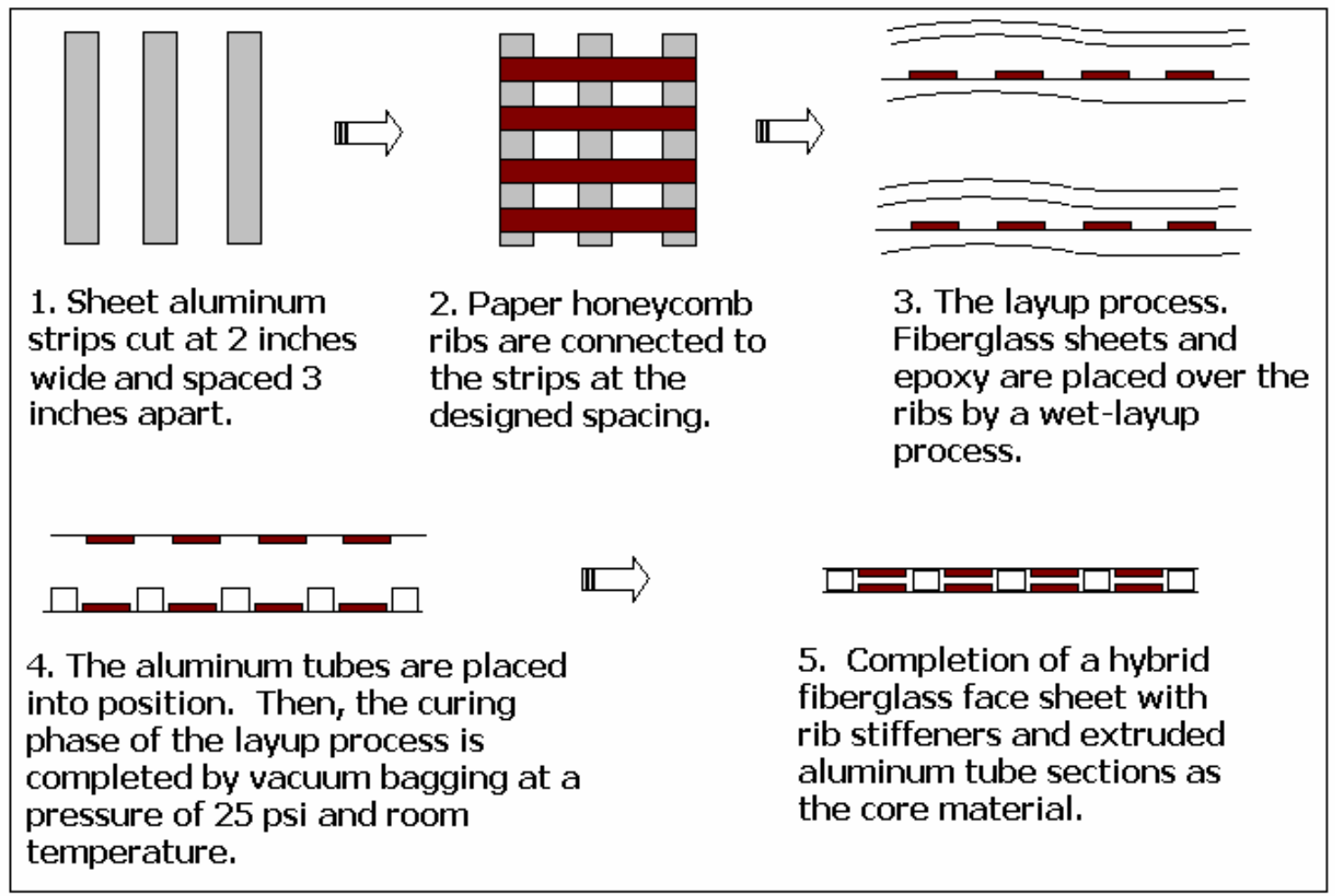

Figure 4.33: Manufacturing process of the fiberplate design. This design incorporates ribbed fiberglass face plates and extruded aluminum tubes as a core material.

The geometry of the ribbed top and bottom plates is an effective feature to incorporate the extruded aluminum tubes in the core of the panel. The interface between the epoxy core and the aluminum tubes does not provide a strong bond. Therefore, the paper honeycomb ribs between the tubes will enclose and secure the positioning of the core cross tube members. The bond or connection between the aluminum tubes and the composite top plate is important for the overall panel bending resistance. The bonding methodology researched in this work and used in the fabrication of the trailer model will be applied to create an effective bond in this area. 

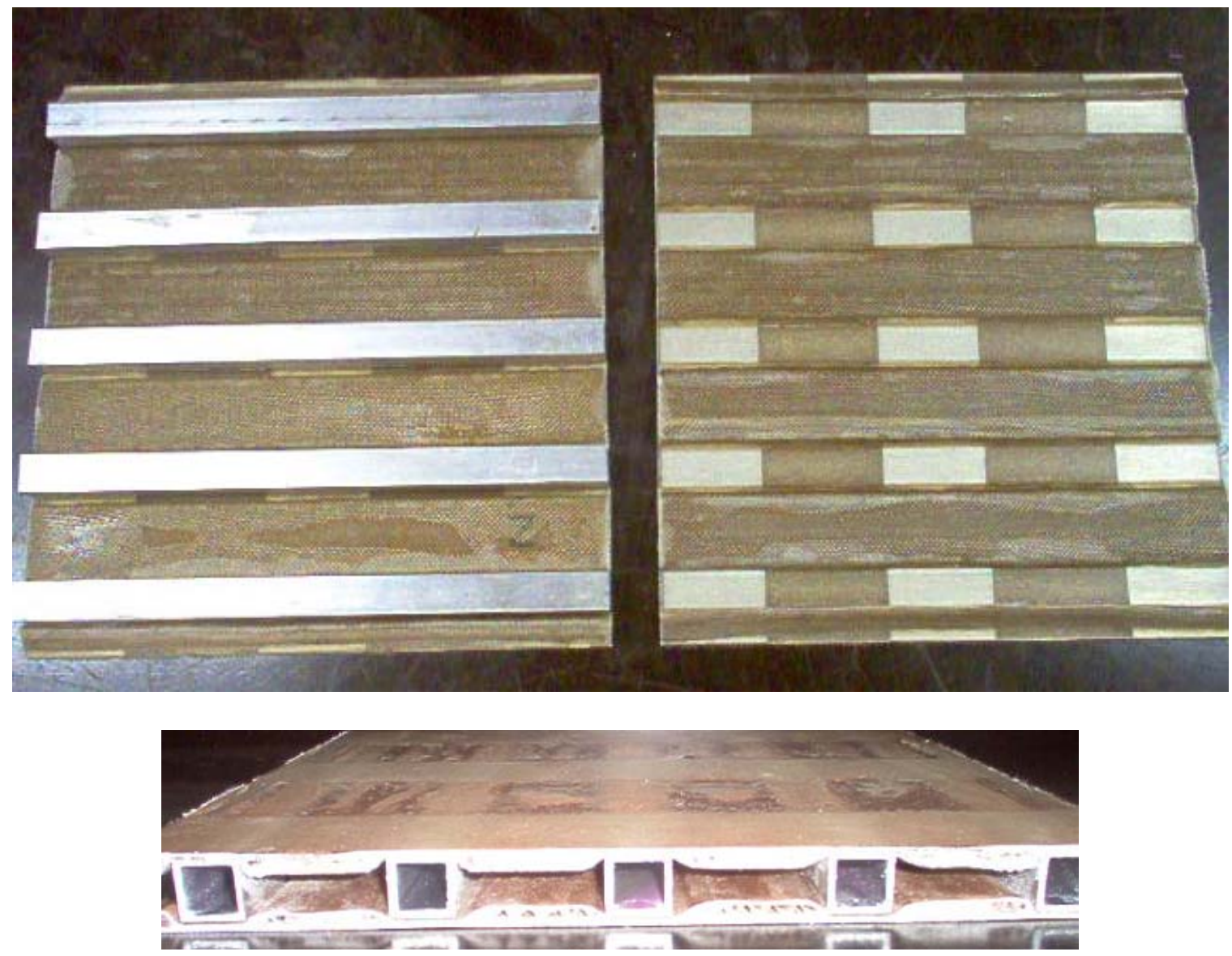

Figure 4.34: The fiberplate design with five aluminum tube cross members, fiberglass top and bottom face plates, and paper honeycomb rib stiffeners.

The finished fiberplate panel is shown in Figure 4.34. This picture illustrates the five aluminum tube cross members and the fiberglass top and bottom plates containing the paper rib stiffeners and the aluminum strips. The method of manufacturing required that the top and bottom plate be made separately for two reasons. First, the vacuum bagging technique would not have applied pressure on the on the top surface of the paper rib stiffeners if the plate was completely assembled and then pressurized. Second, the top and bottom edges of the top plate would have not cured in a flat position but would take on a curved shape from the pressurization.

\subsubsection{Carbonplate}

The carbonplate was manufactured in the same manner as the fiberplate except using carbon fiber sheets instead of fiberglass. Also, the carbonplate layup process was done in one single step instead of manufacturing the top and bottom face plates 
separately. A single phase manufacturing process was intensive and critical for proper alignment of the cross members in relation to the top and bottom face plates. Reinforced foam inserts were placed in the spacing between the core cross members. Pressure was provided from the foam inserts onto the paper honeycomb ribbed sections when the entire panel was vacuum bagged. A release agent was placed on the surfaces between the core and face plates and also between the foam inserts and face plates so the parts could removed after the curing procedure.

The carbon fiber alternative to fiberglass is effective for adding strength and stiffness to the sandwich composite along with weight saving capabilities. The fatigue life of the carbon fiber is superior to that of the fiberglass and is effective for cyclic loading that may occur in structural use of the sandwich composite.

\subsection{Finite Element Modeling (ADINA)}

After manufacturing the panel designs, finite element modeling was done to theoretically determine the performance of the panel structures under simulated loading. The procedure for the modeling of the panels follows the same comparative study as previously performed for the six extruded cross sections. The loading, boundary conditions, and elements used were held constant throughout the study. This enabled the theoretical comparison to be consistent throughout the modeling process and to avoid inaccuracies that could possibly be cause by the differences between the modeled panels.

ADINA version 8.2 finite element software was used for the numerical comparison between alternate panel designs.

\subsubsection{Tubeplate}

Material: 12, 1 inch aluminum tube extruded cross members

Young's Modulus $=10 \mathrm{Msi}$

Poisson's Ratio $=0.33$

Tube Thickness: $2 / 32$ inch

Panel Dimensions: $1 \mathrm{ft}$ x $1 \mathrm{ft} \times 1$ inch

Elements: Shell

Boundary Conditions: All DOF fixed on plate edge perpendicular to cross members. Load: 2 inch $x 3$ inch pressurized load of $100 \mathrm{psi}$ 
The geometry of the tubeplate was created using the Pro Engineer CAD software. The process in Pro Engineer was to create the tube cross section and extrude it to the length of the plate. After one tube was created, the tube was patterned and spaced 0.001 inches apart to account for the natural gap between the adjacent surfaces. The pattern resulted in a total of twelve, 1 inch tubes butted together which yielded a panel of 12 inches by 12 inches or 1 square foot.

The Pro Engineer geometry was imported into ADINA finite element software. The material properties and dimensions for the tubeplate were defined in ADINA. All surfaces in the geometry of the plate were divided into segments to create quadrilateral elements of size 0.2 " upon meshing. To simulate the weld points between tubes, rigid links between adjacent nodes of butted tubes were connected. The rigid link option in ADINA defines the motion/displacement of the selected nodes to be coupled together. The geometry, mesh, and defining parameters of the model can be seen in Figure 4.35.

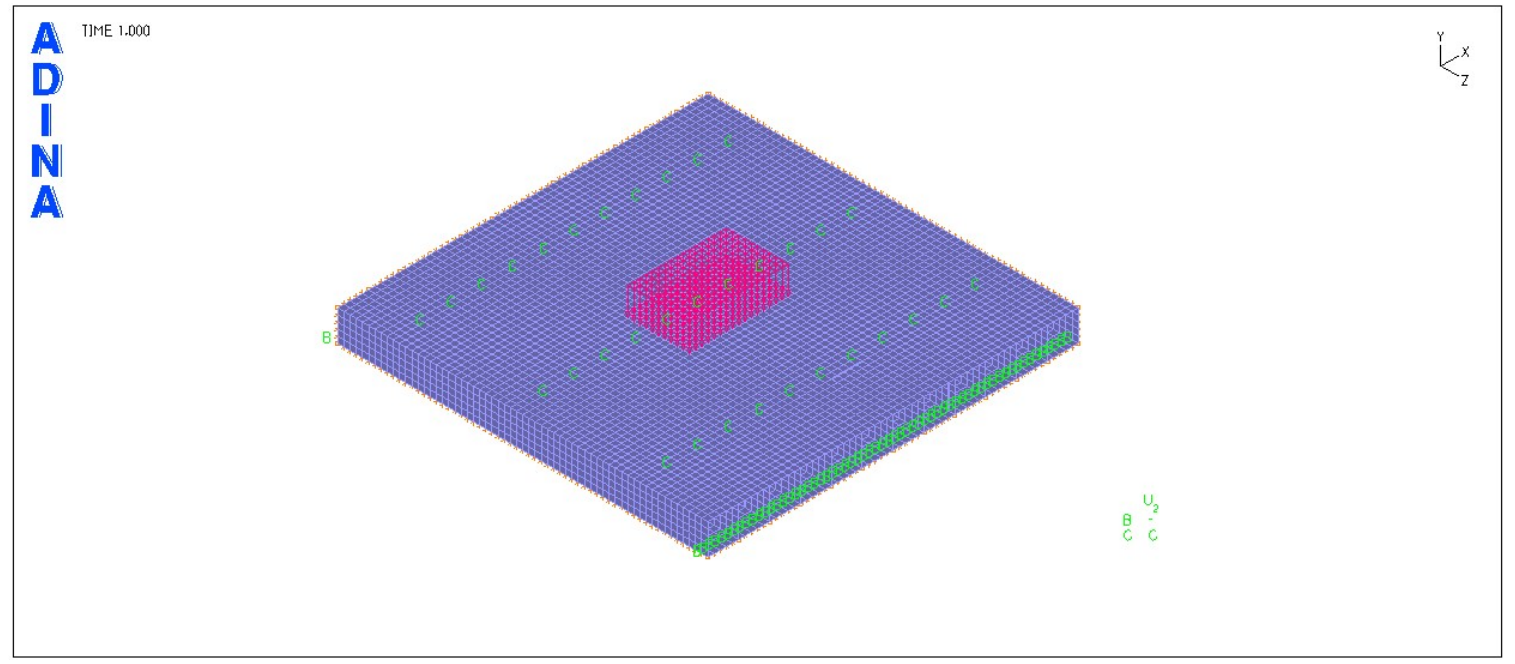

Figure 4.35: Tubeplate geometry, mesh, boundary conditions and applied load.

\subsubsection{Tubegrate}

Material: 6, 1 inch aluminum tube extruded cross members 2, aluminum U-channels

Young's Modulus $=10 \mathrm{Msi}$

Poisson's Ratio $=0.33$

Tube Thickness: $2 / 32$ inch

Panel Dimensions: $1 \mathrm{ft}$ x $1 \mathrm{ft} \times 1$ inch

Elements: Shell 
Boundary Conditions: All DOF fixed on U-channel edge perpendicular to cross members. Load:

Modeling of the tubegrate was similar to the tubeplate model but differed by incorporation of edge U-channels and spacing between tube cross members. The method to model the interface between the U-channels and cross members was determined by the manufacturing process. During manufacturing, the connection of the tubes into the Uchannel was made by an interference fit. This type of connection increased the stability of the overall panel and reduces the emphasis of the weld connection between the cross members and U-channel. To simulate this connection in ADINA the elements on the Uchannel and cross member interface shared common nodes and were defined in thickness by shell elements. The tubegrate model created for theoretical analysis is depicted in Figure 4.36.

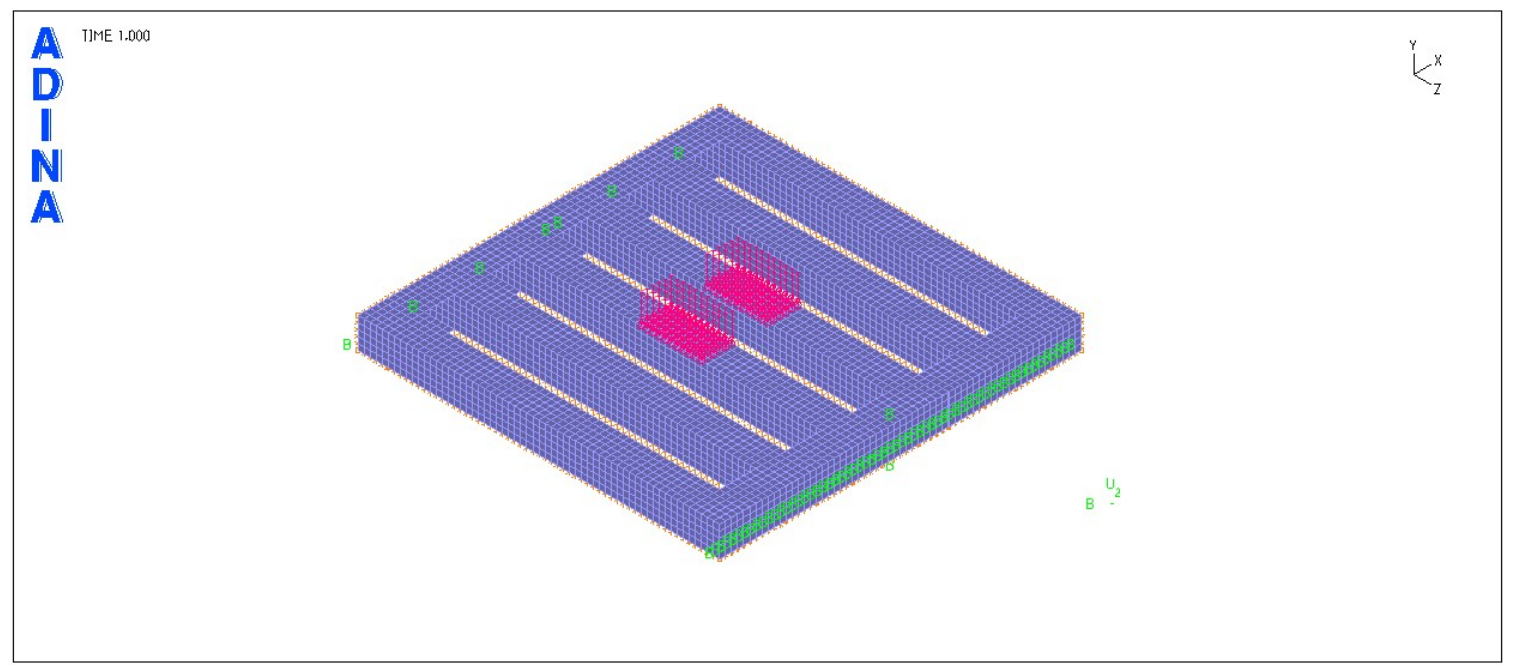

Figure 4.36: Tubegrate geometry, mesh, boundary conditions, and applied load.

\subsubsection{Fiberplate}

Material: $5,3 / 4$ inch aluminum tube cross members

10 paper rib strips

6 aluminum sheet metal strips

12 layers of woven E-glass and epoxy fiberglass composite

Aluminum Tubes

Tube Thickness: $2 / 32$ inch
Paper Ribs

Thickness: $5 / 32$ inch 
Dimensions: $1 \mathrm{ft} \mathrm{x} 3 / 4$ inch $\mathrm{x} 3 / 4$ inch

Young's Modulus $=10 \mathrm{Msi}$

Poisson's Ratio $=0.33$

Elements: Shell

Aluminum Sheet Metal Strips

Thickness: 0.02 inch

Dimensions: $1 \mathrm{ft} \times 2$ inch $\times 0.02$ inch

Young's Modulus $=10 \mathrm{Msi}$

Poisson's Ratio $=0.33$

Elements: Shell

Fiberglass

Glass/Epoxy Fabric

Layer Thickness: 0.025 inch

$\mathrm{Vf}=0.50$

rho $=0.06 \mathrm{lb} /$ in $^{3}$

$\mathrm{E} 11=4.3 \mathrm{Msi}$

$\mathrm{E} 22=4.31 \mathrm{Msi}$

$\mathrm{G} 12=0.77 \mathrm{Msi}$

$v 12=0.17$
Dimensions: $1 \mathrm{ft} \times 13 / 4$ inch x 5/32

Young's Modulus $=652 \mathrm{ksi}$

Poisson's Ratio $=0.3$

Elements: Shell

Elements: Shell with layer definition

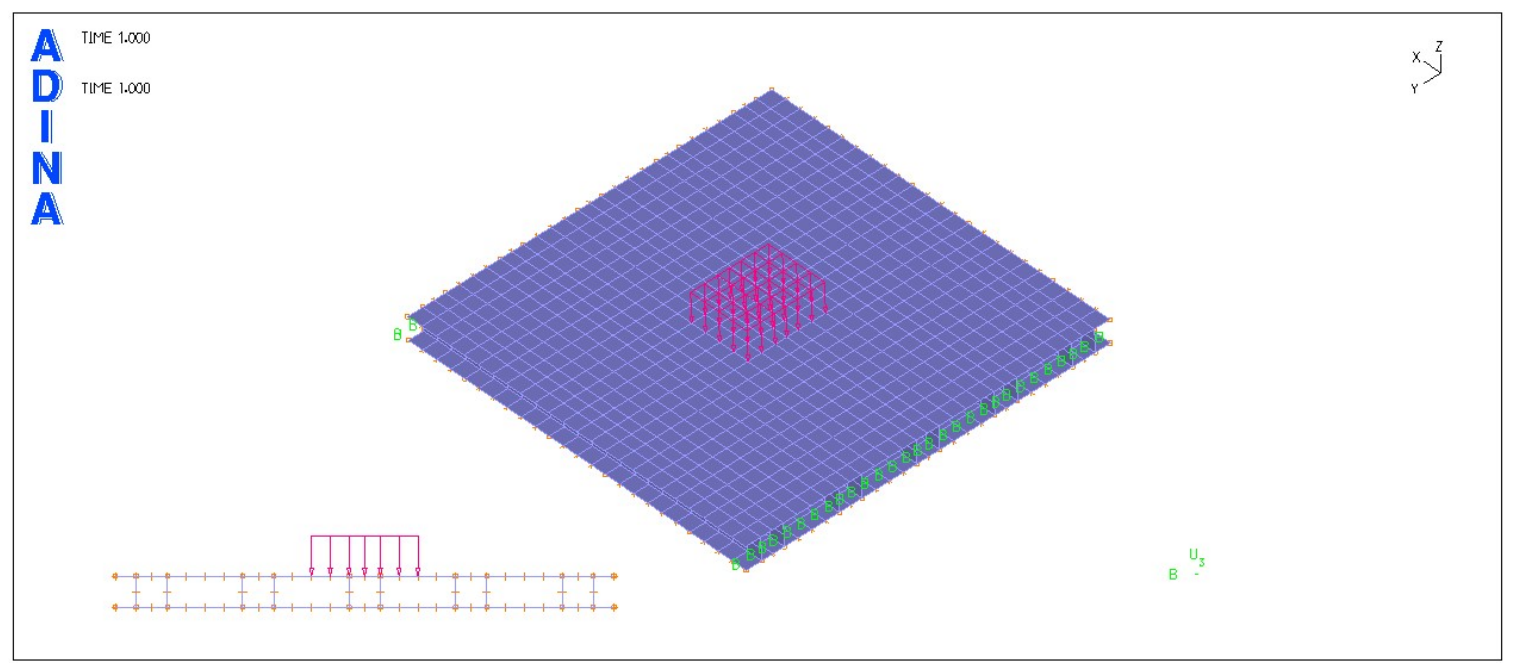

Figure 4.37: Fiberplate design with cross sectional view.

The fiberplate design required a detailed finite element modeling process. The panel consists of four different materials and various sections which are separated by the number and types of these materials used. Using the schematic shown in Figure 4.38, the details of the panel are more visually defined. 


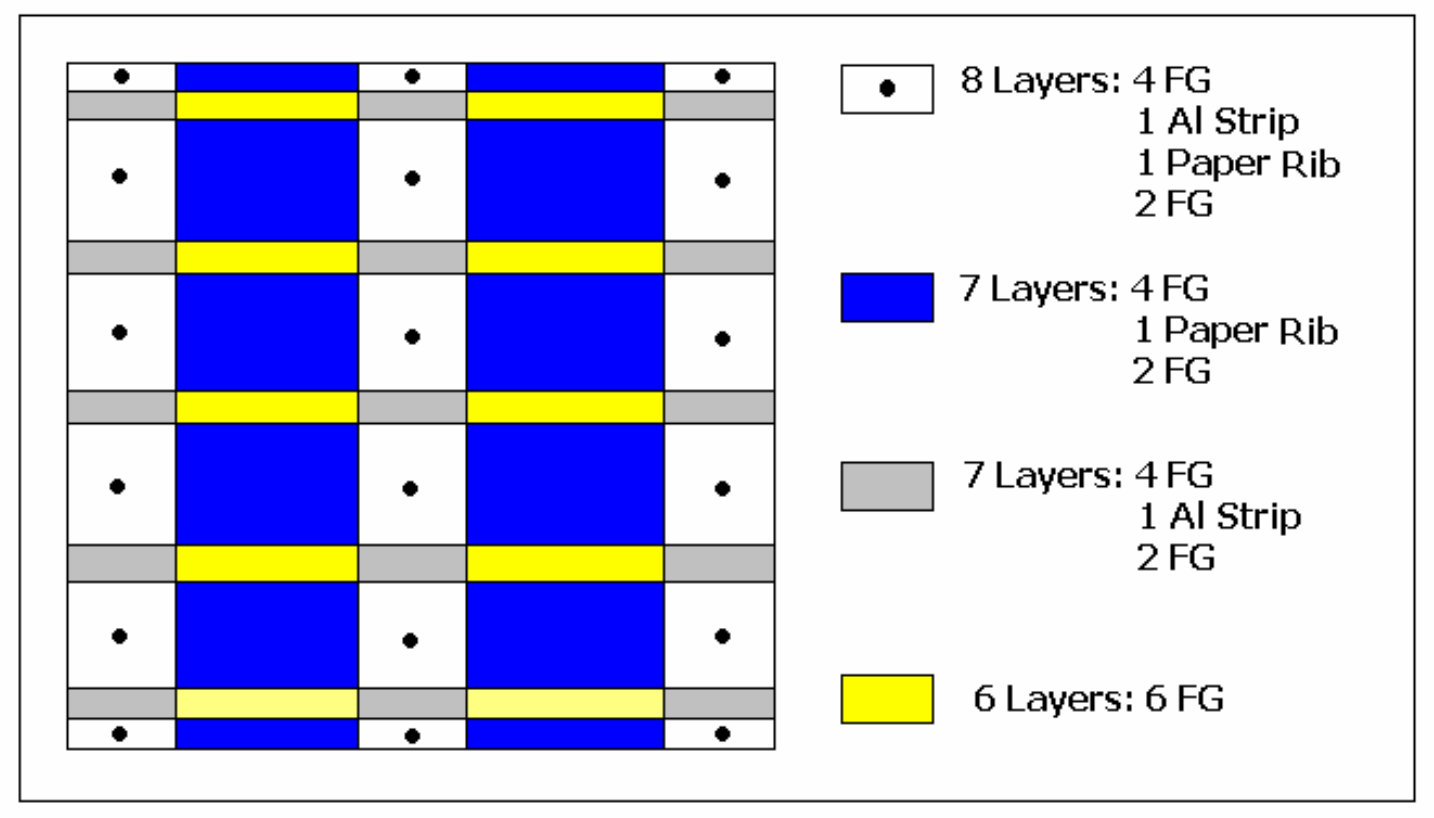

Figure 4.38: Illustration of various surface configurations of the fiberplate design.

Figure 4.38 displays the complexity of the fiberplate panel. The schematic is a representation of one of the two face sheets used in the sandwich composite panel. The various surface configurations require a detailed finite element modeling process. There are four different subdivisions of material configurations, 8 layers, 7 layers (2) and 6 layers. Because of the many divisions of surface configurations, special consideration had to be taken during the finite element modeling process. It was important to group all the different layer surface configurations. This was done by creating all the 8 layer surfaces, next the 7 (two different types) and then the 6 layer. Having all the layers defined sequentially allowed for manipulation of elements, material properties and meshing purposes.

Modeling of this particular design followed the steps listed below:

- Created points of surface corners for both the top and bottom face sheet by specifying $\mathrm{x}, \mathrm{y}$, and $\mathrm{z}$ coordinates.

- Created surfaces for the 8 layer group (36 total) by referencing the corner points previously defined.

- Defined the remaining group surfaces and kept the order of the different groups in sequence. 
- 8 layer-Surfaces 1 to 36

- 7 layer - Surfaces 37 to 60

- 7 layer - Surfaces 61 to 80

- 6 layer - Surface 81 to 110

- Created the individual surfaces of the aluminum tubes by the points previously defined. Four surfaces were created for each tube.

- Aluminum Tubes - Surfaces 111 to 130

- Divided all the surfaces by 0.5 inches. This defined the subdivisions for creating 0.5 inch quadrilateral shell elements.

- Defined material properties, element type, and number of layers to be defined in the different element groups.

- Meshed the model geometry surface by surface and noted the division of elements for each layer type notified in Figure 4.38.

- Defined the elements by thickness, material properties, ply orientation, and composite properties and assigned the parameters to the corresponding layer configuration.

- Contact surfaces between the core material (aluminum tube sections) and the face sheets were defined.

- All loading scenarios and boundary conditions were applied.

The intricacy and the variation of thickness within the fiberplate are shown in detail in Figure 4.38. Figure 4.39 displays graphically the different thickness regions created by various layup sections of the panel.

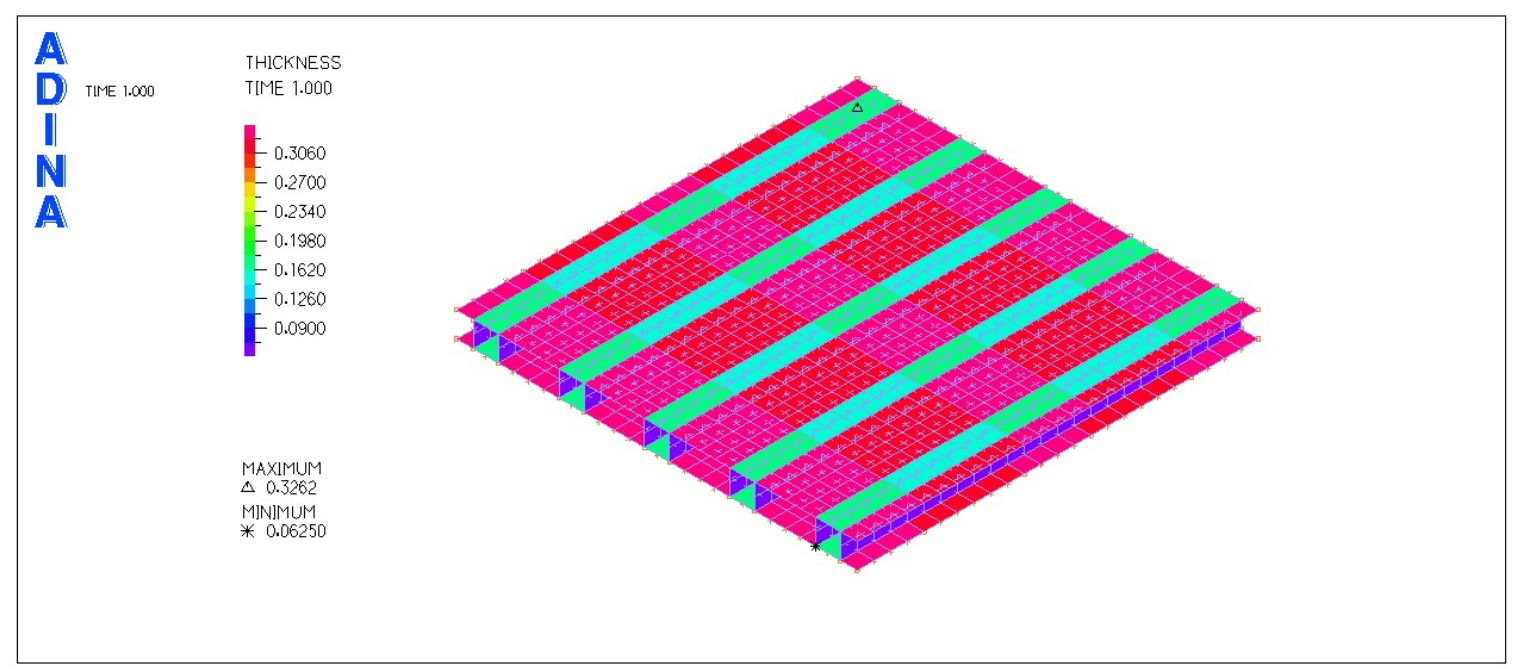

Figure 4.39: Contour plot showing the thickness of each surface segment for the fiberplate design. 


\subsubsection{Carbonplate}

Material: $5,3 / 4$ inch aluminum tube cross members

10 paper rib strips

6 aluminum sheet metal strips

12 layers of $2 \times 2$ twill weave graphite fabric and epoxy carbon fiber composite

Aluminum Tubes

Tube Thickness: $2 / 32$ inch

Dimensions: $1 \mathrm{ft} \mathrm{x} 3 / 4$ inch $\mathrm{x} 3 / 4$ inch

Young's Modulus $=10 \mathrm{Msi}$

Poisson's Ratio $=0.33$

Elements: Shell

Aluminum Sheet Metal Strips

Thickness: 0.02 inch

Dimensions: $1 \mathrm{ft} \times 2$ inch $\mathrm{x} 0.02$ inch

Young's Modulus = 10 Msi

Poisson's Ratio $=0.33$

Elements: Shell

\section{Carbon / Graphite Fabric}

Glass/Epoxy Fabric

Layer Thickness: 0.012 inch

$\mathrm{Vf}=0.50$

rho $=0.052 \mathrm{lb} / \mathrm{in}^{3}$

$\mathrm{E} 11=7.9 \mathrm{Msi}$

$\mathrm{E} 22=7.83 \mathrm{Msi}$

\section{$\underline{\text { Paper Ribs }}$}

Thickness: 5/32 inch

Dimensions: $1 \mathrm{ft} \times 13 / 4$ inch x 5/32

Young's Modulus $=652 \mathrm{ksi}$

Poisson's Ratio $=0.3$

Elements: Shell

Modeling of the carbonplate was performed in the same manner as the fiberplate. The properties of the material were changed to those listed previously for the $2 \times 2$ twill weave graphite fabric sheets. The steps taken in the finite element process are listed in the previous fiberplate section and should be referenced for clarity. 


\section{Chapter 5 - Instrumentation of Sandwich Panels for Experimental Testing}

\subsection{Introduction}

As a method to understand the actual performance of the manufactured cross member panels and sandwich composite panels, experimental analysis was performed. The experimental results provide a method to compare the theoretical finite element models to the actual tested results. There are variables and minor differences in the relation from the finite element models to the actual manufactured panels, but the proper instrumentation is a focal point for creating a reliable comparison between the theoretical and experimental work.

\subsubsection{Tubegrate}

The four panel designs were instrumented with strain gages. The strain gage types were uniaxial and rosette configurations. The uniaxial strain gages were placed on the cross members to attain the maximum bending moment from the midspan deflection of the cross member beams. The strain gage rosette arrangements were placed to determine the shear strain next to the supports of each panel. Also, a rosette gage was placed on the panel on the opposing side of the load and centered directly underneath the load to determine if twisting or torsion effects should be considered.

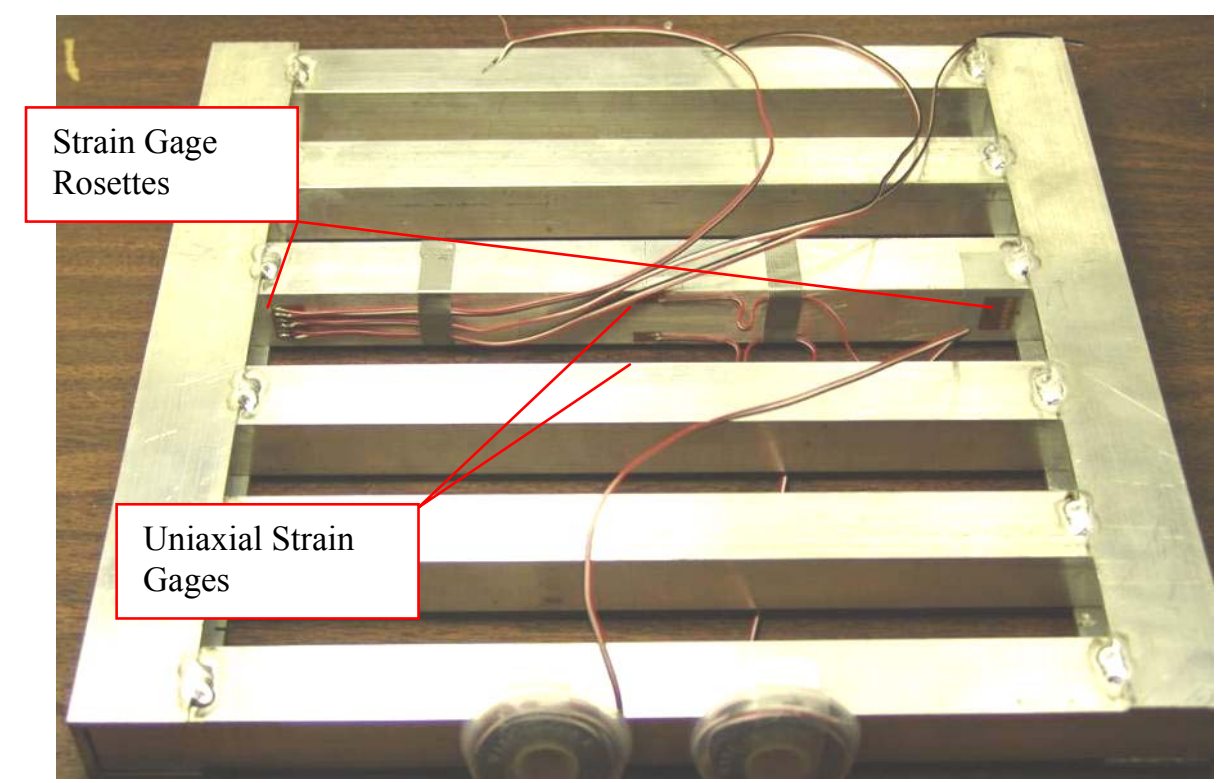

Figure 5.1: Instrumentation of tubegrate panel with uniaxial and rosette gages. 


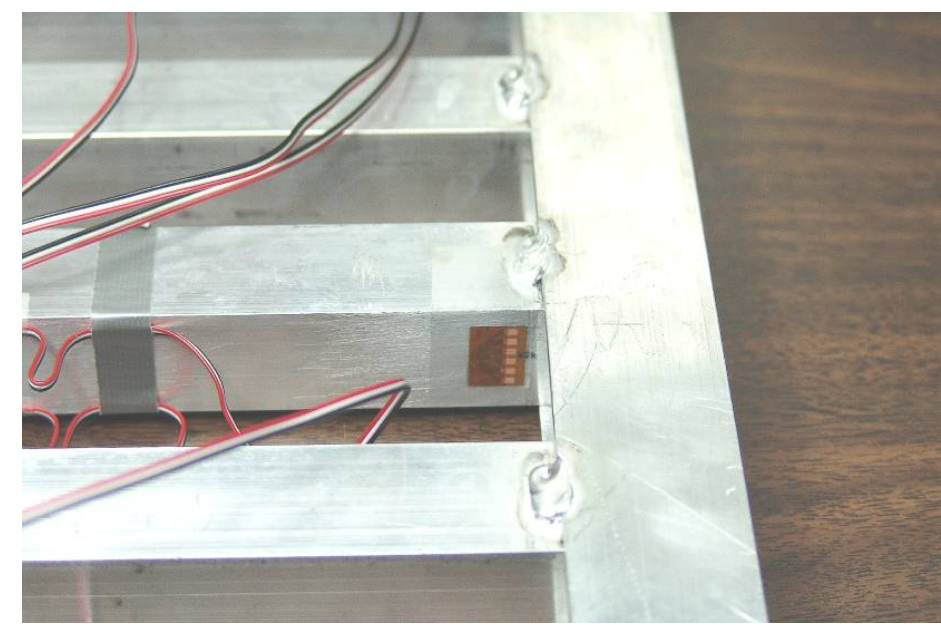

Figure 5.2: Rosette strain gage placement for the tubegrate panel.

\subsubsection{Tubeplate}

Instrumentation of the tubeplate consisted of placing the uniaxial strain gages on the top and bottom of the panel next to the load area. These placements are used to determine the maximum bending moment and for comparison to the correlating finite element locations. The panel and the strain gage placements are depicted in Figure 5.3.

The geometry of the panels made instrumentation difficult in some situations. For the tubeplate it was very difficult to mount the strain gage rosettes on the inside of the cross members as shown in Figure 5.4. The strain gages in this case were not equipped with lead wires, therefore the lead wires had to be manually connected to the resistor pads. The location of the gage placement made the process a difficult procedure. 


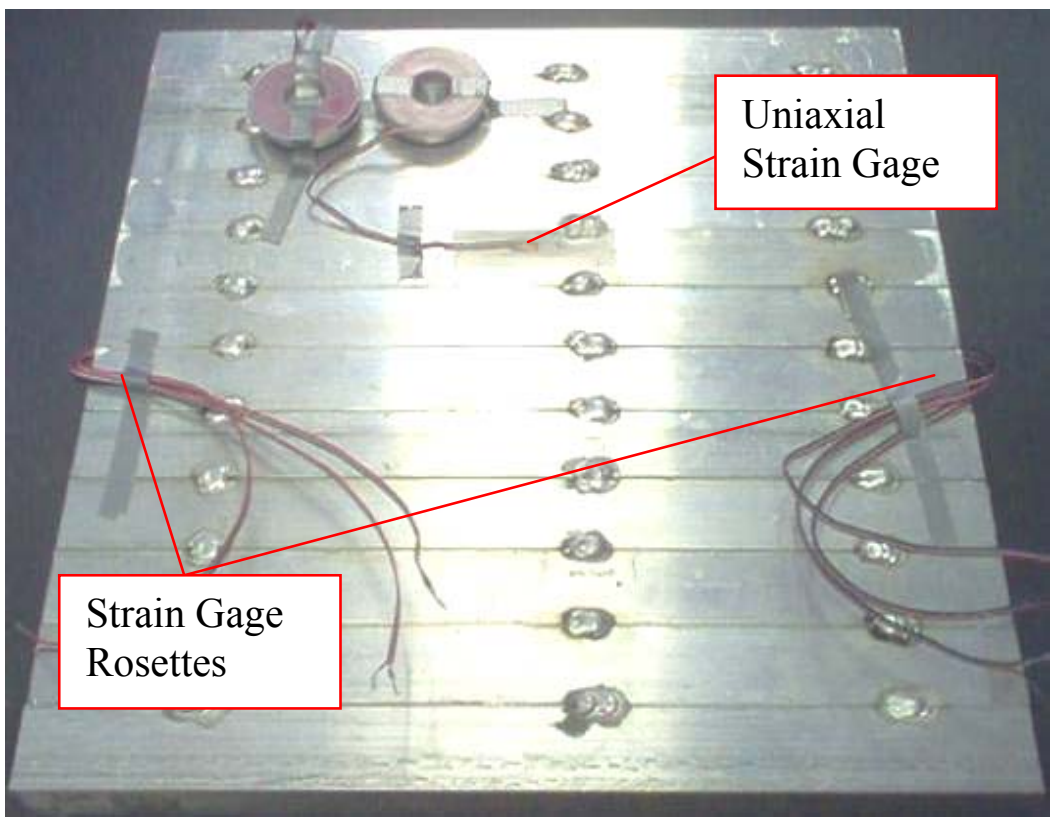

Figure 5.3: Instrumentation of tubepanel with uniaxial and rosette strain gages.

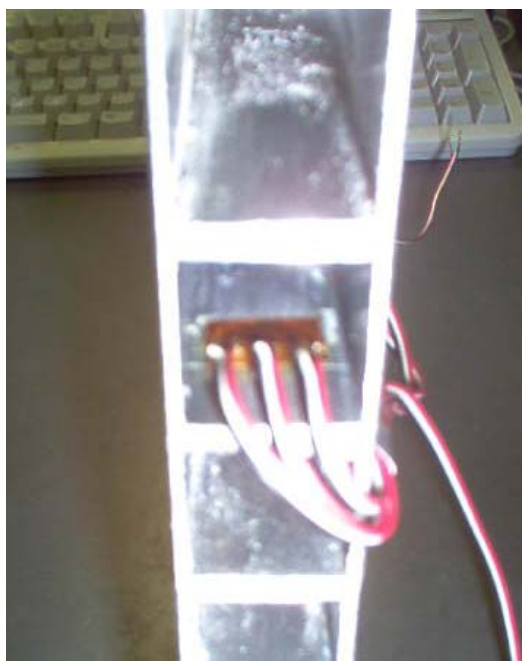

Figure 5.4: The rosette strain gage placement for the tubeplate panel. 


\subsubsection{Fiberplate}

The fiberplate was instrumented in the same manner as the tubegrate with the addition of a strain gage rosette centered on the underneath of the plate to detect any torsional or twisting deformation that may occur due to the nature of the fiber reinforced polymer (FRP) composite top and bottom face plates. As stated earlier in this work, when a composite laminate is symmetric about its midplane there is no coupling between the bending and stretching due to loading, or theoretically, the $B_{i j}$ matrix or bendingstretching coupling matrix is zero. The face plates of the fiberplate are not symmetric about their midplane, however, when considering the entire sandwich panel, symmetry about the midplane is upheld. Therefore, placement of the strain gage rosette on the bottom surface will provide insight to the tendency of twisting within the loaded panel. Perfect symmetry can not be expected due to many variables in the loading procedure, support conditions, and the unlikely possibility that complete symmetry in a wet layup manufacturing process was upheld.

The instrumentation of the fiberplate can be seen in Figure 5.4. The instrumentation of the fiberplate was simplified by making the top face sheet removable from the core structure. Otherwise, the instrumentation would have been performed before construction of the plate and this would have risked inaccurate testing results if epoxy would have contacted the top surface of the gages and hardened. This procedure would have been more suitable if pre-impregnated lamina were used instead of the wet layup process. 


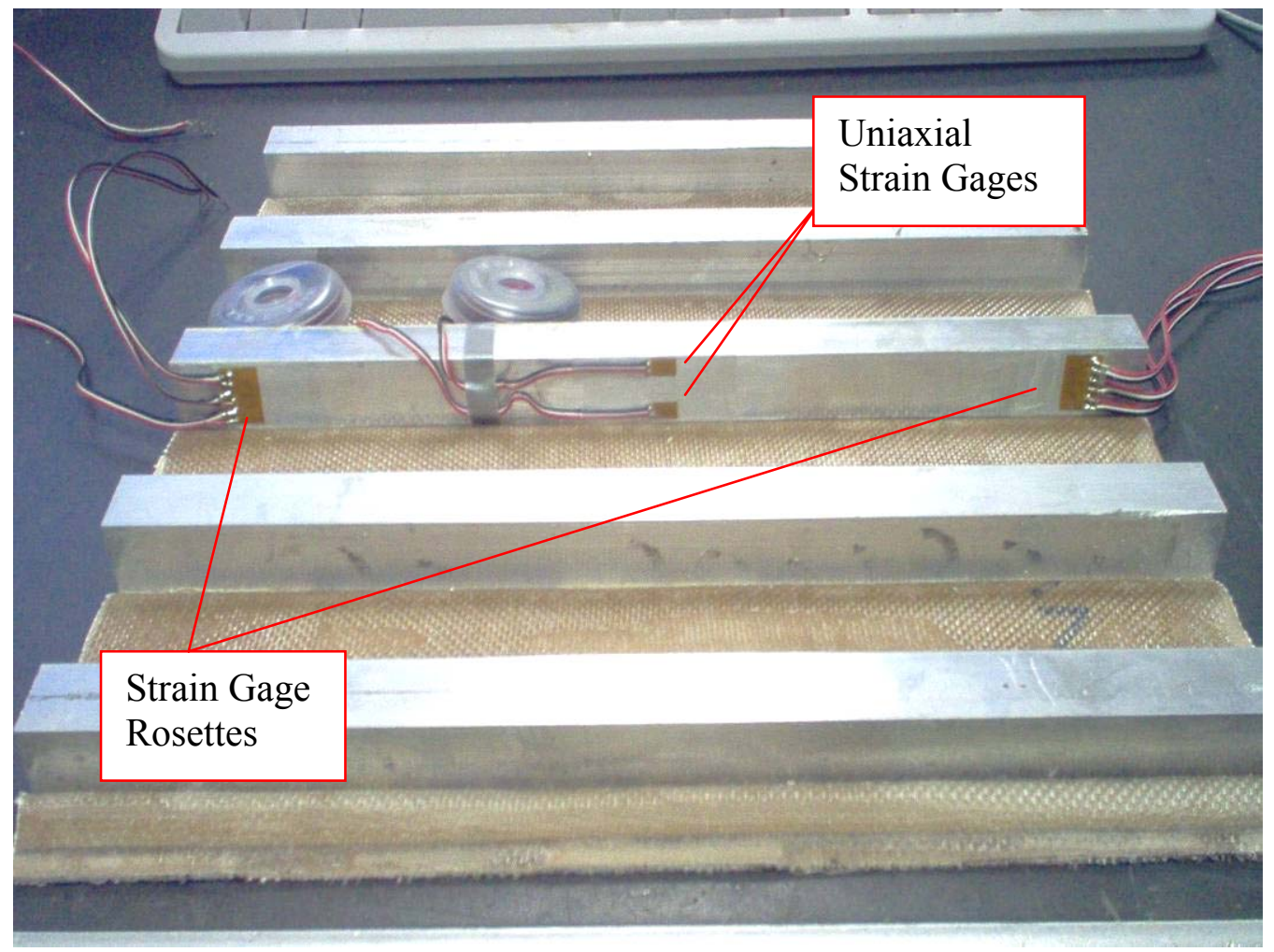

Figure 5.5: Instrumentation of the fiberplate panel with uniaxial strain gages centered on the middle cross member and strain gage rosettes along the cross member edges.

\subsubsection{Carbonplate}

The carbonplate instrumentation is the same as the fiberplate. There are two uniaxial strain gages on the middle cross member of the core structure and are located directly under the load to determine the maximum bending moment. Two strain gage rosettes are placed on a $1 / 2$ inch inset from the edge of the panel to determine the shear strain. The instrumentation of the carbonplate is shown in Figure 5.6.

The top face plate was removed after manufacturing to apply the strain gages to the panel. The ability to remove the top plate without damaging the panel was made possible by waxing the top surface of each core cross member before the layup process to prevent the epoxy from curing to the aluminum surface. The most accurate method would have been to place the strain gages before fabricating the plate, however, with a 
wet layup procedure, keeping the gage surfaces free from epoxy would have been extremely difficult. Using pre-impregnated lamina sheets would have made this method a possibility but was not an option due to high cost and lack of storage facilities.

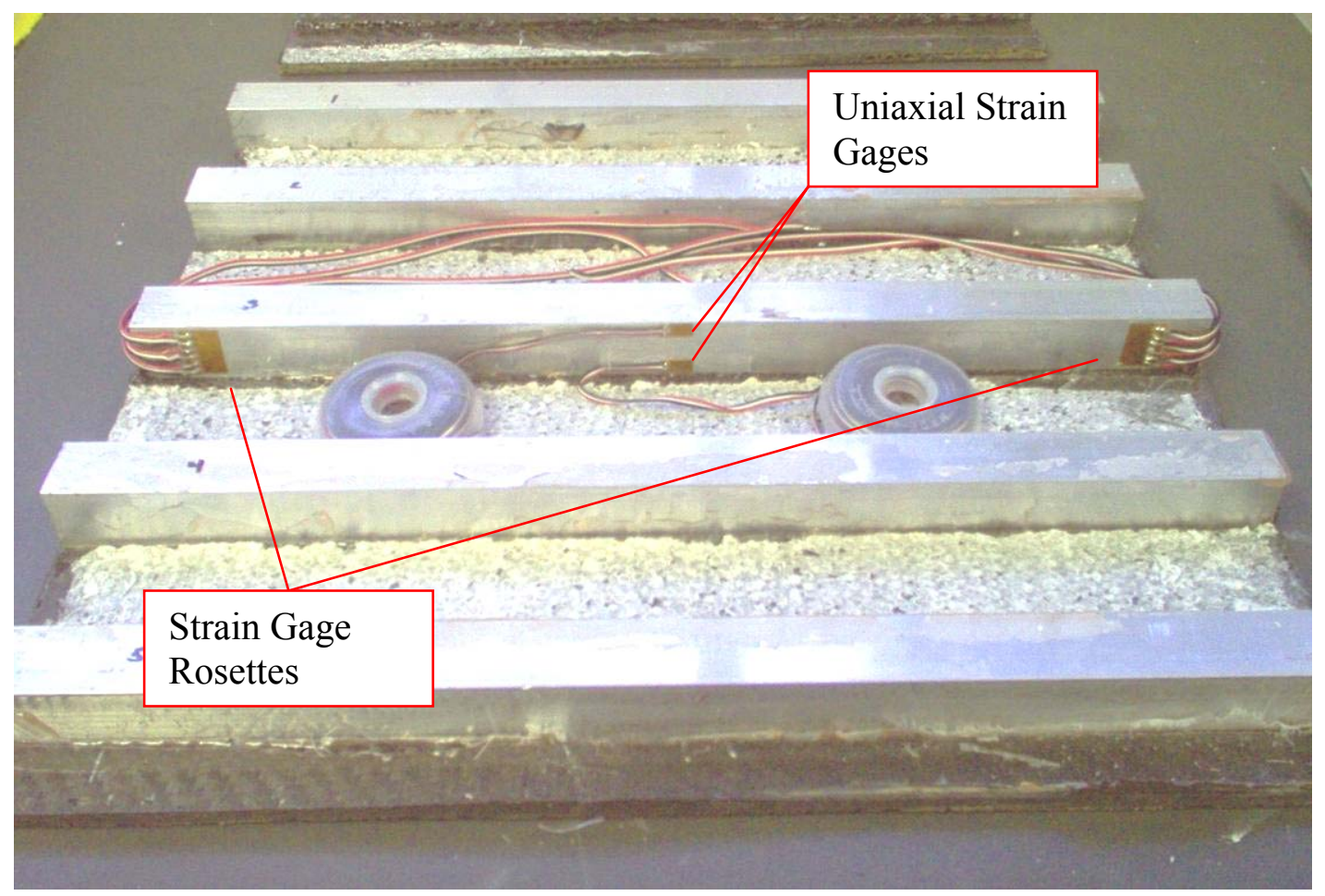

Figure 5.6: Instrumentation of the carbonplate panel with uniaxial strain gages centered on the middle cross member and strain gage rosettes on the inset of the edge supports. 


\section{Chapter 6 - Experimental Testing of Sandwich Panels}

\subsection{Introduction}

Static loading was performed on the four test panels to determine the strains occurring at critical locations and the overall displacement that each panel will yield under the testing procedure. Each panel was simply supported along its respective side edges and loaded in the center of the panel under a 2" by 3" pressure area load. The maximum load reached was 600 pounds.

\subsubsection{Tubeplate}

All the panels in this study were designed with the intention of creating new, lightweight and efficient flooring concepts for a trailer haul. The tubeplate was designed specifically to provide a low-cost, lightweight, and manufacturing efficient alternative to the existing flooring structure. The aluminum tubes are connected by a row of small welds that butte the sides of the square cross section tubes together.

The concerns before experimentally testing the tubeplate were if the welds would effectively sustain the applied load and if the overall panel would carry a concentrated load as used in the testing procedure. 

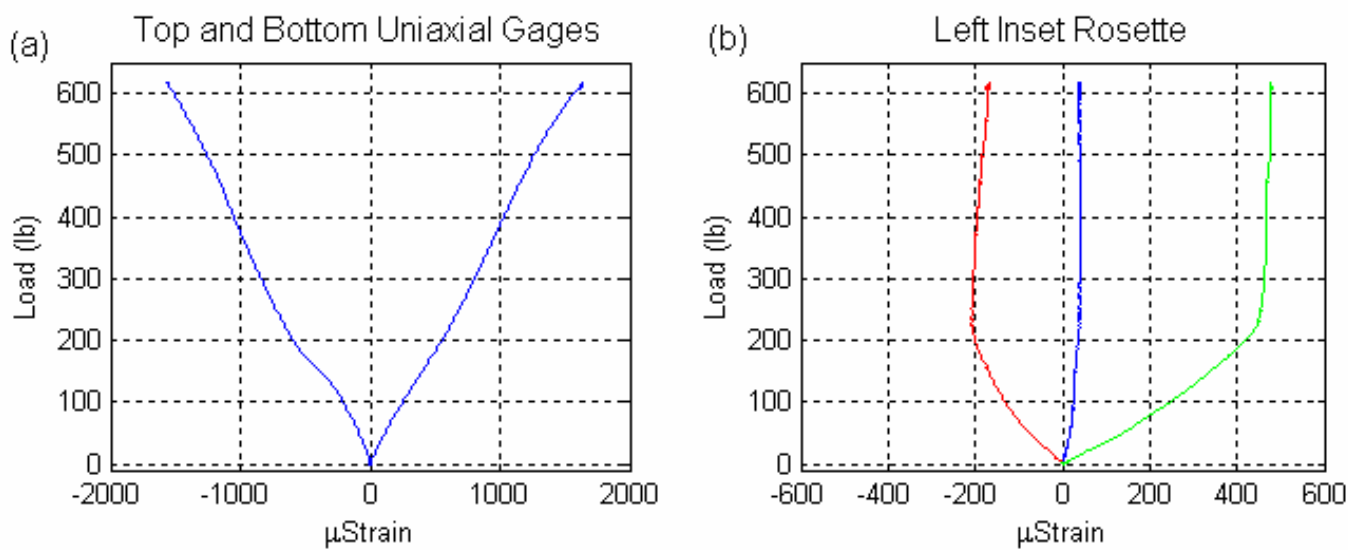

(c)
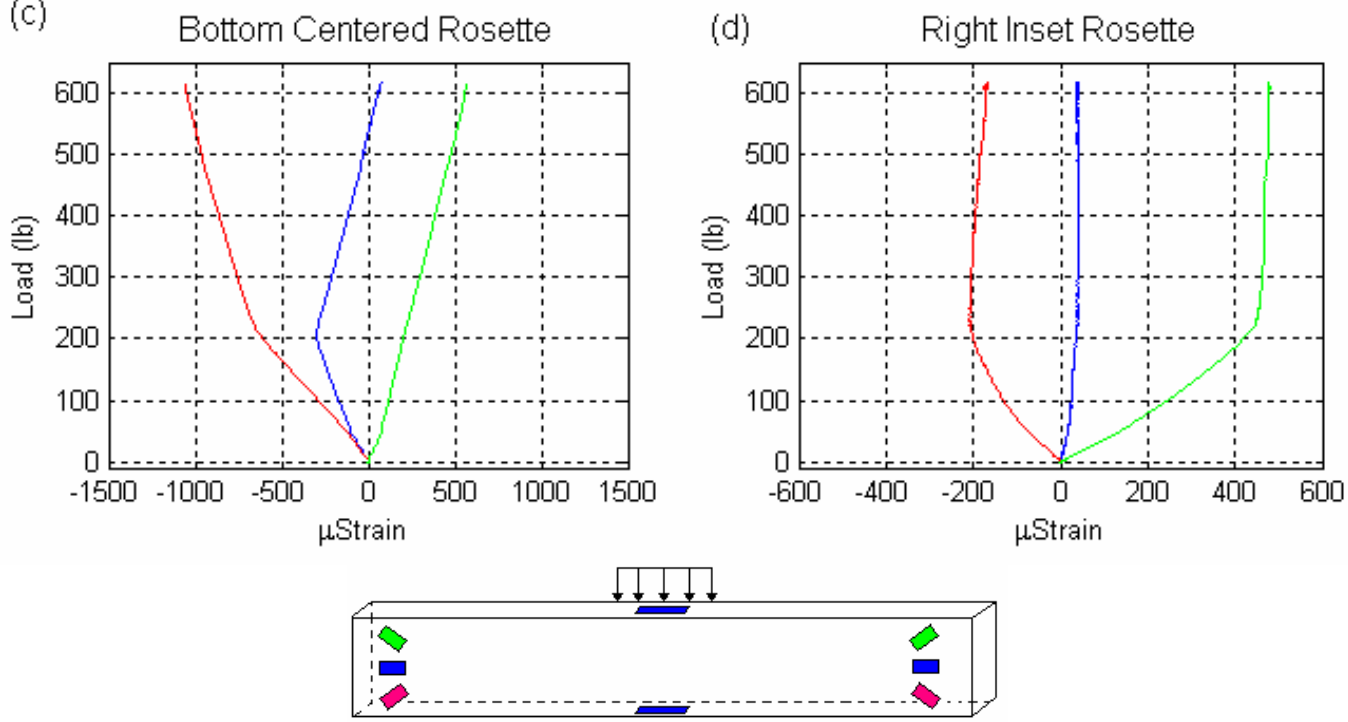

Figure 6.1 (a) - (d): The Load vs. Strain data plots of the tubeplate experimental test and reference figure of strain gage locations.

The strain values shown in Figure 6.1 depict the load bearing reaction of the tubeplate design. The uniaxial gages in Figure 6.1 (a) show maximum bottom and top strain values of approximately 1600 and $-1600 \mu$ Strain. Figure 6.1 (b) and (d) display the rosette strain values on both the left and right side of the load. The color of the plotted data lines corresponds to the illustration at the bottom of Figure 6.1 showing the strain gage placements on the cross member closest to the center of the load. Studying Figure 6.1 (b) and (d) we see that the bottom rosette gage (green) experiences tension throughout the loading process and reaches a maximum strain value of $477 \mu$ Strain and the top rosette strain gage (red) is in compression and attains a maximum strain value of -208 $\mu$ Strain. 
The strain values acquired from the strain gage rosette configurations were used to calculate the shearing strain at this location. The right and left strain gage rosettes were placed on the inset of the simply supported edges which is the location where maximum shear will occur during loading.

To determine the shear strain data, the strain rosettes were analyzed by taking the horizontal $\mathrm{x}$-axis and the center of the middle (blue) gage to be the reference point from which to calculate the gage alignment angles. The equations used for the calculation are shown below.

$$
\begin{aligned}
& \varepsilon_{a}=\varepsilon_{x} \cos ^{2} \theta_{a}+\varepsilon_{y} \sin ^{2} \theta_{a}+\gamma_{x y} \sin \theta_{a} \cos \theta_{a} \\
& \varepsilon_{b}=\varepsilon_{x} \cos ^{2} \theta_{b}+\varepsilon_{y} \sin ^{2} \theta_{b}+\gamma_{x y} \sin \theta_{b} \cos \theta_{b} \\
& \varepsilon_{c}=\varepsilon_{x} \cos ^{2} \theta_{c}+\varepsilon_{y} \sin ^{2} \theta_{c}+\gamma_{x y} \sin \theta_{c} \cos \theta_{c}
\end{aligned}
$$

Where:

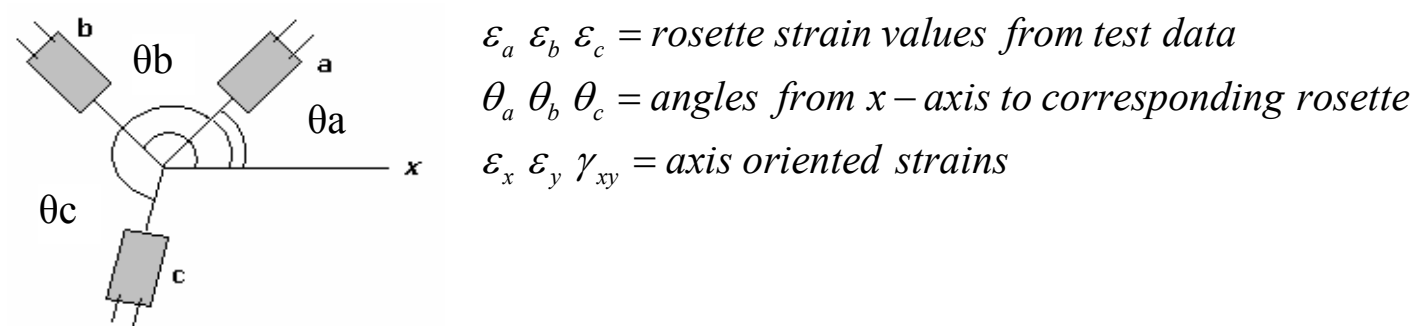

The previously defined equations and MATLAB software were used to solve the system of equations for each set of data points yielding the shearing strain values during the testing procedure. The $\gamma_{\mathrm{xy}}$ shear strain values throughout the loading process are shown in the following data plot. 


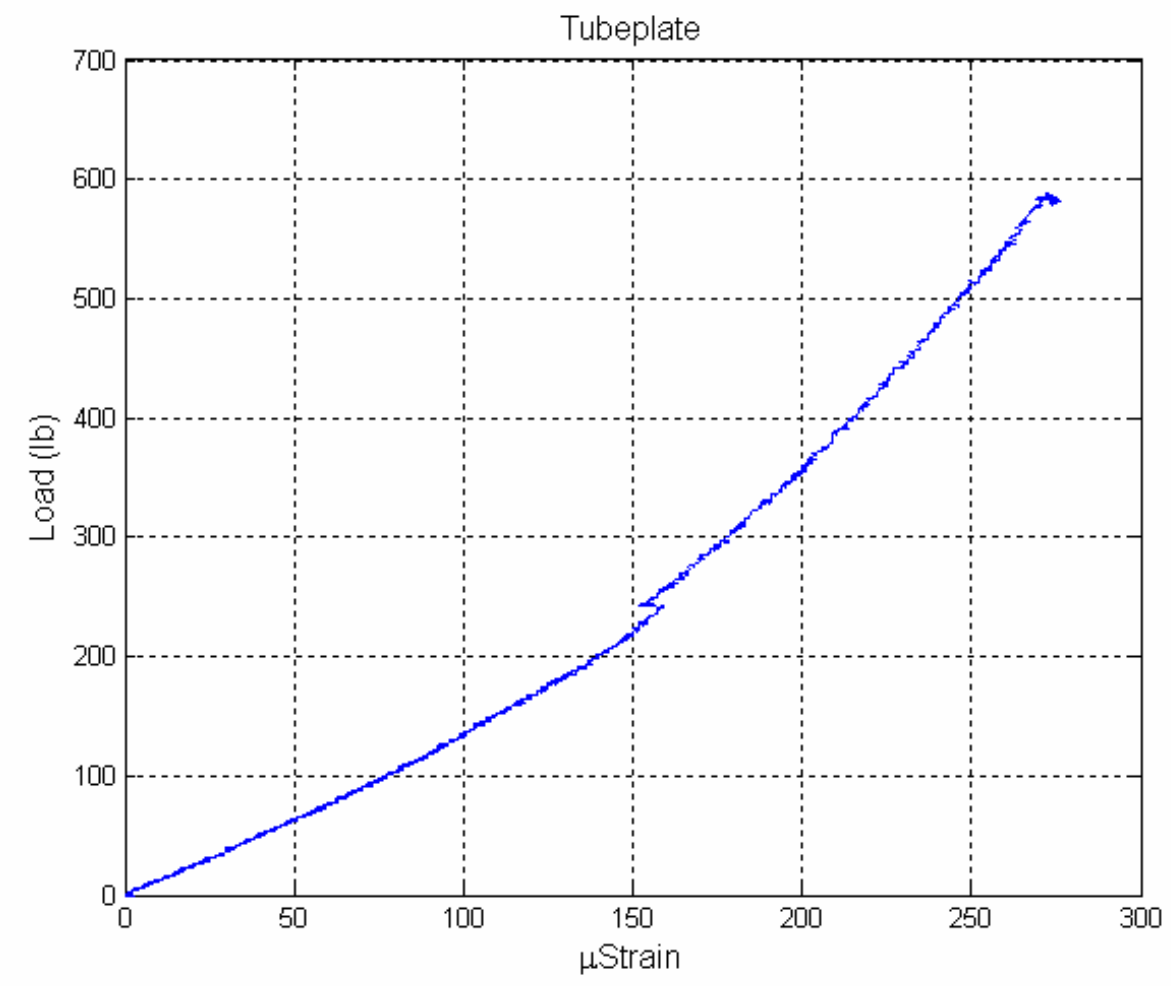

Figure 6.2: Shearing strain values for the tubeplate configuration at the inset of the simply supported edges.

Studying Figure 6.2, one can verify that the shearing strain values increase steadily as the load varies between 0 and 600 (lbs). The maximum strain value at this location is $271 \mu$ Strain.

\subsubsection{Tubegrate}

The tubegrate panel was specifically designed to be a cost and weight effective variation of the tubeplate panel. The concept for cost and weight reduction is to reduce the amount of cross members used in the design and add two U-channel edge rails to secure the cross members by welds at their joints. This reduces the amount of material used which in turn reduces the cost. Also, the configuration of the tubegrate setup reduces the number of welds needed from 66 for the tubeplate to 24 for that of the tubegrate. The structure of spaced aluminum tube cross members are the core structure of the FRP sandwich panels and are tested without top and bottom faceplates to understand their effectiveness as a core material. 
A concern before testing was if the small welds will effectively sustain the stresses and strains occurring during loading and how reducing the amount of cross members and adding the edge channel connection will compare to the tubeplate design.
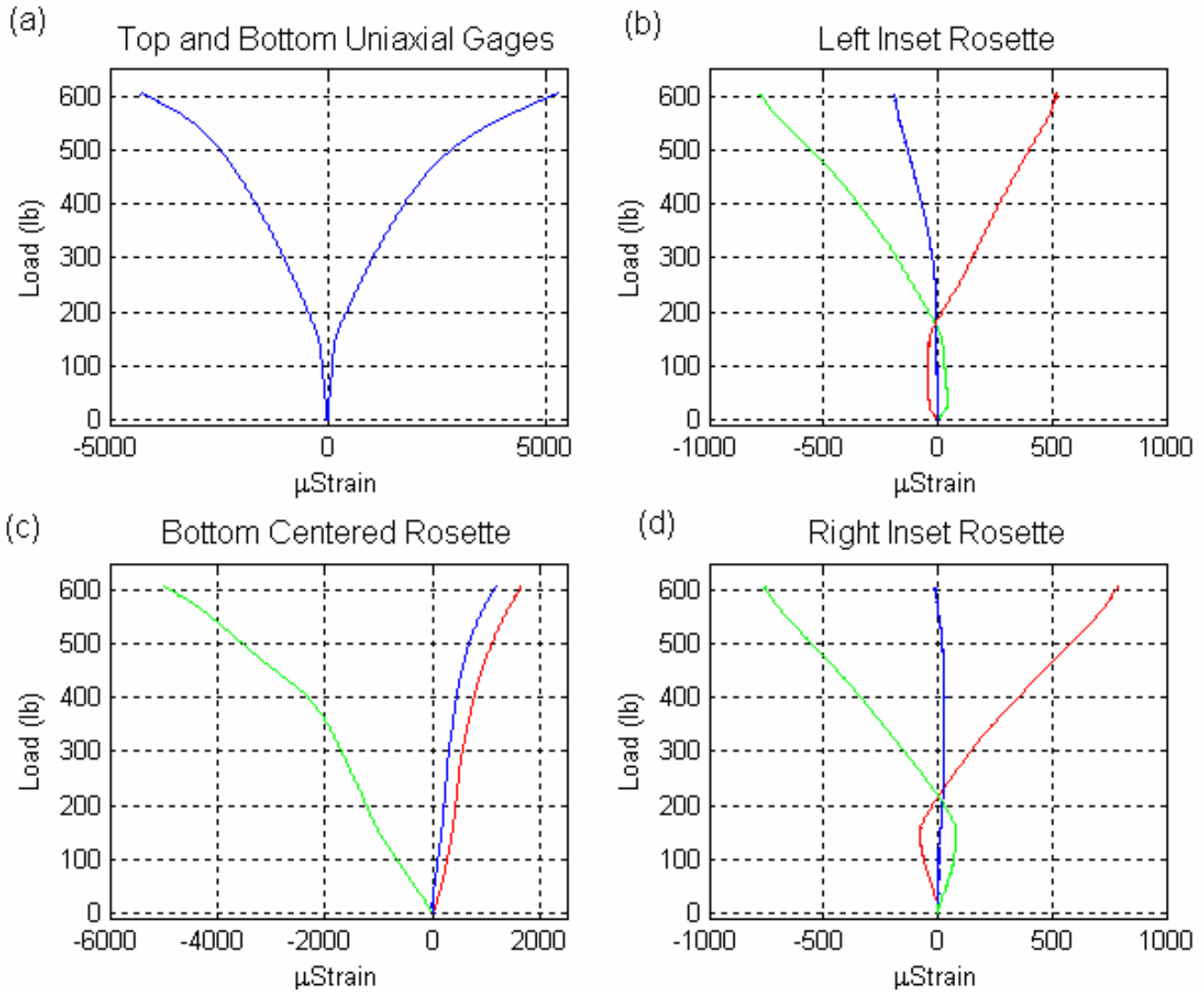

(d)
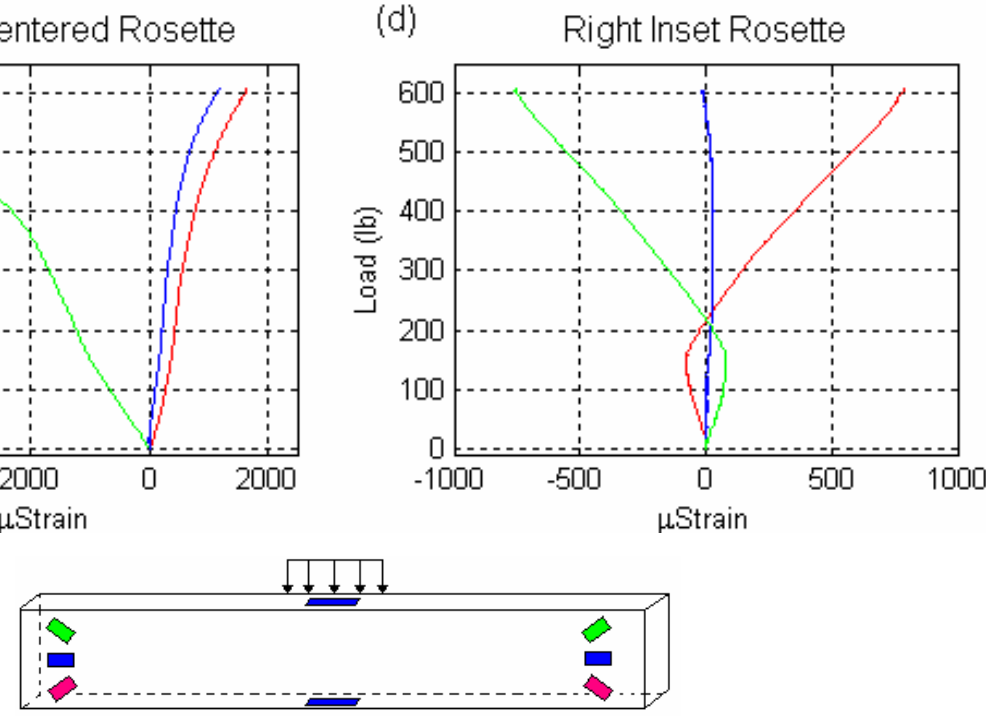

Figure 6.3 (a) - (d): The Load vs. Strain data plots of the tubeplate experimental test and reference figure of strain gage locations.

The uniaxial strain gage results shown in Figure 6.3 (a) have a maximum compression value (top gage) of $-4268 \mu$ Strain and tension value (bottom gage) of 5239 $\mu$ Strain. These values are more than two times the magnitude of the previous uniaxial results from the tubeplate, see Figure 6.3 (a). The higher strain values are a result of the load being distributed over fewer cross members which increases the displacement at these strain gage locations.

An interesting characteristic of the strain gage rosette data in Figure 6.3 (b) and (d) is variation from tension to compression by the top (red) and bottom (green) rosette 
gages. The change in strain direction is due to the U-channel edge supports of the tubegrate. The panel first deforms against the simply supported edges of the test fixture and once the load reaches a critical point, in this case 221 (lbs) the panel begins to deform against the edge of the U-channel supports which changes the direction of the strain. The maximum strain values for the top (red) and bottom (green) gages are 779 and -747 $\mu$ Strain, respectively.

By the same process of calculating the shear strain for the tubeplate, the shear strain on the inset of the simply supported cross member in the tubegrate can be determined. The Load vs. $\mu$ Strain plot occurring at the most critical location is pictured in the plot below.

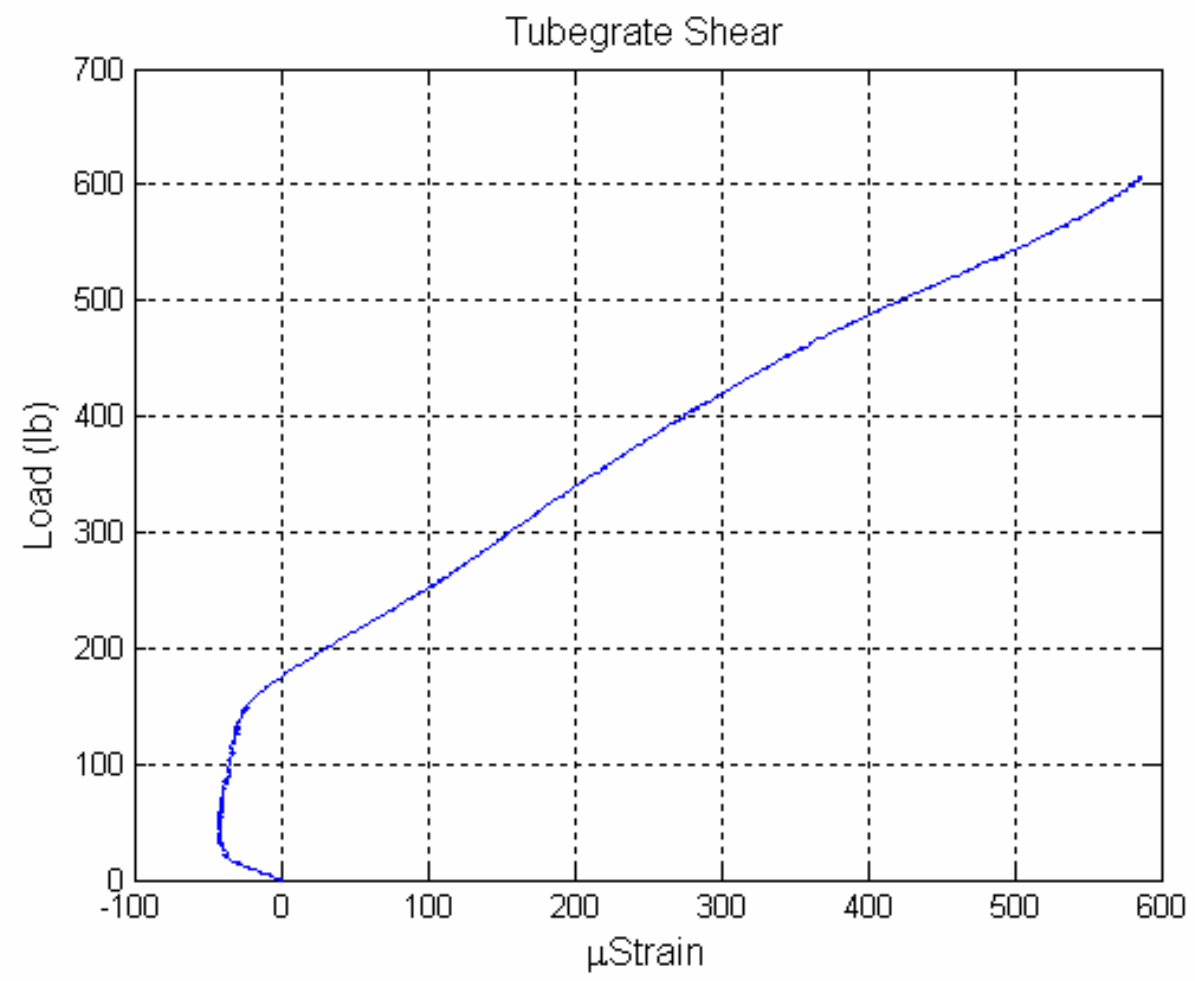

Figure 6.4: Shearing strain values for the tubegrate configuration at the inset of the simply supported U-channel edges.

The shear stain values in Figure 6.4 differ significantly from those of the tubeplate in Figure 6.2. Figure 6.4 shows the change in direction corresponding to the plots in Figure 6.3 (b) and (d), previously discussed and a fairly linear relation between load and strain between load values of 150 (lbs) to 600 (lbs). The maximum shearing 
strain reached is $587 \mu$ Strain. In comparison to the tubeplate, it can be postulated that the tubegrate configuration attains higher strain values at the location of the strain gages. The tubegrate design with the edge channel incorporated focuses the shearing strain directly on the inset of this edge. Concluding that the amount of supporting cross members in the tubegrate is half that of the tubeplate, reveals that the strain values are twice as high in magnitude by comparison.

\subsubsection{Fiberplate}

The fiberplate panel incorporates the tubegrate design as the core structure with the addition of fiberglass top and bottom composite plates. The top and bottom plates also contain ribbed sections (see Figure 4.34). It is important to note that the size of the square tube cross sections in the fiberplate is $3 / 4$ inches compared to a 1 inch section in the tubeplate and tubegrate designs. The difference in sizes allowed for a total 1 inch thickness between all panels, therefore, the overall panel thickness was held constant throughout the test procedures. 
(a) Top and Bottom Uniaxial Gages

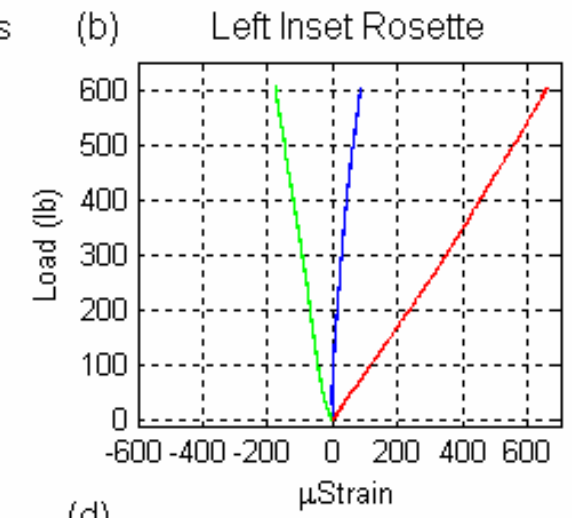

(c)
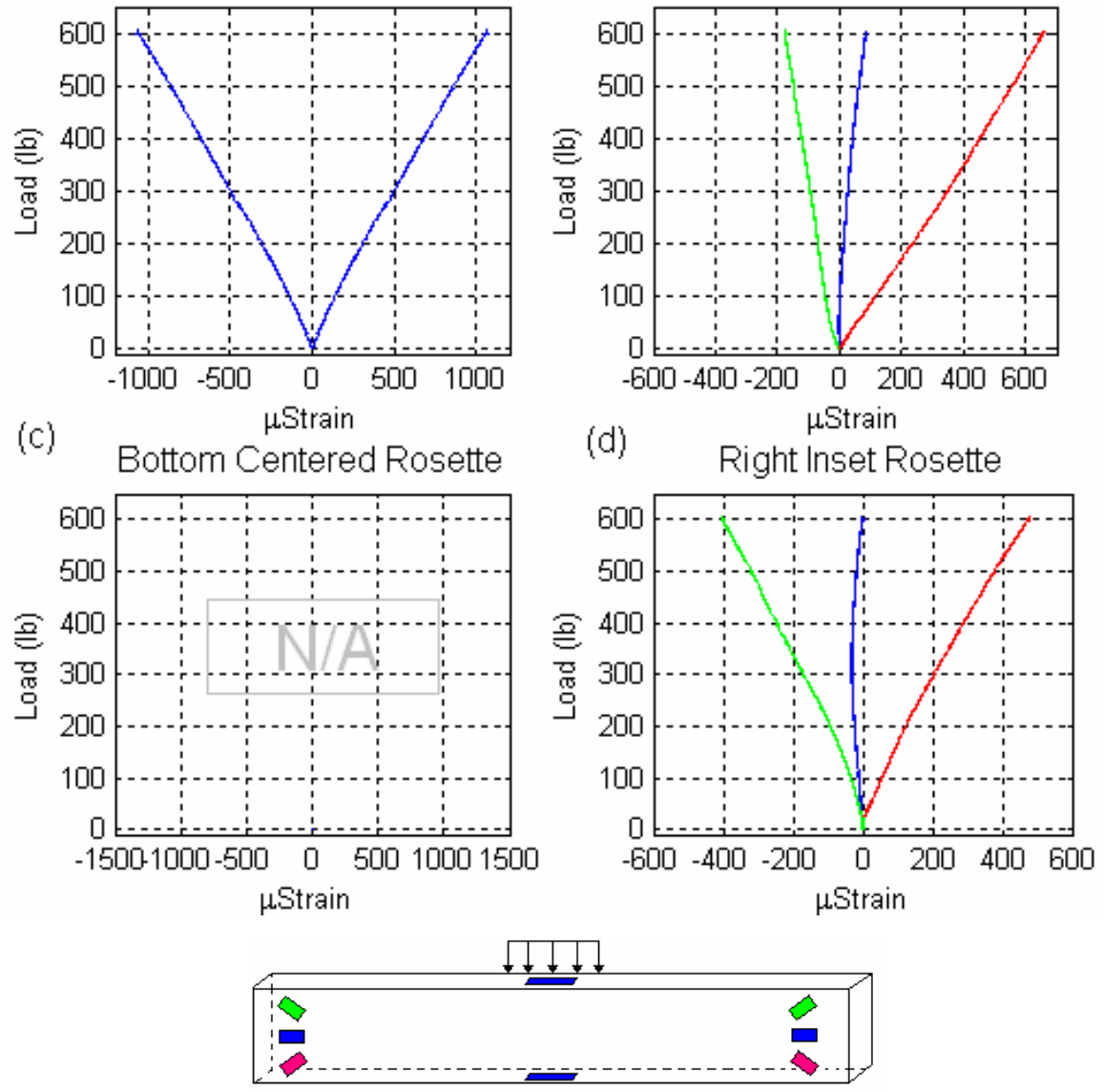

Figure 6.5 (a) - (d): The Load vs. Strain data plots of the fiberplate experimental test and reference figure of strain gage locations.

The uniaxial strain gages shown in Figure 6.5 (a) have a maximum compression value (top gage) of $-1003 \mu$ Strain and tension value (bottom gage) of $1069 \mu$ Strain. These values are approximately five times lower than the strains at this location in the tubegrate panel. Which means, the addition of the top and bottom fiberglass composite plates were effective for increasing the panel stiffness and reducing the strains induced by midplate bending.

The plots for the bottom rosette, Figure 6.5 (c) are not available because the panel was tested on the opposite where the bottom strain gage was originally placed. The rosette on the opposite had to be removed to apply the load to the center of the plate for the test procedure. This did not hinder the analysis or test procedure. 
The shear strain plot was determined in the same manner as the previous tests. The results of the shear strain attained at the inset of the simply supported area can be seen in the Figure 6.6 below.

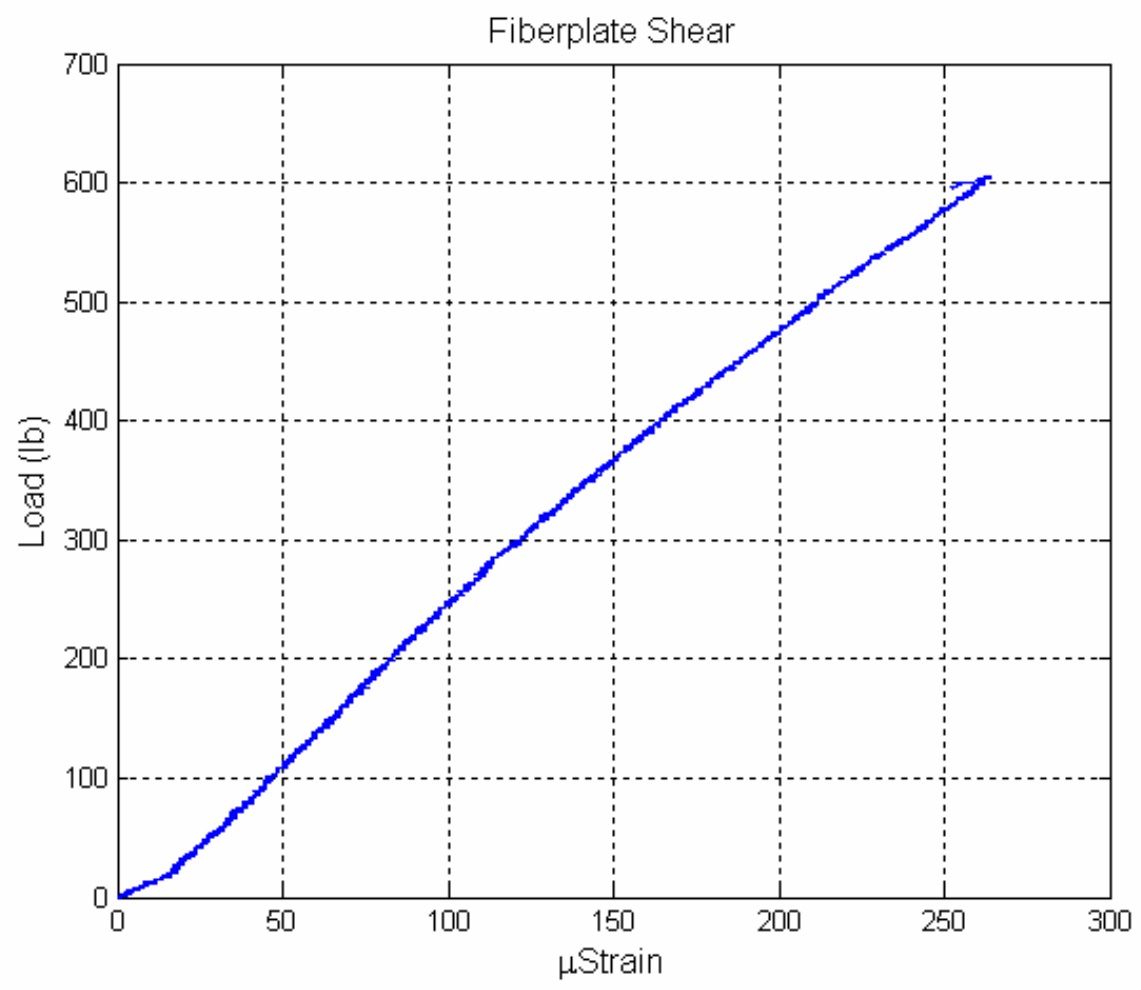

Figure 6.6: Shear strain values for the fiberplate configuration at the inset of the simply supported edges.

The maximum shearing strain reached in the fiberplate design is $267 \mu$ Strain. In comparison to the tubegrate, the shear stain values are significantly lower because of the addition of fiberglass composite top and bottom plates. It should be remembered that the square section core cross members are $1 / 4$ inch smaller in the fiberplate than those in the tubegrate and tubeplate.

\subsubsection{Carbonplate}

The carbonplate panel has the same geometry and design of the fiberplate but uses carbon fiber layers instead of fiberglass. Carbon fiber is superior to fiberglass in 
both weight and material properties; however, testing will determine if the benefits are greater than the cost difference.
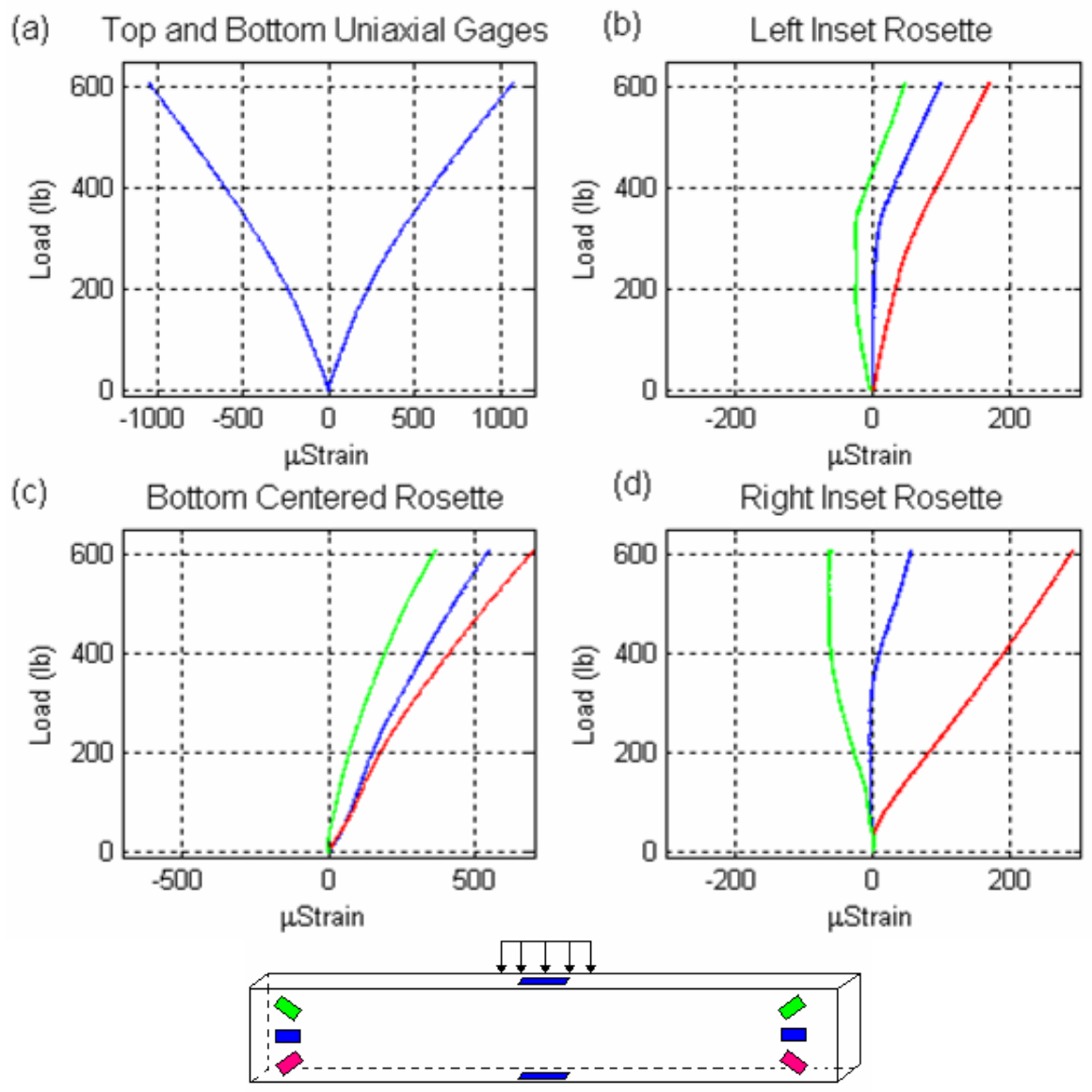

Figure 6.7 (a) - (d): The Load vs. Strain data plots of the carbonplate experimental test and reference figure of strain gage locations.

The uniaxial gages in Figure 6.7 (a) show strain values close to those of the fiberplate. The carbonplate's maximum compression value (top gage) is $-1025 \mu$ Strain and tension value (bottom gage) is $1056 \mu$ Strain. Plot (c) shows that the rosette placed directly under the load has all three gages in tension. This means there is minimal twist or curvature occurring during the loading process.

The carbonplate shear stain plot is shown in Figure 6.8 below. 


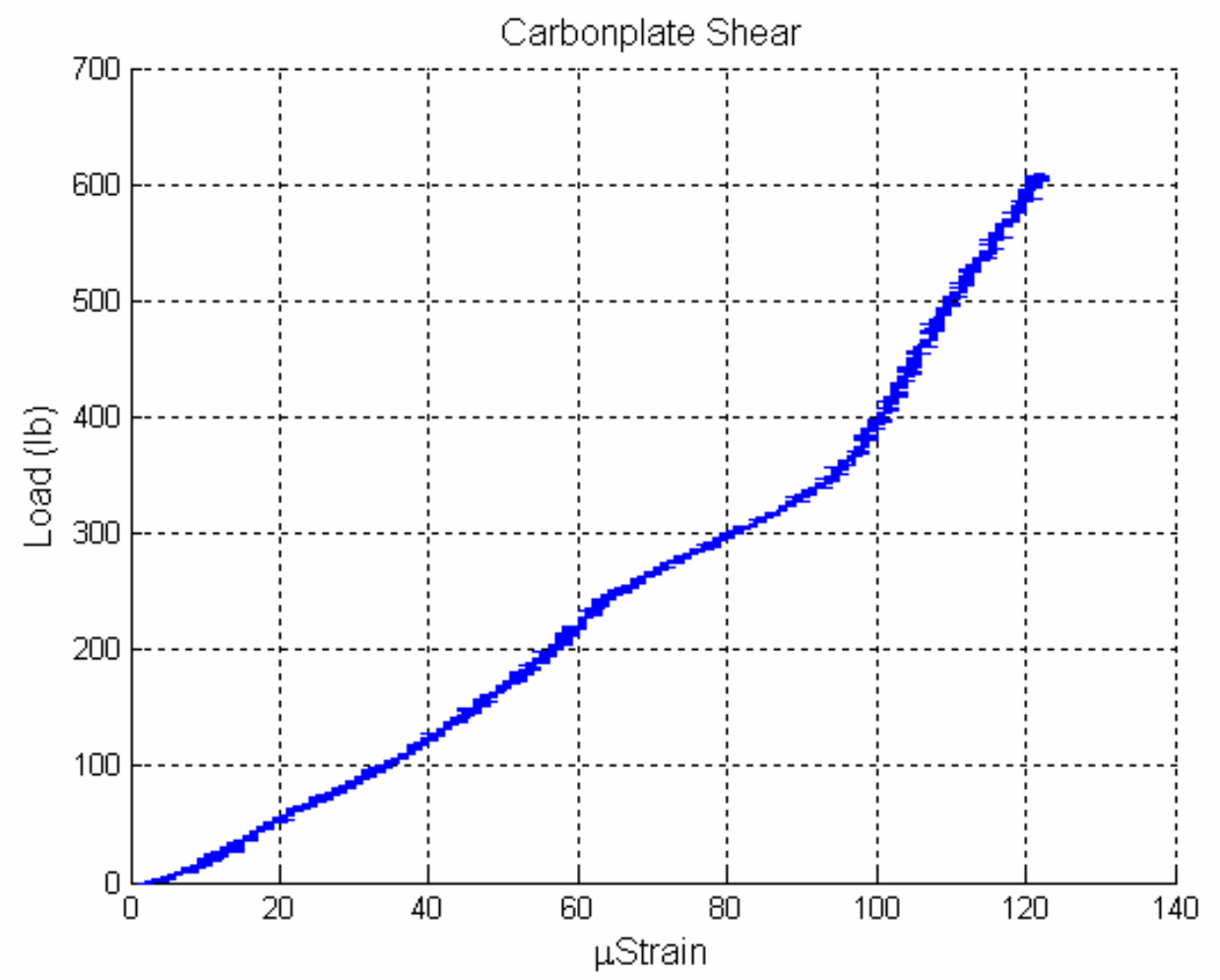

Figure 6.8: The shear strain values for the carbonplate panel at the inset of the simply supported edges.

The shear strain in the carbonplate is shown in Figure 6.8. The maximum strain occurring at the $600 \mathrm{lb}$ load level is $120 \mu \mathrm{Strain}$. The maximum shear strain in the carbonplate is approximately half the maximum shear strain in the fiberplate. From these results, it can be stated that the carbon fiber panels which form a sandwich structure with the aluminum tubing extrusion is the most effective design for bending resistance and reduction of strain on the inset of the simply supported edges. 


\section{Chapter 7 - Finite Element Modeling}

\subsection{Introduction}

Finite element modeling of each panel design was performed to better understand the performance of each structure. Experimental analysis of the designs most accurately characterizes the performance of each design, however, experimental testing is timely and expensive. Creating accurate finite element models will provide insight into the benefits of a specific design concept or prototype before performing the manufacturing process, instrumentation, and experimental test procedures.

\subsubsection{Tubeplate}

Material: 12, 1 inch aluminum tube extruded cross members

Young's Modulus $=10 \mathrm{Msi}$

Poisson's Ratio $=0.33$

Tube Thickness: 2/32 inch

Panel Dimensions: $1 \mathrm{ft}$ x $1 \mathrm{ft}$ x 1 inch

Elements: Shell

Boundary Conditions: The degree of freedon (DOF) opposing the direction of the load was constrained on the plate edges perpendicular to the core cross members.

Load: 2 inch $\mathrm{x} 3$ inch steel plate with a defined displacement into the panel

The geometry of the tubeplate was created using Pro Engineer. The process in Pro Engineer was to create the tube cross section and extrude it to the length of the plate. After one tube was created, the tube was patterned and spaced 0.001 inches apart to account for the natural gap between the adjacent surfaces. The pattern resulted in a total of twelve, 1 inch tubes butted together which yielded a panel of 12 inches by 12 inches or 1 square foot.

The Pro Engineer geometry was imported into ANSYS finite element software. The material properties and dimensions for the tubeplate were defined. In order to create the desired element size, the element size definition was set to 0.2 " before meshing. Simulation of the weld points between tubes was done by "coupling the degrees of freedom" between adjacent nodes where the butted tubes were connected. The Couple DOFs command in ANSYS defines the motion/displacement of the selected nodes to be 
coupled together. The geometry, mesh, and defining parameters of the model can be seen in Figure 7.1.

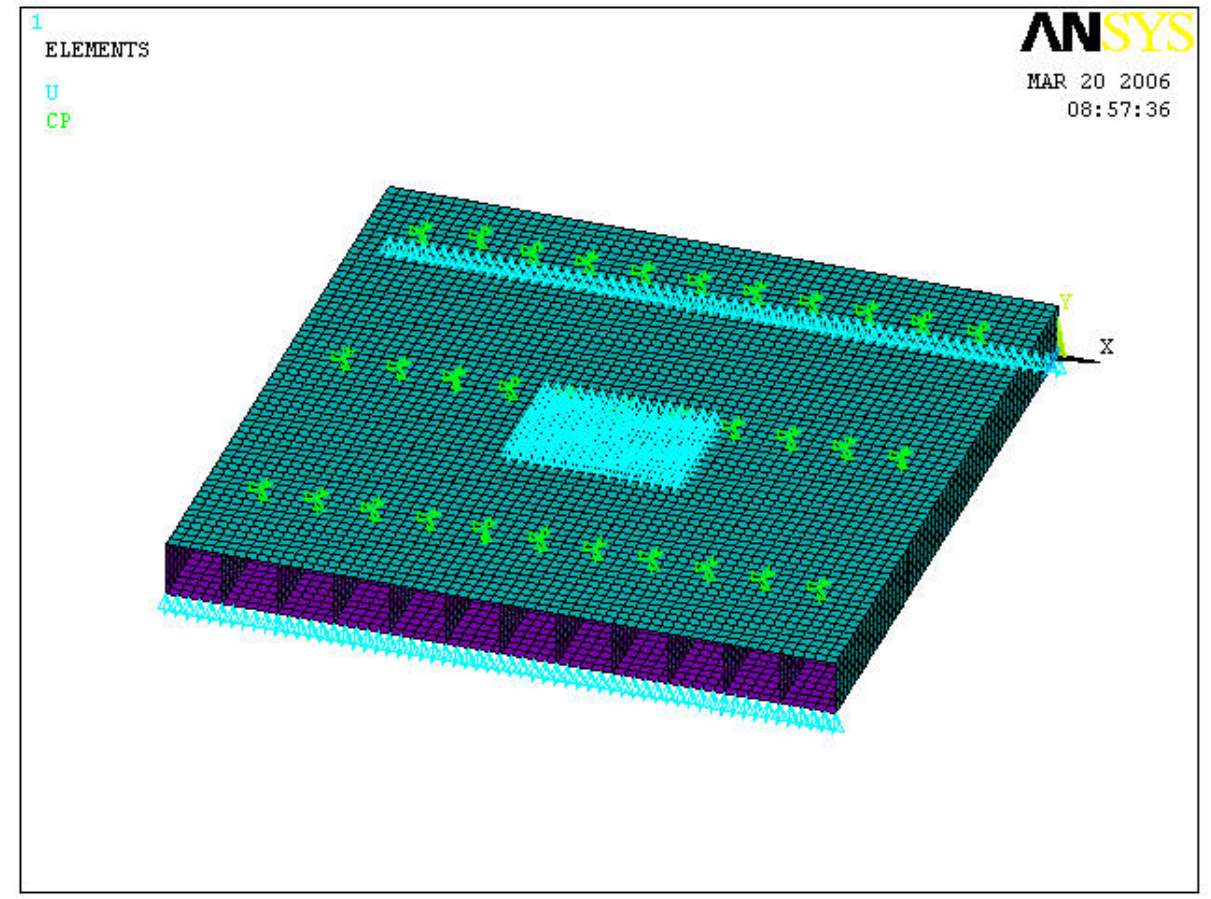

Figure 7.1: Tubeplate finite element model displaying the boundary conditions, load, and coupled degrees of freedom as weld connections.

The results from the finite element modeling are used as a comparison to the displacement and recorded strain gage values from the experimental analysis. The uniaxial measurements are taken next to the load on the top and bottom of the panel. This corresponds to the $\mathrm{x}$-direction strain measurement in the finite element model. Also, the shear strain is analyzed by comparing the nodal and element solutions in the location of the rosette arrangements.

The uniaxial strain from the tubeplate finite element model is shown in Figures 7.2 and 7.3. Studying the contour plots, the uniaxial strain at the location of the strain gage placements is averaged over the elements. The averaged value from the finite element model is $-2033 \mu$ Strain. The average strain values discussed in this section are attained by collecting the strain values in the elements where the strain gage has been placed for experimental analysis and averaging the results. The result for the uniaxial strain attained experimentally was $-1600 \mu$ Strain (see Figure 6.1 (a)). 


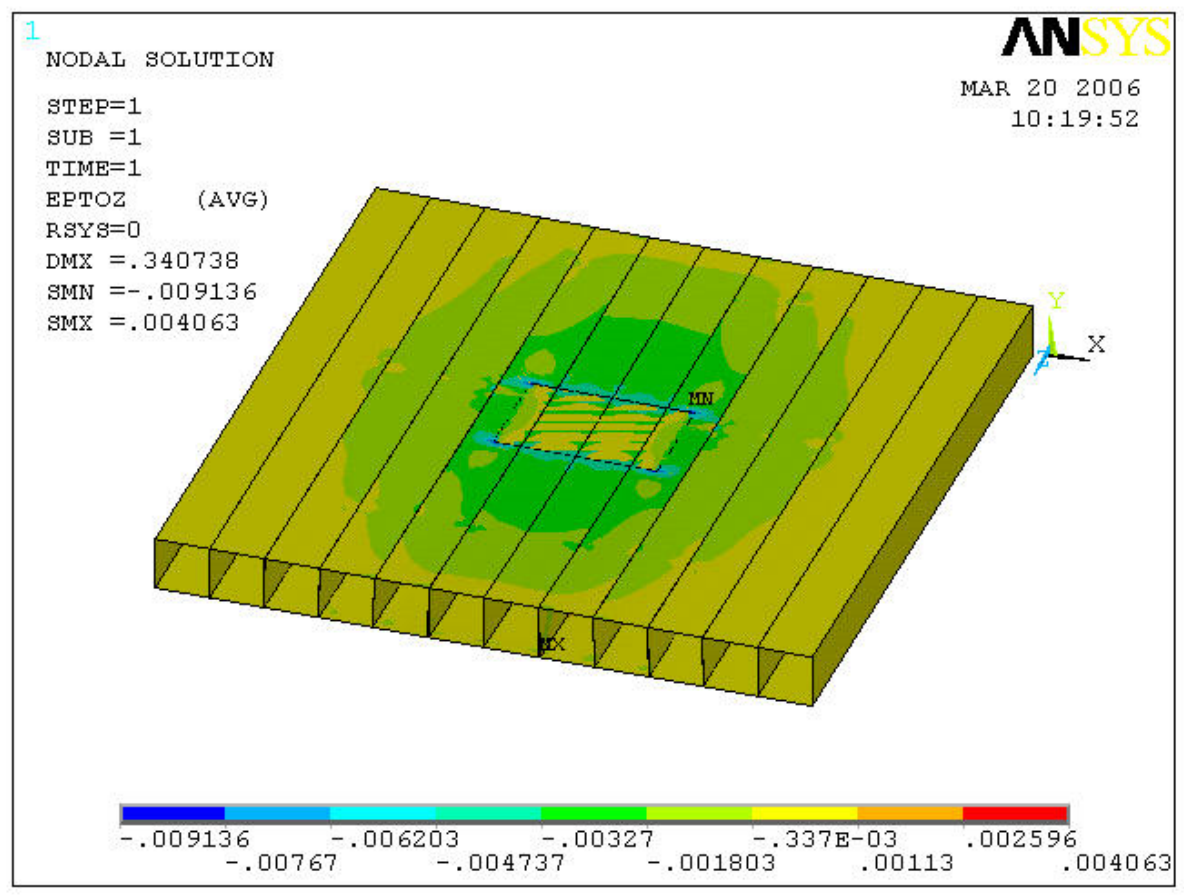

Figure 7.2: Strain in the uniaxial direction corresponding to the strain gage placement in the experimental analysis.

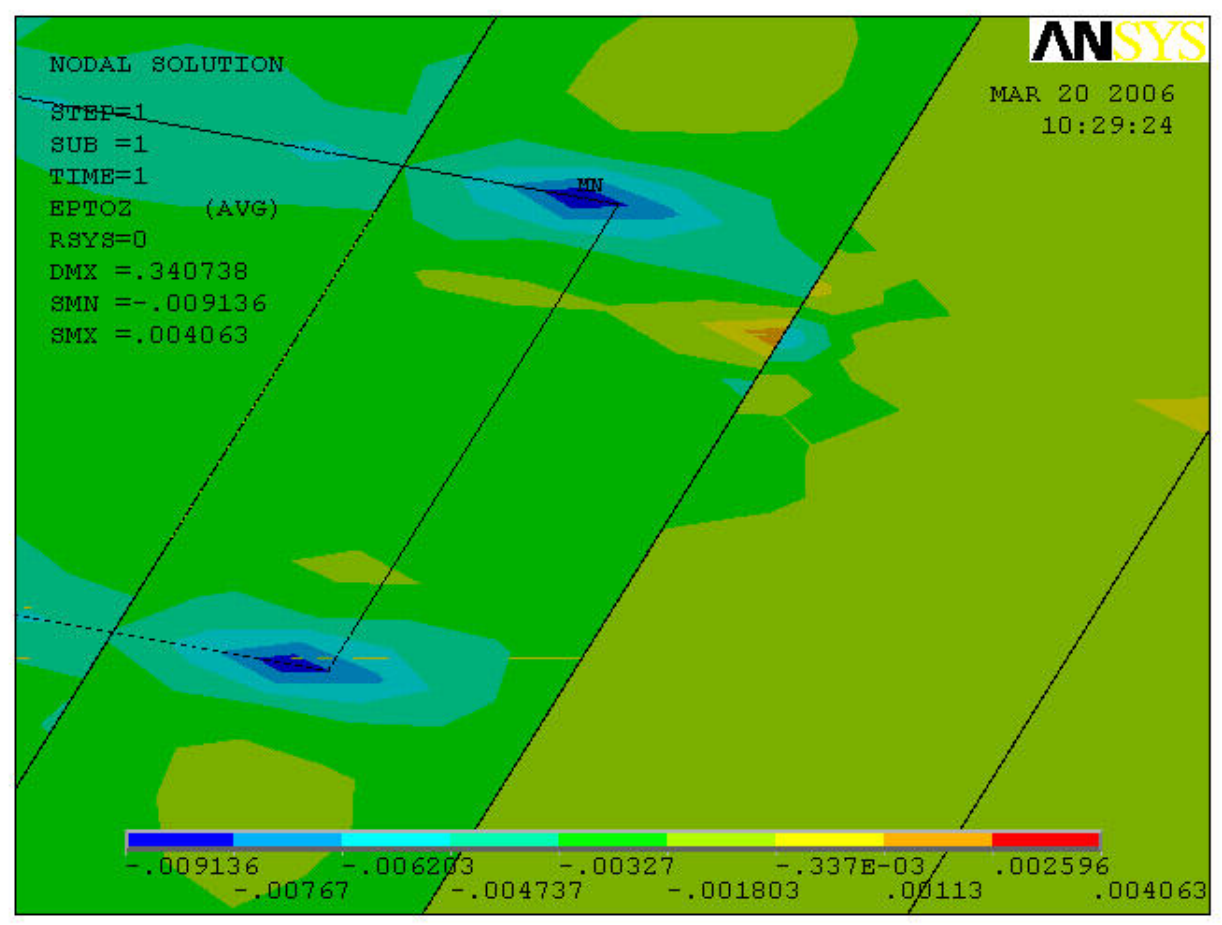

Figure 7.3: Magnified view of the uniaxial strain next to the load area. Notice the stress concentration next to the weld point. 
The shear strain contour plots for the tubeplate are displayed in Figures 7.4 and 7.5. The strain gage rosette arrangements were placed on the inset of the centered cross member. The calculated value from the experimental analysis is $271 \mu$ Strain, Figure 6.2. The averaged shear strain value in the vicinity of the strain gage rosette is $853 \mu$ Strain. There are two points of interest when studying the shear strain of the tubeplate. First, the theoretical shear strain value is approximately three times greater than the experimental value. Second, the adjacent web in the core structure experiences a stress concentration as seen by the dark blue and light blue areas in Figure 7.5. This area is the on the first web offset from the center location. These two points of interest can be explained by the boundary conditions along the edge of the panel. In the theoretical model, the supports are perfect with each node being fixed in the transverse direction. However, in the experimental analysis, it is likely to have a distribution along the simple supports which is not equal throughout the support and edge length of the panel.

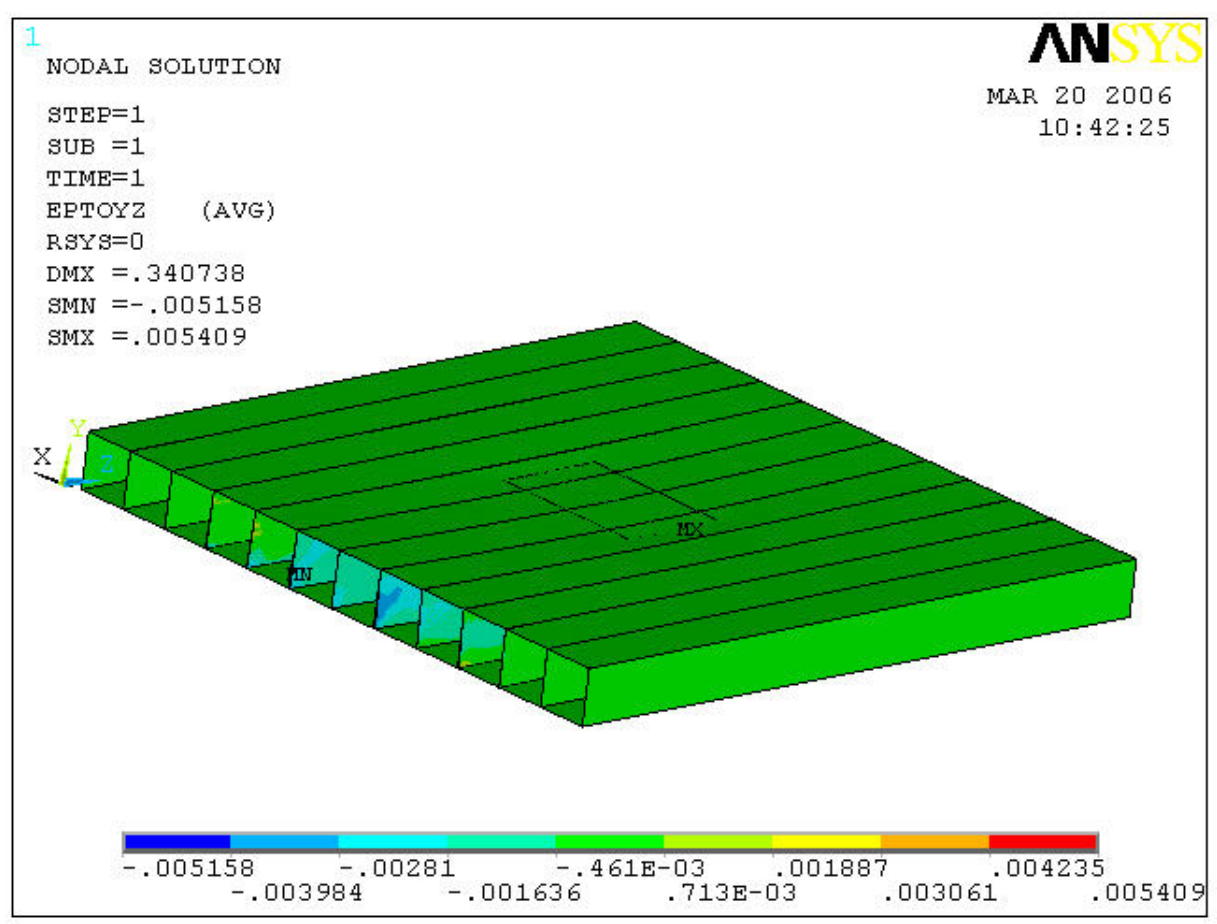

Figure 7.4: Shear strain plot of the tubeplate design. 


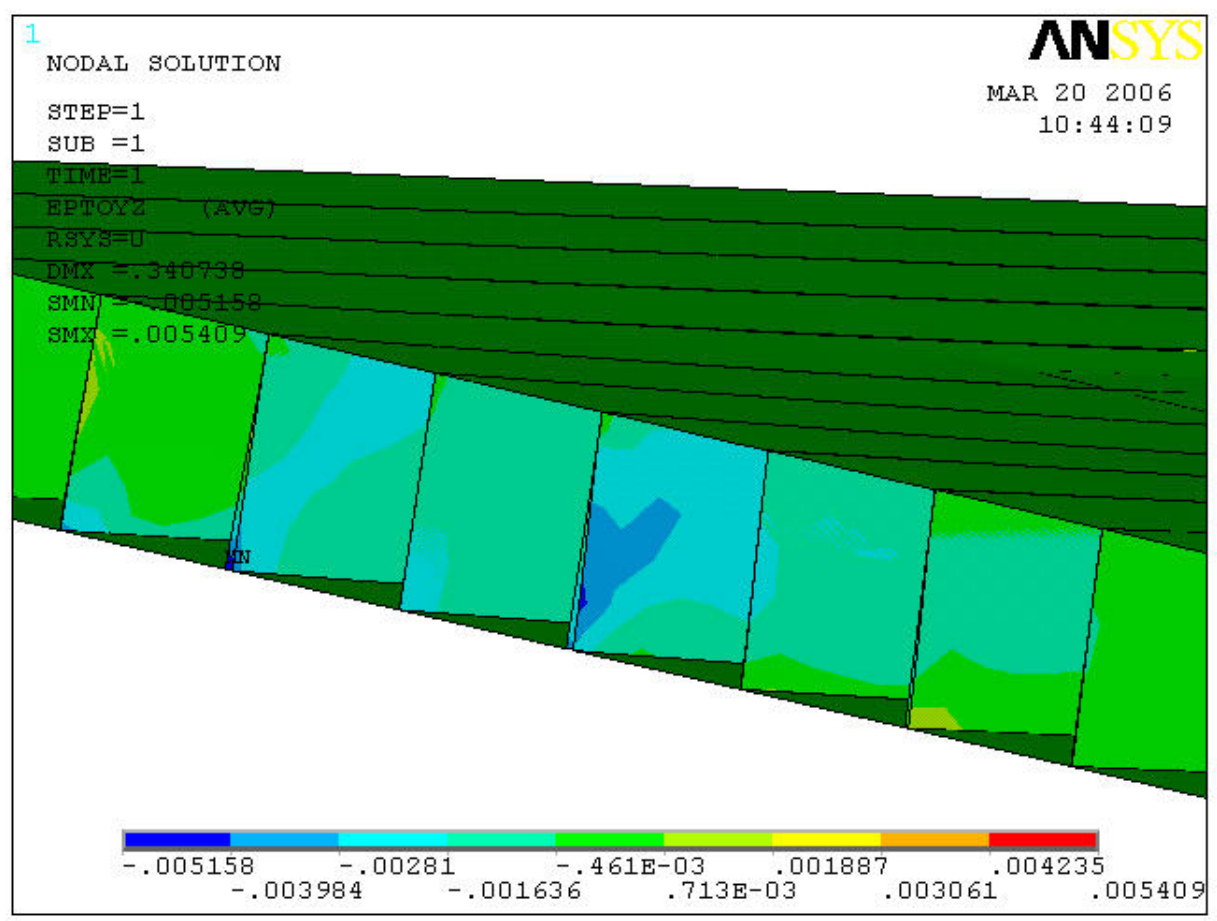

Figure 7.5: Magnification of shear strain contour plot at the rosette gage location.

\subsubsection{Tubegrate}

Material: 6, 1 inch aluminum tube extruded cross members

2, aluminum U-channels

Young's Modulus $=10 \mathrm{Msi}$

Poisson's Ratio $=0.33$

Tube Thickness: $1 / 16$ inch

Panel Dimensions: $1 \mathrm{ft}$ x $1 \mathrm{ft} \times 1$ inch

Elements: Shell

Boundary Conditions: Simply supported on U-channel edge perpendicular to cross members.

Load: 2 inch $x 3$ inch steel plate with a defined displacement into the panel creating contact.

Modeling of the tubegrate was similar to the tubeplate model but differed by incorporation of edge U-channels and spacing between tube cross members. The method to model the interface between the U-channels and cross members was determined by the manufacturing process. During manufacturing, the connection of the tubes into the Uchannel was made by an interference fit. This type of connection increased the stability of the overall panel and reduces the emphasis of the weld connection between the cross members and U-channel. To simulate this connection in ANSYS, the elements on the U- 
channel and cross member interface shared coincident nodes and were defined by the Coincident Nodes command in the ANSYS preprocessing interface. The tubegrate model created for theoretical analysis is depicted in Figure 7.6.

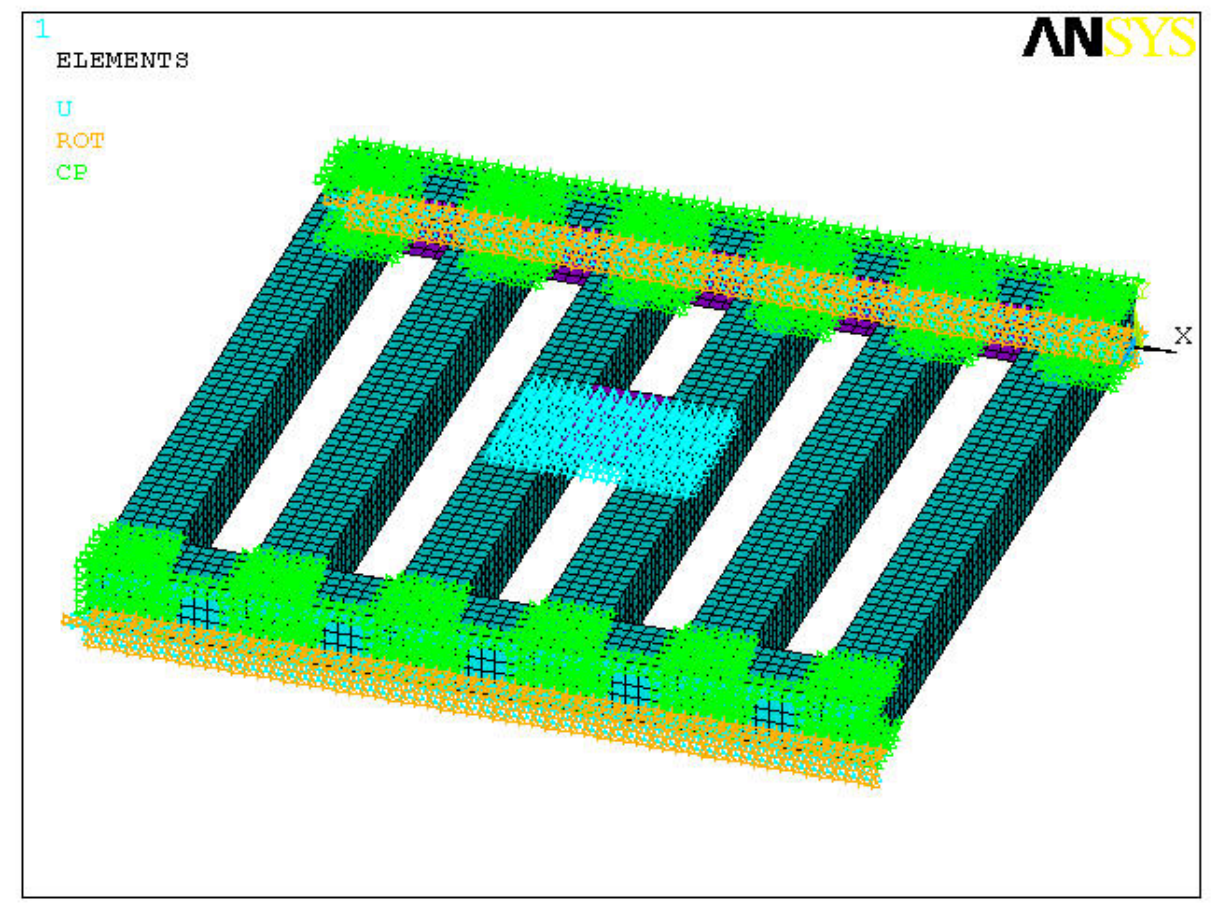

Figure 7.6: Tubegrate finite element model showing the contact load, edge restraints, and coincident nodes.

The uniaxial strain plots are depicted in Figures 7.7 and 7.8. Collecting the strain data from the location of the uniaxial gages, the uniaxial strain is averaged as 5445 $\mu$ Strain. The comparative experimental value at this location is $5239 \mu$ Strain. The top uniaxial gage, located directly under the load, experiences an experimental strain value of $-4268 \mu$ Strain. The finite element strain value at this location is $-6176 \mu$ Strain. 


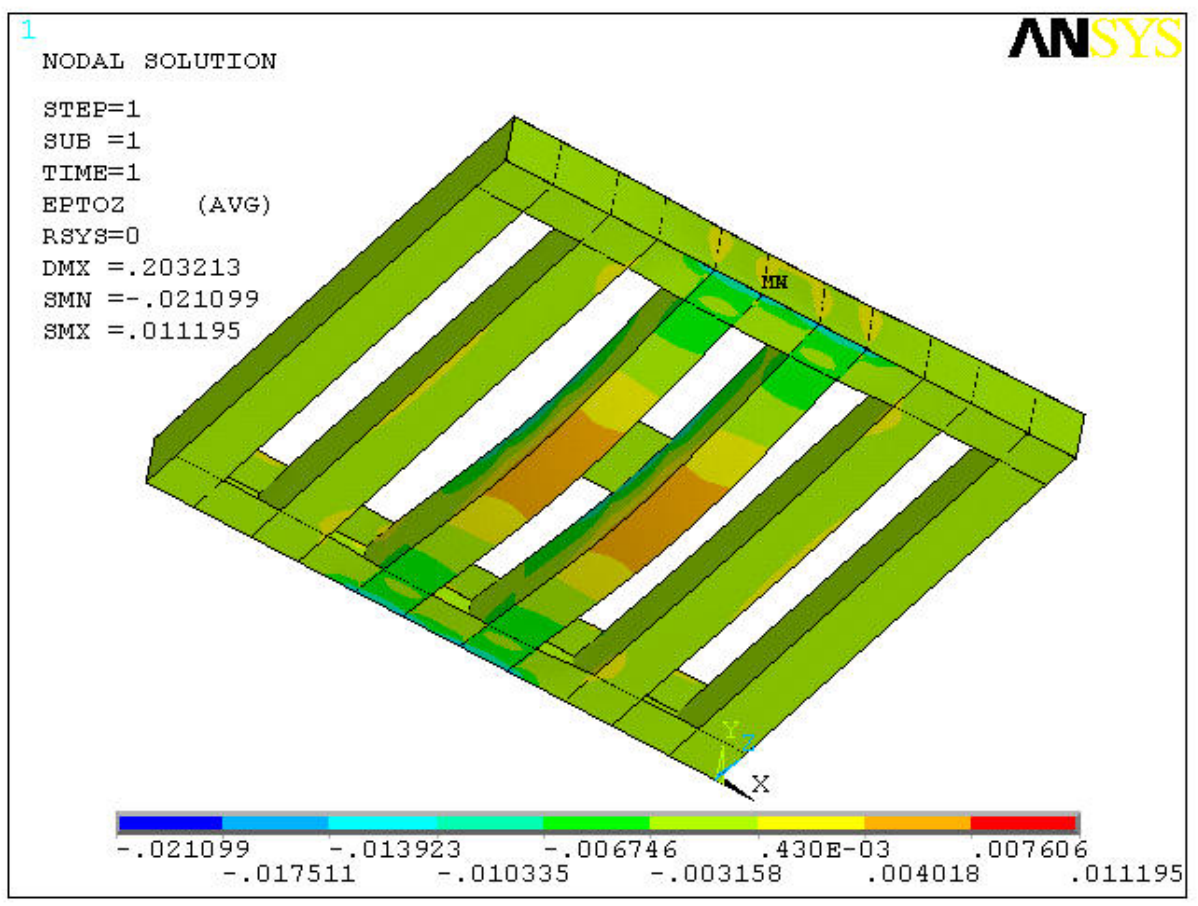

Figure 7.7: Uniaxial strain of the tubegrate panel.

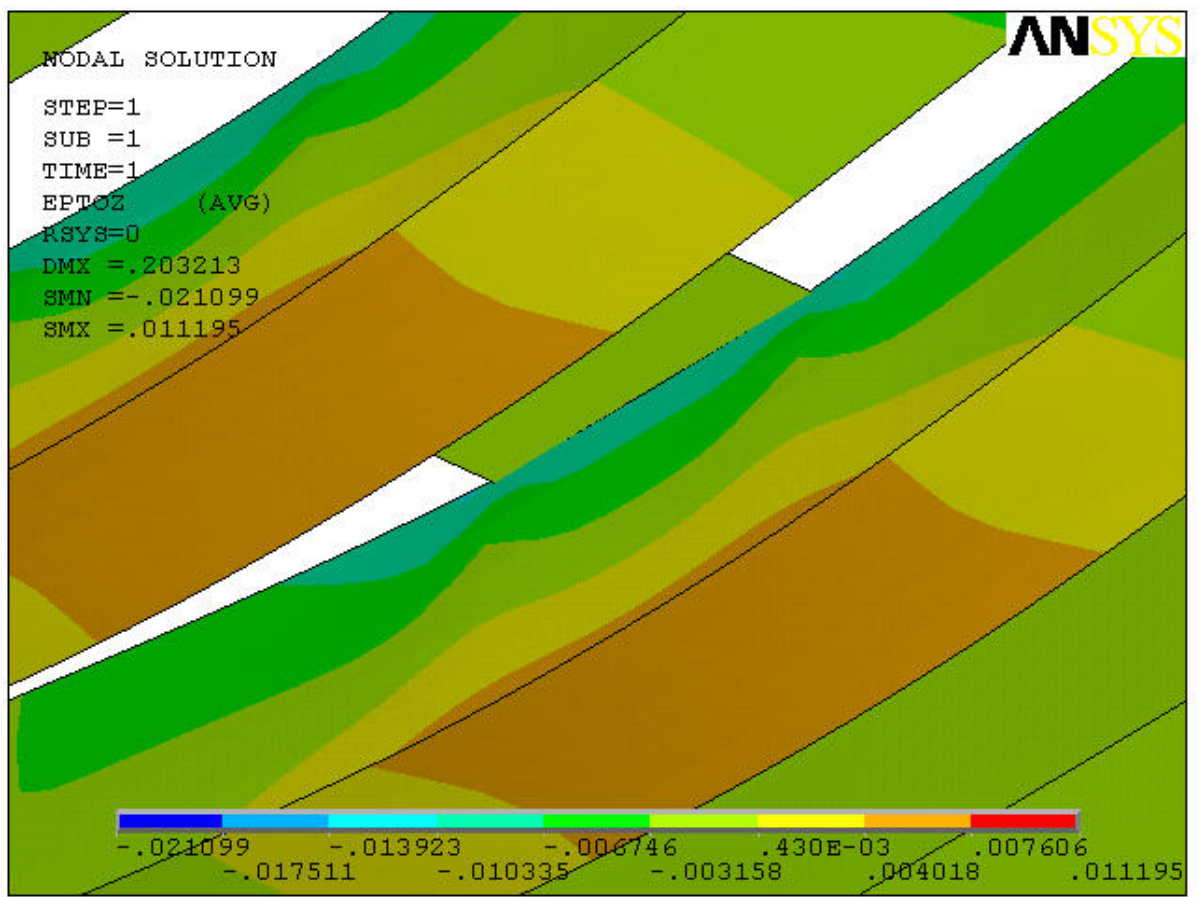

Figure 7.8: Magnified view of tubegrate uniaxial strain at strain gage location. 
Figure 7.9 displays the theoretical shear strain of the tubegrate panel. The strain gage rosettes were located directly in line with the edges of the U-channel edge supports where maximum shear strain was assumed before analysis.

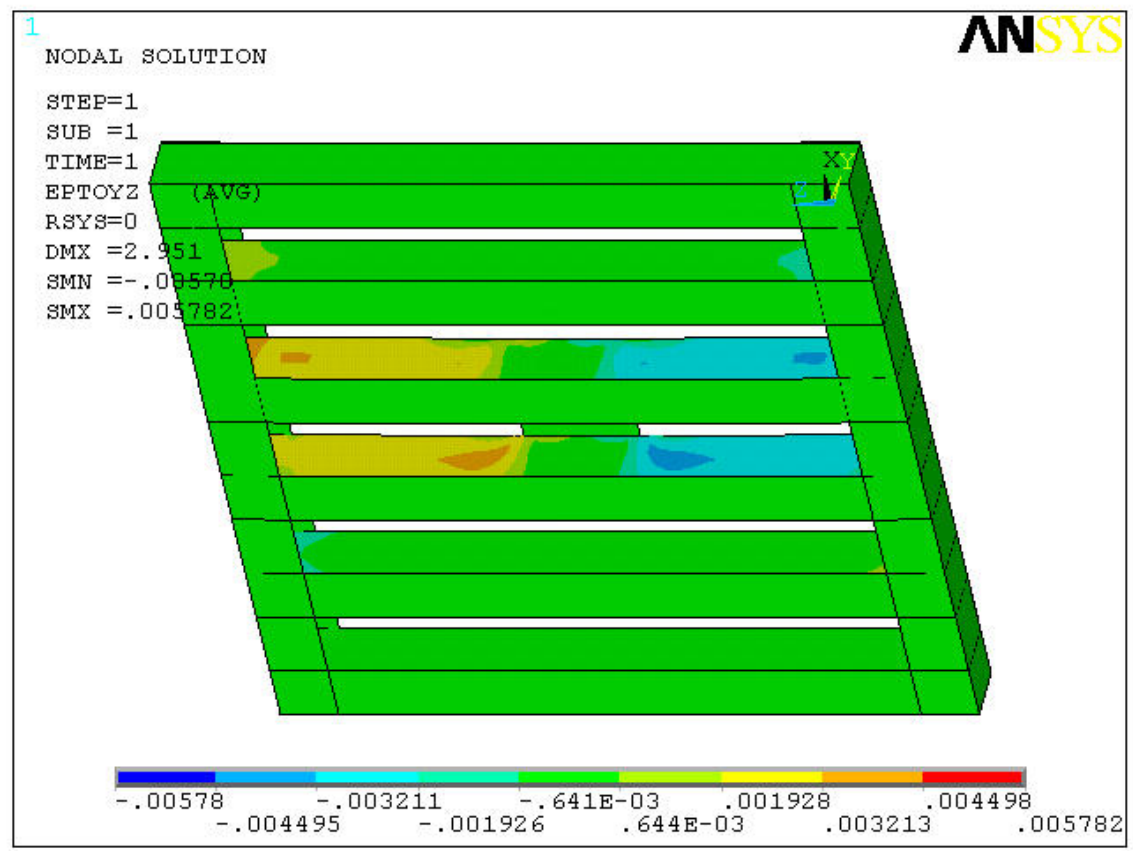

Figure 7.9: Shear strain contour plot of the tubegrate panel.

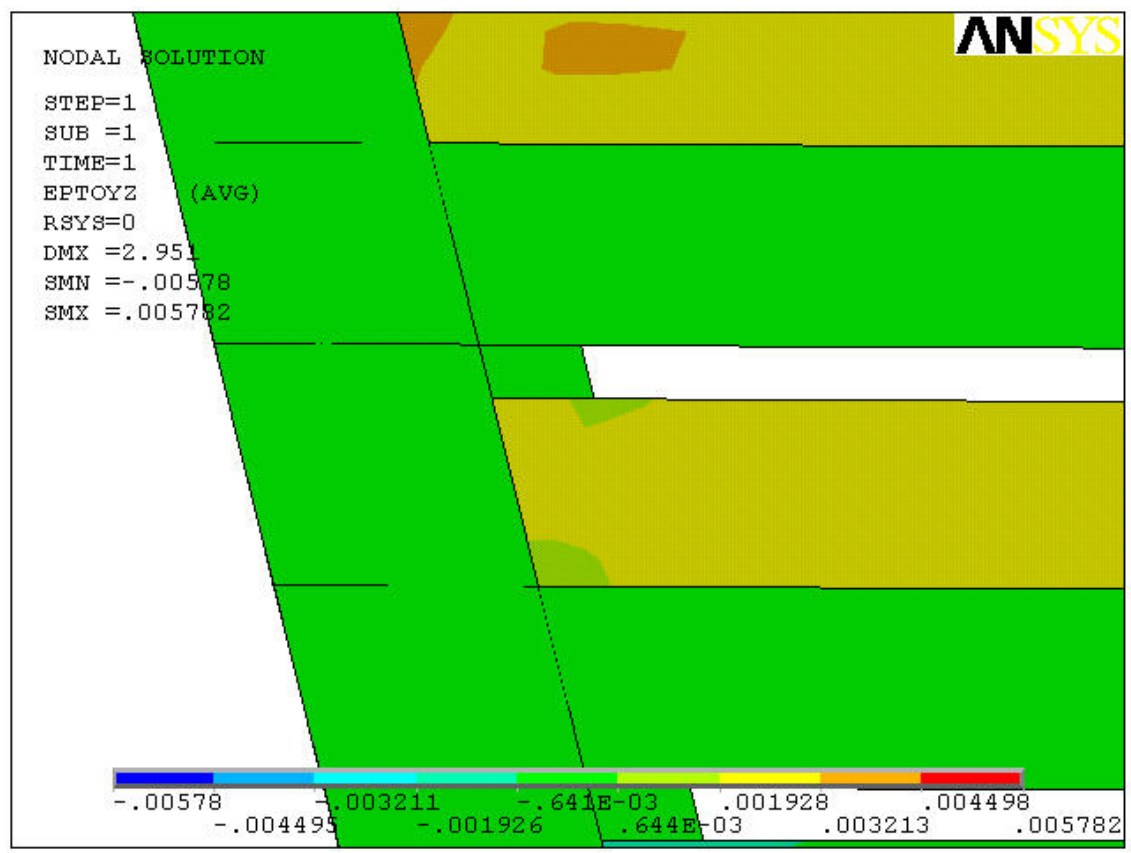

Figure 7.10: Magnification of the tubegrate shear strain rosette location. 
The results shown in Figures 7.9 and 7.10 yield an averaged shear strain of 2160 $\mu$ Strain. The maximum experimental shear strain experienced in the same region is 587 $\mu$ Strain. The theoretical shear strain is 3.68 times greater than the experimental value. A large portion of this difference is due to the boundary conditions established for the tubegrate model. Therefore, modeling the connection of the nodes between the cross members and the U-channel edge rails with coupled degrees freedom effects, ultimately increases the shear strain magnitude by limiting sliding effects between surfaces.

\subsubsection{Fiberplate}

Material: 5,3/4 inch aluminum tube cross members

10 paper rib strips

6 aluminum sheet metal strips

12 layers of woven E-glass and epoxy fiberglass composite

Tube Thickness: $1 / 16$ inch

Panel Dimensions: $1 \mathrm{ft}$ x $1 \mathrm{ft} \times 1$ inch

Elements: Shell

Boundary Conditions: Simply supported on U-channel edge perpendicular to cross members.

Load: 2 inch $\times 3$ inch steel plate with a defined displacement into the panel creating contact.

The fiberplate model involved detailed finite element modeling procedures to most accurately define the panel geometry, materials, and contact characteristics. Modeling was done with shell elements containing layer definition options. Within the fiberplate structure, there are four different layer configurations (reference Figure 4.38). The layer configurations were each defined by the shell element layer definitions in ANSYS. The parameters defined per layer were thickness, material properties, and fiber orientation.

The fiberplate ANSYS finite element model with boundary conditions and load application is displayed in Figure 7.11. 


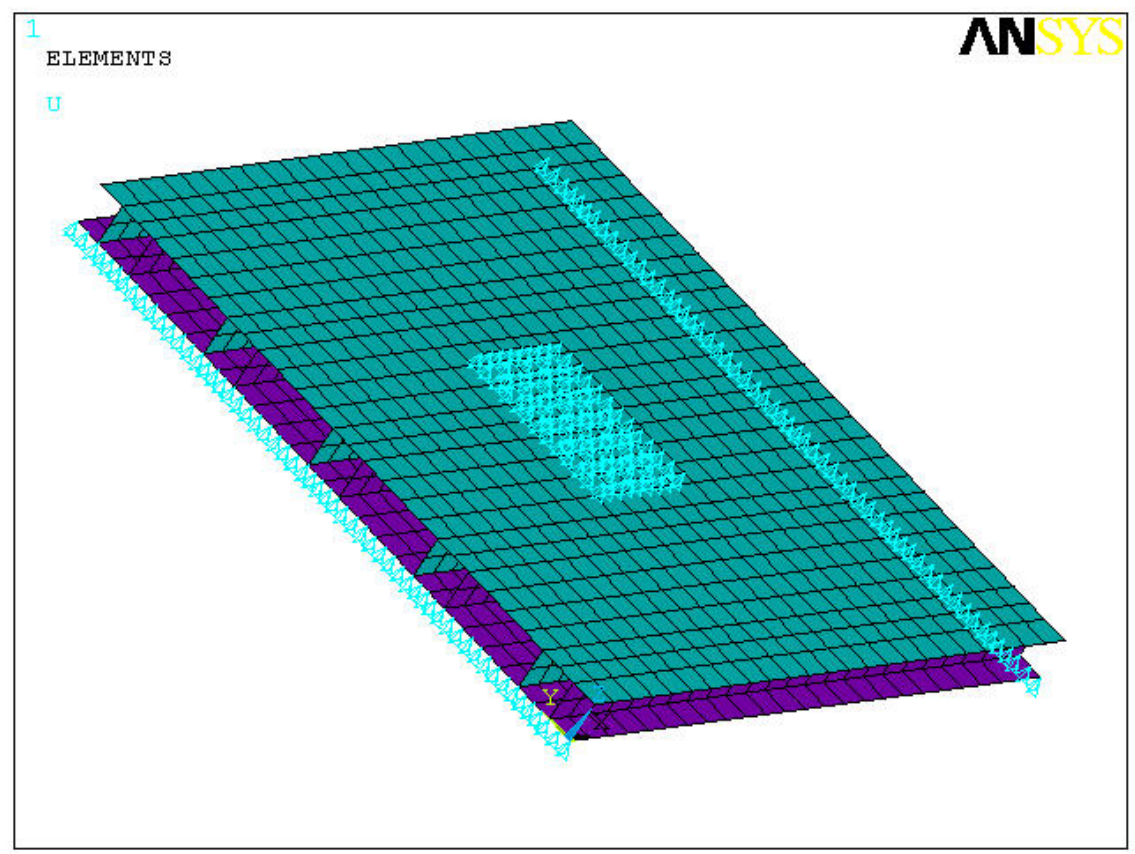

Figure 7.11: The fiberplate finite element model showing the simply supported edges and load.

The uniaxial strains in the fiberplate were predicted to be lower than those of the tubegrate because of the addition of the top and bottom fiberglass face sheets and the reduction in the aluminum tube cross member size. It is important to remember that each design is based on a cross section thickness of 1 inch. Therefore, in order to compensate for the face plate thickness, the cross member cross section height was reduced from 1 inch in the tubeplate and tubegrate design to 0.75 inches in the fiberplate and carbonplate.

Figure 7.12 shows the fiberplate uniaxial strain contour plot. The averaged value of the finite element model in the region of the top uniaxial strain gage is $-1732 \mu$ Strain. The experimental value at this location is $-1003 \mu$ Strain. The bottom uniaxial gage averaged value is $1656 \mu$ Strain and the corresponding experimental value is $1069 \mu$ Strain. 


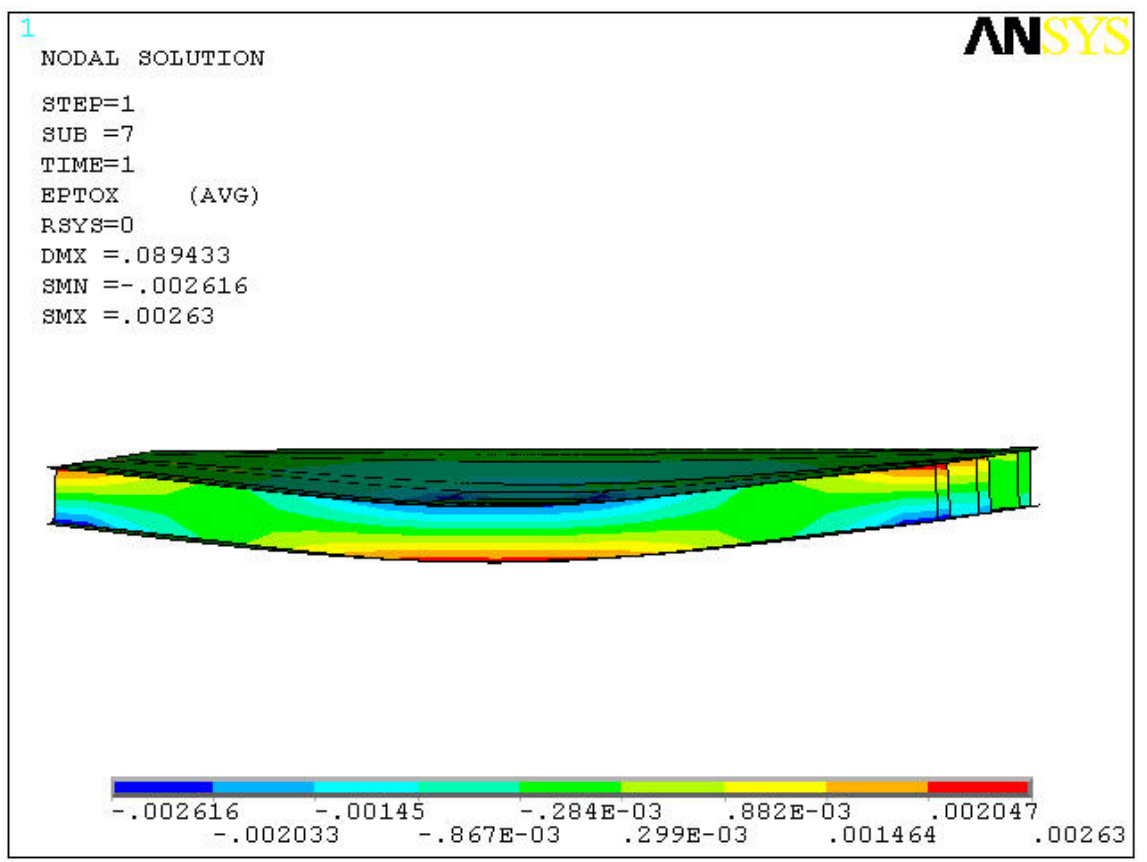

Figure 7.12: Uniaxial strain of the fiberplate panel.

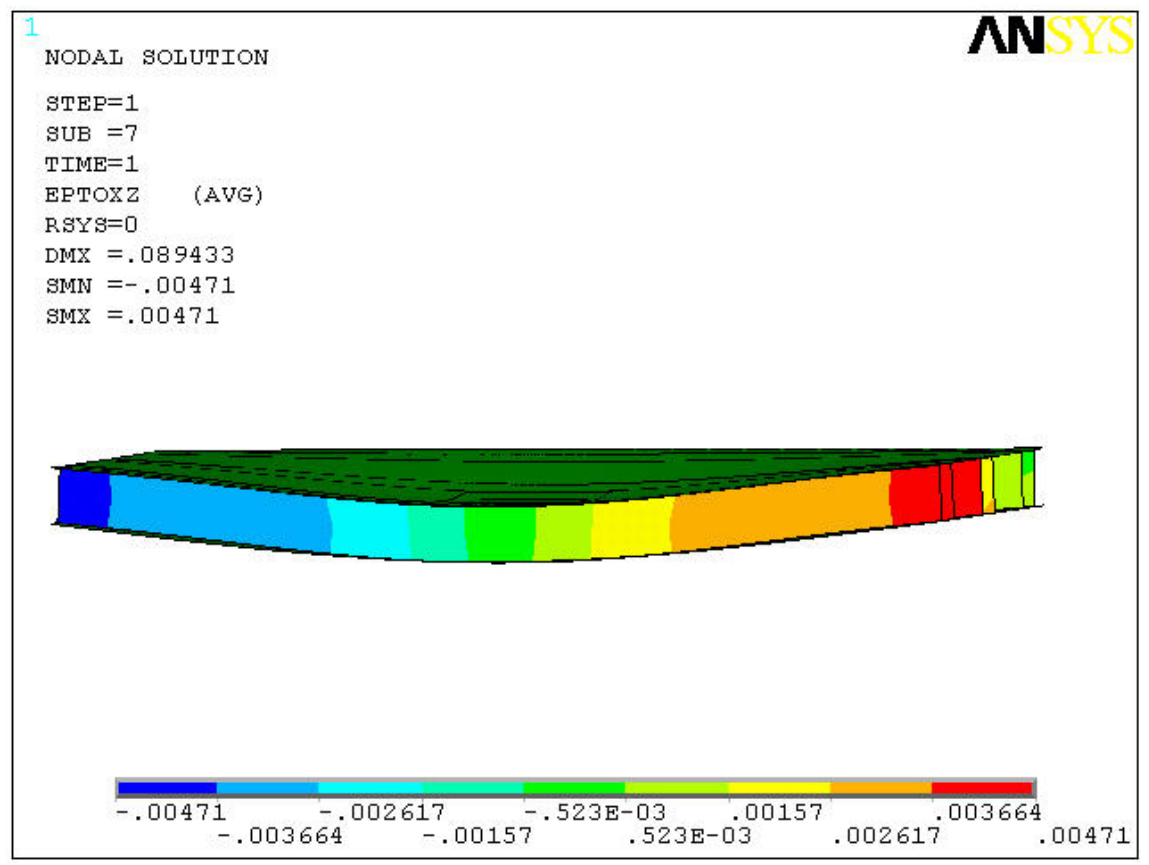

Figure 7.13: Shear strain contour plot of the fiberplate panel.

The fiberplate shear strain contour plot is displayed in Figure 7.13. Following the trend of comparison between theoretical and experimental values, the strains again are calculated to be of higher magnitude than the experimental results. The averaged 
theoretical strain is $2749 \mu$ Strain and the corresponding experimental value is 267 $\mu$ Strain. The theoretical value is greater than the experimental by a magnitude of ten. The large difference is values can be attributed to the contact connection between the core cross members and the top and bottom face sheets. A "bonded" connection is established in the finite element model which coincides the movement of the surfaces in contact between the face sheets and the core cross members. Therefore, the compression action of the top face sheet and tension of the bottom face sheet by flexure is directly transported to the cross member creating a higher shear resultant load. These same actions are produced in the experimental procedure but slippage and ductility in the bond will lessen the magnitude of the shear strain transmitted to the core cross members.

\subsubsection{Carbonplate}

Material: 5, 3/4 inch aluminum tube cross members

10 paper rib strips

6 aluminum sheet metal strips

12 layers of $2 \times 2$ twill weave graphite fabric and epoxy carbon fiber composite

Tube Thickness: $1 / 16$ inch

Panel Dimensions: $1 \mathrm{ft}$ x $1 \mathrm{ft} \times 1$ inch

Elements: Shell

Boundary Conditions: Simply supported on U-channel edge perpendicular to cross members.

Load: 2 inch $\times 3$ inch steel plate with a defined displacement into the panel creating contact.

The carbonplate design is identical to the fiberplate layup except carbon fiber is used in the faceplates instead of fiberglass. The impetus to use carbon as the fiber material was for maximizing the fiber material properties and weight saving characteristics. As seen in the material properties, carbon fiber is superior to fiberglass producing higher stiffness values and ultimately increasing the load carrying capabilities [11].

The finite element uniaxial strain contour plate of the carbonplate is displayed in Figure 7.14 . 


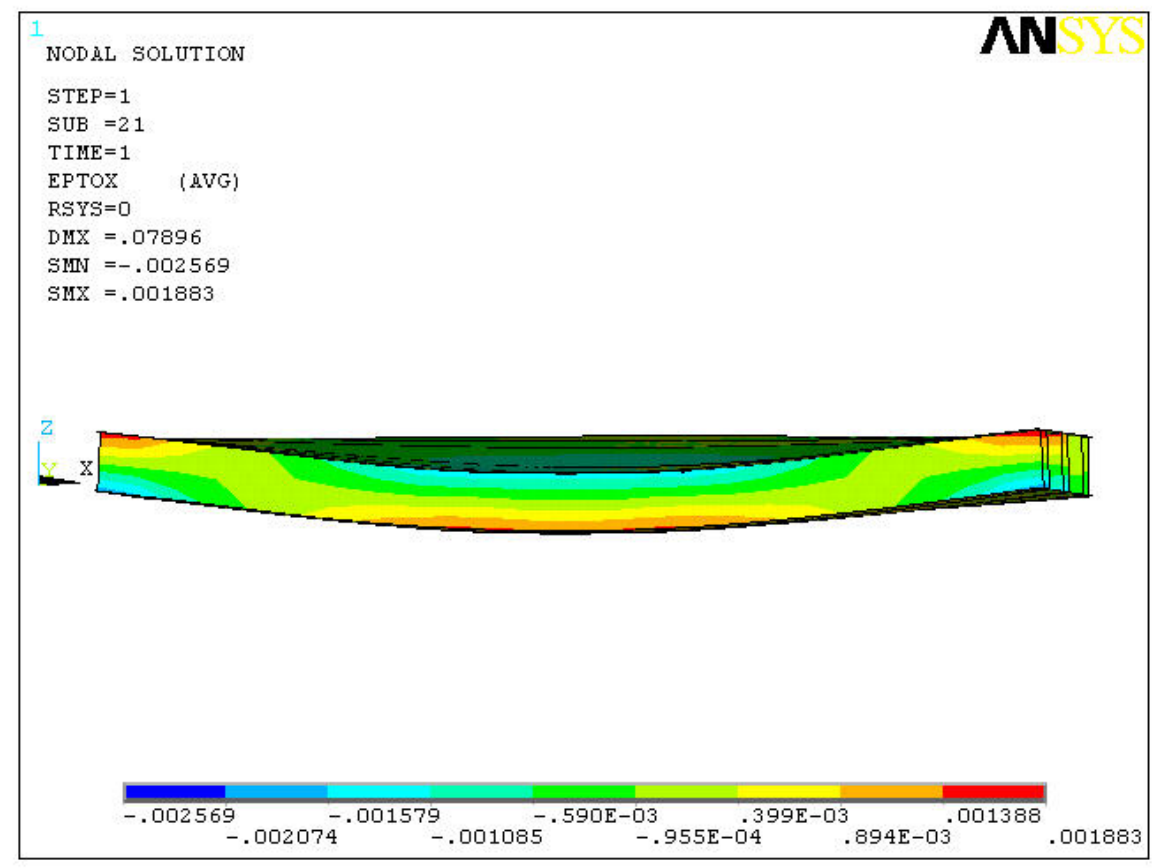

Figure 7.14: Uniaxial strain distribution of the carbonplate

The shear strain contour plot of the carbonplate is displayed in Figure 7.15.

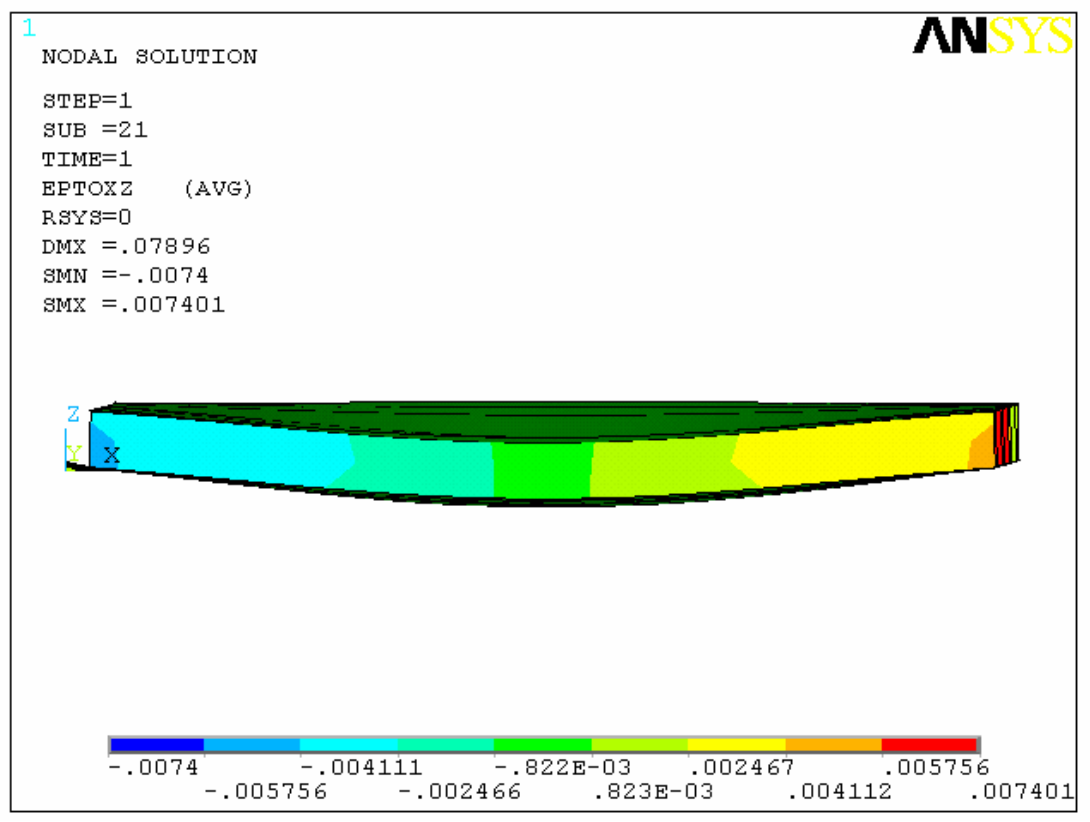

Figure 7.15: Shear strain distribution of the carbonplate. 


\subsection{Failure Analysis}

A triaxial state of stress is developed within the panels during the loading procedure. A triaxial state of stress initiates the use of an equivalent stress value or failure criterion to investigate the effect of material yielding. Von-Mises stress is a stress parameter that expresses the octahedral shear stress, or the strain energy of distortion, at any point within a body which undergoes a triaxial state of stress [23]. Von-Mises stress criteria uses the stress components at any point within the body and is expressed as:

$$
S_{e q}=\sqrt{\frac{1}{2}\left[\left(\sigma_{x}-\sigma_{y}\right)^{2}+\left(\sigma_{y}-\sigma_{z}\right)^{2}+\left(\sigma_{z}-\sigma_{x}\right)^{2}+3 \tau_{x y}^{2}+3 \tau_{y z}^{2}+3 \tau_{x z}^{2}\right]}
$$

The Von-Mises failure criteria states that material yielding begins if the equivalent stress at any point reaches the material yielding point. The stress plots from the fiberplate and carbonplate designs are analyzed using the Von-Mises criteria to determine failure characteristics.

The plots of the Von-Mises stress in the fiberplate and carbonplate designs are shown below.

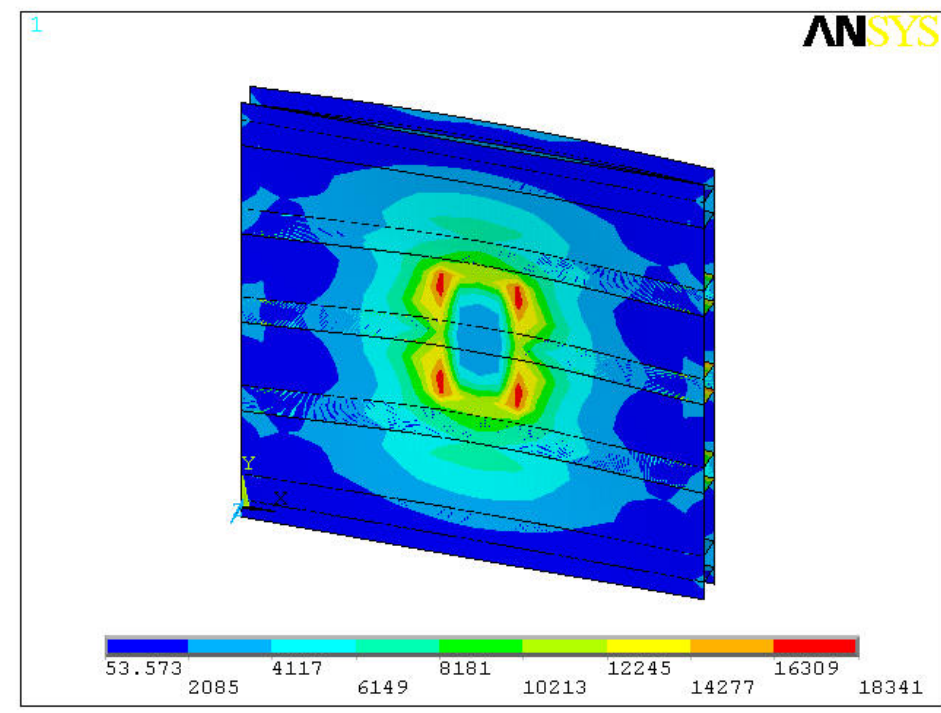

Figure 7.16: Contour plot of Von-Mises stress in the fiberplate. 


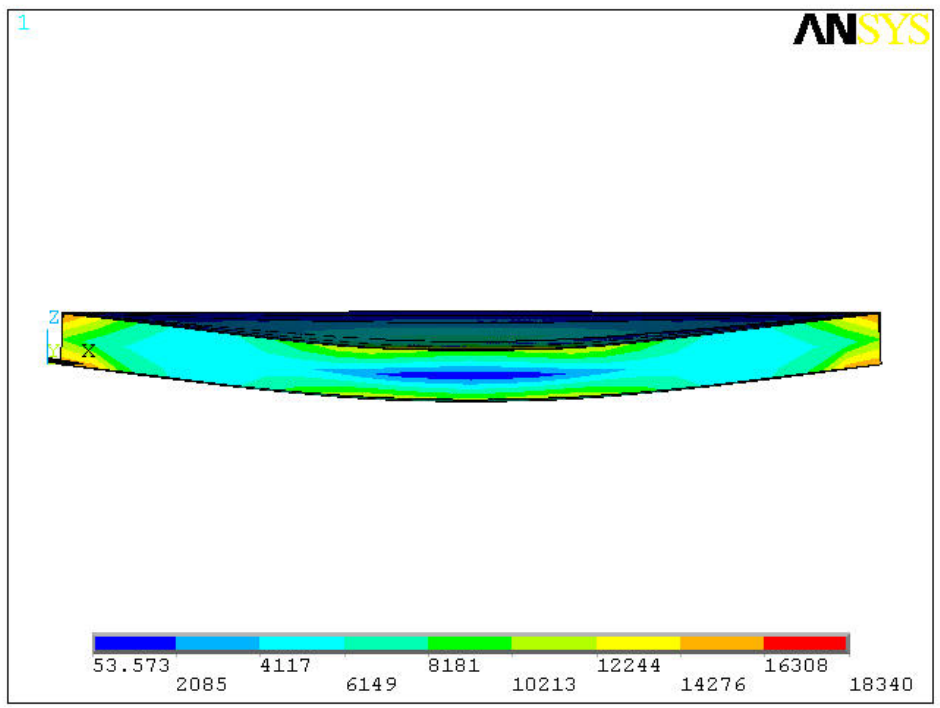

Figure 7.17: Contour plot of the Von-Mises stress in the core of the fiberplate.

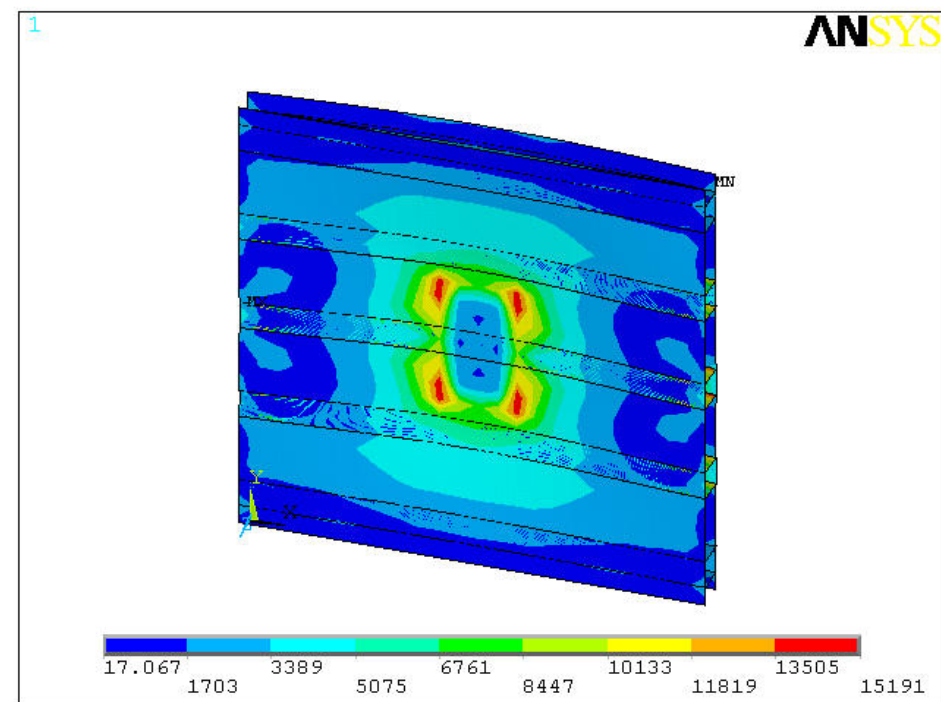

Figure 7.18: Contour plot of the Von-Mises stress in the carbonplate. 


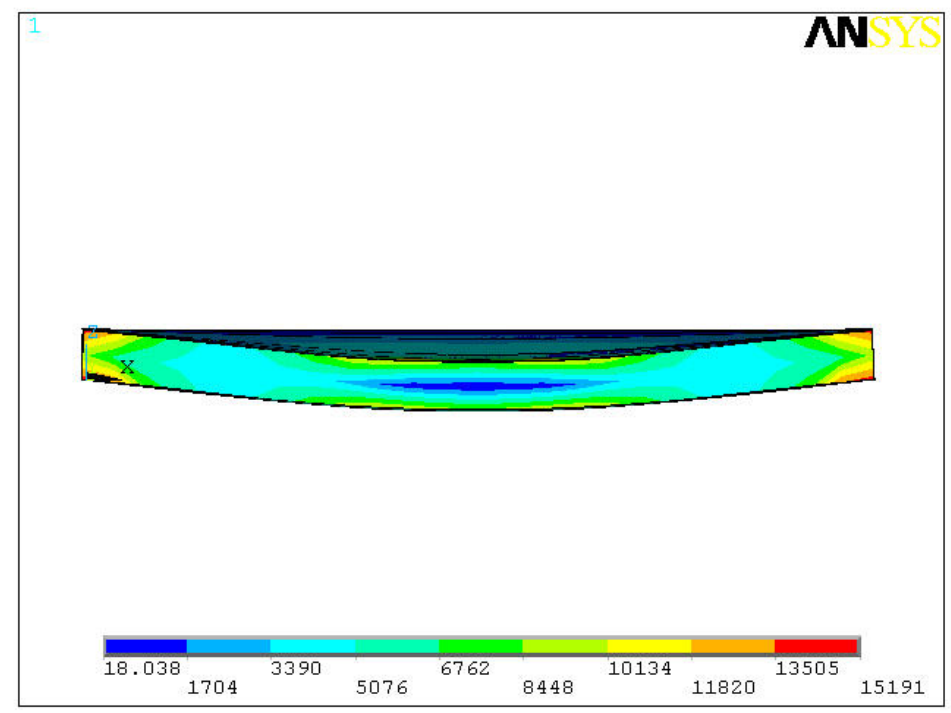

Figure 7.19: Contour plot of the Von-Mises stress in the core of the carbonplate.

The Von-Mises stress values from the finite element contour plots are used to determine if there is failure in the panel core. As previously described, failure according to the Von-Mises criteria occurs when the energy of distortion (plotted values) reaches the same energy for yield/failure under uniaxial tension. The value in which yielding occurs in the aluminum core structure is $60 \mathrm{ksi}$ [24]. The maximum values attained in the fiberplate and carbonplate designs are listed in Table 7.1.

Table 7.1 - Failure Criteria for the Fiberplate and Carbonplate Core Structure

\begin{tabular}{|c|c|c|c|}
\hline Panel Configuration & $\begin{array}{c}\text { Strength of the Core } \\
\text { Structure } \\
\text { (ksi) }\end{array}$ & $\begin{array}{c}\text { Maximum } \\
\text { Von-Mises } \\
\text { Stress in the Core } \\
\text { (ksi) }\end{array}$ & $\begin{array}{c}\text { Factor } \\
\text { Of } \\
\text { Safety }\end{array}$ \\
\hline Fiberplate & 60 & 15.3 & 3.92 \\
\hline Carbonplate & 60 & 12.7 & 4.72 \\
\hline
\end{tabular}

From Table 7.1, it is shown that the maximum Von-Mises stress values attained in the fiberplate and carbonplate designs are almost four times less than the tensile yield strength of $60(\mathrm{ksi})$ for the aluminum core structure. Therefore, it is determined that applying a load of $600 \mathrm{lbs}$ to a square foot section of the fiberplate or carbonplate design will not cause yielding within the core structure. 


\section{Composite Failure}

Failure in composite structures is often complex and involves various modes of failure. Methods of fracture of composite materials include the following.

- Fiber breaking

- Matrix Crazing

- Matrix Cracking

- Fiber Debonding

- Delamination

It is difficult to apply all the failure modes into the design and analysis of the part. The basic approach involves using an empirical failure criterion, similar to the VonMises criteria previously discussed. The maximum stress criterion [2] will most efficiently provide an understanding into the failure prediction of the fiberplate and carbonplate designs.

The maximum stress criterion for composite material analysis involves comparing the stress values attained by theoretical or experimental analysis to the strength values of a single laminate layer within the composite structure. The criterion predicts failure of a layer when one of the stresses in material coordinates $\left(\sigma_{1}, \sigma_{2}, \sigma_{6}, \sigma_{4}, \sigma_{5}\right)$ exceeds the layer strength. The criterion states that failure will occur if any of the following parameters are true

$$
\begin{array}{ll}
\sigma_{1}>F_{1 t} & \text { if } \sigma_{1}>0 \\
\left|\sigma_{1}\right|>F_{1 c} & \text { if } \sigma_{1}<0 \\
\sigma_{2}>F_{2 t} & \text { if } \sigma_{2}>0 \\
\left|\sigma_{2}\right|>F_{2 c} & \text { if } \sigma_{2}>0 \\
\left|\sigma_{4}\right|>F_{4} & \\
\left|\sigma_{5}\right|>F_{5} & \\
\left|\sigma_{6}\right|>F_{6} &
\end{array}
$$

where

$F_{1 t}$ - tensile strength in the fiber direction

$F_{l c}$-compressive strength in the fiber direction

$F_{2 t}$ - tensile strength in the transverse direction

$F_{2 c}$-compressive strength in the transverse direction

$F_{6}$ - inplane shear strength

$F_{4}, F_{5}$ - interlaminar shear strength values 
The comparison of the determined stress values to the strength values of single laminate layer with determine if failure is reached in the composite structure. Tables 7.2 and 7.3 display the maximum stress criterion for the fiberplate and carbonplate composite structures.

Table 7.2 - Fiberplate Maximum Stress Criterion

\begin{tabular}{|c|c|c|c|}
\hline $\begin{array}{c}\text { Strength } \\
\text { Parameter }\end{array}$ & $\begin{array}{c}\text { Fiberplate } \\
\text { Strength } \\
\text { Values } \\
\text { (ksi) }\end{array}$ & $\begin{array}{c}\text { Corresponding } \\
\text { Stress Values } \\
\text { (ksi) }\end{array}$ & $\begin{array}{c}\text { Factor } \\
\text { Of } \\
\text { Safety }\end{array}$ \\
\hline$F_{l t}$ & 53.0 & 14.7 & 3.61 \\
\hline$F_{l c}$ & 79.6 & 21.0 & 3.80 \\
\hline$F_{2 t}$ & 53.2 & 11.0 & 4.84 \\
\hline$F_{2 c}$ & 79.6 & 14.7 & 5.41 \\
\hline$F_{6}$ & 14.1 & 1.65 & 8.55 \\
\hline
\end{tabular}

Table 7.3 - Carbonplate Maximum Stress Criterion

\begin{tabular}{|c|c|c|c|}
\hline $\begin{array}{c}\text { Strength } \\
\text { Parameter }\end{array}$ & $\begin{array}{c}\text { Carbonplate } \\
\text { Strength } \\
\text { Values } \\
\text { (ksi) }\end{array}$ & $\begin{array}{c}\text { Corresponding } \\
\text { Stress Values } \\
\text { (ksi) }\end{array}$ & $\begin{array}{c}\text { Factor } \\
\text { Of } \\
\text { Safety }\end{array}$ \\
\hline$F_{1 t}$ & 80 & 11.4 & 7.01 \\
\hline$F_{1 c}$ & 113 & 12.9 & 8.76 \\
\hline$F_{2 t}$ & 82.5 & 8.0 & 10.3 \\
\hline$F_{2 c}$ & 98.6 & 10.3 & 9.57 \\
\hline$F_{6}$ & 14.2 & 1.52 & 9.34 \\
\hline
\end{tabular}

The previous tables show that the lowest factor of safety attained for the fiberplate composite structure is 3.61 and the carbonplate structure is 7.01 . The determined factors of safety determine that the composite structure within each design will not fail when loaded with a $600 \mathrm{lb}$ load per square foot section.

It should also be stated that if a $600 \mathrm{lb} / \mathrm{ft}^{2}$ load is applied as the load on the floor of a $54 \mathrm{ft}$. trailer platform, the overall trailer cargo load would equal 129,600 $\mathrm{lbs}$ or approximately 65 ton. The average payload capacity is 25 ton per cargo load. Therefore, a 2.5 factor of safety is in included in the applied load. 


\subsection{Discussion}

As shown in the four panel comparative study, there are four options of progressive design, meaning, each design was upgraded or altered from the previous. The designs progressed to efficient load bearing platforms with weight saving properties. The objective of thise study was to create weight efficient platform to initiate in heavy vehicle applications or any application in which lightweight and strength characteristics are desired and mandatory. Table 7.4 lists the four panel designs and their respective weights versus the square foot section of an existing trailer section.

Table 7.4 - Weight of Panel Designs Compared to an Existing Trailer Section

\begin{tabular}{|c|c|}
\hline Panel Design & Weight of Square Foot Section (lbs) \\
\hline Tubeplate & 3.4 \\
\hline Tubegrate & 2.6 \\
\hline Fiberplate & 2.4 \\
\hline Carbonplate & 2.2 \\
\hline Existing Trailer Section & 21.6 \\
\hline
\end{tabular}

In Table 7.4, the cross section thickness of the sandwich panel designs is one inch and the highest weight savings is exhibited in the carbonplate design, with a weight saving capability of approximately 10 times less than the existing current trailer section. The other panel designs also display promising weight saving abilities. The least efficient design is the tubeplate, which has a weight per square foot value of $3.4 \mathrm{lbs}$. Even as the heaviest panel design, the tubeplate contributes a weight savings of $18.2 \mathrm{lbs}$ per square foot versus the existing trailer section.

The weight comparison of Table 7.4 presents extraordinary weight efficient characteristics of the panel designs. However, the existing trailer section is composed of four inch steel I-beams and a $13 / 8$ inch solid oak platform connected to the top flange. It is not expected that the one inch panel sections will compare to the current trailer section on the basis on bending resistance and load carrying capabilities. Increasing the panel dimensions to attain a four inch cross section thickness and comparing to the existing trailer section will reveal if the designs are beneficial in comparison to a trailer platform. 
A final comparative finite element study was performed. The study involves the carbonplate design and a model of the existing trailer section. The carbonplate thickness and dimensions have been increased to create a four inch cross section thickness and will be noted as carbonplate-4. The goal is to determine if the maximum displacement and strain values of the carbonplate- 4 panel will be less than the existing trailer design of four inch steel I-beams and $13 / 8$ inch solid oak platform. The following finite element models of the carbonplate-4 and existing trailer section are shown in Figure 7.20.
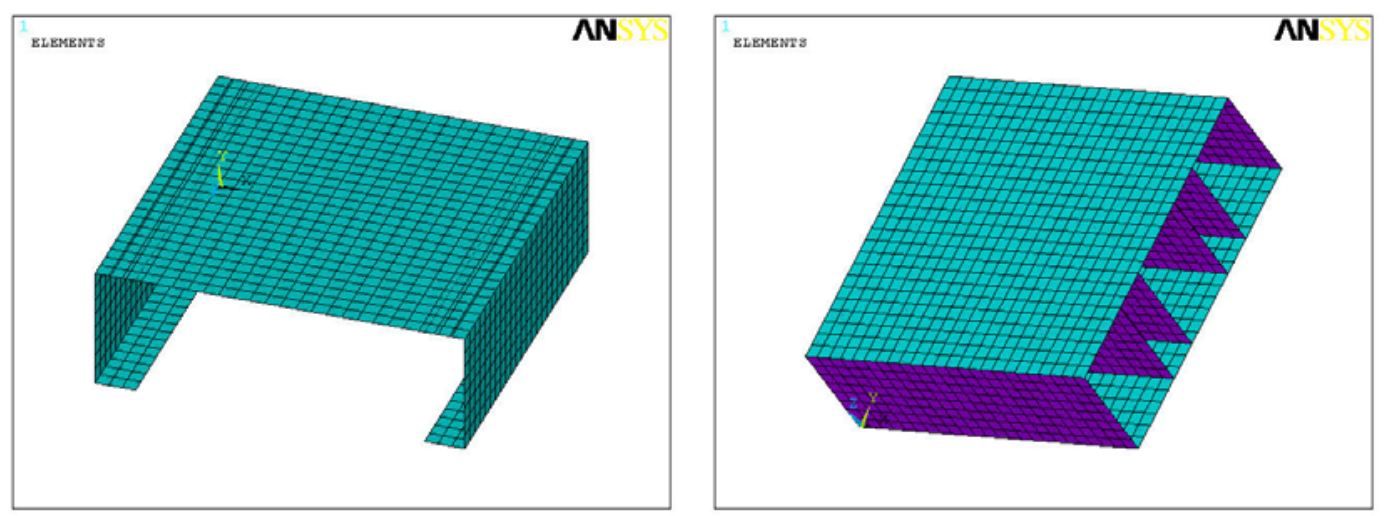

Figure 7.20: Finite element models of the trailer section and the carbonplate.

After applying the same distributed load to each model the displacements were analyzed. Figures 7.21 and 7.22 illustrate the displacement contour plots for the trailer section and the comparative carbonplate-4 model, respectively. It is seen that the maximum displacement of trailer section is $0.737 \mathrm{e}-3$ inches. The maximum displacement in the carbonplate- 4 is $0.104 \mathrm{e}-3$ inches, this value is more than seven times less than the maximum displacement of the existing trailer section. 


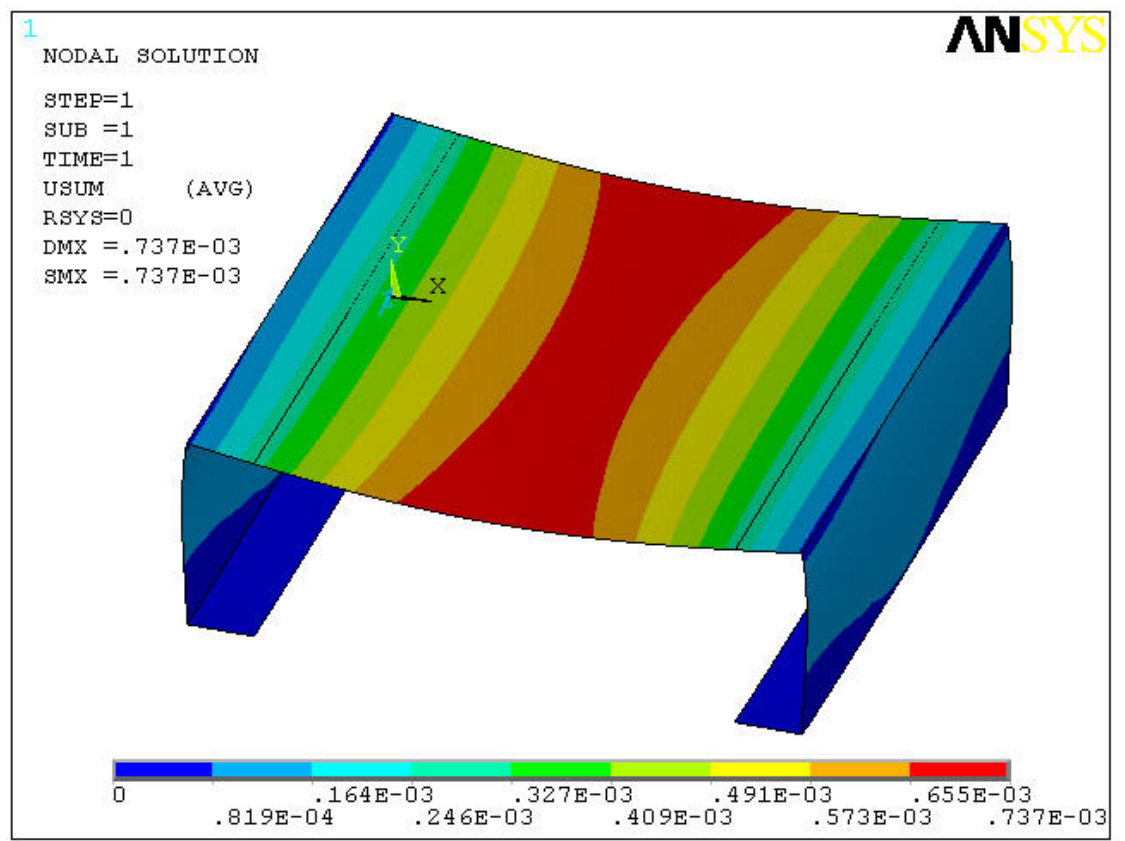

Figure 7.21: Displacement contour plot of the trailer section model.

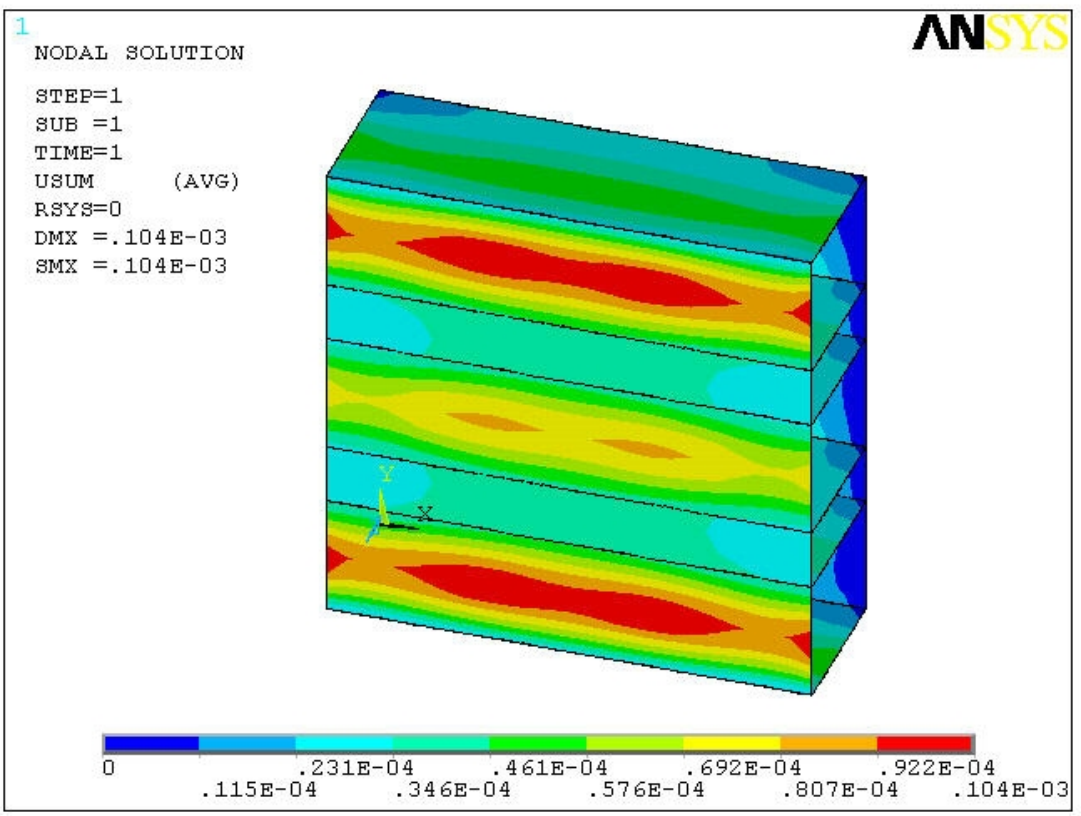

Figure 7.22: Displacement contour plot of the carbonplate-4 section.

The shear strains of each model can also be studied and compared. The maximum shear strain occurring in the trailer section is $37 \mu$ Strain and is shown in the contour shear strain plot of Figure 7.23. 


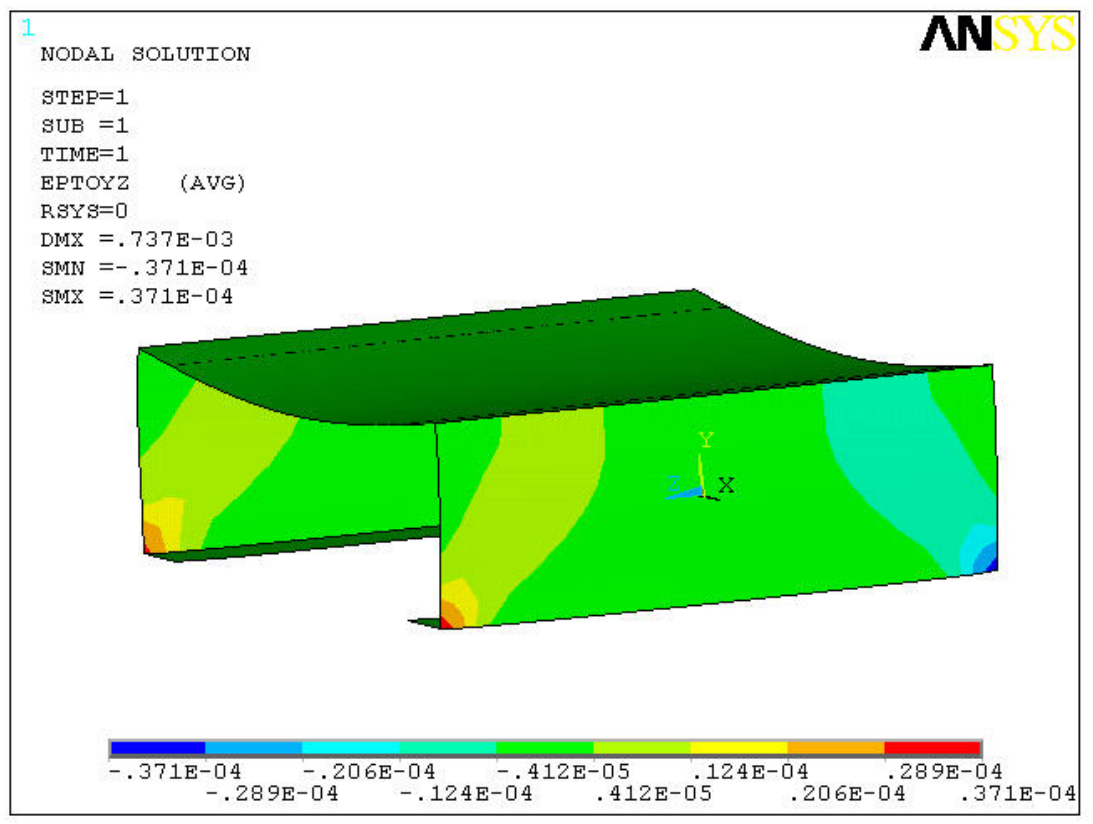

Figure 7.23: Shear strain contour plot of the trailer section model.

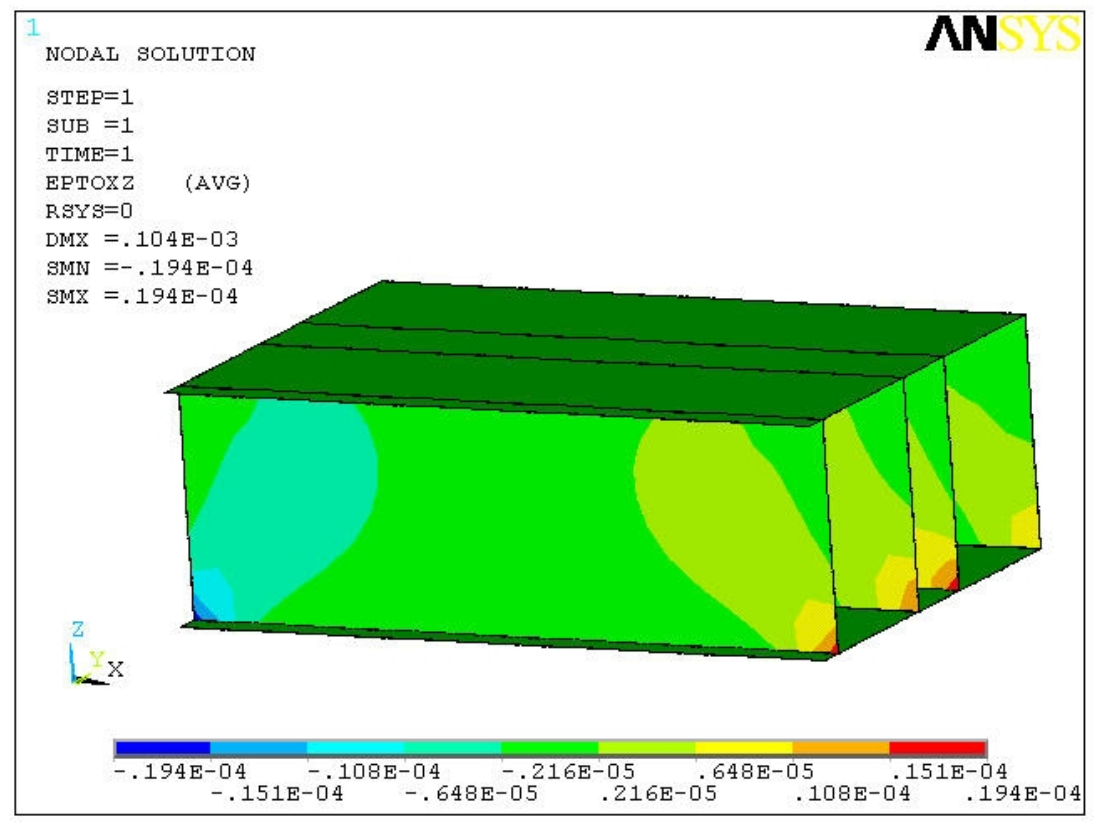

Figure 7.24: Shear strain contour plot of the carbonplate-4 model.

In comparison to Figure 7.23, the maximum shearing strain in the carbonplate- 4 is $19 \mu$ Strain. As seen in Figure 7.24, the bottom corners of the center core cross member are the location of the maximum shear strain. Comparing the maximum strain values of 
each model reveals the trailer section has a shear strain value of approximately two times the carbonplate-4 model.

The square foot weight of the carbonplate-4 panel is $7.0 \mathrm{lbs}$. If the I-beams and oak floor were replaced with the carbonplate- 4 design, the weight savings per square foot would be $14.6 \mathrm{lbs}$ which correlates to a total of $6,307.2 \mathrm{lbs}$ saved for a $54 \mathrm{ft}$. trailer haul. This figure can be maximized by creating the panel thickness which exactly matches the displacements and strains of the current existing trailer. The thickness of this structure would occur in the range between one and four inches. Also, an option to lower the cost of outfitting a 54 or $48 \mathrm{ft}$. trailer floor with the carbonplate- 4 would be to use fiberglass as the faceplate material.

A fiberglass model with a four inch cross section, fiberplate-4, was created to determine if the load bearing capabilities are also superior to the existing trailer design and comparable to the carbonplate-4 panel. The reaction contour plots for the fiberglass4 panel are shown in the following figures.

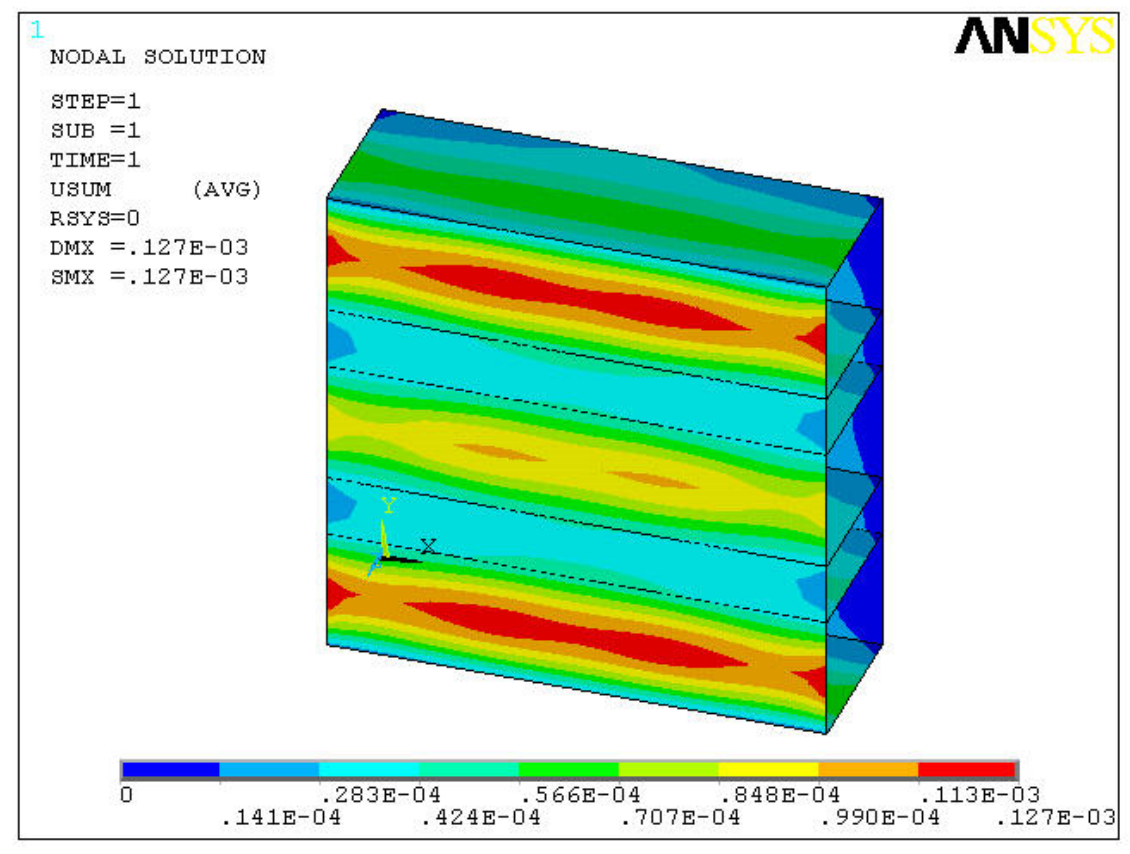

Figure 7.25: Displacement contour plot of the fiberglass-4 model. 


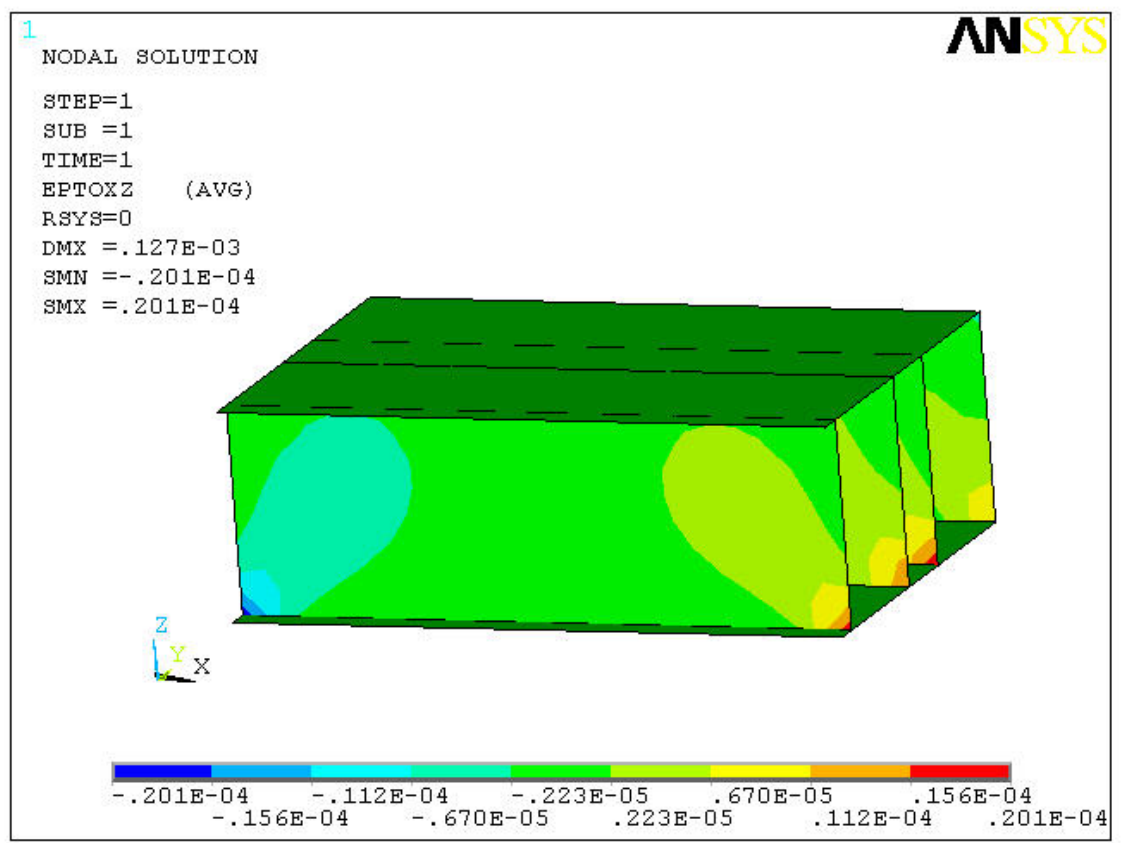

Figure 7.26: Shear strain contour plot of the fiberglass-4 model.

The displacement and shear strain of the fiberplate-4 model are shown in Figures 7.25 and 7.26, respectively. The displacement and strain values are both superior to those of the trailer section, Figures 7.21 and 7.23. The maximum displacement is $0.127 \mathrm{e}-3$ inches and the maximum shear strain is $20 \mu$ Strain. Therefore, the fiberglass design is also an option to replace the existing current floor structure of steel I-beams and solid oak covering. The weight of the fiberplate-4 panel per square foot is $7.206 \mathrm{lbs}$ and is slightly heavier than the carbonplate-4 design. The total weight savings for a $54 \mathrm{ft}$. trailer floor using the fiberplate-4 design is $6,218.2 \mathrm{lbs}$. The weight savings for both the carbon fiber and fiberglass designs are extremely significant. The carbon fiber design is superior for weight savings and load bearing capabilities, however, taking into account the slight margin of difference in performance and the cost of carbon fiber to fiberglass, equipping the trailer floors with a lower cost fiberglass design and sacrificing small weight and stiffness penalties may result in the most practical alternative. 


\subsection{Conclusion}

The carbonplate and fiberplate design is a technology geared toward flooring applications in large trailer systems but can be applied to platforms or load carrying structures. In applications such as the aerospace industry and shipping industry where weight saving is crucial to the performance of the structure, composite sandwich technology with a load-bearing core structure, as shown in this work, is a promising solution. The particular composite sandwich structure studied in this work is revolutionary because it combines a core material which contributes to the bending stiffness as compared to a common sandwich structure with a core material of honeycomb, wood, or foam which do not which do not contribute to bending resistance alone.. The bonding and joining issues of a metallic core and fiber reinforced polymer faceplates has been solved by the combination of panel geometry and adhesive bonding. The application of applying composite material technology to the entire trailer structure has been tested by the manufacturing of a scaled trailer model.

Additional conclusions which can be drawn from this work are as follows:

- Joining concepts between composite parts within a trailer system have been addressed by the construction of a trailer model and study of various joint designs. Adhesive bonding assisted by mating geometry is a method to join structures without the use of mechanical joints such as bolts or rivets.

- If replacement of the steel I-beams and oak flooring in an existing trailer is not acceptable within the trucking industry, an alternative arrangement of replacing the oak flooring alone with the fiberplate or carbonplate designs will also create respectable weight savings. The one-inch thick cross section panels will serve this design purpose.

- The fiberplate and carbonplate designs were created with the objective of designing and manufacturing a sandwich composite structure with a core material that contributes to the bending stiffnes. In theory, a sandwich composite is generally composed of a honeycomb, foam, or wood core. These core materials do not contribute to bending resistance. To create this type of design, issues of bonding 
between the faceplates and core had to be addressed. Developing an interlocking geometry between the core and faceplates assists the adhesive bonding and ultimately strengthens the design. The top and bottom faceplate structures implement a sandwich design between the core cross members by means of paper honeycomb ribbed sections. The ribbed sections serve to provide stiffness at the spaced intervals between the core cross member extrusions.

- The composite structures within this work were produced by hand layup techniques. More advanced manufacturing processes can significantly increase the performance of the part and also further increase weight saving capabilities.

- Several options for optimizing the design of the fiberplate and carbonplate are available if needed. The comparison of the cross section core members revealed that the tube extrusion is not the most effective for loading applications and replacing this extrusion with a more beneficial design will also increase the performance. Optimization of the carbon fiber and fiberglass layups can also be performed to strengthen the laminate. 


\section{REFERENCES}

[1] WVU and DOE Heavy Vehicle Systems Project, Statement of Work, 2003

[2] Barbero, Ever J., Introduction to Composite Material Design, Edwards Brothers, Ann Arbor, MI, pp. 43-58 1998

[3] Slobodzinsky, A., Bag Molding Processes, Handbook of Composites. PLASTEC, Picatinni Arsenal, Dover, NJ. pp 368-390, 1982.

[4] Meade, L.E., "Fabrication of Advanced Composites," Handbook of Composites. Lockheed Aircraft, Marietta, GA. pp 491-513, 1982.

[5] Young, Robert P., "Thermoset Matched Die Molding," Handbook of Composites. P. Robert Young Associates, Brooklyn, NY. pp 391-448, 1982.

[6] Starr, T.F. Structural Applications for Pultruded Profiles, Composite Structures 2, Applied Science Publishers, London, pp. 192-211

[7] Composites / Plastics. http://composite.about.com/library/glossary/f/bldef-f2218.htm About, Inc., 2006.

[8] Nicholls, Robert. Composite Construction Materials Handbook, Prentice Hall Inc., Englewood Cliffs, NJ, 1976.

[9] Vinson, Jack R., The Behavior of Sandwich Structures of Isotropic and Composite Materials, Technomic, Lancaster, PA, 1999.

[10] Zenkert, D. The Handbook of Sandwich Construction. Chameleon Press Ltd., London, United Kingdom. 1997.

[11] Jones R.M., Mechanics of Composite Materials, Scripta Book Company, Washington D.C. 1975.

[12] Hull, Derek, An Introduction to Composite Materials, Cambridge University Press, Cambridge, Great Britain. 1981.

[13] Elzey, Dana, Sofla, A. Haydn, W., "A Shape Memory-based Multifunctional Structural Actuator Panel,” Journal of Solids and Structures, Vol. 42, pp 1943-1955, 2004.

[14] Vinson, Jack R. and Sierakowski, R. L., The Behavior of Structures Composed of Composite Materials. Martinus-Nijhoff Publishers, Dordrecht, The Netherlands, 1986. 
[10] Zenkert, D. The Handbook of Sandwich Construction. Chameleon Press Ltd., London, United Kingdom. 1997.

[15] Whitney, J.M, Structural Analysis of Laminated Anisotropic Plates, Technomic Publishing Co. Inc., Lancaster, PA, 1987.

[16] Dobyns, A.L., "The Analysis of Simply-Supported Orthotropic Plates Subjected to Static and Dynamic Loads," AIAA Journal, pp. 642-650, May 1981.

[17] Levy, M., "Sur L'equilibrie Elastique d'une Plaque Rectangulaire," Compt. Rend 129, pp 535-539, 1899.

[18] Hart-Smith, L.J., Joining Fibre-Reinforced Plastics. Ed. By Mathews F.L., Elsevier Applied Science, Chapter 7, 282-299

[19] John and Kinloch, Measuring and Predicting the Durability of Bonded Carbon Fibre/Epoxy Composite Joints. Composites. 1991

[20] Ojalvo, I.U., Optimization of Bonded Joints. AIAA Journa, Vol. 23, No. 10, pp. 1578-1582, 1985.

[21] Tong and Steven, Analysis and Design of Structural Bonded Joints. Kluwer Academic Publishers, Norwell, MA. 1999.

[22] Slobodzinksy, A., "Bag Molding Processes," Handbook of Composites. P. Robert Young Associates, Brooklyn, NY. pp 368-390, 1982.

[23] Chen, W.F. and D.J. Han (1987), "Plasticity for Structural Engineers," Gau Liu Book Co., Taiwan.

[24] Hibbeler, R.C., "Mechanics of Materials, $6^{\text {th }}$ Edition," Pearson Prentice Hall, Upper Saddle River, NJ, 2005. 